\title{
Analysis of the variation of horizontal stresses and strains in bedded deposits in the eastern and Midwestern United States
}

Dennis R. Dolinar

West Virginia University

Follow this and additional works at: https://researchrepository.wvu.edu/etd

\section{Recommended Citation}

Dolinar, Dennis R., "Analysis of the variation of horizontal stresses and strains in bedded deposits in the eastern and Midwestern United States" (2004). Graduate Theses, Dissertations, and Problem Reports. 1425.

https://researchrepository.wvu.edu/etd/1425

This Thesis is protected by copyright and/or related rights. It has been brought to you by the The Research Repository @ WVU with permission from the rights-holder(s). You are free to use this Thesis in any way that is permitted by the copyright and related rights legislation that applies to your use. For other uses you must obtain permission from the rights-holder(s) directly, unless additional rights are indicated by a Creative Commons license in the record and/ or on the work itself. This Thesis has been accepted for inclusion in WVU Graduate Theses, Dissertations, and Problem Reports collection by an authorized administrator of The Research Repository @ WVU. For more information, please contact researchrepository@mail.wvu.edu. 
Analysis of the Variation of Horizontal Stresses and Strains in Bedded Deposits in the Eastern and Midwestern United States

\author{
by \\ Dennis R. Dolinar \\ Thesis submitted to the College of Engineering and Mineral Resources \\ West Virginia University \\ In partial fulfillment of the requirements for a degree of \\ Master of Science \\ in \\ Mining Engineering \\ Syd S. Peng, Ph.D., Chair \\ Keith Heasley, Ph.D. \\ Yi Luo, Ph.D. \\ Department of Mining Engineering \\ Morgantown, West Virginia \\ 2004
}

Keywords: In situ stress, horizontal stress, horizontal strain Copyright 2004 Dennis R. Dolinar 


\title{
Analysis of the Variation of Horizontal Stresses and Strains in Bedded Deposits in the Eastern and Midwestern United States
}

\author{
by
}

Dennis R. Dolinar

\begin{abstract}
The variation of the horizontal stress magnitude in bedded deposits in the eastern and Midwestern United States is analyzed with respect to the site depth and the rock elastic modulus using data from 40 sites. For the development of adequate regression models with the elastic modulus, zones with sufficiently uniform strains must be established. A low strain zone encompassing much of the eastern United States and a high strain zone encompassing a portion of southern West Virginia are delineated. In each zone, the regression models with the elastic modulus as the independent variable explains about 85 percent of the maximum horizontal stress variation. In general, the minimum horizontal stress is much less dependent on the elastic modulus. Though the site depths range from 275 to $2,300 \mathrm{ft}$, depth can explain only 15 percent of the maximum horizontal stress variation and is apparently not a significant independent factor.
\end{abstract}




\section{DEDICATION}

I dedicate this thesis to my dad who always provided encouragement for me to continue my education but did not see the completion of this work.

Stanley F. Dolinar

1915 to 2003 


\section{ACKNOWLEDGEMENTS}

The author wishes to thank those who have contributed to the preparation and completion of this thesis. Special appreciation is given to the members of his advisory and examination committee: Dr. Yi Luo and Dr. Keith Heasley. A debt of gratitude is especially owed to Dr. Syd S. Peng for supervision, general guidance and development of critical evaluation techniques that were instrumental for this study.

The author also thanks Dr. Chris Mark and Dr. Winton Gale, Mr. Murali Mohan Gadde for critical discussion on horizontal stress. These discussions provided helpful direction to this study. Sincere thanks needs to be given to Kathleen Stabryla for assistance in finding reference material without which the thesis would not have been as complete.

Special appreciation is given to fellow students and staff at CEMR, especially Karen Centofanti who provided assistance and guidance through the graduate school maze.

Finally, I express my deepest appreciation to my mother, Mrs. Emma Dolinar who provided encouragement in the pursuit of higher educational goals. 
Page

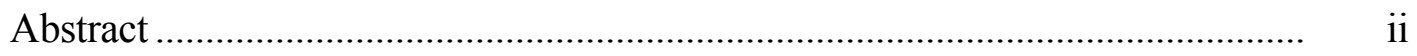

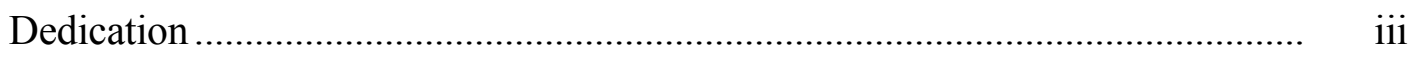

Acknowledgements .................................................................................. iv

Table of Contents ...................................................................................... v

List of Figures ...................................................................................... ix

List of Tables ........................................................................................... xii

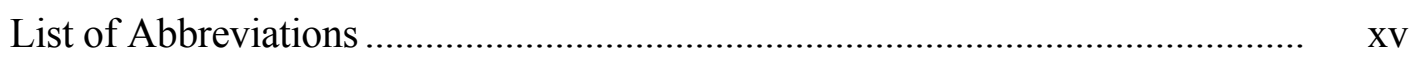

CHAPTER 1 - INTRODUCTION ………………………………………….....

CHAPTER 2 - REVIEW OF LITERATURE …………………………........ 3

CHAPTER 3 - MODEL TYPES AND STRESS MEASUREMENTS USED

IN THE STUDY .................................................................. 6

3.1 Models Used to Analyze the Stress Variation........................................ 6

3.2 Stress Measurements Used in Analysis................................................ 10

CHAPTER 4 - HORIZONTAL STRESS MEASUREMENTS FROM SITES

IN THE EASTERN UNITED STATES .................................. 12

4.1 Central Appalachian Region ........................................................... 12

4.1.1 Beckley Coalfield......................................................................... 14

4.1.2 Olga Mine, Pocahontas \#4 Seam ................................................. 15

4.1.3 Mine, Eagle Seam .................................................................... 15

4.1.4 Hendrix Mine, Elkhorn \#3 Seam ............................................. 16

4.1.5 Summary of Central Appalachian Region .................................... 16

4.2 Northern Appalachian Region ....................................................... 16

4.2.1 Loyalhanna Limestone Formation ............................................... 17

4.2.2 Columbus Limestone ................................................................. 18

4.2.3 Pittsburgh Coal Seam.............................................................. 18

4.2.4 Lower Kittanning Seam ............................................................ 19

4.2.5 Summary of Northern Appalachian Region ………………....... 20

4.3 Eastern Mid-Continent Region ....................................................... 20 


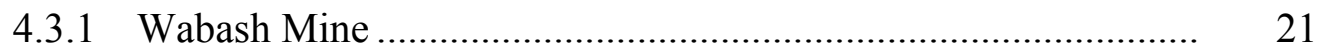

4.3.2 Monterey Mine............................................................................ 22

4.3.3 Galatia Mine.......................................................................... 22

4.3.4 Turris Mine …………………………………...................... 22

4.3.5 Peabody \# 10 Mine ………………………………................... 23

4.3.6 Peabody \#2 Mine ......................................................................... 23

4.3.7 Ft. Campbell Limestone ............................................................... 23

4.3.8 North River Mine ..................................................................... 24

4.3.9 Jim Walters \# 7 Mine............................................................... 24

4.3.10 Immel Mine ............................................................................ 24

4.3.11 Summary of Eastern Mid-Continent Region .............................. 25

CHAPTER 5 - BECKLEY COAL SEAM.................................................... 26

5.1 Variation of the Horizontal Stress with the Elastic Modulus.............. 26

5.2 Variation of Horizontal Stress with Depth ........................................... 33

5.3 Variation of Horizontal Stress with Both the Elastic Modulus and

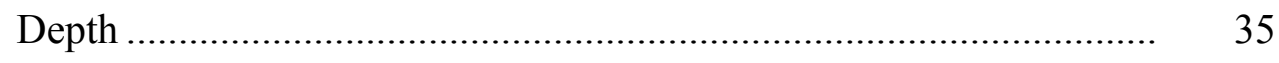

5.4 Excess Horizontal Stress …………………………................... 36

5.5 Variation of the Horizontal Stress with the Elastic Modulus Based on Site Average Stresses ............................................................... 37

5.6 Variation of the Horizontal Stress with the Elastic Modulus at Individual Sites and Mines ................................................................... 38

5.7 Beckley Seam Analysis-Conclusions......................................................... 41

CHAPTER 6 - VARIATION OF STRAINS IN THE EASTERN UNITED STATES ................................................................ 43

6.1 Determination of the Applied Horizontal Strains................................ 43

6.2 Local Strain Variations..................................................................... 44

6.3 Regional Strain Variations ............................................................. 50

6.3.1 Eastern Mid-Continent Region ................................................. 51

6.3.2 Northern Appalachian Region ……………………...................... 51 
6.3.3 Central Appalachian Region ...................................................... 54

6.3.4 Summary of Regional Strain Fields .......................................... 57

6.3.5 Comparison of Regional Strain Fields ......................................... 57

6.4 Strain Variation Across the Eastern United States ............................... $\quad 59$

6.5 Regional Strain Variation-Conclusions............................................... 62

CHAPTER 7 - REGIONAL AND LOCAL STRESS AND STRAIN

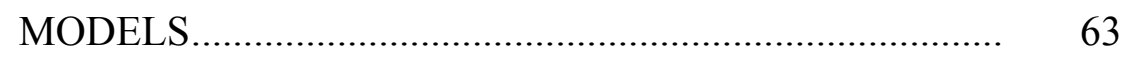

7.1 Regional Stress And Strain Models..................................................... 63

7.1.1 Variation of the Horizontal Stress with the Elastic Modulus ........ 63

7.1.2 Variation of Horizontal Stress with Depth ..................................... 71

7.1.3 Variation of the Horizontal Stress with the Elastic Modulus

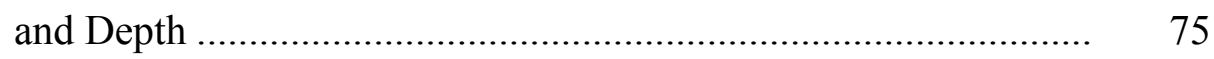

7.1.4 Variation of the Strain from the Maximum Horizontal Stress

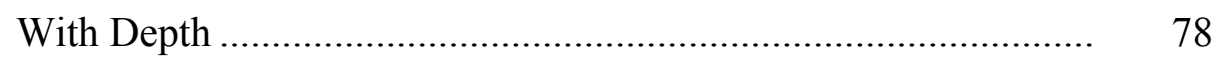

7.1.5 Excess Horizontal Stresses ……………………...................... 78

7.2 Variation of the Horizontal Stresses with the Elastic Modulus for Specific Seams and Mines .............................................................. 80

7.2.1 Pittsburgh Seam ...................................................................... 81

7.2.2 Lower Kittanning Seam .......................................................... 82

7.2.3 Peabody \#10 Mine, Eastern Mid-Continent Region ................... 84

7.3 Regional and Local Models-Conclusions............................................... $\quad 85$

CHAPTER 8 - HORIZONTAL STRESS AND DEPTH MODELS FOR EASTERN UNITED STATES ...................................... 87

8.1 Variation of the Horizontal Stress with the Elastic Modulus ................. 87

8.2 Maximum Horizontal Stress Versus Depth ............................................. 91

8.3 Horizontal Stress and Depth Models for the Eastern United StatesConclusions................................................................................ 95

CHAPTER 9 - SUMMARY AND CONCLUSIONS....................................... 96

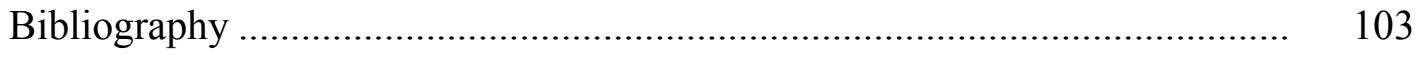




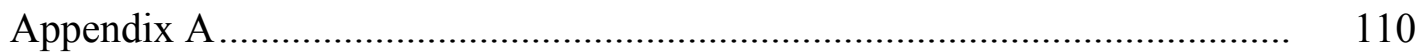

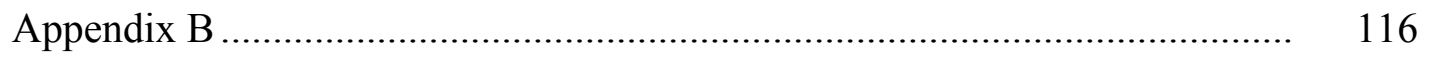

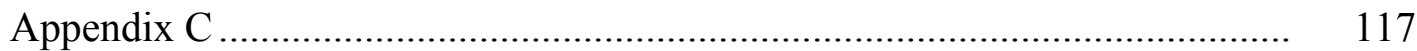

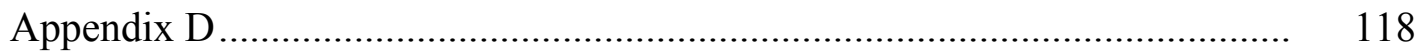




\section{LIST OF FIGURES}

$\underline{\text { Page }}$

Figure 4-1 Location of stress measurements sites used in study.

Numbers in parentheses indicates multiple sites in close

proximity

12

Figure 4-2 Average mine and district horizontal stresses measured in the

Beckley seam (modified from Agapito et al., 1980A)

Figure 5-1 The maximum horizontal stress versus the elastic modulus, Beckley coal seam (combined strain zones).

Figure 5-2 Low and high strain zones in the Beckley Seam (modified from Agapito et al., 1980A)

Figure 5-3 The maximum horizontal stress versus the elastic modulus, Beckley coal seam (high strain zone)

Figure 5-4 The maximum horizontal stress versus the elastic modulus, Beckley coal seam (low strain zone)

Figure 5-5 The minimum horizontal stress versus the elastic modulus, Beckley coal seam (high strain zone).....

Figure 5-6 The minimum horizontal stress versus the elastic modulus, Beckley coal seam (low strain zone)

Figure 5-7 The maximum horizontal stress versus the depth, Beckley coal seam.

Figure 5-8 The strain from the maximum horizontal stress versus the depth, Beckley coal seam (combined strain zones).

Figure 5-9 The maximum horizontal stress versus the elastic modulus, Bonny mine

Figure 6-1 Distribution of the standard deviation of the maximum applied strain given in percent

Figure 6-2 Distribution of the standard deviation of the minimum applied strain given in percent

Figure 6-3 Maximum applied horizontal strain versus distance of the measurement from the opening, eastern United States 
Figure 6-4 Approximate regional boundaries based on site groupings......... 50

Figure 6-5A Distribution of the applied horizontal strain in the eastern MidContinent region, maximum ....................................................... 52

Figure 6-5B Distribution of the applied horizontal strain in the eastern MidContinent region, minimum .................................................... 52

Figure 6-6A Distribution of the applied horizontal strain in the northern Appalachian region, maximum ................................................. 53

Figure 6-6B Distribution of the applied horizontal strain in the northern Appalachian region, minimum .................................................. 53

Figure 6-7A Distribution of the applied horizontal strain in the central Appalachian region, maximum ................................................ 55

Figure 6-7B Distribution of the applied horizontal strain in the central Appalachian region, minimum ................................................. 55

Figure 6-8A Distribution of the maximum applied horizontal strain across the eastern United States, maximum ................................................... 61

Figure 6-8B Distribution of the maximum applied horizontal strain across the eastern United States, minimum.............................................. 61

Figure 7-1A The maximum horizontal stress versus the elastic modulus, northern Appalachian region .................................................... 64

Figure 7-1B The maximum horizontal stress versus the elastic modulus, eastern Mid-Continent region (with the Turris and North River sites).

Figure 7-1C The maximum horizontal stress versus the elastic modulus, eastern Mid-Continent region (without the Turris and North River sites)

Figure 7-1D The maximum horizontal stress versus the elastic modulus, central Appalachian region (high strain zone)

Figure 7-1E The maximum horizontal stress versus the elastic modulus, central Appalachian region (low strain zone). 
Figure 7-2A The minimum horizontal stress versus the elastic modulus, northern Appalachian region .................................................... 69

Figure 7-2B The minimum horizontal stress versus the elastic modulus, eastern Mid-Continent region

Figure 7-2C The minimum horizontal stress versus the elastic modulus, central Appalachian region (low strain zone)............................. $\quad 70$

Figure 7-2D The minimum horizontal stress versus the elastic modulus, central Appalachian region (high strain zone)

Figure 7-3A The maximum horizontal stress versus the depth, northern Appalachian region............................................................... 72

Figure 7-3B The maximum horizontal stress versus the depth, central Appalachian region (low strain zone)

Figure 7-3C The maximum horizontal stress versus the depth, central Appalachian region (high strain zone)

Figure 7-3D The maximum horizontal stress versus the depth, central Appalachian region

Figure 7-3E The maximum horizontal stress versus the depth, eastern Mid-Continent region

Figure 7-4A Strain from the maximum horizontal stress versus the depth for the northern Appalachian region

Figure 7-4B Strain from the maximum horizontal stress versus the depth for the eastern Mid-Continent region

Figure 7-4C Strain from the maximum horizontal stress versus the depth for the central Appalachian region (low strain zone).

Figure 7-4D Strain from the maximum horizontal stress versus the depth for the central Appalachian (high strain zone)

Figure 7-5 The maximum horizontal stress versus the elastic modulus for the Pittsburgh seam 
Figure 7-6 The maximum horizontal stress versus the elastic modulus for the lower Kittanning seam......................................................... 83

Figure 7-7 The maximum horizontal stress versus the elastic modulus for the Peabody \#10 Mine ................................................................... 85

Figure 8-1 The maximum excess horizontal stress versus the elastic modulus for the eastern United States......................................... $\quad 88$

Figure 8-2 The maximum average excess horizontal stress versus the site average elastic modulus for the eastern United States ............... $\quad 89$

Figure 8-3 The maximum average excess horizontal stress versus the site average elastic modulus for the eastern United States (two low

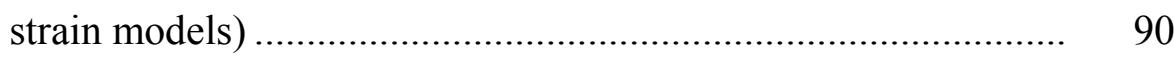

Figure 8-4 The maximum horizontal stress versus the depth in the eastern United States..................................................................... 92

Figure 8-5 The strain from the maximum horizontal stress versus the depth for the eastern United States...................................................... 94 


\section{LIST OF TABLES}

$\underline{\text { Page }}$

Table 4-1 Summary of horizontal stresses by site in the central Appalachian region................................................................ 13

Table 4-2 Summary of stresses by site in the northern Appalachian region .. 17

Table 4-3 Horizontal stresses in the Loyalhanna formation, Fayette County, PA ....................................................................... 18

Table 4-4 Summary of stresses by site in the eastern Mid-Continent region . 21

Table 5-1 Average horizontal strains from the maximum and minimum horizontal stresses by site in the Beckley coal seam .................. 28

Table 5-2 Comparison of the regression parameters and statistics based on individual or average site stresses, Beckley coal seam ................ 38

Table 5-3 Constants and correlations from a regression fit for the maximum horizontal stress from individual sites in the Beckley coal seam... 39

Table 5-4 Constants and correlations from a regression fit for the maximum horizontal stresses from each mine in the Beckley coal seam........

Table 6-1 Average applied horizontal strain in the eastern United States by site and by region................................................................... 45

Table 6-2 Applied horizontal strain by region for the eastern United States.. 50

Table 6-3 Statistical comparison of selected regional average maximum applied horizontal strains.................................................... 58

Table 7-1 Regional regression models for the maximum horizontal stresses versus the elastic modulus

Table 7-2 Regional regression models for the minimum horizontal stress versus the elastic modulus based on the site average stresses........ 68

Table 7-3 Variation of the maximum horizontal stress with depth by region 72

Table 7-4 Variation of the maximum horizontal stress with depth and the elastic modulus by region

Table 7-5 Regression models for the strain from the maximum horizontal stress versus depth for each region 
Table 7-6 Regression models for the maximum excess horizontal stress versus the elastic modulus by region with a zero intercept.............

Table 7-7 Regression models for the minimum excess horizontal stress versus the elastic modulus by region with a zero intercept.. 80

Table 8-1 Coefficients and statistic for the maximum and minimum excess horizontal stress models for the eastern United States with a zero intercept

Table 8-2 Summary of the average parameters including the depth, maximum horizontal strain and the elastic modulus for each region.

Table 9-1 Regression models for the excess maximum and maximum horizontal stress versus the elastic modulus developed in study.... 98 


\section{ABBREVIATIONS OF UNITS}

$\mathrm{ft}$-feet

psi- pounds per square inch 


\section{CHAPTER 1: INTRODUCTION}

The objective of this study is to analyze the variation of the horizontal stress and strain with respect to the elastic modulus of the rock and the depth of the measurement from the surface of the earth based on stress measurements made in mines in bedded deposits in the eastern and Midwestern United States. At the mining depths in coal and limestone deposits, the maximum horizontal stress, generally, exceeds the vertical stress often by several times. Further, the horizontal stress has been linked to ground control problems in a number of mines in both coal and limestone. Therefore, the magnitude of the horizontal stress is an important ground control issue as are the factors that may affect the magnitude of the horizontal stress. Two primary factors that in general influence the magnitude of the horizontal stress are the elastic modulus of the rock and the depth.

Therefore, horizontal stresses measured in the eastern and Midwestern United States are examined to determine if there is any general relationship between the elastic modulus and horizontal stress magnitude. Elastic theory specifies the relationship between the stress and the strain at a point, as the elastic modulus. This study will investigate if there is a relationship between the elastic modulus and the horizontal stress magnitude across larger geographic areas. If such relationships are developed, the implication is that those sets of stress measurements are under a similar or uniform strain field.

Besides the stresses, the horizontal strains are also evaluated. Essentially, this removes the elastic properties of the rock as a factor in a given analysis. Therefore, other factors such as depth can be examined without the influence of the rock properties. The horizontal strains can also be examined for geographic variation and to determine how consistent or variable the strain field is across the eastern and Midwestern United States. The strain field in combination with the elastic properties will determine the magnitude of the horizontal stress.

The effects of depth on the magnitude of the horizontal stress are considered to determine if a general depth factor for the horizontal stress exists and if it does, the magnitude of that depth factor. Essentially, does the magnitude of the horizontal stress increase with depth, and to what degree. 
This study uses the available horizontal stress measurement and elastic property data from mines in sedimentary deposits in the eastern and Midwestern United States. However, such an analysis requires data from the individual stress measurements and the elastic properties of the rock associated with those measurements. This data criterion limits the amount of published stress data that can be used. Initially, the measurements made in the Beckley coalfield are evaluated where an extensive stress measurement program was conducted with the elastic properties of the individual stress measurements and site depths available. Further, an analysis is then conducted based on other stress measurements in the northern and central Appalachian regions and the eastern MidContinent region that includes the Illinois basin. 


\section{CHAPTER 2: REVIEW OF LITERATURE}

In the United Kingdom, the variation in the magnitude of the maximum horizontal stress measured in coal mines can be explained to a high degree by the elastic modulus of the rock and the Poisson's ratio effect from the vertical stress due to gravity (Cartwright 1997). A general model using a multiple correlation analysis was developed for the coal measure rocks in both England and the United Kingdom that shows a strong relationship between the maximum horizontal stress magnitude and the elastic modulus and Poisson's effect from gravity. The multiple correlation coefficient for the United Kingdom as a whole was 0.94 and for England only, 0.95. The high correlation in these models indicates that the coalfields in England are subjected to essentially the same uniform horizontal strain field. Further, the increase in the maximum horizontal stress with depth can be explained by the vertical stress from gravity and Poisson's effect. However, the correlation between the elastic modulus and the minimum horizontal stress was much weaker (Bigby et al., 1995). The multiple correlation coefficient was for the United Kingdom 0.55 and for England 0.41. The relationships were weak enough not to be used to estimate the minimum stress. In the United Kingdom study, the depths of the measurements ranged from 300 to $3,500 \mathrm{ft}$. Therefore, the analysis covers a range in depth applicable to mining. In the English model, the maximum horizontal stress has a tectonic strain component above the gravity affects that ranges between 700 and 800 micro strains. The minimum horizontal stress has a tectonic strain component without gravity that ranges between 30 and 100 micro strains. These tectonic strains are the coefficients for the elastic modulus in the models.

Further, evidence of a relationship between the magnitude of the maximum horizontal stress and the elastic properties at specific sites in the United States have been reported (Hanna et al., 1991, Aggson and Mouyard, 1988A and 1988B). In evaluating horizontal stresses measured in the roof of a coal mine in the Illinois basin, Hanna et al., (1991) stated that "the magnitude of the major principal stress is related linearly to the elastic modulus of the roof rock." Aggson and Mouyard (1988A and 1988B) reported a linear relationship between the elastic modulus and the maximum horizontal stress magnitude for a mine in West Virginia. A relationship between the maximum stress and 
the elastic modulus of the rock has also been shown to exist in China (Guangyu et al., 1986). The explanation given was that a rock mass with a higher elastic modulus accumulates higher elastic strain energy when subjected to the same strain field. This implies the strain field was uniform where the measurements were made. Therefore, there is evidence that the elastic modulus of the rock is an important factor in the variation of the magnitude of at least the maximum horizontal stress.

A theoretical model has also been developed that provides an estimate of the mean horizontal stress based on gravity and Poisson's effect and a thermal gradient component that also involves the elastic constants (Sheorey et al., 2002). There appears to be a reasonable good fit between this model and stress data for North America though the analysis is based on measurements made prior to 1980. It is also stated that the equation shows the horizontal stress has a definite dependence on the elastic modulus. Based on the thermal coefficient and gradient provided in the report, the coefficient for the elastic modulus is 240 micro strains at the surface, 313 micro strains at $1,000 \mathrm{ft}$ and 386 micro strains at 2,500 ft. However, the model is not adequate where there is a strong influence of topography, major geologic features or tectonics.

The increase in horizontal stress with depth in North America has been evaluated by a number of authors (Brown and Hoek, 1978; Herget, 1986; Mark and Mucho, 1994). The studies by Herget (1986) and Brown and Hoek (1978) were conducted based on measurements primarily from igneous and metamorphic rocks while the measurements presented by Mark and Mucho (1994) were from coal measure rocks. Herget (1986) found the magnitude of the average horizontal stress increased by about $2.56 \mathrm{psi} / \mathrm{ft}$ for the depth range from 0 to 2,600 ft while from Brown and Hoek's (1978) analysis the increase ranged from 0.35 to $0.61 \mathrm{psi} / \mathrm{ft}$ of depth. The study by Mark and Mucho (1994) indicates that the maximum horizontal stress increases with depth in coal measure rocks. Although no analysis was conducted on the data, from the graphical presentation, the maximum horizontal stress magnitude appears to be increasing faster than the vertical stress. More recently, Mark et al. (2001), has given the increase in depth for coal mines in the eastern United States in the form of regression equations, one linear and the other logarithmic. The linear increase in the maximum horizontal stress with depth is $1.23 \mathrm{psi} / \mathrm{ft}$ while the logarithmic equation gives a similar increase between 500 and 1,500 ft. 
Except for the data presented by Herget (1986) from the Canadian Shield, the correlation between depth and the horizontal stress for these models is in general poor. Further, based on stress measurements in the United Kingdom, the following statement was made "Unlike the vertical stress, the horizontal stress component is not related to depth but to the rock stiffness" (Hayes et al., 1995). Therefore, the effects of depth on the maximum horizontal stress are reexamined not only based on the stress but the elastic strain. For the depth, the strain data needs to be evaluated because of potential effects of the elastic properties on the stress magnitude.

There is a theoretical basis for the increase of the horizontal stress with depth that develops from the gravity load and Poisson's ratio (Obert and Duvall, 1967; Jaeger and Cook, 1969). Both Sheorey et al. (2002), and Cartwright (1997) include this as a depth factor in their models for estimating the horizontal stress. The increase with gravity is also indicated in the calculation of what is termed the excess or tectonic horizontal stress, the horizontal stress in excess of the expected gravity load (Aggson, 1979A; Bickel, 1993). 


\section{CHAPTER 3: MODEL TYPES AND STRESS MEASUREMENTS USED IN THE STUDY}

\subsection{MODELS USED TO ANALYZE THE STRESS VARIATION}

To analyze the variation of the horizontal stress magnitude with respect to the elastic modulus and the depth, several models are used. A regression analysis on the data is conducted to develop the models and to examine how well the models explain the data variation.

For the relationship between the horizontal stress magnitude and the elastic modulus, the following type of equation is used

$$
\mathrm{P}, \mathrm{Q}=\mathrm{K}_{1} \mathrm{E}+\mathrm{K}_{2}
$$

where $\mathrm{P}=$ maximum horizontal stress, psi,

$\mathrm{Q}=$ minimum horizontal stress, psi,

$\mathrm{K}_{1}=$ strain coefficient for either the maximum or minimum horizontal stress, micro strain,

$\mathrm{E}=$ elastic modulus, $10^{6} \mathrm{psi}$,

and $\quad \mathrm{K}_{2}=$ constant for either the maximum or minimum horizontal stress, psi.

The coefficient $\mathrm{K}_{1}$ is directly related to the strains while the $\mathrm{K}_{2}$ constant is related to other factors that cause an offset in the stress-strain relationship such as the depth or thermally induced strains (Cartwright, 1997; Herget, 1988). A large constant can also result from measurements obtained from a non-uniform strain field where there can also be a different distribution of the elastic modulus that was sampled within those strain fields.

In general, as previously noted, the horizontal stress magnitude does appear to increase with depth. There are at least two aspects to this increase, the change from an increase in the vertical stress, and the change in the excess or tectonic component of the horizontal stress. There are also other potential factors that may cause an increase in the horizontal stress magnitude that may be related to depth such as increases due to thermal 
effects (Sheorey, 1994). In theory, based on plane strain conditions, the horizontal stress from depth and gravity is given by the following equation (Jaeger and Cook, 1969)

$$
\mathrm{P}_{\mathrm{v}}=1.1[v /(1-v)] \mathrm{D}
$$

where $\mathrm{P}_{\mathrm{v}}=$ horizontal stress due to depth, psi,

$$
v=\text { Poisson's ratio, }
$$

and $\quad \mathrm{D}=$ depth, $\mathrm{ft}$.

Based on the average rock density for sedimentary rock, the vertical stress is assumed to increase by about $1.1 \mathrm{psi} / \mathrm{ft}$ of depth.

Equation 3.2 can be used to estimate the contribution of the vertical stress or depth to the measured horizontal stress. Subtracting the gravity effects from the measured horizontal stress will result in the excess stress. The following equations give the excess horizontal stress (Aggson, 1979A; Bickel, 1993)

$$
\begin{gathered}
\mathrm{P}_{\mathrm{e}}=\mathrm{P}-1.1[v /(1-v)] \mathrm{D} \\
\text { and } \\
\mathrm{Q}_{\mathrm{e}}=\mathrm{Q}-1.1[v /(1-v)] \mathrm{D}
\end{gathered}
$$

where $\mathrm{P}_{\mathrm{e}}=$ maximum excess horizontal stress, psi, and $\quad Q_{\mathrm{e}}=$ minimum excess horizontal stress, psi.

Essentially, the excess stress is the component of the horizontal stress that exceeds that due to gravity.

The following equation is used to examine the relationship between the elastic modulus and the excess stress

$$
\mathrm{P}_{\mathrm{e}}, \mathrm{Q}_{\mathrm{e}}=\mathrm{K}_{1} \mathrm{E}+\mathrm{K}_{2} .
$$


As previously discussed, the constant $\mathrm{K}_{2}$ in equation 3.4 can be related to possible thermally induced strains or other unknown factors that may systematically influence the horizontal stresses. This constant can also result from non-uniform strain fields where the stress does not vary linearly with the elastic modulus. If the constant $\mathrm{K}_{2}$ is sufficiently small, the following equation can be used

$$
\mathrm{P}_{\mathrm{e}}, \mathrm{Q}_{\mathrm{e}}=\mathrm{K}_{1} \mathrm{E} .
$$

A part or most of the excess stress may be tectonic in origin. The tectonic stresses being related or developed from the forces that generate plate tectonics (Zoback and Zoback, 1989; Zoback, 1992; Mark and Mucho, 1994). Because a large component of the excess horizontal stress is probably due to tectonics, this component is often referred to as the tectonic stress (Mark and Mucho, 1994; Cartwright, 1997). The portion of the stress field that is influenced by the elastic modulus has been taken to be the tectonic portion of the stress field (Cartwright, 1997). This implies that the tectonic stresses are the result of the coefficient $K_{1}$ in equations 3.4 and 3.5 where this coefficient can be considered related to the tectonic strain. However, in discussions in this paper such stresses and strains above the gravity load will be in general referred to as excess rather than tectonic.

Strains from the maximum and minimum measured and excess horizontal stresses can also be evaluated. These strains are calculated from the following type of equations

$$
\begin{gathered}
\varepsilon_{\mathrm{p}}, \varepsilon_{\mathrm{q}}=\mathrm{P}, \mathrm{Q} / \mathrm{E} \\
\text { and } \\
\varepsilon_{\mathrm{pe}}, \varepsilon_{\mathrm{qe}}=\mathrm{P}_{\mathrm{e}}, \mathrm{Q}_{\mathrm{e}} / \mathrm{E}
\end{gathered}
$$

where $\varepsilon_{\mathrm{p}}=$ strain from the maximum horizontal stress, micro strain, $\varepsilon_{\mathrm{q}}=$ strain from the minimum horizontal stress, micro strain, $\varepsilon_{\mathrm{pe}}=$ strain from the maximum excess horizontal stress, micro strain, and $\quad \varepsilon_{\mathrm{qe}}=$ strain from the minimum excess horizontal stress, micro strain. 
These calculated strains are referred to as the strains resulting from the maximum or minimum horizontal or excess stress. These are not the actual strains that would be measured at a point since those strains involve the complete stress field and not just a stress component. The excess or tectonic strain calculated in equation 3.6 is related to the $\mathrm{K}_{1}$ coefficient of equation 3.5. With equation 3.6, the strains from the maximum horizontal stress for individual measurements are calculated while for equation 3.5 , the coefficient is the average strain from the maximum horizontal stress based on a regression analysis from several measurements. Further, the strains developed from these equations can also be referred to as maximum and minimum horizontal stresses normalized by the elastic modulus of the rock.

The depth factor can be evaluated through an equation of the following type

$$
\mathrm{P}=\mathrm{K}_{\mathrm{D}} \mathrm{D}+\mathrm{P}_{\mathrm{s}}
$$

where $K_{D}=$ depth factor, psi/ft,

and $\quad \mathrm{P}_{\mathrm{s}}=$ maximum horizontal stress at the surface, psi.

The maximum horizontal stress at the surface is the excess or tectonic stress.

Equations that combined both depth and the elastic properties can be developed through a multiple regression analysis. These equations have the following form

$$
P, Q=K_{D} D+K_{1} E+K_{3}
$$

where $\mathrm{K}_{3}=$ constant, psi.

Finally, the following type of equation is used to evaluate the effects of depth on the strain

$$
\varepsilon_{\mathrm{p}}=\mathrm{K}_{\mathrm{ND}} \mathrm{D}+\varepsilon_{\mathrm{s}}
$$

where $\mathrm{K}_{\mathrm{ND}}=$ normalized depth factor, micro strain/ft, 
and $\quad \varepsilon_{\mathrm{s}}=$ strain from the maximum horizontal stress at the surface, micro strain.

Essentially, this equation eliminates the variation of the elastic properties between measurements thus allowing for a comparison between the horizontal stress or strain and depth that is not masked by the elastic properties.

\subsection{STRESS MEASUREMENTS USED IN ANALYSIS}

Stress measurements used in this analysis were determined by two techniques, these were overcoring of either the USBM (United States Bureau of Mines) borehole deformation gage or the CSIRO (Commonwealth Scientific and Industrial Organization of Australia) Hollow Inclusion (HI) cell and hydraulic fracturing stress measurements. The general criteria for using stress data were that both the depth of the site and the elastic properties of the rock were required before a measurement could be used in the analysis. With the USBM borehole deformation gage and hydraulic fracturing, the horizontal stresses can be determined in vertically drilled holes either in the roof or floor of the mine. With the CSIRO HI-cell, the complete 3-dimensional stress is determined and the cell can be placed in any hole orientation to obtain the horizontal stress. All the measurements used in this analysis were obtained from underground test sites.

The technique to measure the stresses with the USBM borehole deformation gage and overcoring are well documented (Bickel, 1985, 1993). The result of an overcoring measurement is the determination of the two dimensional stress in the plane of the measurement. The elastic properties for the overcore are usually determined using a biaxial test of the core and are normally determined for each stress measurement. Several measurements are usually obtained from one hole at a site with the measurements being averaged to determine a site stress (Duval and Aggson, 1980). In general, for the analysis, if the elastic properties for a given overcoring measurement were not determined the measurement was not used though there are some exceptions. All except two of the site stresses were determined using this method.

The CSIRO HI-cell is also overcored and will result in the determination of the 3dimensional stress field. Again, the installation and use of the cell are well reported (International Society of Rock Mechanics, 1987; Wortrucki and Walton, 1976). From the 
three-dimensional stress, the principal stresses in the horizontal plane can be calculated. The elastic properties are obtained by testing the individual overcores.

The hydraulic fracturing technique is also well documented though in this case the underground data was obtained using specially designed equipment (Oyler, 2001). Again, information on the elastic properties was required. However, the elastic properties are not necessary to calculate stresses with this method and must be determined by other methods such as from laboratory testing of core obtained from the tested formation. Measured stresses may be reported from individual tests, as an average stress for several tests or as a range of values from all the tests. 


\section{CHAPTER 4: HORIZONTAL STRESS MEASUREMENTS FROM SITES IN THE EASTERN UNITED STATES}

Figure 4-1 shows the site locations of the stress measurements used in this analysis from the eastern and Midwestern United States. The measurements from forty sites are grouped into three main regions. These are the northern and central Appalachian regions and the eastern Mid-Continent region. In this section, the stress measurements, site depth and elastic modulus of the rock as well as the horizontal strains from the maximum and minimum stresses that will be used in the analysis are presented.

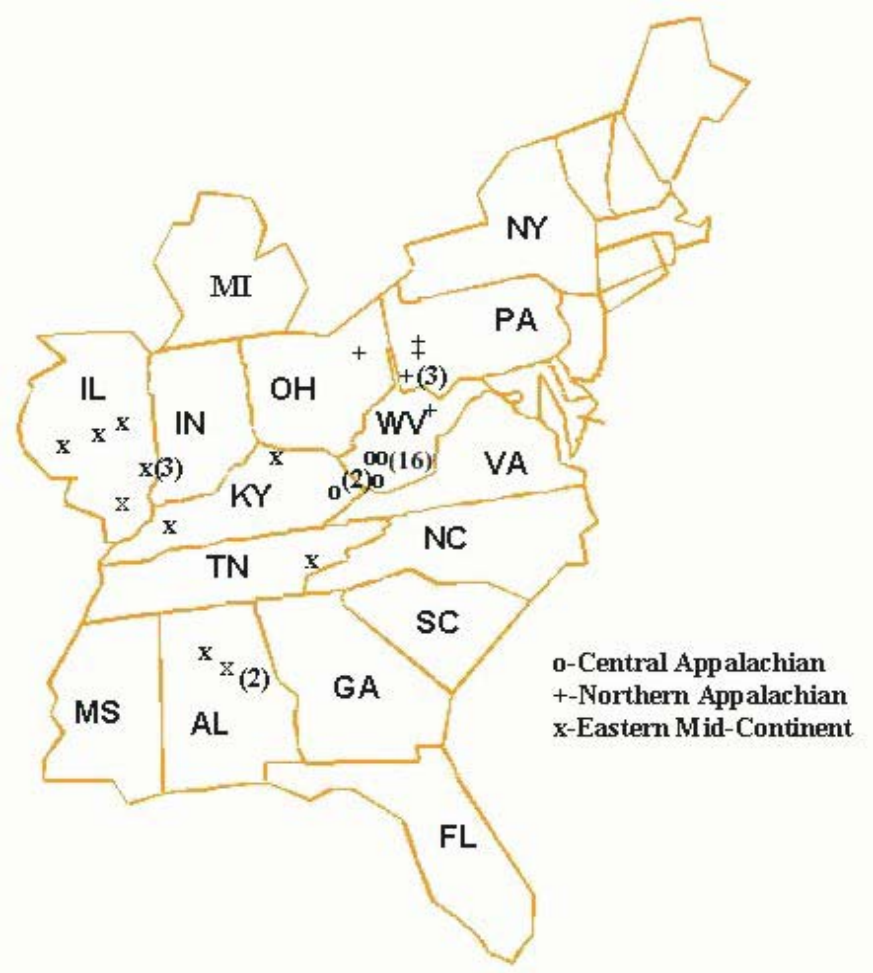

Figure 4-1. Location of stress measurement sites used in study. Numbers in parentheses indicates multiple sites in close proximity.

\subsection{CENTRAL APPALACHIAN REGION}

This region encompasses sites from southern West Virginia and eastern Kentucky. Stress measurements were available from 15 sites in the Beckley seam, one site in the Sewell seam, two sites in the Pocahontas \#4 seam and one site in the Eagle seam in southern West Virginia as well as one site in the Elkhorn \#3 seam in eastern Kentucky. 
Measurements at these sites were made using the USBM borehole deformation gage and overcoring technique. The results of the individual stress measurements including: the maximum and minimum measured and excess horizontal stress, the elastic modulus and the resulting strains are given in Appendix A, table A-1 and A-2 for the Beckley coalfield and in Appendix B, table B-1 for other sites in the central Appalachian region. Table 4-1 shows a summary of the horizontal stress, stress direction, elastic modulus and depth for each site.

Table 4-1. Summary of horizontal stresses by site in the central Appalachian region.

\begin{tabular}{|c|c|c|c|c|c|c|c|c|}
\hline \multirow[b]{2}{*}{ Site } & \multirow[b]{2}{*}{ Seam } & \multicolumn{3}{|c|}{ Horizontal stress } & \multicolumn{2}{|c|}{ Excess stress, psi } & \multirow{2}{*}{$\begin{array}{c}\text { Elastic } \\
\text { modulus, } \\
10^{6} \text { psi }\end{array}$} & \multirow[b]{2}{*}{$\begin{array}{l}\text { Depth, } \\
\mathrm{ft}\end{array}$} \\
\hline & & $\begin{array}{l}\text { Maximum, } \\
\text { psi }\end{array}$ & $\begin{array}{c}\text { Minimum, } \\
\text { psi }\end{array}$ & $\begin{array}{c}\text { Direction of } \\
\text { maximum }\end{array}$ & Maximum & Minimum & & \\
\hline Beckley \#4, hole 1 & Sewell & 1484 & 1141 & $\mathrm{~N} 25^{\circ} \mathrm{W}$ & 1183 & 840 & 1.77 & 820 \\
\hline Beckley\#1, hole 2 & Beckley & 3172 & 1890 & N $75^{\circ} \mathrm{E}$ & 2758 & 1476 & 6.77 & 1130 \\
\hline Beckley \#2, hole 3 & Beckley & 2308 & 1677 & $\mathrm{~N} 52^{\circ} \mathrm{W}$ & 1905 & 1274 & 2.26 & 1100 \\
\hline Bonny, hole 4 & Beckley & 3180 & 3038 & $\mathrm{~N} 54^{\circ} \mathrm{E}$ & 2763 & 2621 & 3.59 & 1136 \\
\hline Bonny, hole 5 & Beckley & 6109 & 3326 & $\mathrm{~N} 57^{\circ} \mathrm{E}$ & 5688 & 2905 & 6 & 1148 \\
\hline $\begin{array}{l}\text { Maple Meadows, } \\
\text { hole } 6\end{array}$ & Beckley & 2730 & 2656 & $\mathrm{~N} 46^{\circ} \mathrm{W}$ & 2470 & 2396 & 6.32 & 708 \\
\hline $\begin{array}{l}\text { Maple Meadows, } \\
\text { hole } 7\end{array}$ & Beckley & 4476 & 3240 & $\mathrm{~N} 63^{\circ} \mathrm{E}$ & 4207 & 2971 & 4.44 & 735 \\
\hline $\begin{array}{l}\text { Maple Meadows, } \\
\text { hole } 8\end{array}$ & Beckley & 4258 & 2362 & $\mathrm{~N} 69^{\circ} \mathrm{E}$ & 3882 & 1986 & 7.09 & 1025 \\
\hline $\begin{array}{l}\text { Maple Meadows, } \\
\text { hole } 9\end{array}$ & Beckley & 3188 & 2354 & $\mathrm{~N} 71^{\circ} \mathrm{E}$ & 2890 & 2056 & 2.46 & 814 \\
\hline $\begin{array}{l}\text { Maple Meadows, } \\
\text { hole } 10\end{array}$ & Beckley & 3326 & 1657 & $\mathrm{~N} 54^{\circ} \mathrm{E}$ & 3030 & 1361 & 6.92 & 807 \\
\hline $\begin{array}{l}\text { Beckley Mining, } \\
\text { hole } 11\end{array}$ & Beckley & 3095 & 2508 & $\mathrm{~N} 54^{\circ} \mathrm{E}$ & 2860 & 2273 & 2.95 & 640 \\
\hline $\begin{array}{l}\text { Beckley Mining, } \\
\text { hole } 12\end{array}$ & Beckley & 3703 & 2902 & $\mathrm{~N} 71^{\circ} \mathrm{E}$ & 3384 & 2583 & 2.94 & 870 \\
\hline $\begin{array}{l}\text { Beckley Mining, } \\
\text { hole } 13\end{array}$ & Beckley & 3124 & 2331 & $\mathrm{~N} 59^{\circ} \mathrm{E}$ & 2831 & 2038 & 2.7 & 800 \\
\hline $\begin{array}{l}\text { Beckley Mining, } \\
\text { hole } 14\end{array}$ & Beckley & 3765 & 2280 & $\mathrm{~N} 55^{\circ} \mathrm{E}$ & 3384 & 1899 & 3.5 & 1040 \\
\hline $\begin{array}{l}\text { Beckley } \# 1 \text {, hole } \\
15\end{array}$ & Beckley & 3199 & 1768 & $\mathrm{~N} 69^{\circ} \mathrm{E}$ & 2942 & 1511 & 7.32 & 700 \\
\hline \begin{tabular}{|l} 
Beckley $\# 2$, hole \\
16 \\
\end{tabular} & Beckley & 1800 & 1346 & $\mathrm{~N} 42^{\circ} \mathrm{W}$ & 1672 & 1218 & 1.72 & 350 \\
\hline Eagle seam mine & Eagle & 1760 & 1370 & $\mathrm{~N} 49^{\circ} \mathrm{E}$ & 1430 & 1040 & 2.95 & 900 \\
\hline Hendrix mine & Elkhorn \#3 & 2254 & 1802 & $\mathrm{~N} 65^{\circ} \mathrm{E}$ & 2052 & 1600 & 5.24 & 550 \\
\hline Olga mine, site 1 & $\begin{array}{c}\text { Pocahontas } \\
\# 4\end{array}$ & 3300 & 2400 & $\mathrm{~N} 62^{\circ} \mathrm{E}$ & 2713 & 1813 & 3.59 & 1600 \\
\hline Olga mine, site 2 & $\begin{array}{c}\text { Pocahontas } \\
\# 4\end{array}$ & 3000 & 1900 & $\mathrm{~N} 61^{\circ} \mathrm{E}$ & 2542 & 1442 & 3.25 & 1250 \\
\hline
\end{tabular}




\subsubsection{Beckley Coalfield}

The Beckley coalfield is located about 10 miles west-northwest of Beckley, West Virginia. Mines in the area have had considerable ground control problems related to the horizontal stress (Aggson, 1978, 1979A; Dolinar et al., 1982; Agaptio et al., 1980; Agapito and Gilbride, 2002). As a result of the stress related ground control problems, an extensive horizontal stress measurement program was conducted in the Beckley coalfield in the late 1970's and early 1980's (Aggson, 1978; Agapito et al., 1980). Stress measurements were made at a total of 16 sites in 6 mines. The data set contains 61 individual stress measurements obtained in sixteen holes drilled in the mine roofs. Fifteen sites were in the Beckley coal seam and one site in the overlying Sewell seam.

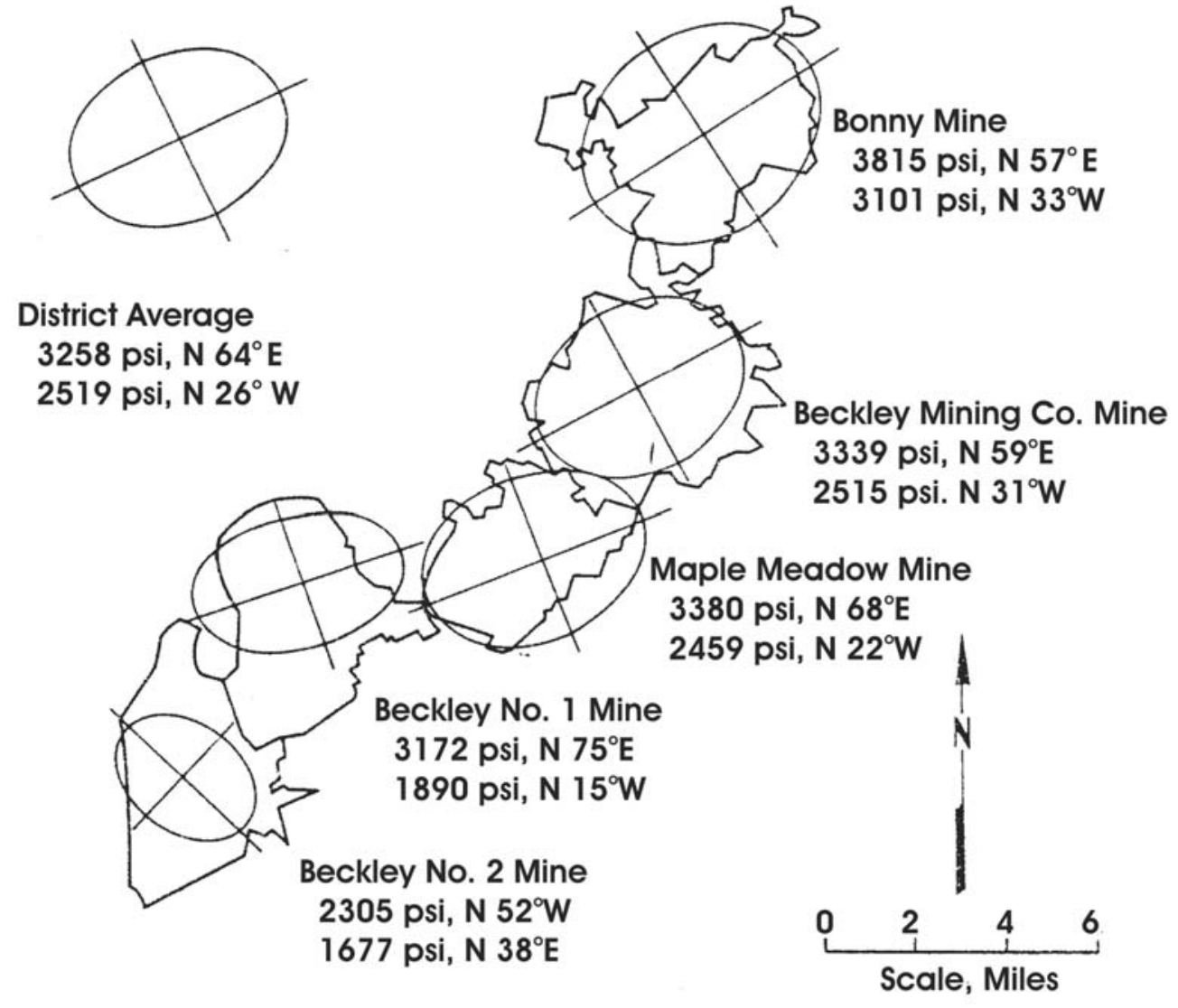

Figure 4-2. Average mine and district horizontal stresses measured in the Beckley seam (modified from Agapito et al., 1980A).

Figure 4-2 shows a map of the mines in the Beckley seam and the average horizontal stresses measured in each mine. The average for the district is also shown 
(Agapito, et al., 1980A). The measurements extend for a distance of about 25 miles with the depth of the sites ranging from 350 to $1,148 \mathrm{ft}$. In general, the Beckley coalfield is subjected to a horizontal stress that is substantially higher than the expected vertical stress at these depths where the maximum horizontal stress by site varies from 1,484 to 6,109 psi. The direction of the maximum horizontal stress is from the northeast except in the Beckley \#2 Mine, and in the Beckley \#4 Mine in the Sewell seam where the directions are from the northwest. One site in the Maple Meadows Mine also has a maximum horizontal stress from the northwest, however, the stresses at the site are nearly hydrostatic. In general, from the Beckley \#1 Mine to the Bonny Mine, both the maximum and minimum horizontal stress magnitudes increase in the northeast direction.

Across the coalfield based on the site measurements, the elastic modulus ranges from 1.77 to 7.32 million psi. The strain from the maximum horizontal stress ranges from 432 to 1,296 micro strains and from the minimum horizontal stress from 242 to 987 micro strains. Clearly, there is a substantial range in both the elastic modulus and in the strains.

\subsubsection{Olga Mine, Pocahontas \#4 Seam}

The mine is located in McDowell county West Virginia in the Pocahontas \#4 seam about 25 miles southwest of the Beckley seam study area (Campoli et al., 1990). Measurements were made at two sites in the mine with the overburden depths of 1,250 and 1,600 ft. However, for the analysis, the measurements at $5.8 \mathrm{ft}$ at the $1,600 \mathrm{ft}$ site and from 2.3 to $6.6 \mathrm{ft}$ at the $1,250 \mathrm{ft}$ site were not used because the measurements were relatively close to the opening and deeper measurements were available. At the two sites, for the measurements used in the analysis, the site strains from the maximum horizontal stress are 919 and 923 micro strains and from the minimum horizontal stress 585 and 668 micro strains. The site elastic modulus is 3.25 million psi for the $1,250 \mathrm{ft}$ site and 3.59 million psi for the $1,600 \mathrm{ft}$ site.

\subsubsection{Mine, Eagle Seam}

The mine is located in Raleigh county West Virginia about 10 miles northwest of the Beckley seam study area. The measurements were made in the Eagle seam with a site 
depth of $900 \mathrm{ft}$. The site strain from the maximum horizontal stress is 597 micro strains and from the minimum horizontal stress, 464 micro strains. The site elastic modulus is 2.95 million psi.

\subsubsection{Hendrix Mine, Elkhorn \#3 Seam}

The mine is located in Letcher County in southeastern Kentucky in the Elkhorn \#3 seam. The measurements were made in shale in the mine roof (Wright et al., 1979; Unrug et al., 1984). The deepest three measurements ranging from 13.7 to 23.4 feet in the mine roof were used to calculate the horizontal stress. Because of delamination of the large diameter overcores, elastic properties had to be determined from small diameter core drilled from the larger cores. The elastic properties used were those determined in the direction parallel to the bedding. One elastic modulus, 5.24 million psi was used to determine the stresses from the three measurements. The maximum and minimum horizontal strains from those stress components are 430 and 343 micro strains. The site depth was $550 \mathrm{ft}$.

\subsubsection{Summary of Central Appalachian Region}

The central Appalachian region includes measurements from southern West Virginia, and eastern Kentucky. Stress measurements used in the analysis were obtained from the Beckley, Sewell, Pocahontas \#4, Eagle and Elkhorn \#3 seams. In general, the Beckley seam dominates the data because of the number of sites. There is a substantial range of strains over the region with the average site strains from the maximum horizontal stress varying from 432 to 1,296 micro strains and the strains from the minimum horizontal stress varying from 242 to 987 micro strains. The sites are located in mountainous topography with the depth ranging from 350 to 1,600 ft. The site elastic modulus varies from 1.77 to 7.32 million psi.

\subsection{NORTHERN APPALACHIAN REGION}

For this study, the northern Appalachian region encompasses parts of eastern Ohio, northern West Virginia and western Pennsylvania. Table 4-2 shows the horizontal stresses for each site. A summary of the individual measurements used in the analysis 
including the maximum and minimum horizontal stress, the maximum and minimum excess horizontal stress, the elastic modulus and the resulting strains are given in Appendix C, table C-1.

Table 4-2. Summary of horizontal stresses by site for the northern Appalachian region.

\begin{tabular}{|c|c|c|c|c|c|c|c|c|}
\hline \multirow[b]{2}{*}{ Site } & \multirow{2}{*}{$\begin{array}{l}\text { Seam/ } \\
\text { formation }\end{array}$} & \multicolumn{3}{|c|}{ Horizontal stress } & \multicolumn{2}{|c|}{ Excess stress, psi } & \multirow{2}{*}{$\begin{array}{c}\text { Elastic } \\
\text { Modulus, } \\
10^{6} \mathrm{psi}\end{array}$} & \multirow{2}{*}{$\begin{array}{c}\text { Depth } \\
\mathrm{ft}\end{array}$} \\
\hline & & \begin{tabular}{|} 
Maximum, \\
psi
\end{tabular} & $\underset{\mathrm{psi}}{\text { Minimum, }}$ & $\begin{array}{c}\text { Direction of } \\
\text { maximum }\end{array}$ & Maximum & Minimum & & \\
\hline Tanoma, PA & \begin{tabular}{|c|} 
Lower \\
Kittanning
\end{tabular} & 3335 & 2787 & $\mathrm{~N} 87^{\circ} \mathrm{E}$ & 3071 & 2523 & 5.8 & 720 \\
\hline Phillippi WV & \begin{tabular}{|c|} 
Lower \\
Kittanning \\
\end{tabular} & 3014 & 2265 & $\mathrm{~N} 75^{\circ} \mathrm{E}$ & 2812 & 2063 & 4.29 & 550 \\
\hline $\begin{array}{l}\text { Fayette County, } \\
\text { PA }\end{array}$ & Loyalhanna & 6910 & 3975 & $\mathrm{~N} 71^{\circ} \mathrm{E}$ & 6763 & 3828 & 11.2 & 400 \\
\hline Barberton, $\mathrm{OH}$ & Columbus & 5500 & 4000 & $\mathrm{E}$ & 4657 & 3157 & 9 & 2300 \\
\hline $\begin{array}{l}\text { Southwest, PA, } \\
\text { site } 1\end{array}$ & Pittsburgh & 1324 & 1024 & $\mathrm{~N} 32^{\circ} \mathrm{E}$ & 1177 & 877 & 1.8 & 400 \\
\hline $\begin{array}{l}\text { Southwest, PA, } \\
\text { site } 2\end{array}$ & Pittsburgh & 2370 & 2260 & $\mathrm{~N} 78^{\circ} \mathrm{E}$ & 2113 & 2003 & 4.4 & 700 \\
\hline $\begin{array}{l}\text { Southwest, PA, } \\
\text { site3 }\end{array}$ & Pittsburgh & 3080 & 2180 & $\mathrm{~N} 70^{\circ} \mathrm{E}$ & 2787 & 1887 & 7.65 & 800 \\
\hline
\end{tabular}

\subsubsection{Loyalhanna Limestone Formation}

Horizontal stress measurements were made in a limestone mine in the Loyalhanna Limestone in Fayette County, Pennsylvania. This mine has had a history of roof falls many of which are related to the horizontal stress (Iannacchione et al., 1997, 2002). The stress measurements were made in the roof and floor using the hydraulic fracturing technique (Oyler, 2001). The depth of the site was $400 \mathrm{ft}$.

Table 4-3 shows the horizontal stress measured at a given depth in the roof and floor. An average horizontal stress is also given for the site. Based on a Poisson's ratio of 0.25 and the average horizontal stress at the site, the excess stresses were calculated as $\mathrm{P}_{\mathrm{e}}=6,765$ psi and $\mathrm{Q}_{\mathrm{e}}=3,830$ psi.

An elastic modulus for the site was determined from testing of vertically drilled core from another nearby limestone mine in the same formation. The range in the elastic modulus was 8.5 to 14.2 million psi with an average of 11.2 million psi. This average is based on 12 specimens obtained from through out the Loyalhanna formation. Using the 
average elastic modulus of 11.2 million psi, the strains from the average maximum and minimum horizontal stresses are 617 and 355 micro strains.

Table 4-3. Horizontal stresses in the Loyalhanna formation, Fayette County, PA

\begin{tabular}{|c|c|c|c|c|}
\hline \multirow[b]{2}{*}{ Location } & \multirow{2}{*}{$\begin{array}{c}\text { Depth of } \\
\text { measurement, } \mathrm{ft}\end{array}$} & \multicolumn{3}{|c|}{ Horizontal stress } \\
\hline & & Maximum, psi & Minimum, psi & $\begin{array}{c}\text { Direction of } \\
\text { maximum }\end{array}$ \\
\hline Roof & 10.5 & 7200 & 4456 & $\mathrm{~N} 76^{\circ} \mathrm{E}$ \\
\hline Roof & 11.5 & 6117 & 3145 & $\mathrm{~N} 76^{\circ} \mathrm{E}$ \\
\hline Average & & 6659 & 3800 & $\mathrm{~N} 76^{\circ} \mathrm{E}$ \\
\hline Floor & 10 & 5800 & 3319 & $\mathrm{~N} 66^{\circ} \mathrm{E}$ \\
\hline Floor & 11 & 8524 & 4993 & $\mathrm{~N} 66^{\circ} \mathrm{E}$ \\
\hline Average & & 7162 & 4150 & $\mathrm{~N} 66^{\circ} \mathrm{E}$ \\
\hline Average & & 6910 & 3975 & $\mathrm{~N} 71^{\circ} \mathrm{E}$ \\
\hline
\end{tabular}

\subsubsection{Columbus Limestone}

Stress measurements were made at a limestone mine near Barberton, Ohio using the USBM borehole deformation gage and overcoring technique (Obert, 1962). The site was in the Columbus Limestone at a depth of 2,300 ft. The measured horizontal stresses at the site were $\mathrm{P}=5,500 \mathrm{psi}$ and $\mathrm{Q}=4,000$ psi. Using a Poisson's ratio of 0.25 , the excess stresses are $P_{e}=4,665$ psi and $Q_{e}=3,165$ psi.

The elastic modulus was not available for the individual measurements but the range of the elastic modulus for the limestone was 8.0 to 9.7 million psi. The strains are calculated using an elastic modulus of 9 million psi. The strains from the maximum and minimum horizontal stresses are 611 and 444 micro strains.

\subsubsection{Pittsburgh Coal Seam}

The Pittsburgh coal seam is located in southwestern Pennsylvania, southeastern Ohio and northern West Virginia. There was information available on the horizontal stress from three different sites in three different mines. Site one was in the Bethlehem Steel Mine \# 60 located about 10 miles east of Washington, PA (Agarwal and Mayer, 1979). Sites 2 and 3 were located about 3 miles apart and about 20 miles southwest of site one. The stresses were measured using the USBM borehole deformation gage and overcoring technique. 
The horizontal stresses at site one were calculated from a three-dimensional stress determination (Agarwal and Mayer, 1979). The three holes used to determine the stress field were drilled into the roof but none were vertical holes. Therefore, the horizontal stress determined from the three-dimensional analysis must be used for the site and not the stresses from the individual measurements. All the measurements at the site were made in a sandstone unit. Based on the tests conducted on rock from the site, the elastic modulus in the horizontal plane ranged from 1.5 to 2.0 million psi and averaged 1.8 million psi. This average elastic modulus and the calculated horizontal stresses from the three-dimensional stress determination were used to calculate the elastic strains for the site.

At sites 2 and 3, the stresses were determined in vertical holes drilled in the roof. Therefore, the individual stress measurements as well as the average horizontal stress at each site were used in the analysis.

For the Pittsburgh seam measurements, the site elastic modulus ranges from 1.8 to 7.65 million psi and the depth from 400 to $800 \mathrm{ft}$. The average site strain from the maximum horizontal stress varies from 403 to 736 micro strains and the strains from the minimum horizontal stress from 285 to 569 micro strains.

\subsubsection{Lower Kittanning Seam}

The lower Kittanning Seam is mined in northern West Virginia and central and southwestern Pennsylvania. Stress data was available from 2 mines, the Tanoma Mine near Indiana, Pennsylvania and a mine near Philippi, West Virginia. The mines are approximately 100 miles apart. Both mines have experienced sufficiently severe ground control problems related to the horizontal stress that the mines have either experimented with or used stress relief mining techniques (Dolinar et al., 2000; Aggson and Mouyard, 1988A, 1988B). The USBM borehole deformation gage and overcoring technique was used to determine the stresses at both mines.

The average site strains from the maximum horizontal stress are 575 and 703 micro strains and the strains from the minimum horizontal stress are 481 and 528 micro strains. In general, the levels of strain appear to be about 20 pct higher in the mine in West 
Virginia. The site elastic modulus and depths are for the Tanoma site 4.29 million psi and $720 \mathrm{ft}$ and for the Philippi site 5.8 million psi and $720 \mathrm{ft}$.

\subsubsection{Summary of Northern Appalachian Region}

This region includes stress measurements made in the coal and limestone mines of southwestern Pennsylvania, northern West Virginia and eastern Ohio. The data indicates that there is a substantial range of the maximum horizontal stress magnitude as well as a large range in the site depths. The maximum site stresses range from 1,324 to 6,910 psi. Over the region the site depth varies from 400 to 2,300 feet and the site elastic modulus from 1.8 to 11.2 million psi. The strains from the maximum horizontal stress for this region range from 403 to 736 micro strains and the strain from the minimum horizontal stress from 285 to 569 micro strains.

\subsection{EASTERN MID-CONTINENT REGION}

This region encompasses sites west of the Appalachian Mountains located in the Illinois basin, Alabama, Tennessee and northern Kentucky. In the Illinois basin, stress measurements from 8 sites in six mines were examined with the measurements being made in both the Springfield \# 5 and the Herrin \# 6 seams. These measurements were made using the USBM borehole deformation gage and overcoring technique. Some mines within the Illinois basin have experienced ground control problems related to the horizontal stress (Blevins, 1982; Blevins and Dopp, 1985; Hanna et al, 1986; Miller 1998). Core disking, another indication of a substantial horizontal stress in comparison to the rock strength has also been observed at some locations (Hanna et al., 1986). There is one site in a limestone mine in northern Kentucky, two sites from the Pratt coal seam in Alabama and one site from a zinc mine in the dolomite formations of eastern Tennessee. The measurements from these mines were also obtained using the USBM borehole gage and overcoring technique. The CSIRO HI-cell was used to determine the horizontal stresses at a site in the Blue Creek/Mary Lee seams in Alabama.

A summary of the individual stress measurement data from each site including the maximum and minimum horizontal stresses, excess horizontal stresses, elastic modulus 
and calculated strains are given in Appendix D, table D-1. Table 4-4 gives a summary of the horizontal stresses for each site.

Table 4-4. Summary of horizontal stresses by site in the eastern Mid-Continent region.

\begin{tabular}{|c|c|c|c|c|c|c|c|}
\hline \multirow[b]{2}{*}{ Mine } & \multicolumn{3}{|c|}{ Horizontal stress } & \multicolumn{2}{|c|}{ Excess stress, psi } & \multirow[b]{2}{*}{$\begin{array}{c}\text { Elastic } \\
\text { modulus, } \\
10^{6} \mathrm{psi}\end{array}$} & \multirow[b]{2}{*}{$\begin{array}{l}\text { Depth } \\
\mathrm{ft}\end{array}$} \\
\hline & $\underset{\text { psi }}{\text { Maximum, }}$ & $\begin{array}{l}\text { Minimum, } \\
\text { psi }\end{array}$ & $\begin{array}{l}\text { Direction } \\
\text { of } \\
\text { maximum } \\
\end{array}$ & Maximum & Minimum & & \\
\hline Wabash, site 1 & 1245 & 963 & East-West & 889 & 607 & 3.11 & 970 \\
\hline Wabash, site 2 & 1429 & 823 & $\mathrm{~N} 80^{\circ} \mathrm{E}$ & 1117 & 511 & 2.9 & 850 \\
\hline Wabash, site 3 & 1459 & 589 & $\mathrm{~N} 75^{\circ} \mathrm{W}$ & 1144 & 274 & 2.85 & 860 \\
\hline Monterey & 888 & 573 & $\mathrm{~N} 64^{\circ} \mathrm{E}$ & 782 & 467 & 1.67 & 290 \\
\hline Galatia & 1767 & 531 & $\mathrm{~N} 73^{\circ} \mathrm{E}$ & 1558 & 322 & 2.96 & 570 \\
\hline Peabody \#2 & 969 & 896 & $\mathrm{~N} 81^{\circ} \mathrm{E}$ & 859 & 786 & 2.2 & 300 \\
\hline Peabody \#10 & 1800 & 750 & $\mathrm{~N} 69^{\circ} \mathrm{E}$ & 1668 & 618 & 2.84 & 360 \\
\hline Turris & 1986 & 1010 & $\mathrm{~N} 49^{\circ} \mathrm{E}$ & 1885 & 909 & 8.57 & 275 \\
\hline $\begin{array}{l}\text { Campbell } \\
\text { County, KY }\end{array}$ & 3784 & 1320 & $\mathrm{~N} 78^{\circ} \mathrm{E}$ & 3516 & 1052 & 9.32 & 730 \\
\hline $\begin{array}{l}\text { Immel Mine, } \\
\text { TN }\end{array}$ & 3294 & 1281 & $\mathrm{~N} 61^{\circ} \mathrm{E}$ & 2954 & 942 & 7.96 & 925 \\
\hline $\begin{array}{l}\text { North River } \\
\text { Mine, site 1, } \\
\text { AL }\end{array}$ & 2123 & 297 & $\mathrm{~N} 57^{\circ} \mathrm{E}$ & 1940 & 114 & 5.42 & 500 \\
\hline $\begin{array}{l}\text { North River } \\
\text { Mine, site 2, } \\
\text { AL }\end{array}$ & 1042 & 385 & $\mathrm{~N} 69^{\circ} \mathrm{E}$ & 870 & 213 & 4.72 & 470 \\
\hline $\begin{array}{l}\text { Jim Walters } \\
\# 7, \text { AL }\end{array}$ & 3050 & 1520 & $\mathrm{~N} 71^{\circ} \mathrm{E}$ & 2364 & 834 & 5.4 & 1870 \\
\hline
\end{tabular}

\subsubsection{Wabash Mine}

The mine is in the Springfield \# 5 seam located near Keansburg, Illinois. There were three measurement sites within the mine (Ingram and Molinda, 1988). For the more general analysis and for calculation of the elastic strains for each site, all measurements are used from hole 1, only the deepest three measurements from hole 2 and only the four deepest measurements from hole 3. This resulted in measurements that were $9.9 \mathrm{ft}$ or deeper into the roof being used in the analysis. The deeper measurements reduced the potential influence of the opening on the results. The average strains from the maximum horizontal stress are for hole 1, 400 micro strains, for hole 2, 493 micro strains, and for 
hole 3, 512 micro strains. From the minimum horizontal stress, the average strains are for hole one, 310 micro strains, for hole two, 284 micro strains and for hole three, 207 micro strains. The range of the individual elastic modulus from 2.63 to 3.39 million psi and the variation of the site depths from 860 to $950 \mathrm{ft}$ are both limited. Hole 1 was about 1,500 ft from a large normal fault with the site possibly influenced to some degree by that feature.

\subsubsection{Monterey Mine}

The mine is located near Carlinville, Illinois in the Herrin \# 6 seam. Because, the two shallower measurements at 4.33 and $6.33 \mathrm{ft}$ show less strain from the maximum horizontal stress than the other measurements, these measurements may be under the influence of the opening. Therefore, only the two deeper measurements are used in the analysis. Based on the deepest two measurements, the average strain due to the maximum horizontal stress is 532 micro strains while the average strain from the minimum horizontal stress is 343 micro strains. The range of the individual elastic modulus is from 1.44 to 1.9 million psi while the site depth is $290 \mathrm{ft}$ (Beerkircher, 1994).

\subsubsection{Galatia Mine}

The mine is located near Galatia, Illinois in the Springfield \# 5 seam. Although measurements were obtained at three sites in the mine, elastic properties were available from only one hole (Ingram and Molinda, 1988). Only the three deepest measurements from 10.1 to $13.1 \mathrm{ft}$ are used in the analysis. The average strain from the maximum horizontal stress is 579 micro strains while the strain from the minimum horizontal stress is 179 micro strains. The range of the elastic modulus for the last three measurements is only from 2.81 to 3.17 million psi. The site depth is $570 \mathrm{ft}$.

\subsubsection{Turris Mine}

The mine is located near Elkhart, Illinois in the Springfield \#5 seam. The measurements are at a relatively shallow depth in the roof at 5.8 and $6.2 \mathrm{ft}$ and may be under the influence of the opening. The range in the elastic modulus is only from 8.08 to 9.05 million psi. The average strain from the maximum horizontal stress is 232 micro 
strains while the average strain from the minimum horizontal stress is 118 micro strains. The site is at a depth of $275 \mathrm{ft}$ and is near a bedrock valley.

\subsubsection{Peabody \# 10 Mine}

The mine is located near Pawnee, Illinois in the Herrin \# 6 seam. The depth of the site is $360 \mathrm{ft}$. For the general analysis only the last three measurements obtained at depths from 9 to 11 feet from the opening are used (Hanna et al., 1991). For these last three measurements there is a large range in the elastic modulus from 1.28 to 5.7 million psi. The average strain from the maximum horizontal stress based on these last three measurements is 634 micro strains while the average strain from the minimum horizontal stress is 264 micro strains.

\subsubsection{Peabody \#2 Mine}

The mine is located near Henderson, Kentucky in the Springfield \# 5 seam. Only the deeper three measurements are used in the more general analysis (Wright et al., 1980; Unrug et al., 1984). At this site, for the last three measurements only one elastic modulus was obtained, an elastic modulus of 2.2 million psi, therefore the stresses and strains are averaged from the last three measurements. Based on these last three measurements, the strain from the maximum horizontal stress is 440 micro strains while the strain from the minimum horizontal stress is 407 micro strains. The depth of the site is $300 \mathrm{ft}$.

\subsubsection{Ft. Campbell Limestone}

The mine is located in the Ft. Campbell Limestone in Campbell County, KY at a depth of $730 \mathrm{ft}$. A complete three-dimensional stress determination was made using the USBM borehole deformation gage and overcoring technique.

The horizontal stresses were calculated from the three-dimensional stress determination. The elastic modulus for the measurements used in the calculations ranged from 8.1 to 11.0 million psi where the average elastic modulus was 9.32 million psi. The resulting average strains from the maximum and minimum horizontal stresses are 406 and 142 micro strains. 


\subsubsection{North River Mine}

This mine is located near Tuscaloosa, Alabama in the Pratt seam with stress measurements made at two sites. The depth of site one was 500 feet. At site one, there were 5 measurements made at depths ranging from 7 to $11 \mathrm{ft}$ in the mine roof, however, the elastic modulus was determined for only 4 of the measurements. The elastic modulus ranges from 5.11 to 5.91 million psi. At site one, the strains from the maximum and minimum site stresses are 392 and 55 micro strains.

Site 2 was at a depth of $470 \mathrm{ft}$ and about 2.3 miles from site one. The site was 600 $\mathrm{ft}$ from a large normal fault. Only the deepest 3 measurements from 8 to $10 \mathrm{ft}$ are used in the analysis. The elastic modulus ranges from 4.45 to 5.12 million psi. The average site strains from the maximum and minimum stress are 221 and 87 micro strains.

\subsubsection{Jim Walters \# 7 Mine}

The mine is located near Brookwood, Alabama in the Blue Creek/Mary Lee seams. The stresses were determined using the CSIRO HI-Cell and overcoring technique (Brasfield and Hendon, 1994; Hendon et al., 1995). The site depth was 1,870 ft. The specific elastic modulus used in the calculations is not given but the average elastic modulus of the main roof where the measurements appear to have been obtained is reported. The elastic modulus based on physical properties determined on vertically oriented core is 5.4 million psi with a standard deviation 1.1 million psi. Using this elastic modulus, the average site strain from the maximum horizontal stress is 565 micro strains and from the minimum horizontal stress 281 micro strains.

\subsubsection{Immel Mine}

The mine is located about 10 miles east of Knoxville, Tennessee in the dolomite and limestone formations that contain zinc mineralization (Crawford and Hoagland, 1968). The depth of the site was $925 \mathrm{ft}$. Measurements were made in a vertical down hole, hole 3 and a vertical up hole, hole 4 . The elastic modulus varied from 4.86 to 11.94 million psi while the average site elastic modulus was 7.96 million psi. Much of the variation in the elastic modulus may be due to mineralization. The average site 
strains are from the maximum horizontal stress, 414 micro strains and from the minimum horizontal stress, 161 micro strains.

\subsubsection{Summary of Eastern Mid-Continent Region}

The region includes sites in Illinois and western Kentucky in both the Springfield \#5 and Herrin \# 6 seams of the Illinois basin, a site in limestone in northern Kentucky, two sites in the Pratt seam and one site in the Blue Creek/Mary Lee seams in Alabama and a site in dolomite formations in eastern Tennessee. Over this region the site elastic modulus varies from 1.67 to 9.32 million psi and the depth ranges from 275 to $1,870 \mathrm{ft}$. The average site strains from the maximum horizontal stress range from 221 to 634 micro strains while the average site strains from the minimum horizontal stress ranges from 55 to 407 micro strains. In general, most sites in this region have very biaxial horizontal stresses and strains. 


\section{CHAPTER 5: BECKLEY COAL SEAM}

Information regarding the depth of the sites and the elastic modulus for the individual stress measurements was available from 15 sites within the Beckley coal seam. Therefore, this geographically concentrated set of data is analyzed with respect to the elastic modulus and the depth. In this part of the analysis, the site data from the Beckley \#4 mine in the Sewell seam is not included. The developed regression models are based on the data found in Appendix A, tables A1 and A2.

In the analysis throughout most of this section, the individual measurements are used rather than site averages. This is done to evaluate more completely the variation that may occur between the stress and the elastic modulus since the elastic modulus will change between each measurement. However, local variation between measurements may occur beyond that caused by the elastic modulus, therefore to eliminate the local variation in one section an analysis is done using the average site stresses and elastic properties. Further, several measurements from a site are usually combined to produce an average site stress that is then used in mine design evaluation.

\subsection{VARIATION OF THE HORIZONTAL STRESS WITH THE ELASTIC MODULUS}

To evaluate the variation of the horizontal stress with respect to the elastic modulus, a regression line is fit through all 60 individual stress measurements from the Beckley seam. Figure 5-1 shows a graph of the maximum horizontal stress versus the elastic modulus along with the resulting regression line. The regression equation is

$$
\mathrm{P}=180 \mathrm{E}+2666
$$

The coefficient of determination is only 0.12 . There is little correlation between the elastic modulus and the maximum horizontal stress. This indicates that the strain field is not very uniform across the Beckley coal seam. 


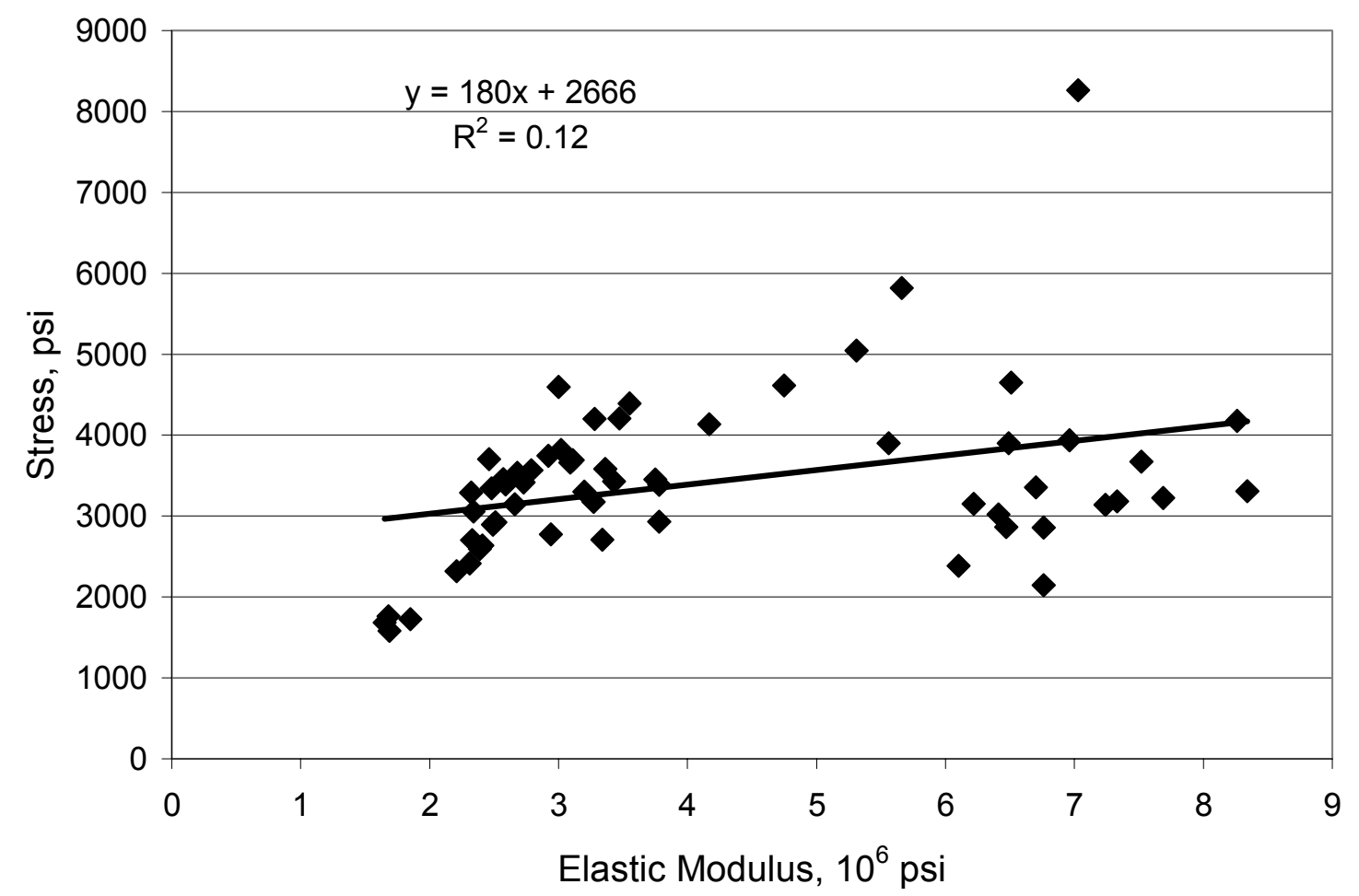

Figure 5-1. The maximum horizontal stress versus the elastic modulus, Beckley coal seam (combined strain zones).

Table 5-1 shows the average strain resulting from the maximum and minimum horizontal stress for each hole. The average strain is calculated based on the strains determined from the individual stress measurements at each site. Essentially, in the Beckley seam/coalfield there are two different strain conditions, a high strain and a low strain field. The high strain field has average site strains above 885 micro strains while the low strain field has average site strains below 602 micro strains. Further, the two strain conditions are geographically distinct. The low strain area includes the sites from the Beckley \#1 Mine and the adjacent southwest section of the Maple Meadows Mine (Figure 5-2). The high strain area includes the sites from the northeast section of the Maple Meadows Mine and the adjoining Beckley and Bonny Mines as well as the Beckley \#2 Mine.

Because of the two distinct strain fields, each strain field is analyzed separately to determine if the horizontal stress varies with the elastic modulus. Figure 5-3 shows a graph of the maximum horizontal stress versus the elastic modulus from the individual 
stress measurements for the high strain area. A regression line is fit through the data with the resulting equation of

$$
\mathrm{P}=878 \mathrm{E}+703
$$

Table 5-1. Average horizontal strains from the maximum and minimum horizontal stresses by site in the Beckley coal seam ${ }^{1}$.

\begin{tabular}{|c|c|c|c|c|c|c|c|c|c|c|}
\hline Mine & Hole & $\begin{array}{c}\text { Average } \\
\text { maximum } \\
\text { micro strain }\end{array}$ & $\begin{array}{l}\text { Standard } \\
\text { deviation }\end{array}$ & $\begin{array}{l}\text { Pct of } \\
\text { strain }\end{array}$ & $\begin{array}{c}\text { Average } \\
\text { minimum } \\
\text { micro strain }\end{array}$ & $\begin{array}{l}\text { Standard } \\
\text { deviation }\end{array}$ & $\begin{array}{l}\text { Pct of } \\
\text { strain }\end{array}$ & $\begin{array}{c}\text { Elastic } \\
\text { modulus } \\
10^{6} \mathrm{psi}\end{array}$ & $\begin{array}{l}\text { Standard } \\
\text { deviation }\end{array}$ & $\begin{array}{l}\text { Depth, } \\
\mathrm{ft}\end{array}$ \\
\hline \multicolumn{11}{|c|}{ Low Strain } \\
\hline Beckley 1 & 2 & 469 & 36 & 7.7 & 279 & 25 & 9.0 & 6.77 & 0.55 & 1130 \\
\hline $\begin{array}{c}\text { Maple } \\
\text { Meadows }\end{array}$ & 6 & 432 & 41 & 9.5 & 420 & 53 & 12.6 & 6.32 & 0.2 & 708 \\
\hline $\begin{array}{c}\text { Maple } \\
\text { Meadows }\end{array}$ & 8 & 601 & 104 & 17.3 & 333 & 41 & 12.3 & 7.09 & 1.02 & 1025 \\
\hline $\begin{array}{c}\text { Maple } \\
\text { Meadows }\end{array}$ & 10 & 481 & 66 & 13.7 & 239 & 30 & 12.6 & 6.92 & 0.24 & 807 \\
\hline Beckley 1 & 15 & 437 & 86 & 19.7 & 242 & 54 & 22.3 & 7.32 & 0.5 & 700 \\
\hline Average & & 484 & 69 & 14.3 & 303 & 78 & 25.7 & 6.88 & & 874 \\
\hline \multicolumn{11}{|c|}{ High Strain } \\
\hline Beckley \#2 & 3 & 1021 & 2 & 0.2 & 742 & 12 & 1.6 & 2.26 & 0.07 & 1100 \\
\hline Bonny & 4 & 886 & 192 & 21.7 & 846 & 185 & \begin{tabular}{|l|}
21.9 \\
\end{tabular} & 3.59 & 0.24 & 1136 \\
\hline Bonny & 5 & 1018 & 114 & 11.2 & 554 & 137 & 24.7 & 6 & 0.96 & 1148 \\
\hline $\begin{array}{c}\text { Maple } \\
\text { Meadows }\end{array}$ & 7 & 1008 & 423 & 42.0 & 730 & 344 & 47.1 & 4.44 & 1.31 & 735 \\
\hline $\begin{array}{c}\text { Maple } \\
\text { Meadows }\end{array}$ & 9 & 1296 & 147 & 11.3 & 957 & 201 & 21.0 & 2.46 & 0.08 & 814 \\
\hline $\begin{array}{l}\text { Beckley } \\
\text { Mining }\end{array}$ & 11 & 1049 & 215 & 20.5 & 850 & 282 & 33.2 & 2.95 & 0.58 & 640 \\
\hline $\begin{array}{l}\text { Beckley } \\
\text { Mining }\end{array}$ & 12 & 1260 & 53 & 4.2 & 987 & 32 & 3.2 & 2.94 & 0.29 & 870 \\
\hline $\begin{array}{l}\text { Beckley } \\
\text { Mining }\end{array}$ & 13 & 1157 & 128 & 11.1 & 863 & 134 & 15.5 & 2.7 & 0.24 & 800 \\
\hline $\begin{array}{l}\text { Beckley } \\
\text { Mining }\end{array}$ & 14 & 1076 & 104 & 9.7 & 651 & 82 & 12.6 & 3.5 & 0.41 & 1040 \\
\hline Beckley \#2 & 16 & 1047 & 61 & 5.8 & 783 & 10 & 1.3 & 1.72 & 0.09 & 350 \\
\hline Average & & 1082 & 123 & 11.4 & 796 & 133 & 16.7 & 3.26 & 1.23 & 863 \\
\hline
\end{tabular}

${ }^{1}$ Each hole is a separate site location. The individual measurements used to develop the average values are given in Appendix A. 


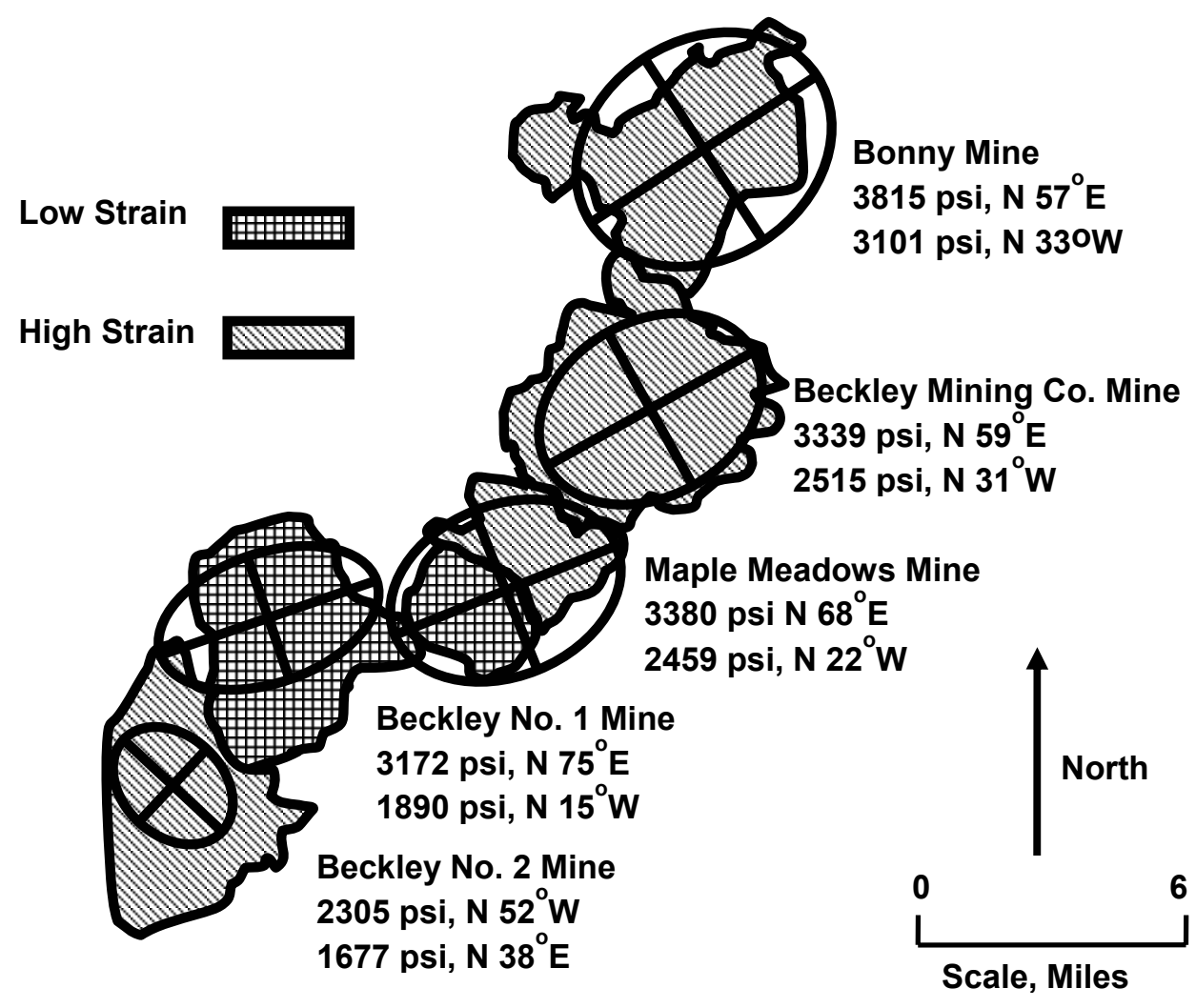

Figure 5-2. Low and high strain zones in the Beckley Seam (modified from Agapito et al., 1980A).

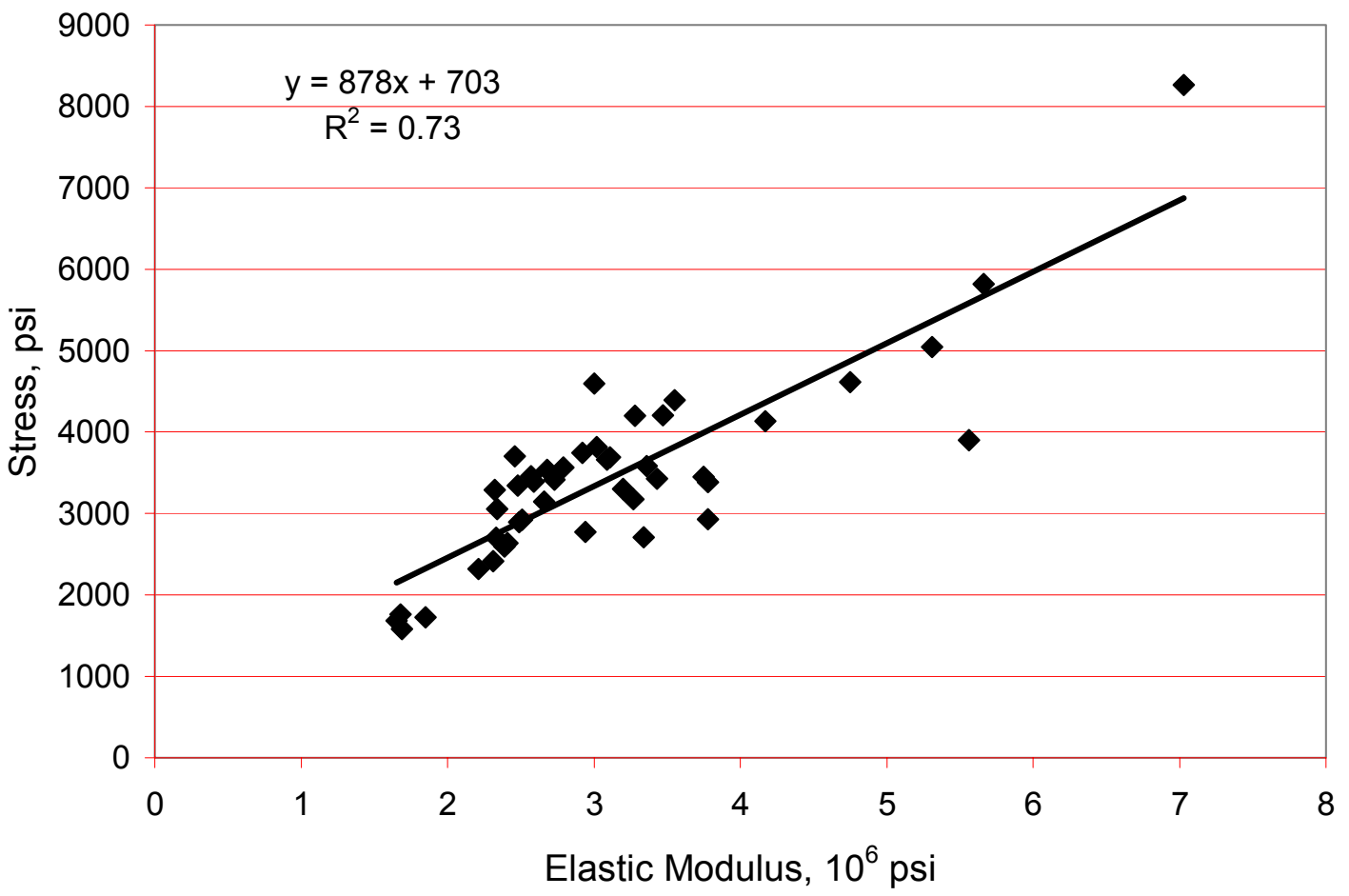

Figure 5-3. The maximum horizontal stress versus the elastic modulus, Beckley coal seam (high strain zone). 
The coefficient of determination is 0.73 . There is a fairly strong correlation between the maximum horizontal stress and the elastic modulus. However, there is still sufficient variation in the strain field to result in a coefficient of determination that is somewhat less than one. Some of this variation is the result of the strains varying horizontally across the zone as seen by the difference in average between holes (table 5-1). However, some of the variation is also the result of the strain field varying vertically or between measurements in the same hole as can be seen by the standard deviation for each hole in table 5-1. Further, any difference in the strain field resulting from the variation in depth between sites has not been taken into account.

Figure 5-4 shows a graph of the maximum horizontal stress versus the elastic modulus for the low strain region. Again, a linear regression is fit through the data with the resulting equation of

$$
\mathrm{P}=267 \mathrm{E}+1439
$$

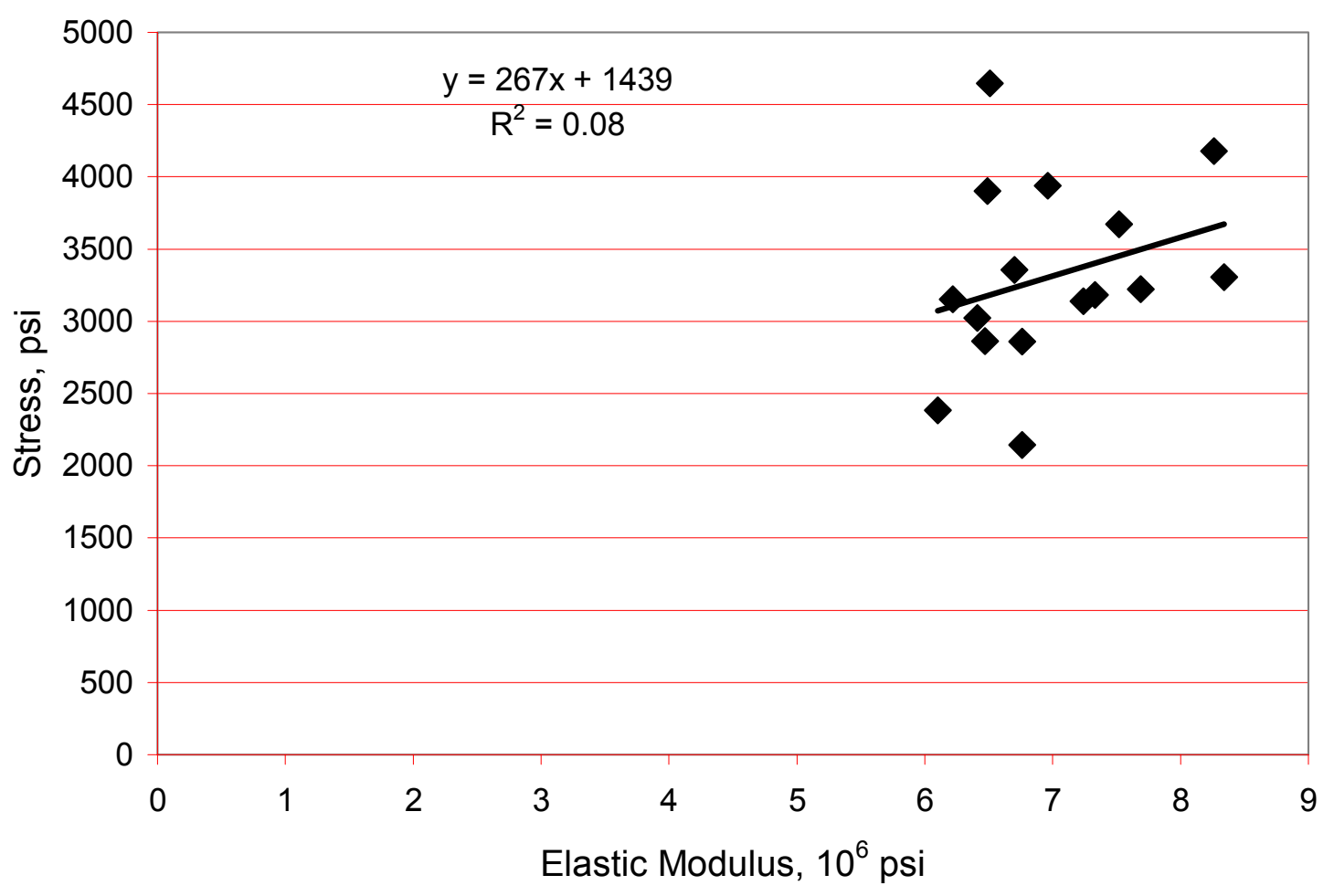

Figure 5-4. The maximum horizontal stress versus the elastic modulus, Beckley coal seam (low strain zone). 
The coefficient of determination is only 0.08 . Although the trend is for increasing horizontal stress with the elastic modulus, the correlation is very poor even though it appears the measurements are taken from essentially the same strain field. Further, the increase in stress with the elastic modulus is much less than for the high strain field as indicated by the coefficients for the elastic modulus for each equation. With the lower strain field, the affects on the increase in the horizontal stress are proportionally less than for a higher strain field and in this case, the changes are not sufficient to overcome the local or mine wide variations in the strain field. Further, the range of the elastic modulus is limited with this set of measurements, ranging only from 6.1 to 8.34 million psi. This limited range results in a less reliable model.

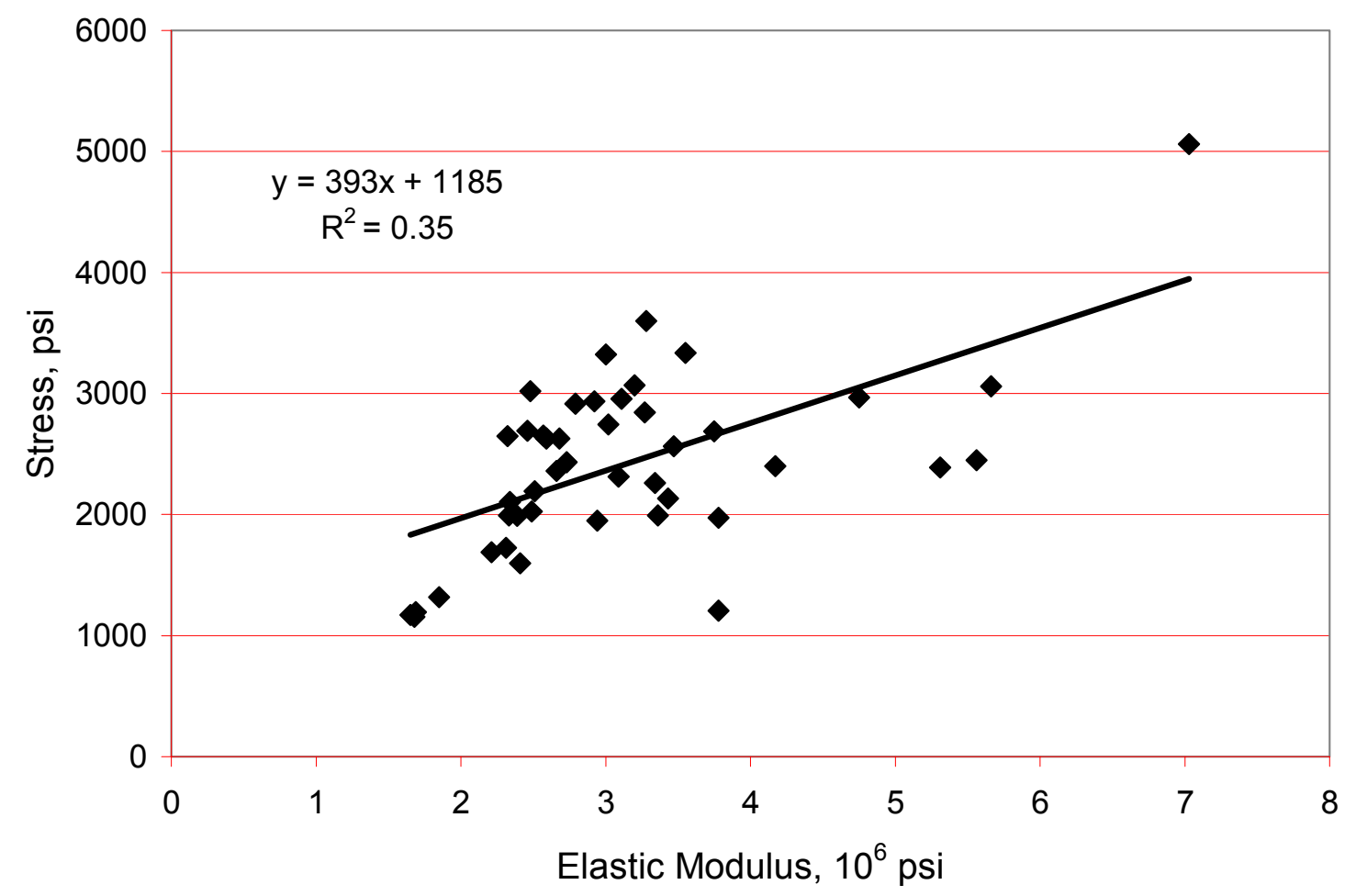

Figure 5-5. The minimum horizontal stress versus the elastic modulus, Beckley coal seam (high strain zone).

The relationship between the minimum horizontal stress and the elastic modulus is also examined. Again, the minimum horizontal stress is segmented into two distinct 
strain fields. Figure 5-5 shows the minimum horizontal stress versus the elastic modulus for the high strain zone. The resulting regression equation is

$$
Q=393 E+1185 .
$$

The coefficient of determination is 0.35 . Although there is trend of increasing horizontal stress with the elastic modulus, the correlation is much less than for the maximum horizontal stress. The larger constant, the relatively higher standard deviation of the strain and the greater site strain range indicates that the strain field from the minimum horizontal stress across the Beckley seam is not as uniform as the strain from the maximum horizontal stress. Further, the lowest strain site has the highest elastic modulus (table 5-1).

Figure 5-6 shows the minimum horizontal stress versus the elastic modulus for the low strain zone. Again a regression line is fit through the data. The coefficient of determination is only 0.03 . Essentially, there is no correlation between the minimum horizontal stress and the elastic modulus for the low strain zone.

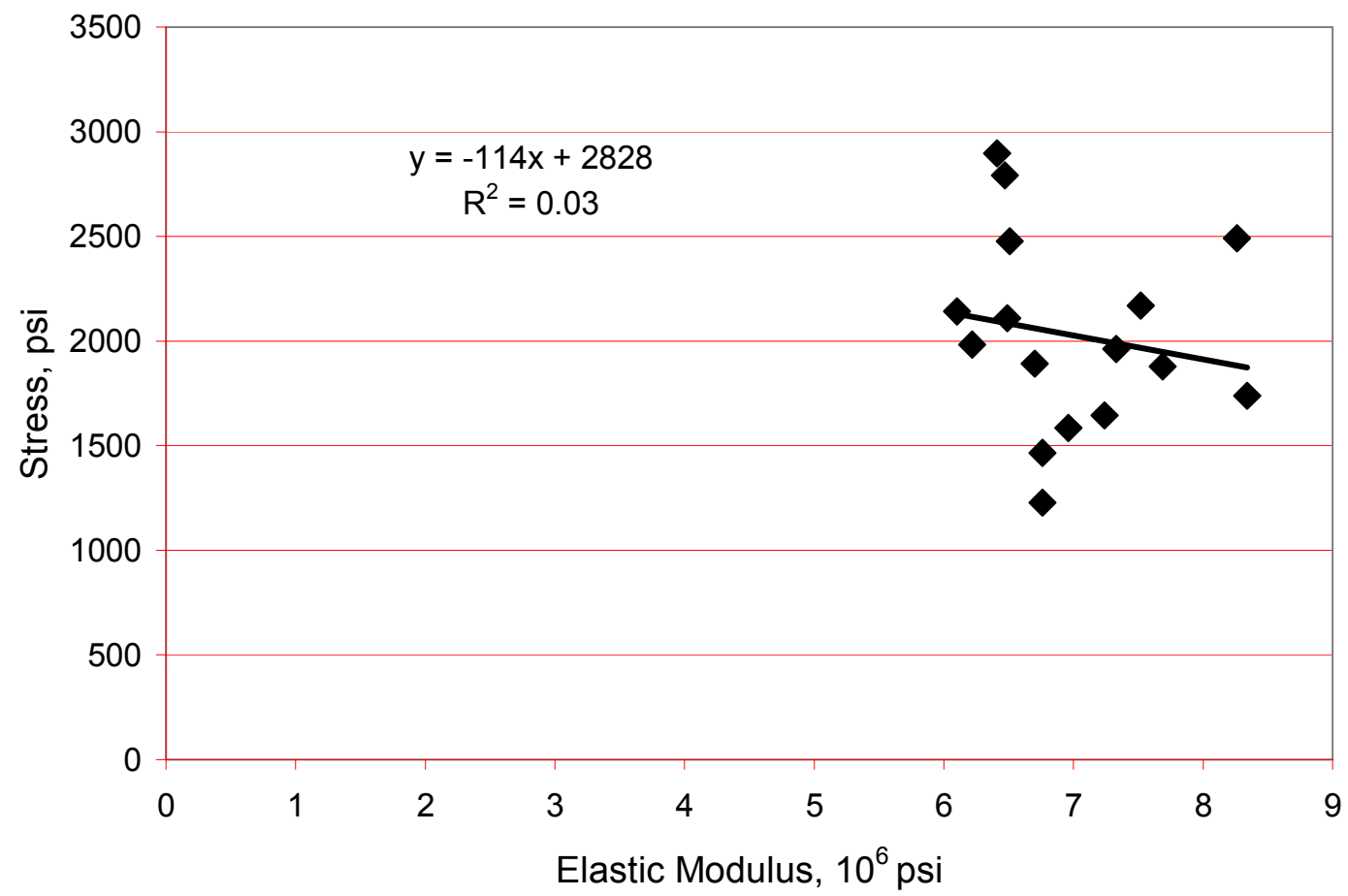

Figure 5-6. The minimum horizontal stress versus the elastic modulus, Beckley coal seam (low strain zone). 
There is only a very weak relationship between the minimum horizontal stress and the elastic modulus. This in part is due to the strain fields from the minimum horizontal stress being less uniform. This can be seen with the standard deviation of the minimum strain being a much higher percent of the average than for the maximum strain (table 5-1). Further, these strains are much lower than the maximum strains and, therefore, there will be less increase in stress with the elastic modulus. There does appear to be a difference between the two stress components with the minimum component not being as strongly influenced by the elastic modulus.

\subsection{VARIATION OF HORIZONTAL STRESS WITH DEPTH}

Since there is a range of depths for the sites in the Beckley seam, the influence of depth on the measurements is evaluated. When examining the Beckley data for depth effects, all the data is combined where the data is not separated based on the two distinct strain fields. Further, only the site average maximum horizontal stress is used in the analysis. The average is used to give equal weight to all sites. Figure 5-7 shows a graph of the average maximum horizontal stress from each site versus the depth with a regression line fit through the data. The resulting equation is

$$
\mathrm{P}=2.08 \mathrm{D}+1629 \text {. }
$$

However, the coefficient of determination is only 0.22 . The correlation is low but there is a general trend of increasing maximum horizontal stress with depth. In fact, the horizontal stress is increasing at a rate of $2.1 \mathrm{psi} / \mathrm{ft}$. This is twice the rate for the expected increase of the vertical stress. However, when the depth coefficient is compared to zero, the $t$ statistic of 1.94 indicates that the coefficient is not significantly greater than zero at a 0.05 significance level.

Further, one data point controls to a large extent the increase of the maximum horizontal stress with depth, the Bonny Mine, hole 5, with a maximum horizontal stress of $6,109 \mathrm{psi}$ at a depth of $1,148 \mathrm{ft}$. Without this data point, the depth factor drops to $1.1 \mathrm{psi} / \mathrm{ft}$ of depth while the coefficient of determination is only 0.12 . However, it may not be the depth that is causing such a high horizontal stress at this site but the relatively 
high elastic modulus of 6 million psi in the high strain zone. Therefore, no apparent significant increase in the maximum horizontal stress with depth over the Beckley seam is observed. However, the topography in the Beckley area is mountainous and therefore variable and complex.

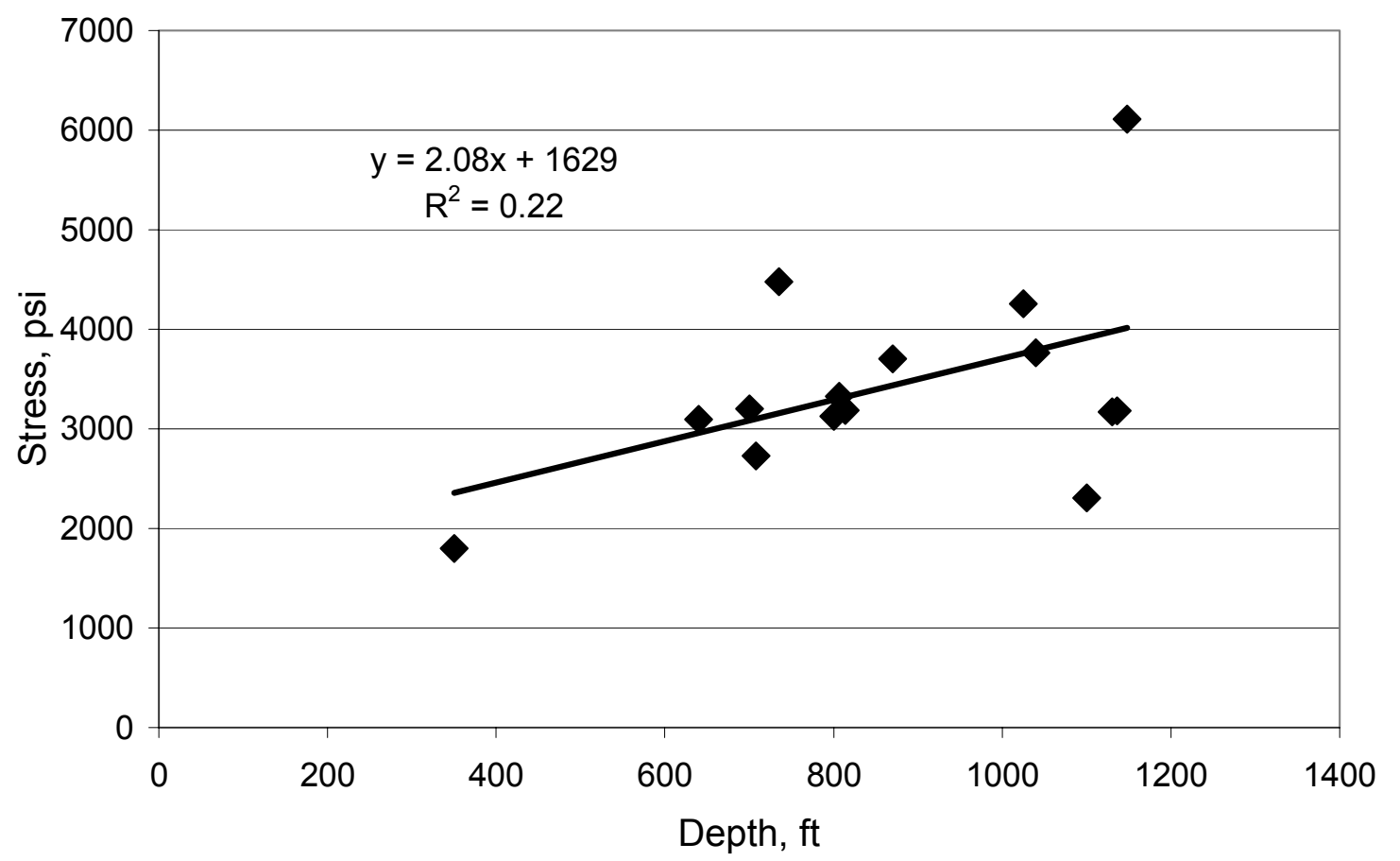

Figure 5-7. The maximum horizontal stress versus the depth, Beckley coal seam.

Figure 5-8 shows the strain from the maximum horizontal stress versus the depth. These strains can be considered as the stress normalized by the elastic modulus. The strain actually decreases slightly with depth though the coefficient of determination of only 0.001 indicates that there is no relationship between the depth and the strain. Essentially, when the effects of the elastic modulus are removed from the stress data, there is no depth factor. Further, the difference in the two strain fields (low and high) is not the result of depth otherwise there should be a strong relationship between depth and the strain. 


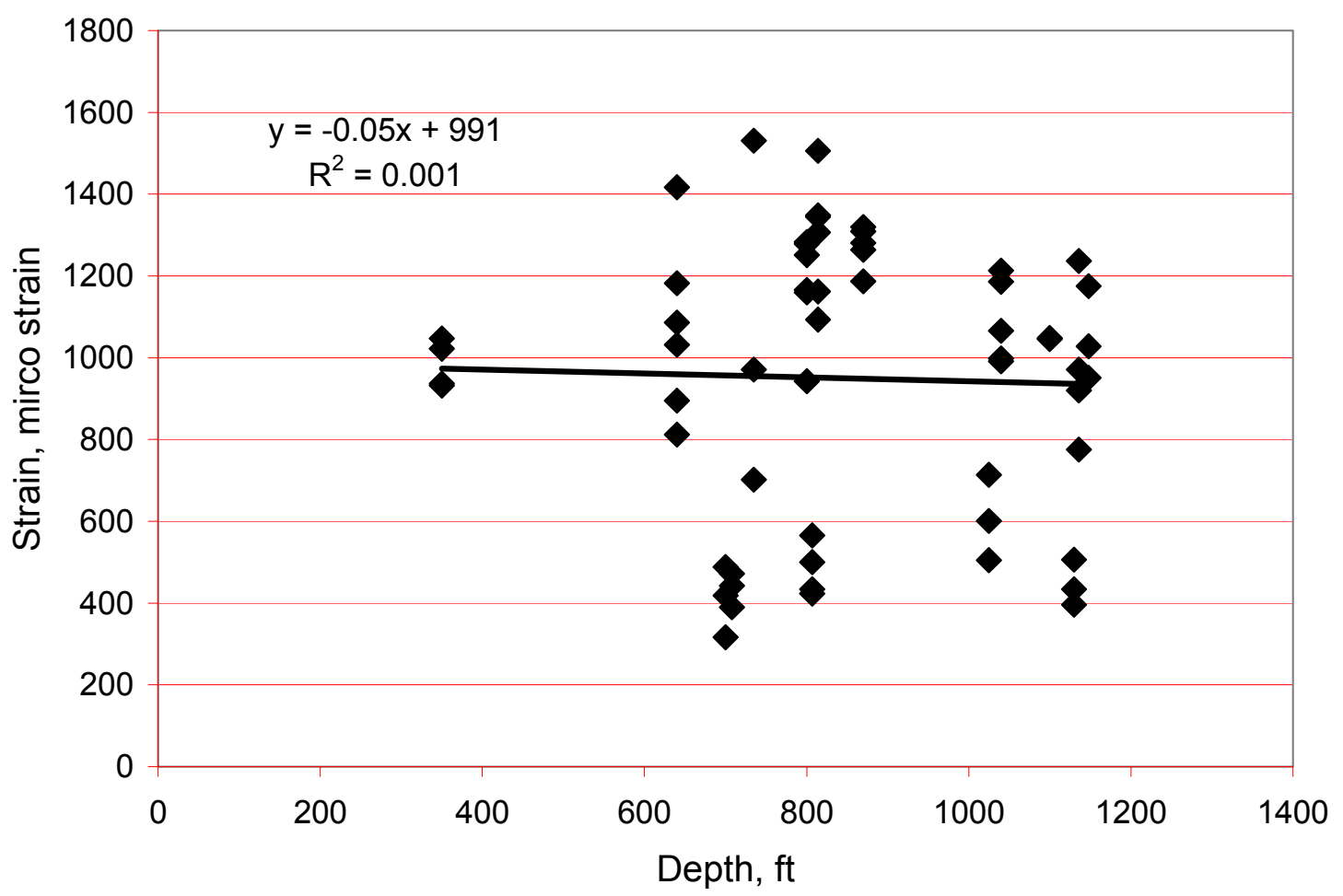

Figure 5-8. The strain from the maximum horizontal stress versus the depth, Beckley coal seam (combined strain zones).

\subsection{VARIATION OF HORIZONTAL STRESS WITH BOTH THE ELASTIC MODULUS AND DEPTH}

A multiple regression analysis with the horizontal stress as the dependent variable and the elastic modulus and depth as the independent variables is also conducted. In this case, the individual stress measurements are used. However, with the inclusion of the elastic modulus, the analysis must be separated into the low and high strain zones. From a regression analysis on the data from the low strain zone, the following equation results

$$
\mathrm{P}=1.53 \mathrm{D}+169 \mathrm{E}+797 .
$$

The multiple correlation coefficient squared is 0.24 . This is certainly an improvement over the coefficient of determination for just the elastic modulus. The maximum horizontal stress is increasing at $1.5 \mathrm{psi} / \mathrm{ft}$ but the $\mathrm{t}$ statistic of 1.67 indicates that the coefficient is not significantly greater than zero at a 0.05 significance level. The strain coefficient is low at 169 micro strains. 
For the high strain zone, the multiple regression analysis results in the following equation

$$
\mathrm{P}=0.73 \mathrm{D}+797 \mathrm{E}+343 .
$$

The multiple correlation coefficient is 0.75 . There is little improvement over the regression analysis with only the elastic modulus. Further, the $t$ statistic for the depth coefficient is only 1.55 where the coefficient is not significantly greater than zero at a 0.05 significance level.

The multiple linear regression analysis provides little or no additional information to explain the variation of the maximum horizontal stress in the high strain zone. This is to a large measure due to the weak influence of the depth on the maximum horizontal stress. For the low strain zone, although the inclusion of depth has improved the model, the depth factor is not significantly greater than zero. Therefore, the depth does not appear to be a major factor in the change in magnitude of the maximum horizontal stress in the Beckley seam.

\subsection{EXCESS HORIZONTAL STRESS}

To establish the relationship between the elastic modulus and excess horizontal stress, a linear regression is fit through both the high and low strain data sets. For the maximum excess horizontal stress from the high strain zone, the resulting equation is

$$
\mathrm{P}_{\mathrm{e}}=824 \mathrm{E}+578 .
$$

The coefficient of determination is 0.72 . There is fairly good correlation between the elastic modulus and the maximum excess horizontal stress where the model can explain about 72 percent of the variation in the maximum excess horizontal stress. Fitting the linear regression through zero results in the relationship between the elastic modulus and the maximum excess horizontal stress without a constant. The resulting equation is

$$
P_{e}=988 \text { E. }
$$


The coefficient of determination is 0.69 . The model fit is only slightly reduced by constraining the fit through zero. From the coefficient of the equation, the excess or tectonic strain component producing the maximum excess stress is 988 micro strains.

The equation for the minimum excess horizontal stress for the high strain zone is

$$
\mathrm{Q}_{\mathrm{e}}=339 \mathrm{E}+1061 \text {. }
$$

The coefficient of determination is 0.30 . The correlation is poor and the model can only explain 30 percent of the variation of the minimum excess horizontal stress. Fitting the regression line through zero results in a negative coefficient of determination. The variation of the minimum excess horizontal stress is much less dependent on the elastic modulus than the maximum excess horizontal stress.

For the low strain region, the coefficient of determination from fitting a regression through the data is for the maximum excess horizontal stress only 0.07 and for the minimum excess horizontal stress only 0.04 . Essentially, for the low strain zone, there is little or no relationship between the excess horizontal stress and the elastic modulus. Regression line fits are so poor that the model coefficients are meaningless.

\subsection{VARIATION OF THE HORIZONTAL STRESS WITH THE ELASTIC MODULUS BASED ON SITE AVERAGE STRESSES}

The relationship between the horizontal stress and the elastic modulus is evaluated using the site average stresses and not the individual stress measurements. This should reduce the effects of local variations in the stress and strain fields. Further, individual measurements are normally combined to develop the average stress field at a site. Table 5-2 shows the regression equations for the maximum horizontal stress versus the elastic modulus based on both the individual measurements and the site averages. 
Table 5-2. Comparison of the regression parameters and statistics based on individual or average site stresses, Beckley coal seam.

\begin{tabular}{|c|c|c|c|c|}
\hline Analysis & $\begin{array}{c}\text { Stress } \\
\text { component }\end{array}$ & $\begin{array}{c}\text { Elastic modulus coefficient, } \\
\mathrm{K}_{1}, \text { micro strain }\end{array}$ & $\begin{array}{c}\text { Constant, } \\
\mathrm{K}_{2}\end{array}$ & $\begin{array}{c}\text { Coefficient of } \\
\text { determination, } \\
\mathrm{R}^{2}\end{array}$ \\
\hline \multicolumn{5}{|c|}{ Measured stress-high strain zone } \\
\hline Individual & Maximum & 878 & 703 & 0.73 \\
\hline Average & Maximum & 926 & 459 & 0.92 \\
\hline Individual & Minimum & 393 & 1185 & 0.35 \\
\hline Average & Minimum & 437 & 1077 & 0.69 \\
\hline \multicolumn{5}{|c|}{ Measured stress-low strain zone } \\
\hline Individual & Maximum & 268 & 1439 & 0.08 \\
\hline Average & Maximum & 867 & -2637 & 0.33 \\
\hline Individual & Minimum & -114 & 2828 & 0.03 \\
\hline Average & Minimum & -702 & 6897 & 0.38 \\
\hline
\end{tabular}

For the high strain zone, the regression coefficients and constants are similar. However, the correlations are much better when the site averages are used. For the maximum stress, the coefficient of determination went from 0.73 to 0.92 while for the minimum stress the coefficient of determination went from 0.35 to 0.69 . This difference reflects the local variations in the strain field between individual measurements at a site.

For the low strain zone, the coefficient of determination certainly improves when the averages are used. However, the regression coefficients and constants for the equations are quite different. This reflects the narrowing of an already small range of the elastic modulus. For the individual stress measurements, the elastic modulus ranges from 6.1 to 8.34 million psi while for the site averages, the elastic modulus ranges from only 6.32 to 7.32 million psi.

\subsection{VARIATION OF THE HORIZONTAL STRESS WITH THE ELASTIC MODULUS AT INDIVIDUAL SITES AND MINES}

By looking at the individual sites and mines, there should be less variation in the strain field and potentially better correlation between the horizontal stress magnitude and the elastic modulus. Therefore, the relationship between the elastic modulus and the horizontal stress for individual sites and mines is evaluated. 
Equation 3.1 is used as the regression model to fit to the maximum horizontal stress and elastic property data for each of the individual sites. Table 5-3 shows the resulting coefficients, constants and the coefficients of determination from the equations for each site.

Table 5-3. Constants and correlations from a regression fit for the maximum
horizontal stress from individual sites in Beckley coal seam.

\begin{tabular}{|l|c|c|c|c|c|c|}
\hline \multicolumn{1}{|c|}{ Site/hole } & $\begin{array}{c}\text { Number of } \\
\text { measurements }\end{array}$ & $\begin{array}{c}\text { Coefficient } \\
\mathrm{K}_{1}\end{array}$ & $\begin{array}{c}\text { Constant } \\
\mathrm{K}_{2}\end{array}$ & $\begin{array}{c}\text { Coefficient of } \\
\text { determination } \\
\mathrm{R}^{2}\end{array}$ & $\begin{array}{c}\text { Elastic } \\
\text { modulus } \\
\text { range, } \\
10^{6} \mathrm{psi}\end{array}$ & $\begin{array}{c}\text { Elastic } \\
\text { modulus } \\
\text { span, } 10^{6} \\
\mathrm{psi}\end{array}$ \\
\hline \multicolumn{7}{|c|}{ Low Strain } \\
\hline Beckley\#1, hole 2 & 3 & 52 & 2868 & 0.40 & $6.22-8.34$ & 2.12 \\
\hline Maple Meadows, hole 6 & 3 & 1262 & -5357 & 0.97 & $6.1-6.47$ & 0.37 \\
\hline Maple Meadows, hole 8 & 3 & -55 & 4559 & 0.02 & $6.47-8.26$ & 1.79 \\
\hline Maple Meadows, hole 10 & 4 & 328 & 976 & 0.02 & $6.76-7.24$ & 0.48 \\
\hline Beckley \#1, hole 15 & 3 & 1386 & -7148 & 0.78 & $6.76-7.69$ & 0.93 \\
\hline \multicolumn{7}{|c|}{ High Strain } \\
\hline Beckley \#2, hole 3 & 2 & -1050 & 4888 & 1.00 & $2.21-231$ & 0.1 \\
\hline Bonny, hole 4 & 4 & -220 & 4243 & 0.01 & $3.27-3.78$ & 0.51 \\
\hline Bonny, hole 5 & 3 & 1706 & -4045 & 1.00 & $5.31-7.03$ & 1.72 \\
\hline Maple Meadows, hole 7 & 3 & -206 & 5132 & 0.52 & $3-5.56$ & 2.56 \\
\hline Maple Meadows, hole 9 & 6 & 1976 & -1735 & 0.19 & $2.34-2.57$ & 0.23 \\
\hline Beckley Mining, hole 11 & 6 & 224 & 2338 & 0.15 & $2.32-3.78$ & 1.46 \\
\hline Beckley Mining, hole 12 & 5 & 878 & 1045 & 0.83 & $2.59-3.28$ & 0.69 \\
\hline Beckley Mining, hole 13 & 6 & 122 & 2582 & 0.01 & $2.33-2.94$ & 0.61 \\
\hline Beckley Mining, hole 14 & 5 & 446 & 2188 & 0.31 & $3.09-4.17$ & 1.08 \\
\hline Beckley \# 2, hole 16 & 4 & 211 & 1453 & 0.06 & $1.65-1.85$ & 0.2 \\
\hline
\end{tabular}

There is a wide range of coefficients of determination with several sites showing poor or little or no correlation. The poor correlations result to a large degree from the very narrow range of the elastic modulus measured at each site. The span for the elastic modulus ranged from 0.1 to 2.56 million psi. In general, the regression analysis with the wider ranges of the elastic modulus gives a better correlation. Therefore, a sufficient range of the elastic modulus is usually required to overcome the local variations in the strain field and to establish a reliable model. However, there are some exceptions where a narrow range has resulted in a higher correlation. There is also at least one site with a 
wider range of elastic modulus yet with almost no correlation. This reflects the significant variation of the strain field between measurements.

There is also a wide range of coefficients and constants that were determined even in essentially the same strain field with some of the coefficients being negative. Again this reflects the narrow range of the elastic properties used in the regression analysis. With such a narrow range of the elastic modulus, the values of the coefficients and constants can vary significantly.

To develop a broader range of the elastic modulus, the data from each mine is considered. Table 5-4 shows the coefficients, constants and the coefficients of determination from a regression analysis for each mine. However, the Maple Meadows Mine sites are separated into high and low strain groups for the analysis.

Table 5-4. Constants and correlations from a regression fit for the maximum horizontal stresses from each mine in the Beckley coal seam.

\begin{tabular}{|l|c|c|c|c|c|c|}
\hline \multirow{2}{*}{ Mine } & \multirow{2}{*}{$\begin{array}{c}\text { Number of } \\
\text { measurements }\end{array}$} & $\begin{array}{c}\text { Coefficient } \\
\mathrm{K}_{1}\end{array}$ & $\begin{array}{c}\text { Constant } \\
\mathrm{K}_{2}\end{array}$ & $\begin{array}{c}\text { Coefficient of } \\
\text { determination } \\
\mathrm{R}^{2}\end{array}$ & \multicolumn{2}{|c|}{ Elastic modulus, $10^{6} \mathrm{psi}$} \\
\cline { 5 - 7 } & 6 & 309 & 845 & 0.2 & $6.22-8.34$ & 2.12 \\
\hline Beckley \#1 & 6 & 968 & 161 & 0.93 & $1.65-2.31$ & 0.66 \\
\hline Beckley \#2 & 22 & 545 & 1780 & 0.31 & $2.51-4.17$ & 1.66 \\
\hline Beckley & 7 & 1267 & -1132 & 0.9 & $3.27-7.03$ & 3.7 \\
\hline $\begin{array}{l}\text { Bonny } \\
\text { Maple Meadows }\end{array}$ & 10 & 502 & 18 & 0.18 & $6.1-8.26$ & 2.66 \\
\hline $\begin{array}{l}\text { Maple Meadows } \\
\text { (High) }\end{array}$ & 9 & 354 & 2474 & 0.36 & $2.34-5.56$ & 3.22 \\
\hline
\end{tabular}

At the Bonny Mine, the span of the elastic modulus is sufficient to result in a very good correlation between the maximum horizontal stress and the elastic modulus. Figure 5-9 shows the maximum horizontal stress versus the elastic modulus for the mine. At the Bonny Mine, the strain field is sufficiently uniform with a large enough range of the elastic modulus for an adequate model to be developed. Further, fitting a regression line through the maximum excess horizontal stress data and zero results in the following equation

$$
P_{e}=933 E
$$


The resulting coefficient of determination is 0.85 . The mine is being subjected to a strain from the maximum excess horizontal stress of 933 micro strains.

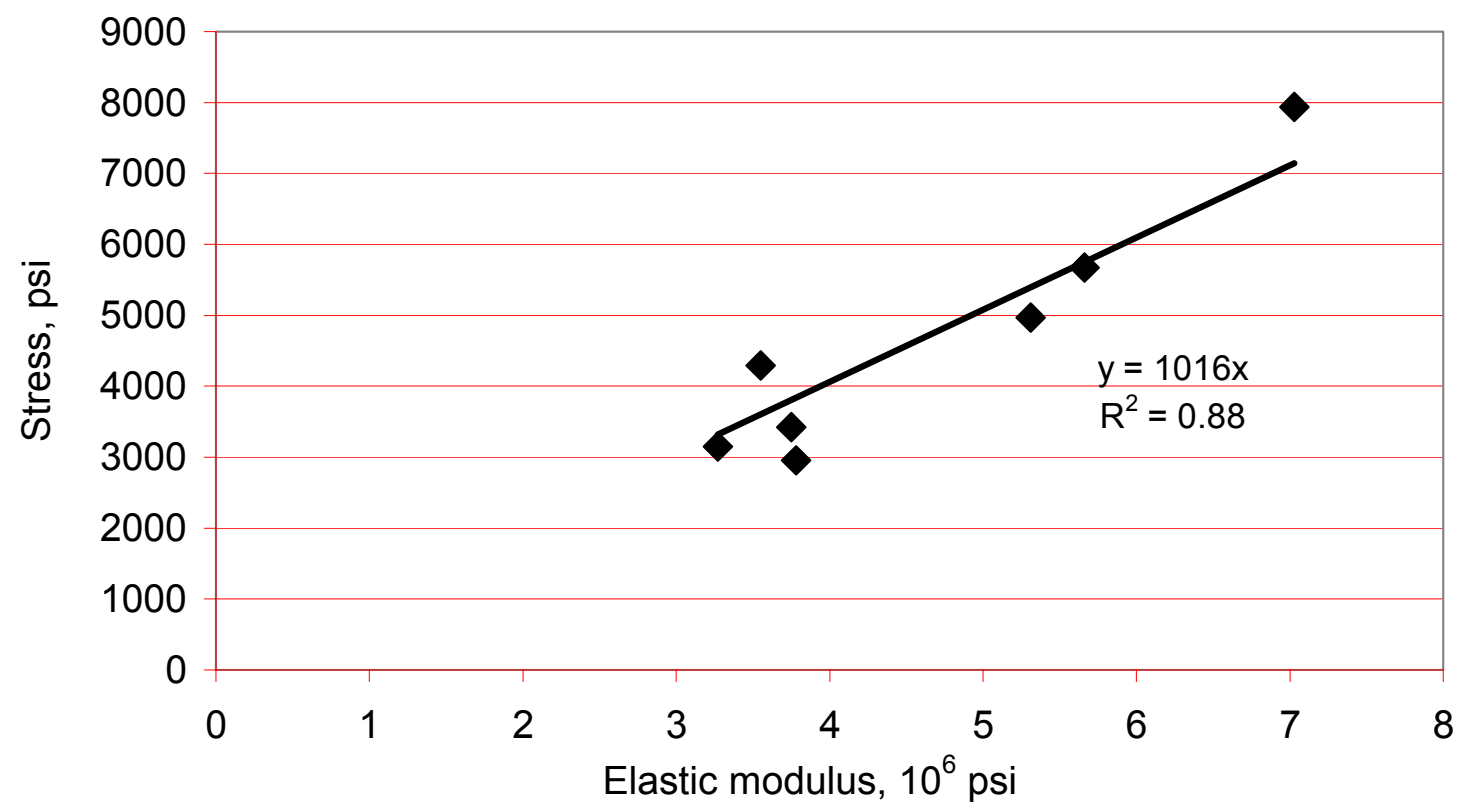

Figure 5-9. The maximum horizontal stress versus the elastic modulus, Bonny mine.

\subsection{BECKLEY SEAM ANALYSIS-CONCLUSIONS}

A sufficiently uniform strain field is required to develop adequate regression models. When all the Beckley seam data was combined there was little correlation between the maximum horizontal stress and the elastic modulus because of the large range in site maximum horizontal strains.

The sites in the Beckley seam can be separated into high and low strain zones that are geographically distinct. The high strain group contains those sites with strains from the maximum horizontal stress above 885 micro strains and the low strain group contains sites with strains from the maximum horizontal stress below 602 micro strains.

The elastic modulus explains much of the variation of the maximum horizontal stress in the high strain zone. For the high strain zone models, the coefficient of determination is 0.73 when individual stress measurements are used and 0.92 when the site averages are used. 
A sufficient range of the elastic modulus is required to establish adequate relationships between the maximum horizontal stress and the elastic modulus. For the low strain zone there was little correlation between the maximum horizontal stress and the elastic modulus in part because of the limited elastic modulus range.

The minimum horizontal stress variation is less dependent on the elastic modulus than the maximum horizontal stress variation. For the minimum horizontal stress in the high strain zone, the coefficient of determination is only 0.35 for the individual measurements.

Depth did not cause a significant increase in the maximum horizontal stress across the seam even though the depth factor is $2.1 \mathrm{psi} / \mathrm{ft}$. Further, the maximum horizontal stress normalized by the elastic modulus actually decreases with depth though not significantly. Essentially, the variation of the maximum horizontal stress that might be attributed to the depth can be explained by the elastic modulus. 


\section{CHAPTER 6.0: VARIATION OF STRAINS IN THE EASTERN UNITED STATES}

If general or more general models are to be developed between the horizontal stress and the elastic modulus, the distribution of strains across the eastern United States needs to be examined. Based on the previous Beckley seam analysis, geographic regions where the strain fields are sufficiently uniform must be identified. Essentially, strains can be used to delineate what zones any stress models can be applied across and whether regional groupings can be used in the evaluation of the variation of the horizontal stress magnitude. If geographic regions with sufficiently uniform strains are established, the variation in the magnitude of the horizontal stress should be to a large degree dependent on the elastic modulus.

The analysis of regional site variation is developed by evaluation of the average site strains. However, the local site variations to the strain field are also examined. Essentially, this establishes the reliability of the average site strains. Besides the elastic properties, the variation of the strain field both locally and regionally will directly affect the magnitude and the variation in the magnitude of the horizontal stress.

In this section, the actual applied horizontal strains are calculated and used to evaluate the strain variation both locally and regionally. There are two horizontal strain components, the maximum and minimum applied horizontal strains that produce a horizontal stress. Further, to determine the strains locally, the average strain based on each measurement from a site is calculated and to develop strains regionally, the average strain from each site is combined with the average strains from other sites within a region.

\subsection{DETERMINATION OF THE APPLIED HORIZONTAL STRAINS}

The relationship between the maximum horizontal stress and the applied maximum and minimum horizontal strain is given by the following equation (Amadi, 1996)

$$
\mathrm{P}=\mathrm{E}\left(\varepsilon_{\mathrm{pA}}+v \varepsilon_{\mathrm{qA}}\right) /\left(1-v^{2}\right)+1.1[v /(1-v)] \mathrm{D}
$$


where $\varepsilon_{\mathrm{pA}}=$ applied maximum horizontal strain, micro strain,

and $\quad \varepsilon_{\mathrm{qA}}=$ applied minimum horizontal strain, micro strain.

Rewriting the equation results in the maximum excess horizontal stress

$$
\mathrm{P}_{\mathrm{e}}=\mathrm{P}-1.1[v /(1-v)] \mathrm{D}=\mathrm{E}\left(\varepsilon_{\mathrm{pA}+} v \varepsilon_{\mathrm{qA}}\right) /\left(1-v^{2}\right) .
$$

A similar equation can be developed for the minimum excess horizontal stress

$$
\mathrm{Q}_{\mathrm{e}}=\mathrm{Q}-1.1[v /(1-v)] \mathrm{D}=\mathrm{E}\left(\varepsilon_{\mathrm{qA}}+v \varepsilon_{\mathrm{pA}}\right) /\left(1-v^{2}\right) .
$$

Solving equations 6.2 and 6.3 for the strains results in the following equations

$$
\varepsilon_{\mathrm{pA}}=\left(\mathrm{P}_{\mathrm{e}}-v \mathrm{x} \mathrm{Q}_{\mathrm{e}}\right) / \mathrm{E}
$$

and

$$
\varepsilon_{\mathrm{qA}}=\left(\mathrm{Q}_{\mathrm{e}}-v \mathrm{P}_{\mathrm{e}}\right) / \mathrm{E}
$$

The applied strains are then calculated using equations 6.4 and 6.5 with a Poisson's ratio of 0.25 . These strain components are the actual strains that are being applied.

\subsection{LOCAL STRAIN VARIATIONS}

In examining the local strain fields, both the average applied strain for a given site and the standard deviation are determined. The site average strains are calculated from the average excess stresses at each site. The standard deviations are calculated from strains from the individual stress measurements. This standard deviation provides a measure of the variation of the strain field locally. The average and the standard deviations for both the maximum and minimum applied horizontal strains for each site across the eastern United States are given in table 6-1. 
Table 6-1. Average applied horizontal strain in the eastern United States by site and by region.

\begin{tabular}{|c|c|c|c|c|c|c|c|c|c|}
\hline \multirow[b]{2}{*}{ Site } & \multicolumn{3}{|c|}{ Maximum } & \multicolumn{3}{|c|}{ Minimum } & \multirow[b]{2}{*}{$\begin{array}{c}\text { Elastic } \\
\text { modulus, } \\
10^{6} \mathrm{psi}\end{array}$} & \multirow[b]{2}{*}{$\begin{array}{l}\text { Standard } \\
\text { deviation }\end{array}$} & \multirow[b]{2}{*}{$\begin{array}{c}\text { Depth, } \\
\mathrm{ft}\end{array}$} \\
\hline & $\begin{array}{c}\text { Average } \\
\text { applied } \\
\text { strain, } \\
\text { micro } \\
\text { strain }\end{array}$ & $\begin{array}{l}\text { Standard } \\
\text { deviation }\end{array}$ & $\begin{array}{c}\text { Percent } \\
\text { of } \\
\text { strain }\end{array}$ & $\begin{array}{l}\text { Average } \\
\text { applied } \\
\text { strain, } \\
\text { micro } \\
\text { strain }\end{array}$ & $\begin{array}{l}\text { Standard } \\
\text { deviation }\end{array}$ & $\begin{array}{c}\text { Percent } \\
\text { of } \\
\text { strain }\end{array}$ & & & \\
\hline \multicolumn{10}{|c|}{ Central Appalachian Region } \\
\hline \multicolumn{10}{|c|}{ Low Strain } \\
\hline \begin{tabular}{|l|l|} 
Beckley $\# 1$, hole \\
2
\end{tabular} & 353 & 37 & 10 & 117 & 36 & 31 & 6.77 & 0.55 & 1130 \\
\hline \begin{tabular}{|l|} 
Maple \\
Meadows, hole 6 \\
\end{tabular} & 296 & 29 & 10 & 282 & 44 & 16 & 6.32 & 0.2 & 708 \\
\hline \begin{tabular}{|l|} 
Maple \\
Meadows, hole 8 \\
\end{tabular} & 478 & 90 & 19 & 144 & 14 & 10 & 7.09 & 1.02 & 1025 \\
\hline \begin{tabular}{|l|l} 
Maple \\
Meadows, hole \\
10
\end{tabular} & 389 & 65 & 17 & 88 & 29 & 33 & 6.92 & 0.24 & 807 \\
\hline \begin{tabular}{|l|}
$\begin{array}{l}\text { Beckley } \# 1, \text { hole } \\
15\end{array}$ \\
\end{tabular} & 351 & 74 & 21 & 106 & 34 & 32 & 7.32 & 0.5 & 700 \\
\hline Eagle & 397 & 30 & 8 & 232 & 74 & 32 & 2.95 & 0.12 & 900 \\
\hline Elkhorn \#3 & 316 & - & & 208 & - & & 5.24 & - & 550 \\
\hline Average & 369 & 61 & & 168 & 73 & & 6.08 & & 831 \\
\hline \multicolumn{10}{|c|}{ Intermediate Strain } \\
\hline \begin{tabular}{|l|} 
Beckley $\# 4$, hole \\
1
\end{tabular} & 551 & - & & 309 & - & & 1.77 & - & 820 \\
\hline \begin{tabular}{|l|}
$\begin{array}{l}\text { Pocahontas \#4, } \\
\text { site } 1\end{array}$ \\
\end{tabular} & 631 & - & - & 317 & - & - & 3.59 & - & 1600 \\
\hline $\begin{array}{l}\text { Pocahontas \#4, } \\
\text { site } 2\end{array}$ & 672 & 66 & 10 & 249 & 83 & 33 & 3.25 & 1.09 & 1250 \\
\hline Bonny, hole 4 & 588 & 151 & 26 & 539 & 139 & 26 & 3.59 & 0.24 & 1136 \\
\hline Average & 611 & 52 & - & 354 & 127 & - & 2.87 & - & 1223 \\
\hline \multicolumn{10}{|c|}{ High Strain } \\
\hline \begin{tabular}{|l|} 
Beckley $\# 2$, hole \\
3
\end{tabular} & 703 & 6 & 1 & 354 & 8 & 2 & 2.26 & 0.07 & 1100 \\
\hline \begin{tabular}{|l|l} 
Bonny, hole 5 \\
\end{tabular} & 827 & 88 & 11 & 248 & 117 & 47 & 6 & 0.96 & 1148 \\
\hline $\begin{array}{l}\text { Maple Meadows, } \\
\text { hole } 7\end{array}$ & 781 & 322 & 41 & 433 & 222 & 51 & 4.44 & 1.31 & 735 \\
\hline $\begin{array}{l}\text { Maple Meadows, } \\
\text { hole } 9\end{array}$ & 967 & 109 & 11 & 543 & 173 & 32 & 2.46 & 0.08 & 814 \\
\hline $\begin{array}{l}\text { Beckley Mining, } \\
\text { hole } 11\end{array}$ & 778 & 157 & 20 & 529 & 234 & 44 & 2.95 & 0.58 & 640 \\
\hline $\begin{array}{l}\text { Beckley Mining, } \\
\text { hole } 12\end{array}$ & 932 & 43 & 5 & 592 & 70 & 12 & 2.94 & 0.29 & 870 \\
\hline $\begin{array}{l}\text { Beckley Mining, } \\
\text { hole } 13\end{array}$ & 861 & 95 & 11 & 494 & 105 & 21 & 2.7 & 0.24 & 800 \\
\hline $\begin{array}{l}\text { Beckley Mining, } \\
\text { hole } 14\end{array}$ & 832 & 80 & 10 & 302 & 54 & 18 & 3.5 & 0.41 & 1040 \\
\hline $\begin{array}{l}\text { Beckley \#2, hole } \\
16\end{array}$ & 851 & 63 & 7 & 521 & 23 & 4 & 1.72 & 0.09 & 350 \\
\hline Average & 836 & 80 & - & 446 & 119 & - & 3.21 & 1.3 & 833 \\
\hline
\end{tabular}


Table 6-1. Average applied horizontal strain in the eastern United States by site and by region (Cont.).

\begin{tabular}{|c|c|c|c|c|c|c|c|c|c|}
\hline \multirow[b]{2}{*}{ Site } & \multicolumn{3}{|c|}{ Maximum } & \multicolumn{3}{|c|}{ Minimum } & \multirow[b]{2}{*}{$\begin{array}{c}\text { Elastic } \\
\text { modulus, } \\
10^{6} \mathrm{psi}\end{array}$} & \multirow[b]{2}{*}{$\begin{array}{l}\text { Standard } \\
\text { deviation }\end{array}$} & \multirow[b]{2}{*}{$\begin{array}{c}\text { Depth, } \\
\mathrm{ft}\end{array}$} \\
\hline & $\begin{array}{l}\text { Average } \\
\text { applied } \\
\text { strain, } \\
\text { micro } \\
\text { strain }\end{array}$ & $\begin{array}{l}\text { Standard } \\
\text { deviation }\end{array}$ & $\begin{array}{c}\text { Percent } \\
\text { of } \\
\text { strain }\end{array}$ & $\begin{array}{c}\text { Average } \\
\text { applied } \\
\text { strain, } \\
\text { micro strain }\end{array}$ & $\begin{array}{l}\text { Standard } \\
\text { deviation }\end{array}$ & $\begin{array}{c}\text { Percent } \\
\text { of } \\
\text { strain }\end{array}$ & & & \\
\hline \multicolumn{10}{|c|}{ Northern Appalachian Region } \\
\hline Tanoma, PA & 421 & - & & 303 & - & & 5.8 & & 720 \\
\hline Phillippi WV & 536 & 58 & 11 & 317 & 65 & 21 & 4.29 & 2.57 & 550 \\
\hline $\begin{array}{l}\text { Fayette County, } \\
\text { PA }\end{array}$ & 519 & - & - & 191 & - & - & 11.2 & - & 400 \\
\hline Barberton, $\mathrm{OH}$ & 430 & - & - & 222 & - & - & 9 & - & 2300 \\
\hline $\begin{array}{l}\text { Southwest, PA, } \\
\text { site } 1\end{array}$ & 533 & - & - & 325 & - & - & 1.8 & - & 400 \\
\hline $\begin{array}{l}\text { Southwest, PA, } \\
\text { site } 2\end{array}$ & 367 & 30 & 8 & 336 & 25 & 7 & 4.4 & 0.45 & 700 \\
\hline $\begin{array}{l}\text { Southwest, PA, } \\
\text { site3 }\end{array}$ & 303 & 67 & 22 & 156 & 19 & 12 & 7.65 & 0.98 & 800 \\
\hline Average & 444 & 90 & & 264 & 73 & & 6.31 & 3.19 & 838 \\
\hline \multicolumn{10}{|c|}{ Eastern Mid-Continent Region } \\
\hline Wabash, site 1 & 237 & 36 & 15 & 124 & 28 & 22 & 3.11 & 0.19 & 970 \\
\hline Wabash, site 2 & 341 & 19 & 6 & 80 & 26 & 32 & 2.9 & 0.25 & 850 \\
\hline Wabash, site $3^{1}$ & 377 & 28 & 7 & 0 & 1 & 100 & 2.85 & 0.09 & 860 \\
\hline Monterey & 398 & 107 & 27 & 163 & 50 & 32 & 1.67 & 0.32 & 290 \\
\hline Galatia $^{2}$ & 499 & 36 & 5 & 0 & 0 & - & 2.96 & 0.19 & 570 \\
\hline Peabody \#10 & 533 & 44 & 8 & 71 & 205 & 289 & 2.84 & 2.47 & 360 \\
\hline Peabody \#2 & 301 & - & - & 260 & - & - & 2.2 & - & 300 \\
\hline $\begin{array}{l}\text { St. Genevieve } \\
\text { Limestone }\end{array}$ & 349 & - & - & 19 & - & - & 9.32 & & 730 \\
\hline $\begin{array}{l}\text { North River, site } \\
1, \mathrm{AL}^{3}\end{array}$ & 353 & 26 & 7 & 0 & 18 & - & 5.42 & 0.35 & 500 \\
\hline Immel, TN & 342 & 130 & 38 & 26 & 42 & 162 & 7.96 & 1.06 & 925 \\
\hline $\begin{array}{l}\text { Jim Walters \#7, } \\
\text { AL }\end{array}$ & 399 & - & - & 45 & - & - & 5.4 & 1.1 & 1870 \\
\hline Average & 375 & 87 & 23 & 72 & 85 & 115 & 4.24 & 2.49 & 748 \\
\hline $\begin{array}{l}\text { North River, site } \\
2, \mathrm{AL}\end{array}$ & 173 & 38 & 24 & 0 & 27 & - & 4.72 & 0.35 & 470 \\
\hline Turris & 193 & 8 & 4 & 51 & 15 & 29 & 8.57 & 0.69 & 275 \\
\hline
\end{tabular}

${ }^{1}$ The calculated minimum site strain is a -4 micro strains but the minimum site strain is assumed to be zero.

${ }^{2}$ The calculated minimum site strain is a -23 micro strains but the minimum site strain is assumed to be zero.

${ }^{3}$ The calculated minimum site strain is a -68 micro strains but the minimum site strain is assumed to be zero.

For the maximum strain, the standard deviation given in percent of the average strain ranges from 1 to $41 \mathrm{pct}$ of the average while for the minimum strain, the standard 
deviation given in percent of the average strain ranges from 2 to 289 pct. There is a wide range in the standard deviations for both components but especially for the minimum strain.

Figure 6-1 shows a histogram of the standard deviation as a percentage of the average strain for the maximum horizontal strain. Although a few sites have a fairly high standard deviation, in general, the standard deviations are less than 24 percent of the average strain. The average standard deviation given in percent of the average strain is only 14 percent while the mode is between 8 and 12 percent.

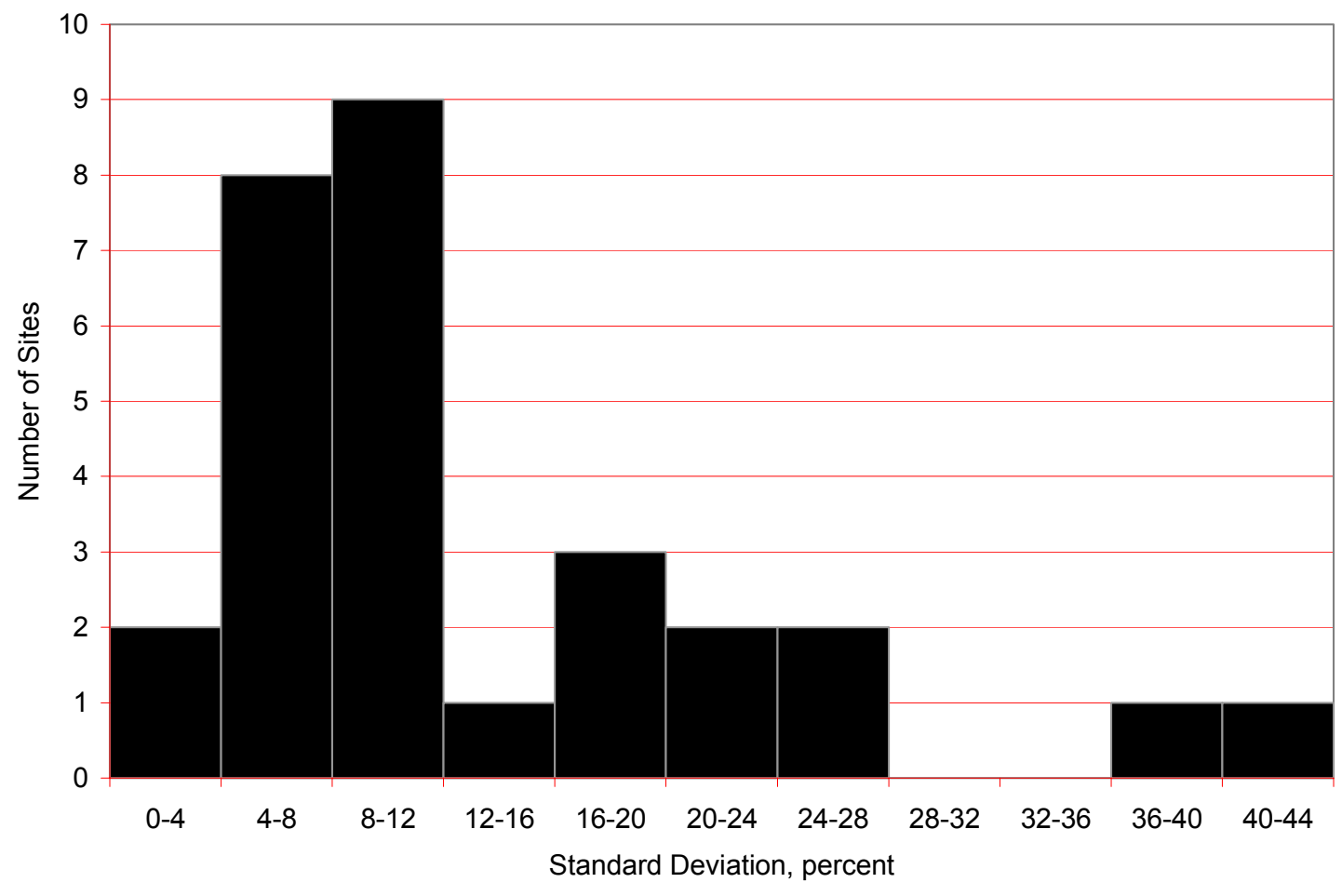

Figure 6-1. Distribution of the standard deviation of the maximum applied horizontal strain given in percent.

Figure 6-2 shows a histogram of the percent of standard deviation of the minimum horizontal strain. In general, the standard deviations are less than 56 percent of the average strain. The average standard deviation given in percent of the average strain is 44 percent with the mode between 24 and 32 percent. However, the outliers increase the average significantly. 


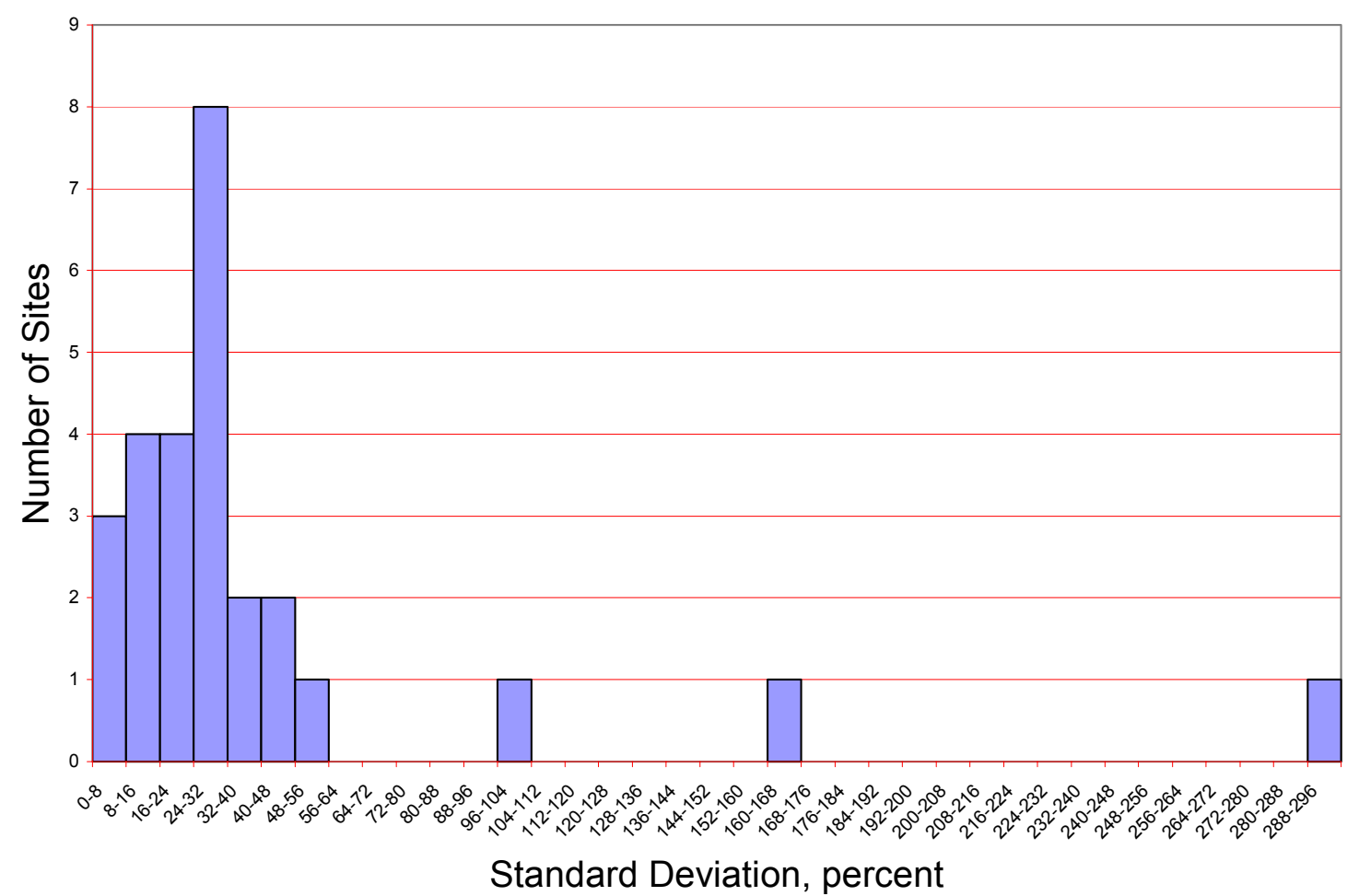

Figure 6-2. Distribution of the standard deviation of the minimum applied horizontal strain given in percent.

In general, the variation in strain is not as large for the maximum horizontal strain as indicated by both the mode and the average standard deviation. The outliers do not have a large effect on the average for the maximum horizontal strain while the majority of the sites have a standard deviation less than 12 percent of the average maximum strain. However, there is a larger range in the standard deviation of the minimum strain while the outliers have a larger effect on the average. The outliers are caused by a combination of low minimum strains and in part higher standard deviations at those sites. The mode for the standard deviations though is clearly higher for the minimum strain. Locally, the maximum horizontal strain is more uniform than the minimum horizontal strain.

The standard deviation reflects the natural variation in the strain field as well as errors in measurements and determination of the elastic properties. Some of the variation could also be due to the influence of mining. These local variations can mask the variations of the stresses due the elastic modulus. Therefore, the range in elastic modulus must be sufficient to overcome these local variations. 
Another factor that could influence the results is the distance of the measurements from the opening. The measurements used in the analysis range in depth from 5.2 to $24.8 \mathrm{ft}$ into the roof though only 13 percent of the measurements are less than $10 \mathrm{ft}$. To determine if there is a significant effect on the individual measurements of the distance from the opening, the applied maximum strains versus the distance from the opening are examined for the eastern United States. Figure 6-3 shows a graph of this data with the measurements separated into high and low strain groups. A linear regression analysis is performed on each data set. The coefficients for the distance are for the low strain group 2.4 micro strains/ft and for the high strain group 7.7 micro strains/ft indicating that the strain does appear to increase by a small amount with distance from the opening. However, the coefficients of determination of 0.01 and 0.05 indicate there is no correlation between the distance from the opening and the maximum applied strain while the coefficients for the distance developed from the regression analysis are not significantly greater than zero. Therefore, the strains do not appear to increase significantly with distance from the opening indicating that the distance from the opening appears to have a minimal influence on the measurements and should have minimal affect on the results from the analysis of this data set.

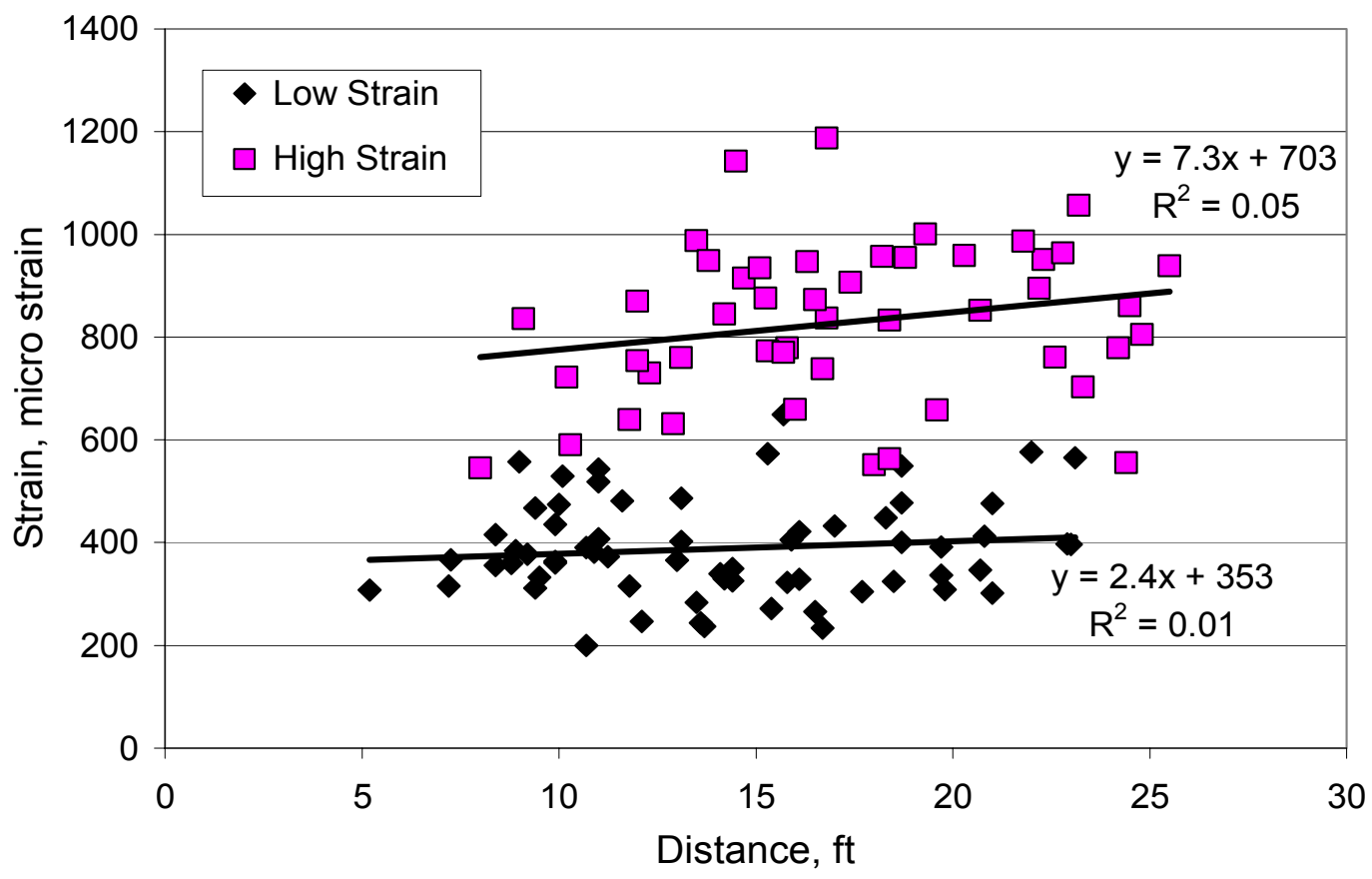

Figure 6-3. Maximum applied horizontal strain versus distance of the measurement from the opening, eastern United States. 


\subsection{REGIONAL STRAIN VARIATIONS}

To evaluate the regional strain variations, the applied horizontal strains are examined with the analysis of the strains based on three regions, the eastern MidContinent region, and the northern and central Appalachian regions. The approximate regional boundaries based on site groupings is given in figure 6-4. Table 6-2 shows the average maximum and minimum applied horizontal strain and the standard deviation for each region. The following analysis for each region is based on the average strains determined at each site (table 6-1).

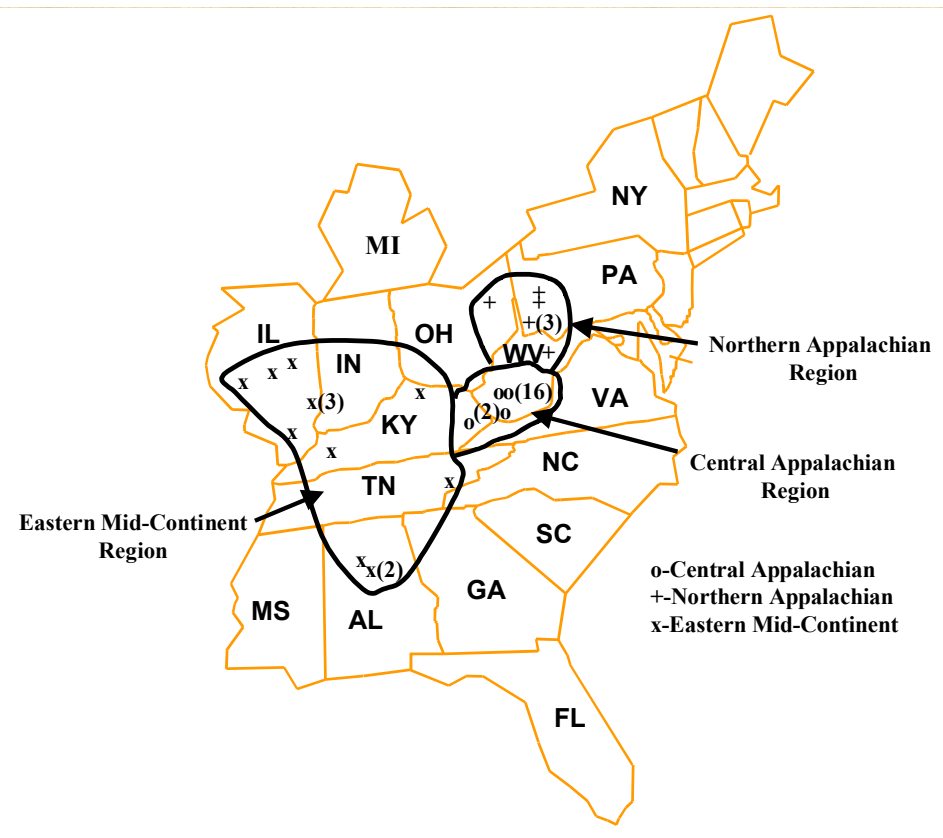

Figure 6-4. Approximate regional boundaries based on site groupings.

Table 6-2. Applied horizontal strain by region for the eastern United States.

\begin{tabular}{|l|c|c|c|c|c|c|}
\hline Zone & $\begin{array}{c}\text { Maximum } \\
\text { strain, micro } \\
\text { strain }\end{array}$ & $\begin{array}{c}\text { Standard } \\
\text { deviation }\end{array}$ & $\begin{array}{c}\text { Range of site } \\
\text { maximum } \\
\text { strain, micro } \\
\text { strain }\end{array}$ & $\begin{array}{c}\text { Minimum } \\
\text { strain, micro } \\
\text { strain }\end{array}$ & $\begin{array}{c}\text { Standard } \\
\text { deviation }\end{array}$ & $\begin{array}{c}\text { Strain ratio } \\
\text { max/min }\end{array}$ \\
\hline \multicolumn{7}{|c|}{ Northern Appalachian } \\
\hline \multicolumn{7}{|c|}{ Central Appalachian } \\
\hline Low & 444 & 90 & $303-536$ & 73 & 1.68 \\
\hline Intermediate & 611 & 60 & $296-478$ & 168 & 73 & 2.2 \\
\hline High & 836 & 81 & $703-967$ & 439 & 116 & 1.73 \\
\hline \multicolumn{7}{|c|}{ Eastern Mid-Continent } \\
\hline
\end{tabular}




\subsubsection{Eastern Mid-Continent Region}

The maximum applied horizontal strain by site ranges from 173 to 533 micro strains with a standard deviation that is 21 percent of the average strain. Figure 6-5A shows a histogram of the average maximum horizontal strain from each site. The mode is between 300 and 400 micro strains with 8 of the 13 sites within this range.

The average regional maximum strain of 375 micro strains also falls within this range. The low strain Turris and North River site 2 sites however, are not included in the average strain calculations though the sites are included on the histogram. The Turris measurements are not very deep into the roof and are probably under the influence of the opening. Further, the Turris Mine is also the shallowest site and may be influenced by near surface stress relief effects from glacial filled bedrock valleys. At the North River Mine in Alabama, site 2 appears to be influenced by the normal fault located $600 \mathrm{ft}$ from the site. The average site strain is only 173 micro strains. These sites are also excluded from the general analysis. Without the Turris and the North River site 2, the site strains range from 238 to 533 micro strains. Further, the Wabash site one, has an average strain of 238 micro strains. However, this site is near a fault that appears to have reduced the strain level locally. The other two sites in the Wabash mine have maximum strains of 341 and 377 micro strains. Excluding the Wabash site one, the average maximum regional strain is 388 micro strains.

Figure 6-5B shows a histogram of the minimum horizontal strain. The minimum strain ranges from 0 to 260 micro strains with an average strain of 72 micro strains. However, the standard deviation is 118 pct of the average minimum strain. The minimum strain for the Turris and North River site 2 are not outliers in this case. Most of the sites have a minimum applied strain that is less than 100 micro strains.

\subsubsection{Northern Appalachian Region}

In this region, the maximum horizontal strain by site ranges from 303 to 536 micro strains with a standard deviation that is 20 percent of the average strain. Figure 6-6A shows a histogram of the maximum horizontal strain for each site. The strains are distributed fairly evenly across the range. 


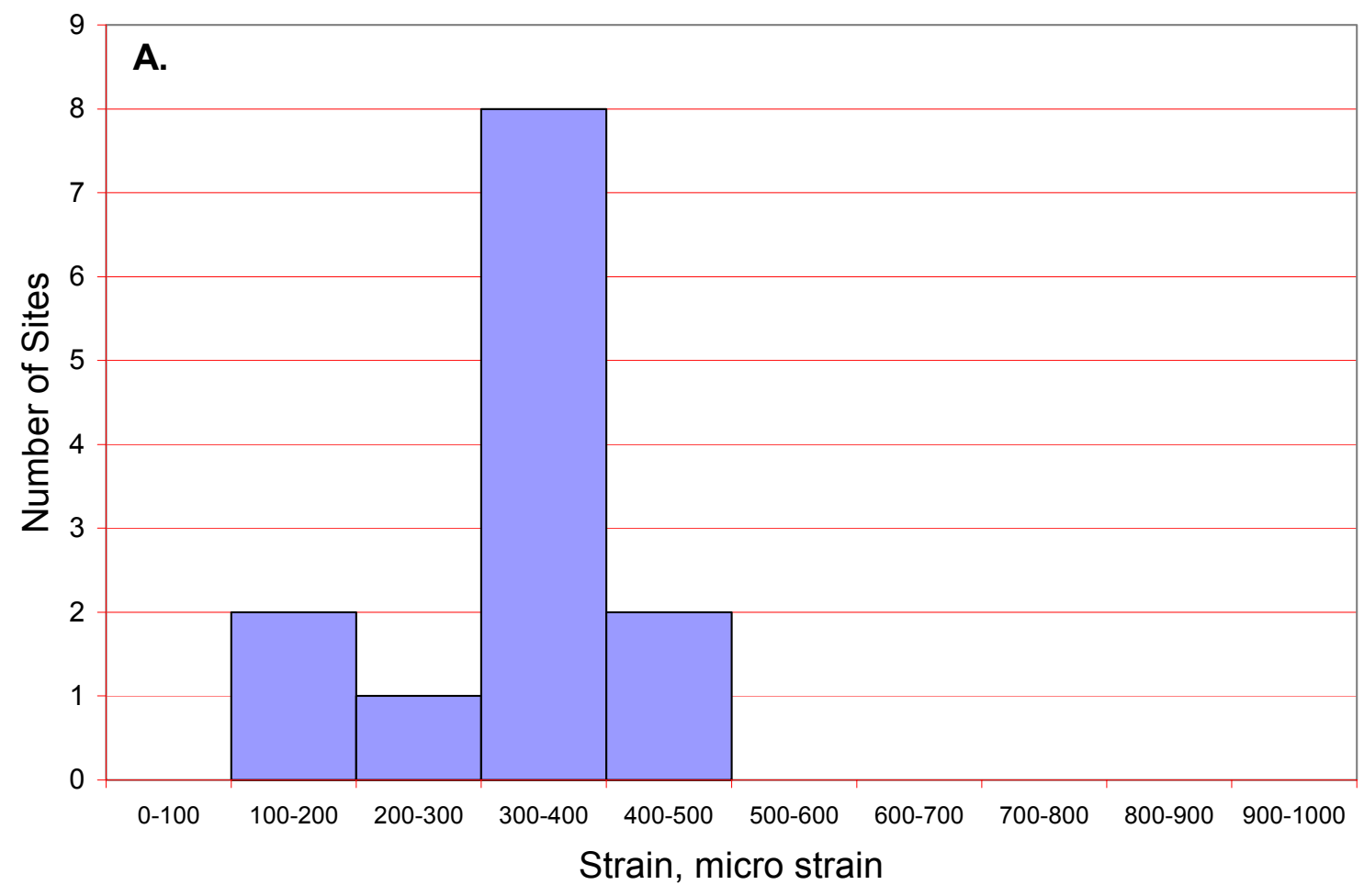

Figure 6-5A. Distribution of the applied horizontal strain in the eastern MidContinent region, maximum.

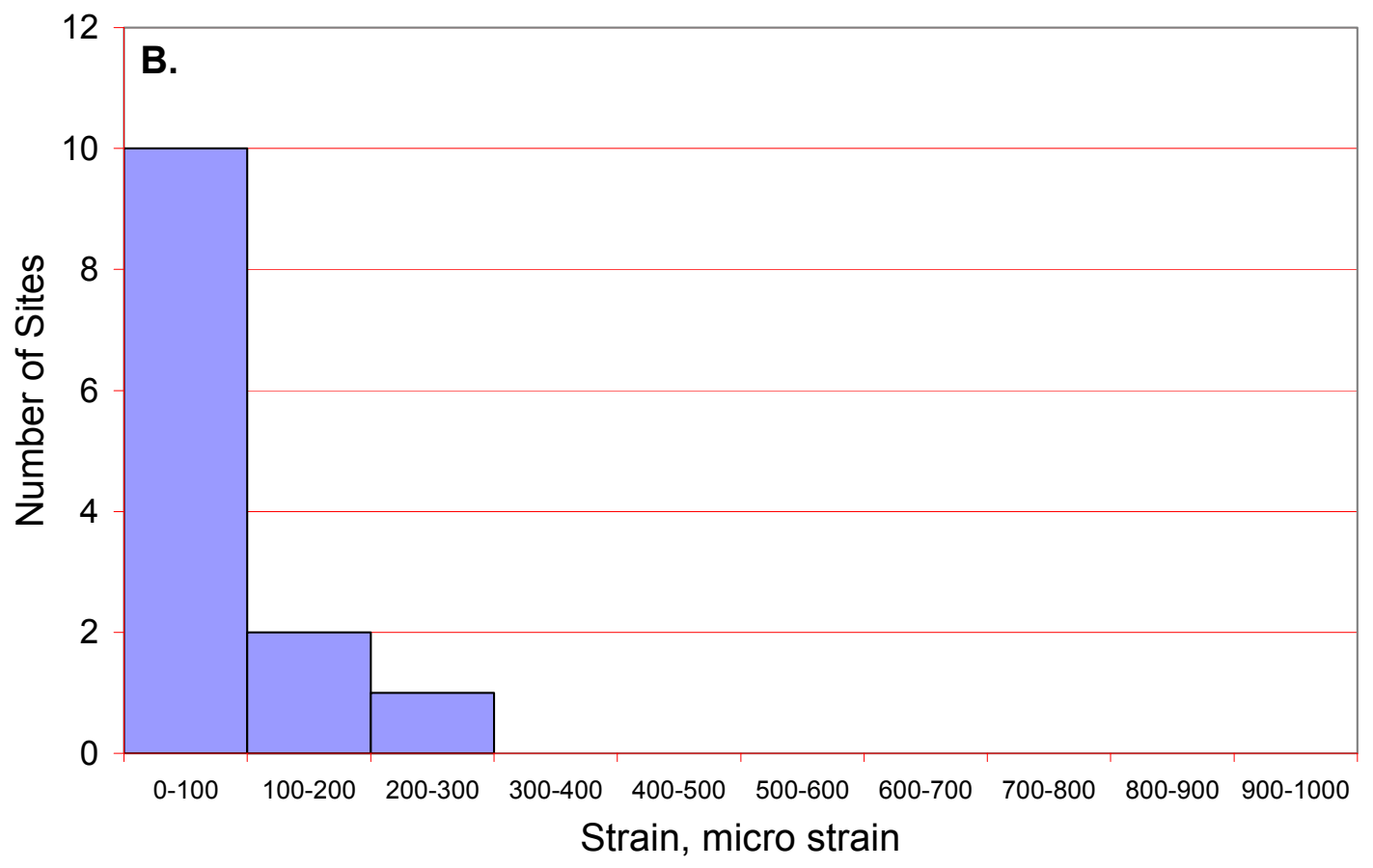

Figure 6-5B. Distribution of the applied horizontal strain in the eastern MidContinent region, minimum. 


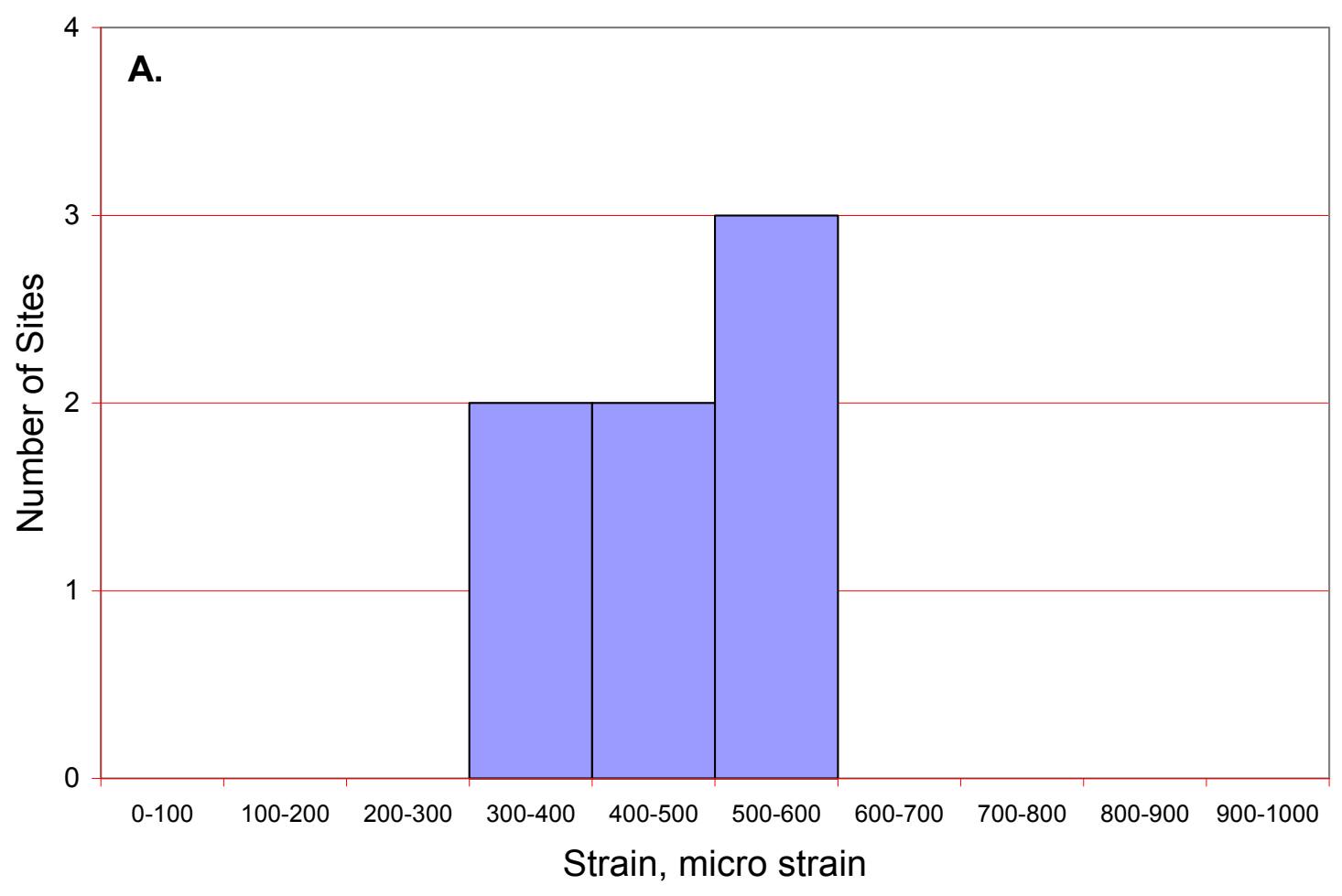

Figure 6-6A. Distribution of the applied horizontal strain in the northern Appalachian region, maximum.

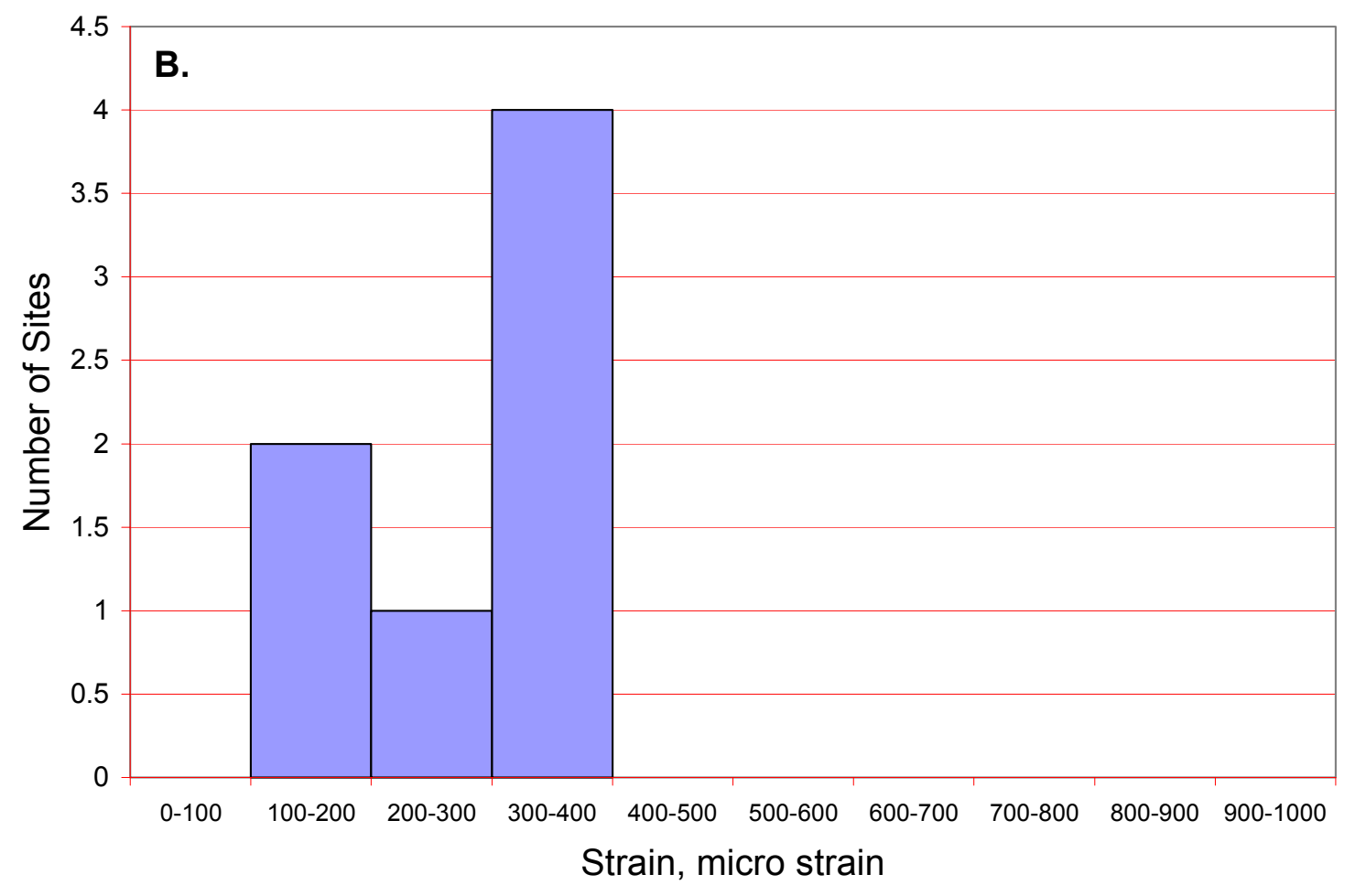

Figure 6-6B. Distribution of the applied horizontal strain in the northern Appalachian region, minimum. 
The minimum strain ranges from 156 to 336 micro strains with a standard deviation that is 28 percent of the average strain. Figure 6-6B shows a histogram of the minimum strain distribution across the region. The histogram indicates that for the majority of the sites, the minimum strains are between 300 to 400 micro strains.

\subsubsection{Central Appalachian Region}

In the central Appalachian region, the maximum horizontal strain ranges from 296 to 967 micro strains. This reflects the low and high strain zones that have been identified in the region. Figure 6-7A shows a histogram of the average maximum horizontal strain from each site. The distribution is bimodal indicating the existence of both low and high strain zones within the region. The lower strain region includes the low strain sites in the Beckley, Elkhorn \#3 and Eagle seams with strains below 500 micro strains and the high strain region includes the high strain sites in the Beckley seam with strains above 700 micro strains. There also appears to be a third intermediate strain zone that includes the Sewell, Pocahontas \#4 seam sites and one Beckley seam site (table 6-1). The third or intermediate zone of strain can be designated between 550 to 700 micro strains.

Although there is a substantial variation of strains across the region, the strain variation within each strain zone is much less. For the high strain zone, the maximum strain ranges from 703 to 967 micro strains with a standard deviation that is 10 percent of the average strain. The distribution indicates that the largest number of sites have an average strain of between 827 to 967 micro strains. For the low strain zone, the strain ranges from 296 to 478 micro strains with a standard deviation that is 17 percent of the average strain. Most of the strains fall between 316 to 397 micro strains. For the intermediate strain zone, the strains range from 551 to 672 micro strains with a standard deviation that is 9 percent of the average strain

The minimum applied horizontal strain ranges from 88 to 592 micro strains. Figure 6-7B shows a histogram of the average minimum strain. The distribution is not as clear as the maximum strain distribution in indicating two or possibly three strain zones. Further, there is some overlap between the low, intermediate and high strain zones as designated by the maximum strain. For the high strain region, the strain ranges between 248 to 592 micro strains with a standard deviation that is 28 percent of the average. For 
the low strain zone, the average strain ranges from 88 to 282 micro strains with a standard deviation that is 43 percent of the average strain. For the intermediate zone, the average strains range from 249 to 539 micro strains with a standard deviation that is 36 percent of the average minimum strain.

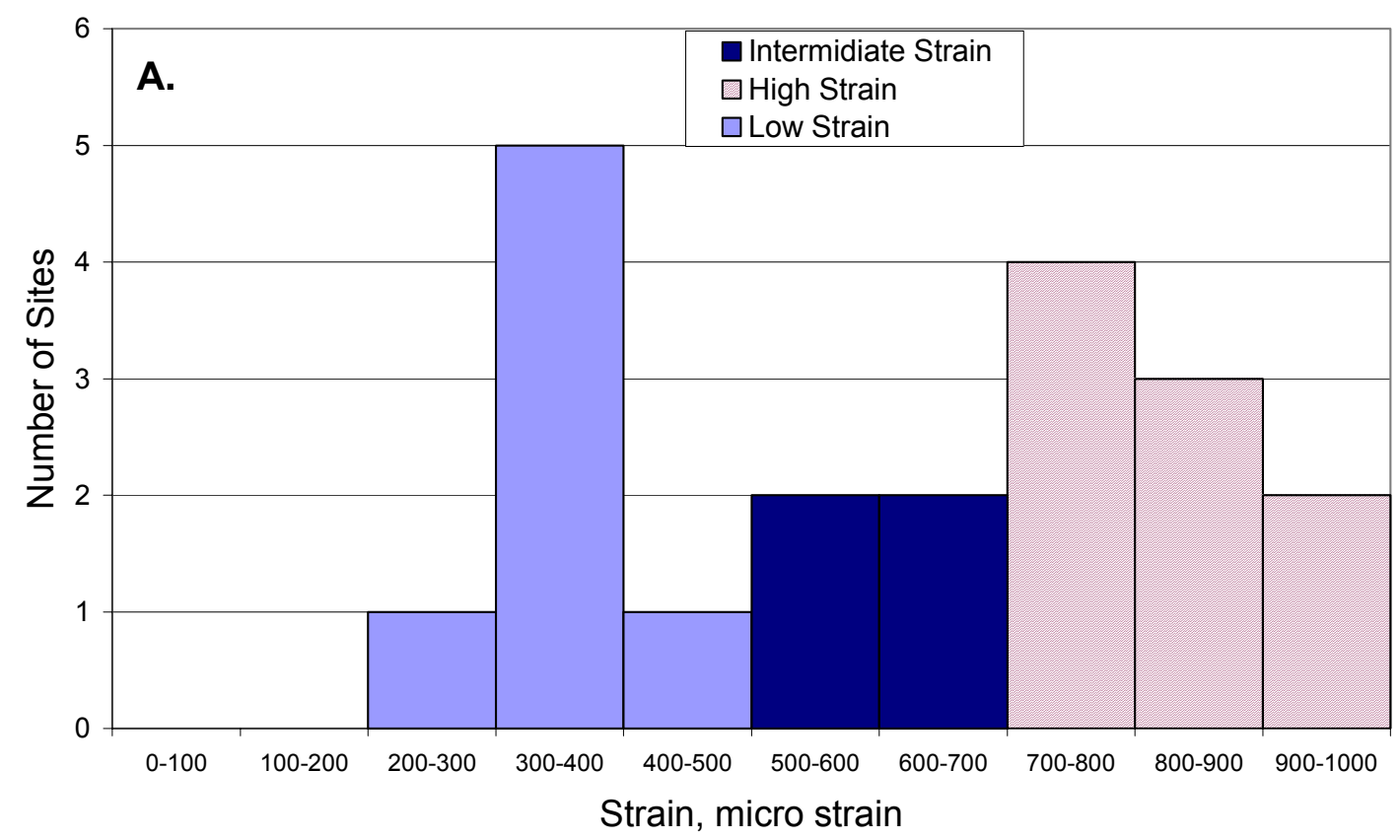

Figure 6-7A. Distribution of the applied horizontal strain in the central Appalachian region, maximum.

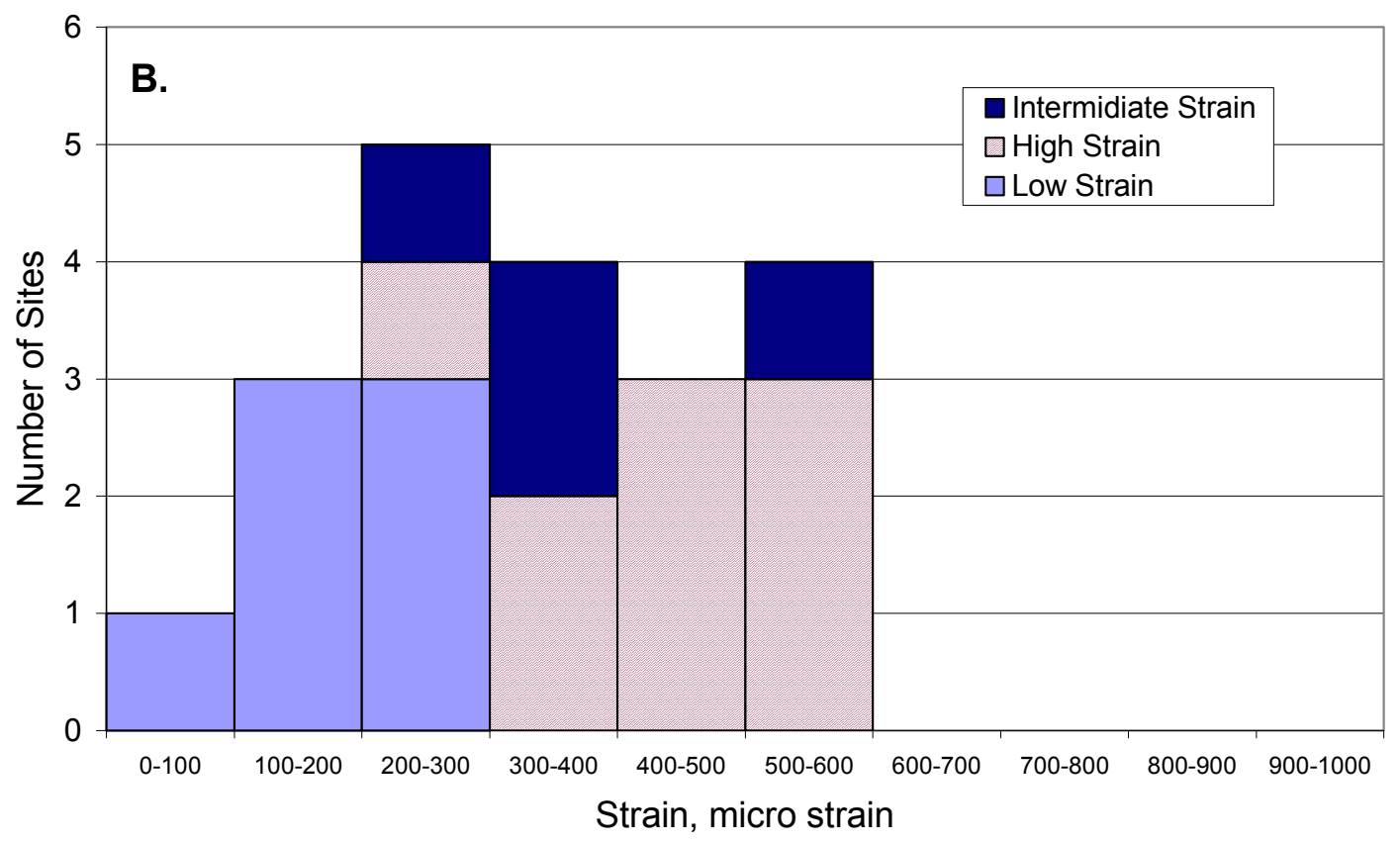

Figure 6-7B. Distribution of the applied horizontal strain in the central Appalachian region, minimum. 
There are high and low strain sites in the central Appalachian region and except for the Beckley seam the geographic distribution is not clear. The high strain sites include sections of the Beckley seam and possibly sites in the Sewell and Pocahontas \#4 seams. In the Beckley seam, all but two of the high strain sites are in a coterminous area of several hundred square miles. All the low strain sites in the Beckley seam are in an adjacent area encompassing tens of square miles. The other low strain sites in the region are somewhat isolated from the Beckley seam. To develop a clearer outline of the geographic distribution of the strain field across the region will require more stress measurements. However, if a reason for the existence of the high and low strain fields can be deduced, a better understanding of the strain patterns for the region could be developed.

A possible cause of the two or three strain fields could be the strength of the rock mass or faults. Essentially, the magnitude of the maximum horizontal stress is limited by the rock mass or fault strength (Zoback et al., 2003). An important parameter in this concept is the confinement or minimum stress. With increasing confinement, the rock mass or fault strength also increases thus being able to withstand higher maximum horizontal stresses.

The possible affects of the strength limiting the stress magnitude can be seen with the Beckley seam data where the high and low strain sites group into distinct geographic zones. For the high strain zone in the Beckley seam excluding the Beckley \#2 sites, the average maximum horizontal stress is 3,800 psi. For the five sites in the low strain zone, the average maximum horizontal stress is 3,300 psi. Further, in the Beckley seam, the minimum or confining stress is the vertical stress. For the 8 high strain sites used in this analysis, the average site depth is $900 \mathrm{ft}$ while for the 5 low strain sites, the average site depth is $875 \mathrm{ft}$. Essentially, both zones have approximately the same vertical or confinement stress that could result in similar rock mass or fault strengths and therefore result in about the same maximum horizontal stress magnitude. The average maximum horizontal stresses for the two zones are within 15 percent.

The average elastic modulus for the low strain zone sites is 6.9 million psi and for the high strain zone sites, 3.6 million psi. Based on the average elastic modulus and maximum horizontal stress for each zone, the average horizontal strain from the 
maximum horizontal stress for the high strain zone is 1060 micro strains and for the low strain zone 480 micro strains. Essentially, strength limits the maximum horizontal stress in both zones to approximately the same magnitude while the much higher elastic modulus in the low strain zone results in the much lower strain field.

\subsubsection{Summary of Regional Strain Fields}

The regional average maximum applied horizontal strain ranges from 369 to 836 micro strains with the lowest and highest regional strains found in the central Appalachian region. The minimum average strain ranges from 72 to 440 micro strains. The lowest is found in the eastern Mid-Continent region and the highest in the high strain zone of the central Appalachian region.

As with the local strain fields, the regional strain fields are not completely uniform. However, the regional strain fields appear to be sufficiently uniform except for the central Appalachian region to allow for the development of adequate regression models between the maximum horizontal stress and the elastic modulus of the rock. Regionally, for the maximum applied strain, the standard deviation in percent of the average strain varies from only 10 to 21 percent. Further, the range of the site averages for a region or zone is less than 270 micro strains. Therefore, the regional average strains, standard deviations and range of strains can be used to determine or estimate the horizontal strains and stresses that may occur elsewhere within the region. Essentially, the measurements are a sampling of the stress and strain field across a region. The exception is the central Appalachian region where the geographic demarcation of the zones is not clear.

The minimum strain shows more variation as indicated by equal or higher standard deviations than those for the maximum strain. This results in the standard deviation being a much higher percent of the minimum average strain.

\subsubsection{Comparison of Regional Strain Fields}

Clearly, the central Appalachian region has areas with substantially higher maximum applied strains than the other regions. Except for the central Appalachian region, the other regions appear to have similar maximum horizontal strain fields. For two of the regions, the northern Appalachian region and the eastern Mid-Continent 
region, the average maximum applied regional strains are within 70 micro strains. Even the low strain zone of the central Appalachian region has an average maximum strain that is only 8 micro strains below that of the eastern Mid-Continent region. However, for the low strain zones, the average regional strain in the northern Appalachian region is about 20 percent higher than the other two regions.

Table 6-3. Statistical comparison of selected regional average maximum applied horizontal strains.

\begin{tabular}{|l|c|c|c|}
\hline Regional comparison & t-statistic & $\begin{array}{l}\text { Degrees of } \\
\text { freedom }\end{array}$ & $\begin{array}{l}\text { Significant } \\
\text { difference }\end{array}$ \\
\hline $\begin{array}{l}\text { Northern Appalachian vs. } \\
\text { Eastern Mid-Continent }\end{array}$ & 1.64 & 16 & No \\
\hline $\begin{array}{l}\text { Northern Appalachian vs. } \\
\text { Central Appalachian (low strain zone) }\end{array}$ & 1.85 & 10 & No \\
\hline $\begin{array}{l}\text { Northern Appalachian vs. } \\
\text { Central Appalachian (high strain zone) }\end{array}$ & 8.9 & 12 & Yes \\
\hline $\begin{array}{l}\text { Central Appalachian (high strain zone) vs. } \\
\text { Central Appalachian (low strain zone) }\end{array}$ & 13.1 & 14 & Yes \\
\hline
\end{tabular}

Table 6-3 gives a statistical comparison between the regional maximum strain averages. Even though the northern Appalachian region has a higher strain, statistically there is no significant difference between the northern Appalachian, eastern MidContinent and central Appalachian low strain zone regional maximum strain. The maximum strain in the central Appalachian high strain zone is significantly higher than any of the low strain zones. Essentially, the central Appalachian high strain zone does have a significantly higher maximum applied strain than any other region.

There is a somewhat larger difference in the minimum average strains between the low strain zones. The eastern Mid-Continent region has a lower minimum strain and a more biaxial strain field than the northern and central Appalachian regions while the northern Appalachian region has minimum strains that are higher than those in the central Appalachian low strain zone. The highest minimum strains are found in the intermediate and high strain zones of the central Appalachian region followed by the northern Appalachian region. However, there is less difference between the minimum strain in the central Appalachian region for all three zones and the northern Appalachian region than 
for the maximum strain. The strain fields in these regions are less biaxial than the eastern Mid-Continent region.

The eastern Mid-Continent region encompasses a very large area of the eastern United States and has a fairly uniform applied maximum strain, however, the strain field is very biaxial with a maximum to minimum strain ratio of 5.3. In the northern Appalachian region the maximum strain is about 20 percent higher though the strain field is less biaxial with a ratio of only 1.68. The northern Appalachian strain region is smaller than the eastern Mid-Continent region but still fairly large. Clearly, the intermediate and high strain zones of the central Appalachian region have the highest maximum applied strains. However, the distribution of the strain fields in this region is much more complex though this distribution appears to still be geographic. Geographically, the high and low strain zones in the Beckley seam appear to only cover tens or hundred of square miles.

\subsection{STRAIN VARIATION ACROSS THE EASTERN UNITED STATES}

Figure 6-8A shows a histogram of the maximum applied horizontal strain by site across the eastern United States. Twenty-four of the 38 sites have a maximum strain between 300 and 550 micro strains with 26 sites between 300 and 600 micro strains. These sites are spread across all the main geographic regions. Therefore, the typical maximum strain field across the eastern United States appears to have a magnitude between 300 to 600 micro strains. This range is somewhat broadened because of the strains in the northern Appalachian region being about 20 percent higher than those in the other low strain regions. Further, for both the eastern Mid-Continent and low strain central Appalachian regions, the maximum strains are concentrated at the mode between 300 to 400 micro strains with only one or two sites for each region between 400 and 550 micro strains. The strains between 550 to 700 micro strains are all in the central Appalachian region.

From the histogram, the maximum strain field is skewed with only three sites well below 300 micro strains. Since the mode is between 300 and 400 micro strains with these strains from all the regions as well as from a range in depths that are not subject to near surface strain relief, those strains in the eastern United States that fall below about 
300 micro strains may have been to some degree subject to strain relief. Two sites, both in the eastern Mid-Continent region are below 200 micro strains, the Turris Mine and North River site 2. The Wabash mine, site one is also below 300 micro strains. The Wabash and North River site 2 were near faults that could have resulted in some strain relief. The Turris Mine is the shallowest site at $275 \mathrm{ft}$ in a region with bedrock valleys that are filled with unconsolidated material. Essentially, the distribution is skewed because the strains cannot realistically fall below zero and the location of the mode indicates that those strains below about 300 micro strains are possibly in partial strain relief.

From the histogram, the distribution is spread out toward the right because of the high strain zone in the Beckley seam and the other intermediate sites in the central Appalachian region. The number of sites in the high strain zone is due to increased sampling in this zone and therefore the distribution does not represent the true geographic extent of the high strain zone that appears to be geographically limited. Because of ground control problems, there was a concentration of stress measurements made in the seam. What this distribution indicates is that there is a high strain zone but not the extent of that zone.

Figure 6-8B shows a histogram of the minimum applied horizontal strains across the eastern United States. Most of the sites (22) have strains between 100 to 400 micro strains. Eleven of the sites have strains that are below 100 micro strains with ten of the sites found in the eastern Mid-Continent region. This reflects the low minimum horizontal stresses found in the region. All the sites with strains above 400 micro strains are again found in the Beckley seam and central Appalachian region. However, although the distribution is again skewed, it is not as well defined as that for the maximum horizontal strain. 


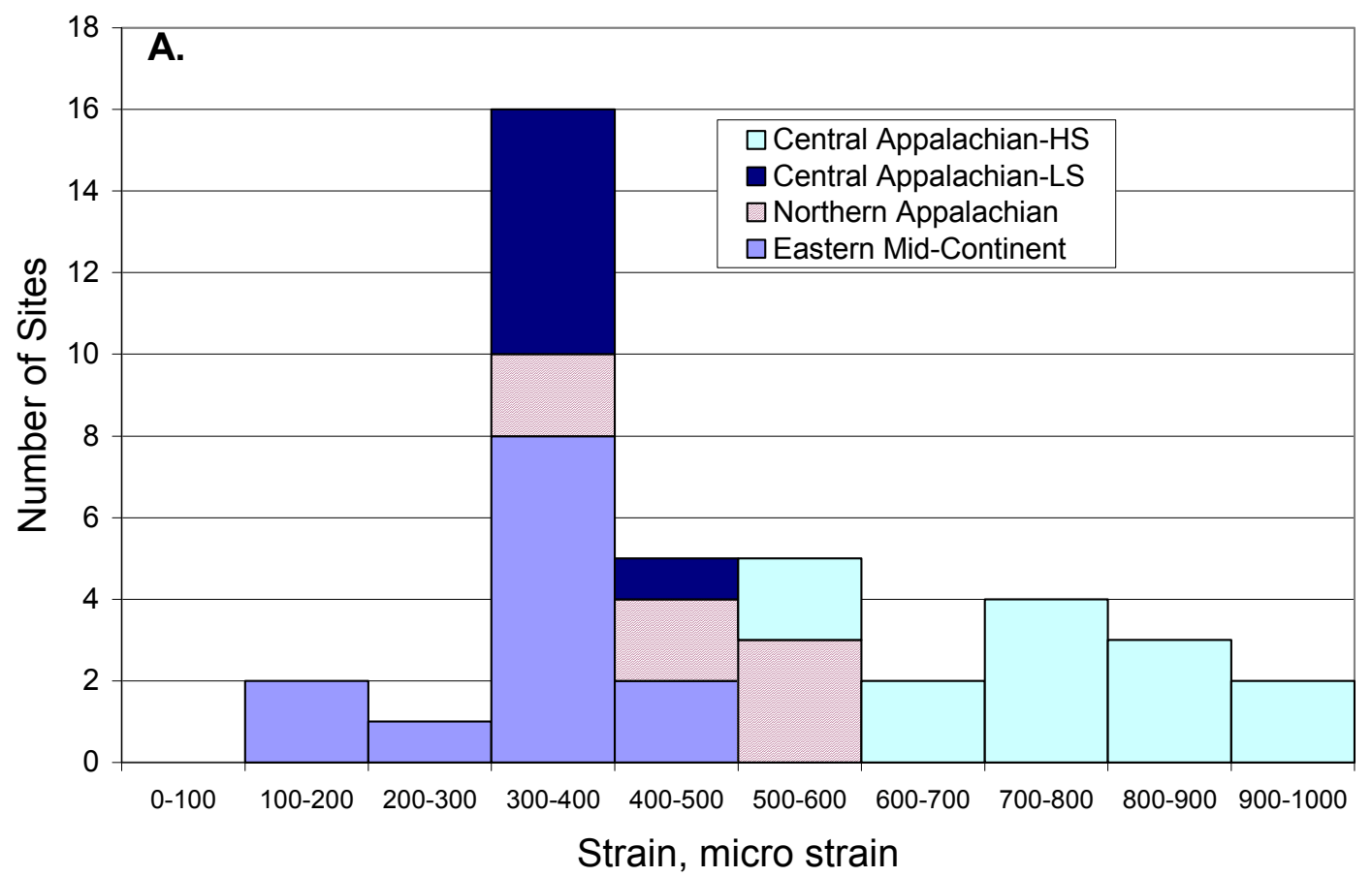

Figure 6-8A. Distribution of the applied horizontal strain across the eastern United States, maximum.

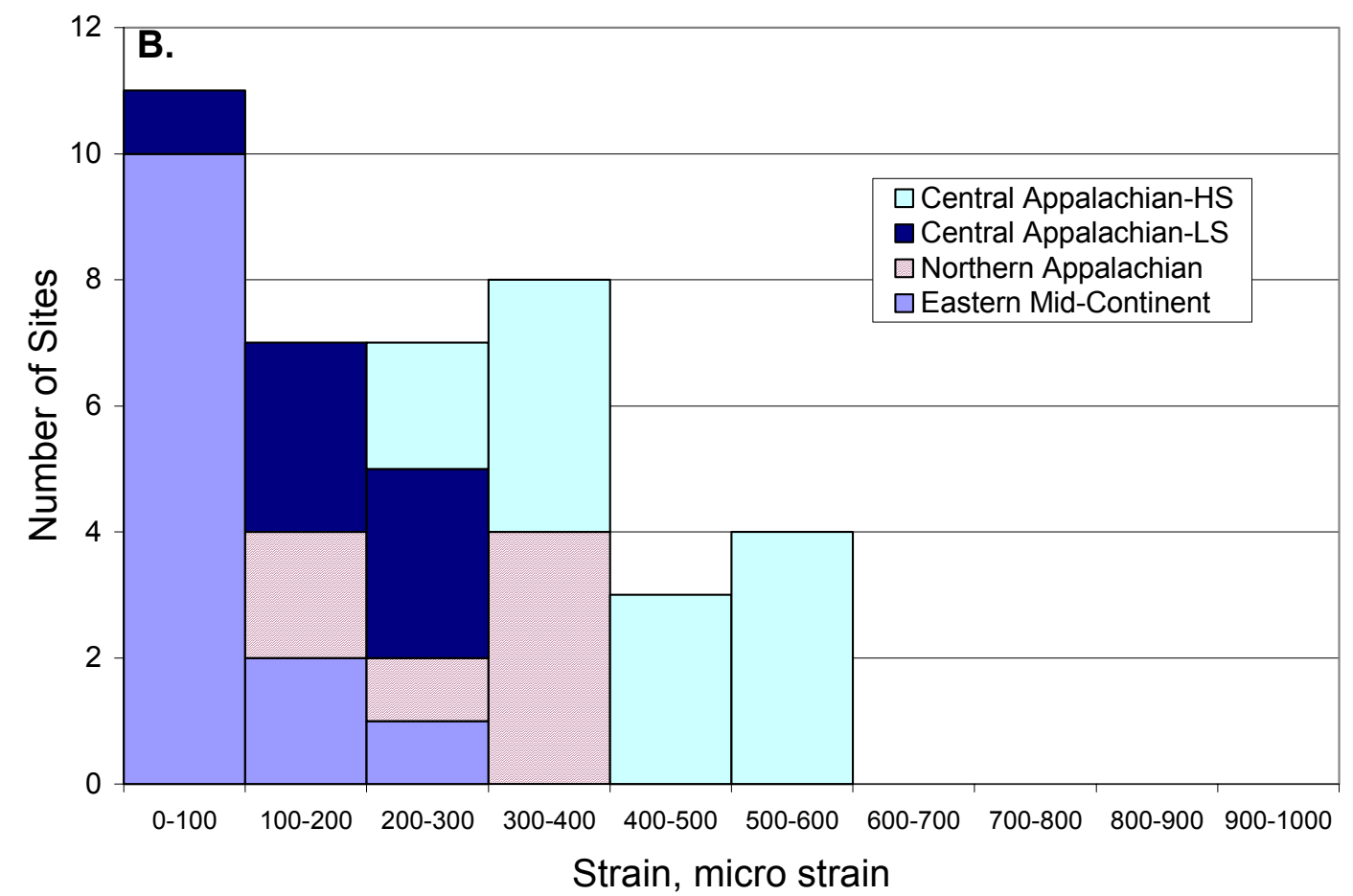

Figure 6-8B. Distribution of the applied horizontal strain across the eastern United States, minimum. 


\subsection{REGIONAL STRAIN VARIATION-CONCLUSIONS}

Locally, the maximum applied horizontal strains are fairly uniform with an average standard deviation that is 14 percent of the average site strain. The minimum applied horizontal strains are much more variable with an average standard deviation that is 44 percent of the average site strain.

Distance of a measurement from the opening is not a significant factor in the variation of the applied maximum horizontal strain. Therefore, the distance of the measurement from the opening appears to have minimal influence on the results.

Based on the maximum applied horizontal strains, the eastern United States can be separated into three regions that include the eastern Mid-Continent region, the northern Appalachian region and the central Appalachian region. The central Appalachian region is further divided into high and low strain zones. The regional or zonal maximum applied strains are fairly uniform with standard deviations that are between 9 and 21 percent of the regional average.

The regional averages for the maximum applied horizontal strains are not significantly different for the northern Appalachian region, eastern Mid-Continent region and the central Appalachian low strain zone though the north Appalachian region has strains that are about 20 percent higher.

There is a high strain zone in the central Appalachian region with maximum applied horizontal strains that are significantly higher than any other region.

The applied horizontal minimum strains are lowest in the eastern Mid-Continent region. This results in much more directional or biaxial horizontal strain and stress fields in this region as compared to the other regions.

The typical average maximum applied horizontal site strain in the eastern United States is between 300 and 600 micro strains. 


\section{CHAPTER 7: REGIONAL AND LOCAL STRESS AND STRAIN MODELS}

In general, the linear relationship between the stress and the elastic modulus should be strongest locally or at a specific site where the strains would show more uniformity with the stresses then varying with the elastic modulus. However, the limitation of the local or site analysis is that the range in the elastic modulus may not be sufficient to establish a reliable model. For the individual mines and seam analysis, the individual measurements are used.

A more general horizontal stress model that encompasses larger geographic regions that examines the relationship between the horizontal stress, the elastic properties and depth can also be developed. Over the larger regions, the variation of the elastic modulus may be sufficient to establish a regional model. However, any larger geographic region must have a sufficiently uniform strain field where the relationship that exists between stress, strain and the elastic modulus is not masked by the variation in the strain field. Three larger areas are examined that include the northern and central Appalachian regions and the eastern Mid-Continent region. Based on the previous strain analysis, both the northern Appalachian and eastern Mid-Continent regions appear to have sufficiently uniform strain fields. The strain field is more complex in the central Appalachian region so the analysis is separated into high and low strain zones. For the regional analysis, the average site stresses are used.

\subsection{REGIONAL STRESS AND STRAIN MODELS}

Regional models are developed for the northern Appalachian and eastern MidContinent regions as well as the high and low strain zones for the central Appalachian region. Regression models are presented for the horizontal stresses with respect to the elastic modulus and depth for each region while the excess stresses and strains from the maximum horizontal are also considered.

\subsubsection{Variation of the Horizontal Stress with the Elastic Modulus}

To evaluate the variation of the horizontal stress with the elastic modulus, a regression analysis using equation 3.1 is conducted on the data for each region. 
Figure 7-1 shows graphs of the maximum horizontal stress versus the elastic modulus for each region. Table 7-1 shows the resulting regression coefficients, constants and coefficients of determination from the regression analysis.

Table 7-1. Regional regression models for the maximum horizontal stress versus the elastic modulus.

\begin{tabular}{|l|c|c|c|c|}
\hline \multicolumn{1}{|c|}{ Model } & Number of sites & Coefficient, $\mathrm{K}_{1}$ & Constant, $\mathrm{K}_{2}$ & $\begin{array}{c}\text { Coefficient of } \\
\text { determination, } \mathrm{R}^{2}\end{array}$ \\
\hline \multicolumn{5}{|c|}{ Central Appalachian Region } \\
\hline Low strain & 7 & 444 & 252 & 0.72 \\
\hline High strain & 13 & 965 & 215 & 0.9 \\
\hline \multicolumn{5}{|c|}{ Northern Appalachian Region } \\
\hline General & 7 & 576 & 0 & 0.89 \\
\hline General & 7 & 564 & 94 & 0.89 \\
\hline \multicolumn{5}{|c|}{ Eastern Mid-Continent Region } \\
\hline General $^{1}$ & 11 & 445 & 0 & 0.87 \\
\hline General $^{1}$ & 11 & 375 & 393 & 0.91 \\
\hline General $^{2}$ & 13 & 292 & 564 & 0.65 \\
\hline
\end{tabular}

${ }^{\mathrm{T}}$ Regression analysis without the Turris Mine, Illinois and the North River mine site 2.

${ }^{2}$ Regression analysis with all the site data.

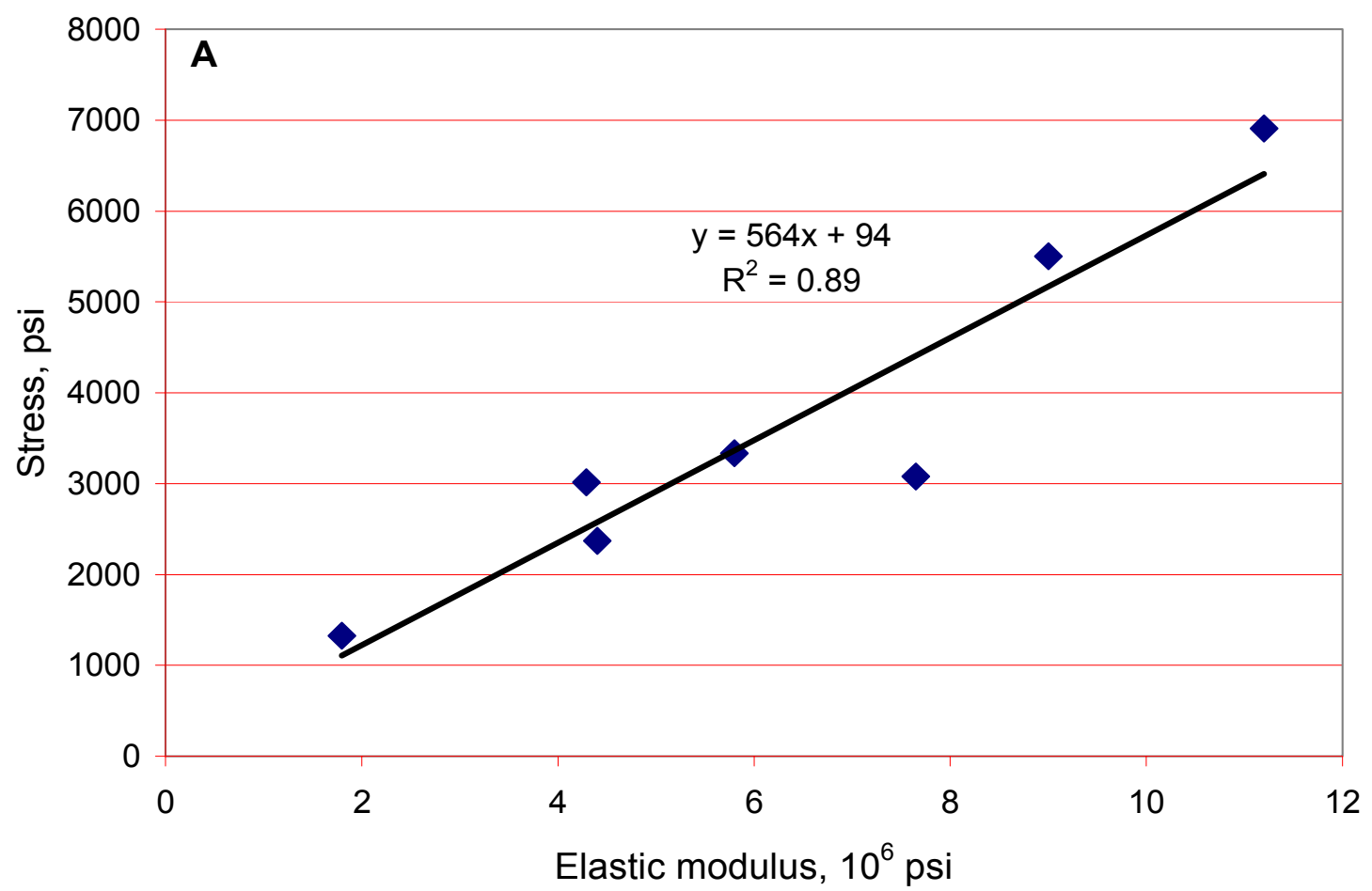

Figure 7-1A. The maximum horizontal stress versus the elastic modulus, northern Appalachian region. 


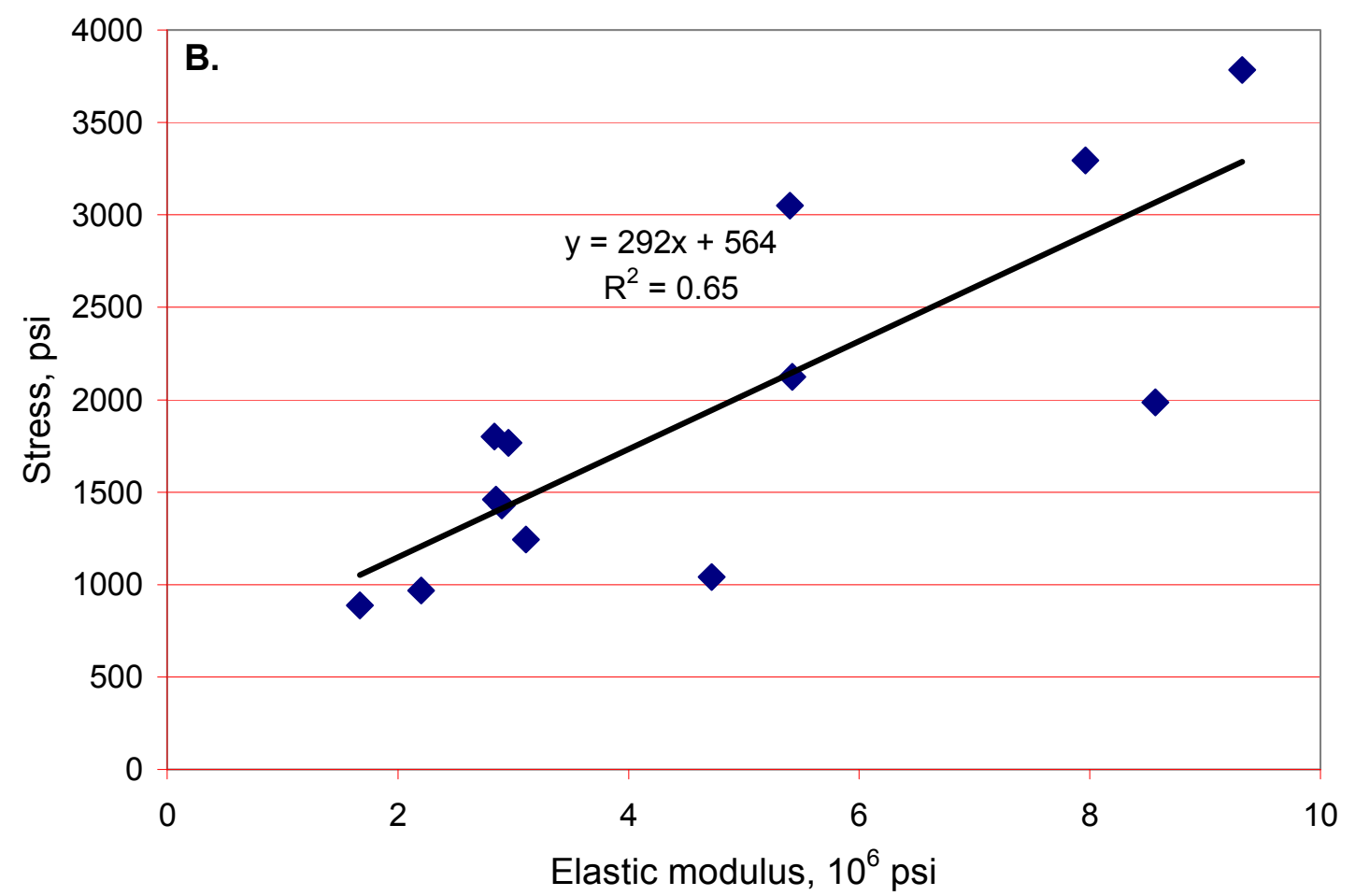

Figure 7-1B. The maximum horizontal stress versus the elastic modulus, eastern Mid-Continent region (with the Turris and North River sites).

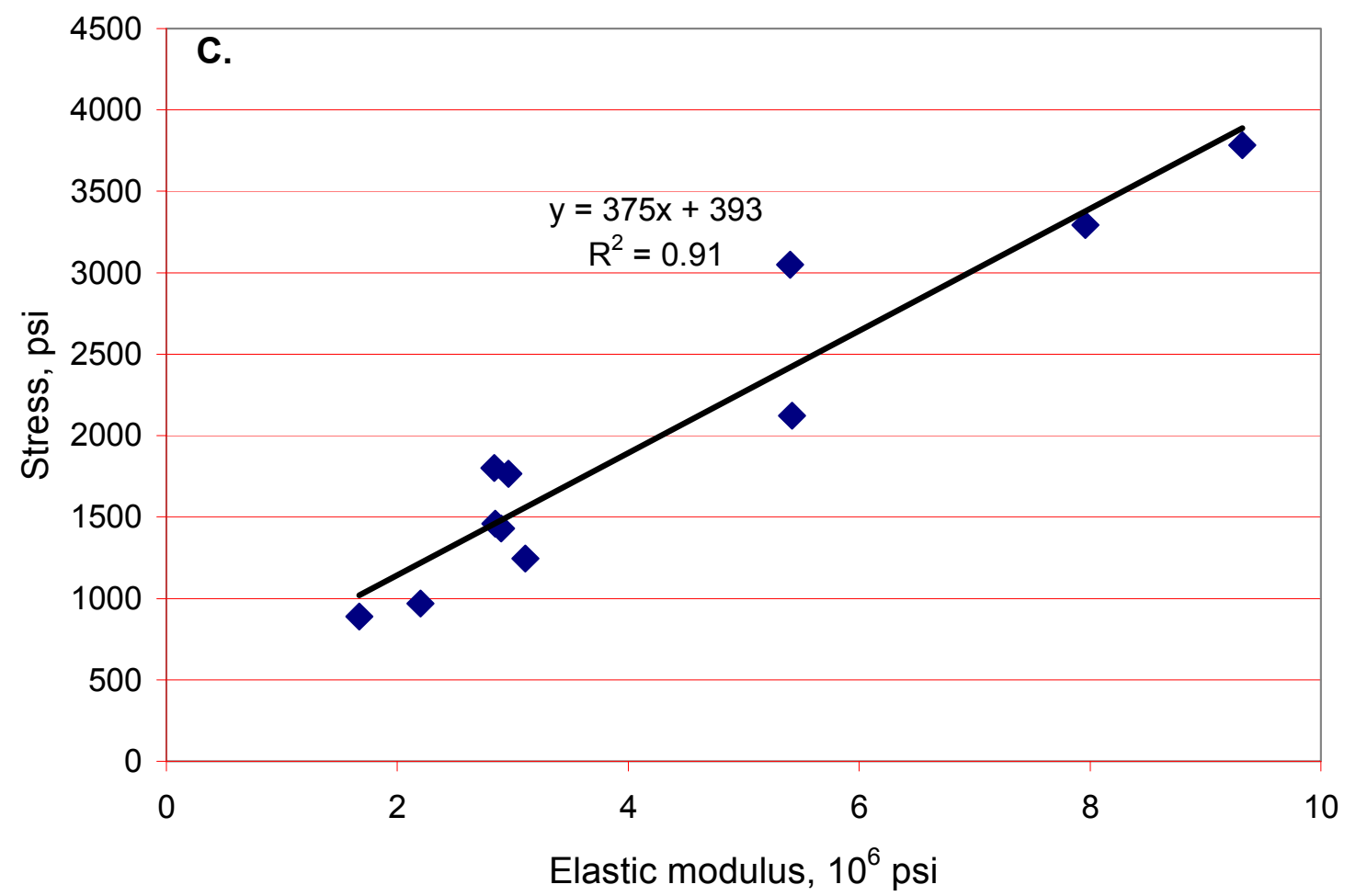

Figure 7-1C. The maximum horizontal stress versus the elastic modulus, eastern Mid-Continent region (without the Turris and North River sites). 


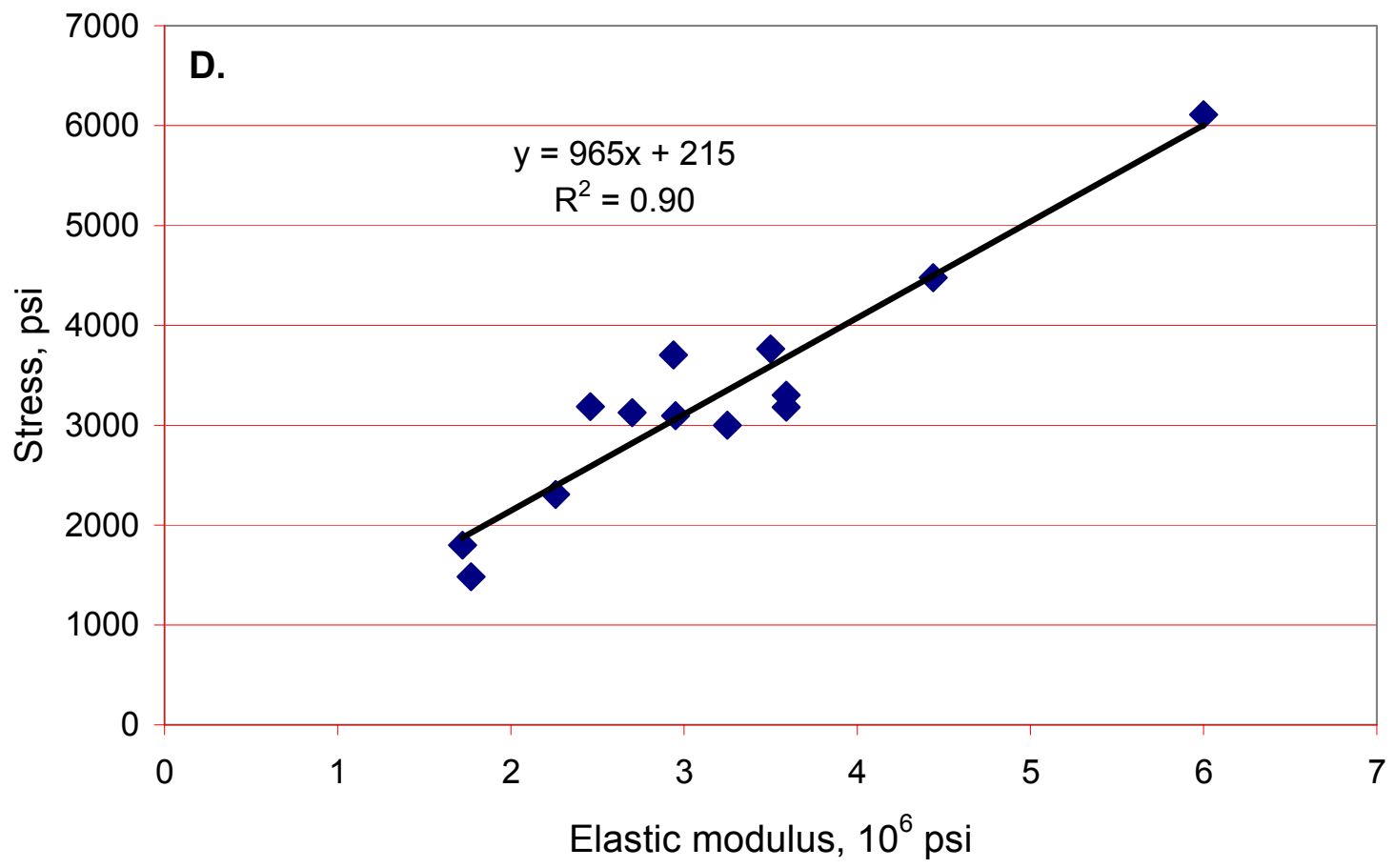

Figure 7-1D. The maximum horizontal stress versus the elastic modulus, central Appalachian region (high strain zone).

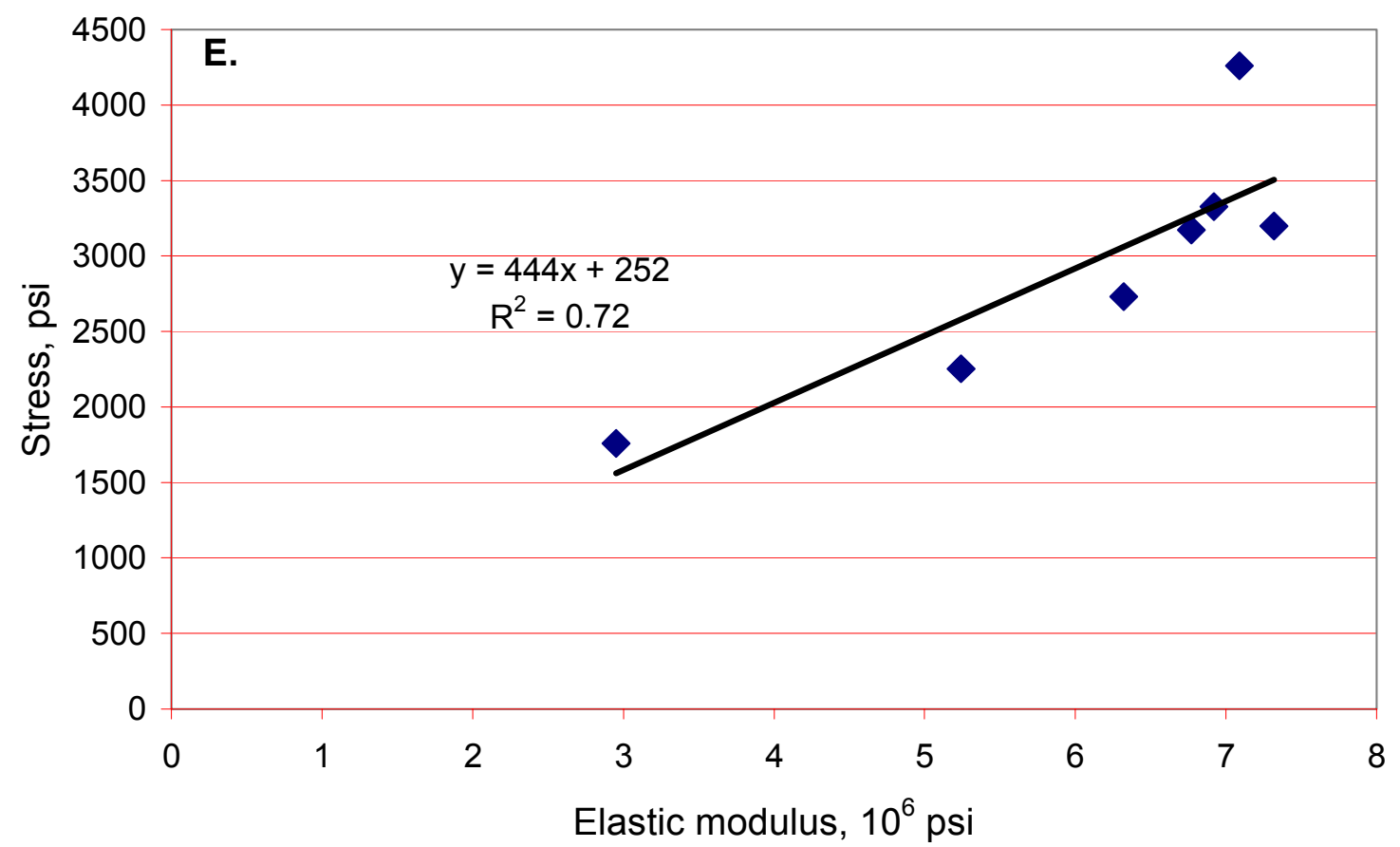

Figure 7-1E. The maximum horizontal stress versus the elastic modulus, central Appalachian region (low strain zone). 
The coefficients of determination identifies how much of the variation of the maximum horizontal stress can be explained by the elastic modulus. The models can explain from 72 to 91 percent of the variation. The highest correlation is found in the eastern Mid-Continent region with the lowest in the central Appalachian region low strain zone. The lower correlation in the central Appalachian low strain zone results from the grouping and limited distribution of the elastic modulus where only one site elastic modulus was below 5 million psi. Again, this reflects what was observed with the Beckley seam analysis. In the case of the eastern Mid-Continent and northern Appalachian regions, the regression fit is also forced through zero with little reduction in the fit.

For the eastern Mid-Continent region, with all the sites, the coefficient of determination is only 0.65 . Examining the strain data reveals that two sites, the Turris Mine and North River site 2 have strains that are much lower than the other sites. Based on previous discussions, the sites may be partially strained relieved. The average strain from the maximum horizontal stress at Turris is only 232 micro strains and at the North River site 2, only 221 micro strains. Without these sites, the range of strain from the maximum horizontal stress is from 400 to 633 micro strains.

Without the Turris Mine and North River site 2, the coefficient of determination is 0.91 for the eastern Mid-Continent region. The coefficient of determination has increased substantially without the two low strain sites. It is not only the low strains for these sites but also the high elastic modulus for the Turris Mine that affects the results of the regression analysis for the maximum horizontal stress. Therefore, because of substantially lower strains, these two sites are excluded from all further analysis of the eastern Mid-Continent region.

For the high strain zone of the central Appalachian region, the equation and coefficient of determination are close to that obtained for the Beckley seam. However, for the low strain zone, the coefficient of determination of 0.72 is much higher than for just the Beckley seam and reflects the increased range of the elastic modulus.

Figure 7-2 shows graphs of the minimum horizontal stress versus the elastic modulus for each region. For the minimum horizontal stress in each region, equation 3.1 
is used for the regression analysis. Table 7-2 shows the resulting regression coefficients, constants and coefficient of determination for the minimum horizontal stress.

The coefficient of determination ranges form 0.25 to 0.81 and is in general much less than for the maximum horizontal stress. However, the northern Appalachian region and central Appalachian high strain zone have correlations that are fairly good. For these regions, the variation of both the maximum and minimum horizontal stress can be explained to a large extent by the elastic modulus of the rock. The poor fit in the eastern Mid-Continent region is due to the low average minimum strain and the relatively high standard deviation of the strain that is larger than the average strain. In the central Appalachian low strain zone, the poor fit is due to the limited range of the elastic modulus, the lower average minimum strain and the relatively high standard deviation.

Table 7-2. Regional regression models for the minimum horizontal stress versus the elastic modulus based on site average stresses.

\begin{tabular}{|l|c|c|c|c|c|c|c|}
\hline Model & $\begin{array}{c}\text { Number } \\
\text { of sites }\end{array}$ & $\begin{array}{c}\text { Coefficient } \\
\mathrm{K}_{1}\end{array}$ & $\begin{array}{c}\text { Constant } \\
\mathrm{K}_{2}\end{array}$ & $\begin{array}{c}\text { Coefficient of } \\
\text { determination } \\
\mathrm{R}^{2}\end{array}$ & $\begin{array}{c}\text { Stress } \\
\text { ratio, } \\
\mathrm{max} / \mathrm{min}\end{array}$ & $\begin{array}{c}\text { Standard } \\
\text { deviation } \\
\text { of ratio }\end{array}$ & $\begin{array}{c}\text { Range of } \\
\text { ratio }\end{array}$ \\
\hline \multicolumn{7}{|c|}{ Central Appalachian Region } \\
\hline Low strain & 7 & 141 & 1072 & 0.25 & 1.55 & 0.36 & $1.03-2.01$ \\
\hline High strain & 13 & 490 & 789 & 0.67 & 1.39 & 0.2 & $1.05-1.84$ \\
\hline \multicolumn{7}{|c|}{ Northern Appalachian Region } \\
\hline General & 7 & 298 & 762 & 0.81 & 1.34 & 0.21 & $1.05-1.74$ \\
\hline General & 7 & 397 & 0 & 0.7 & 1.34 & 0.21 & $1.05-1.74$ \\
\hline \multicolumn{7}{|c|}{ Eastern Mid-Continent Region } \\
\hline General ${ }^{1}$ & 11 & 90 & 480 & 0.35 & 2.59 & 1.66 & $1.08-7.15$ \\
\hline
\end{tabular}

${ }^{1}$ Without the Turris Mine, Illinois and the North River site 2, Alabama 


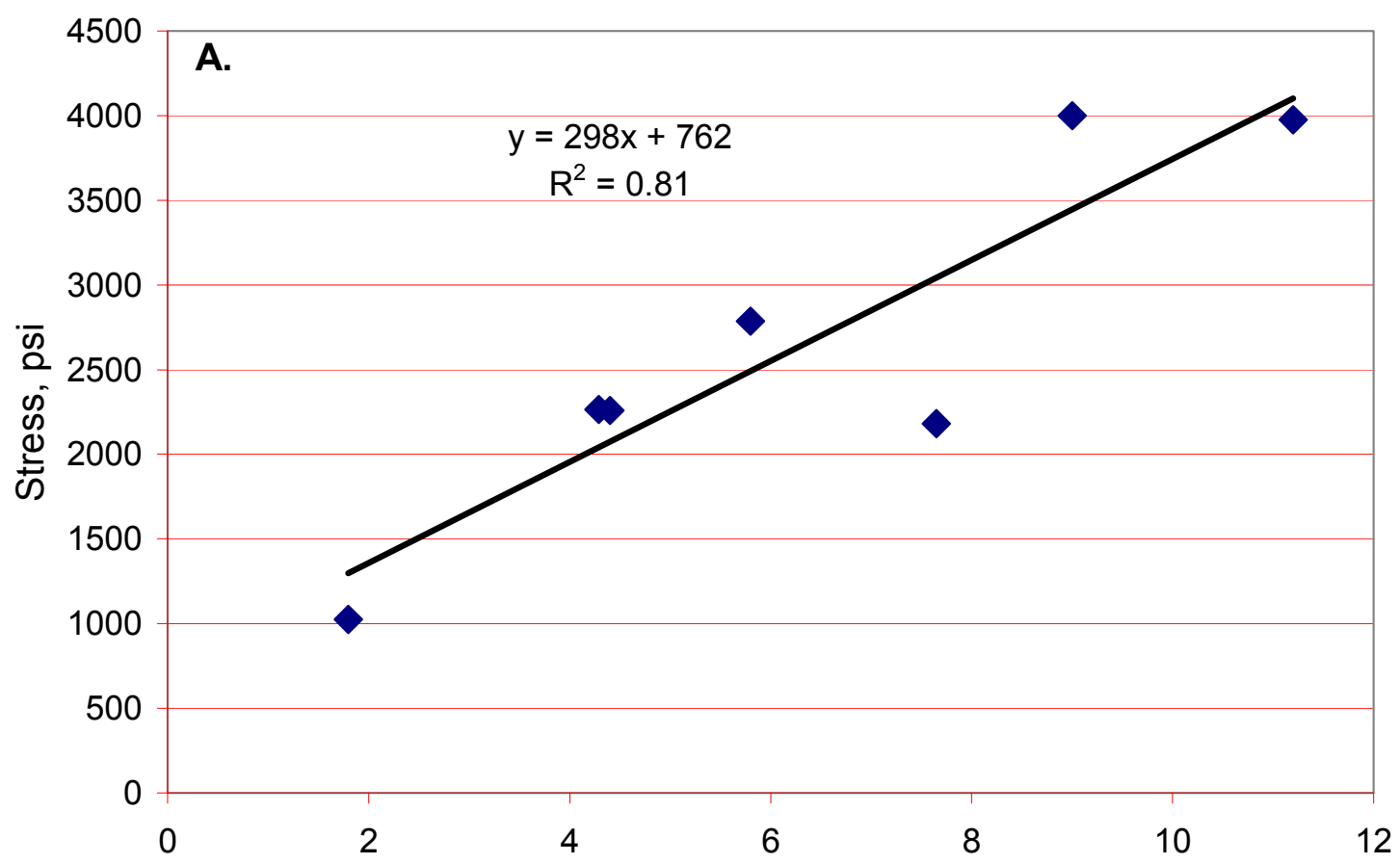

Elastic modulus, $10^{6} \mathrm{psi}$

Figure 7-2A. The minimum horizontal stress versus the elastic modulus, northern Appalachian region.

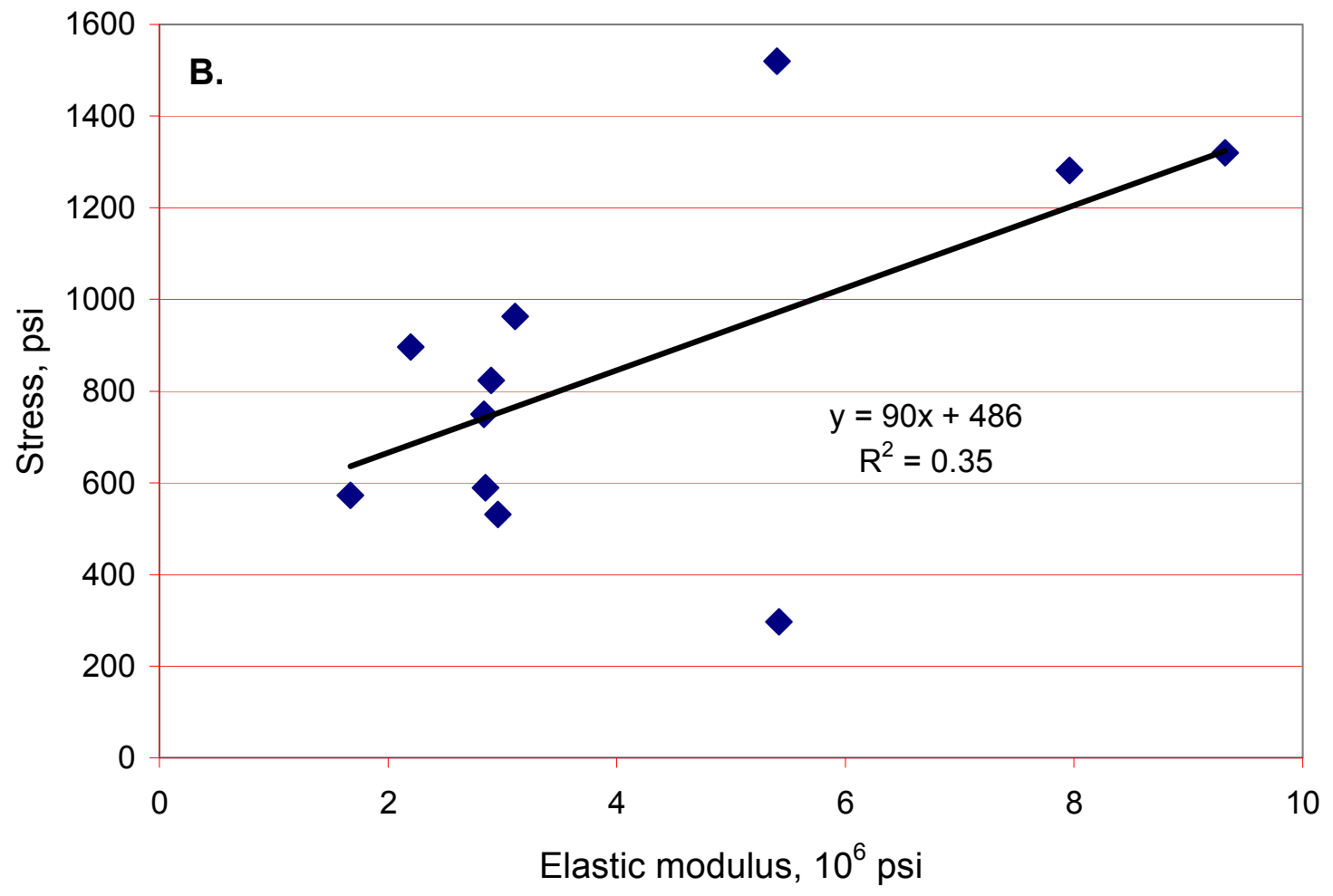

Figure 7-2B. The minimum horizontal stress versus the elastic modulus, eastern Mid-Continent region. 


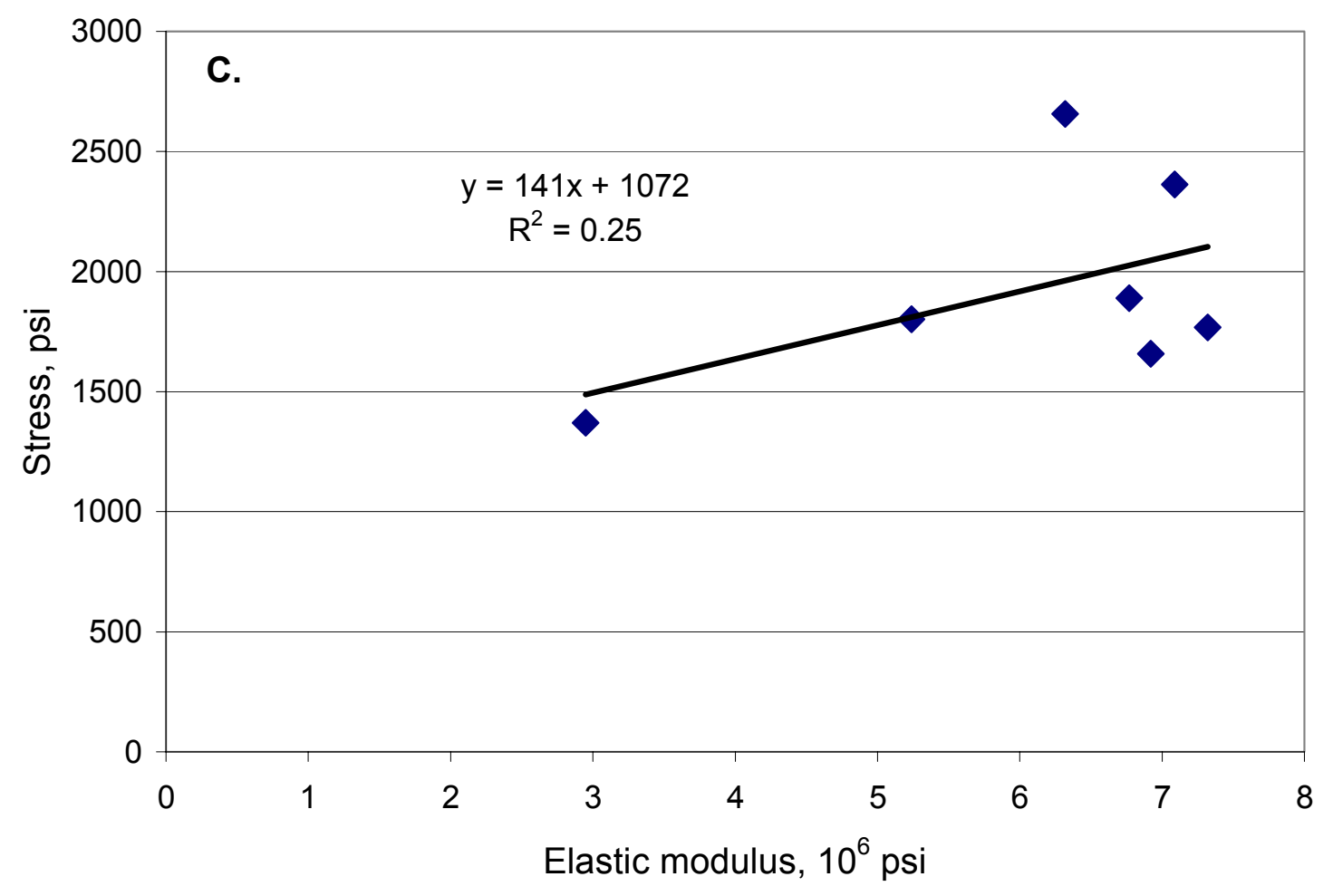

Figure 7-2C. The minimum horizontal stress versus the elastic modulus, central Appalachian region (low strain zone).

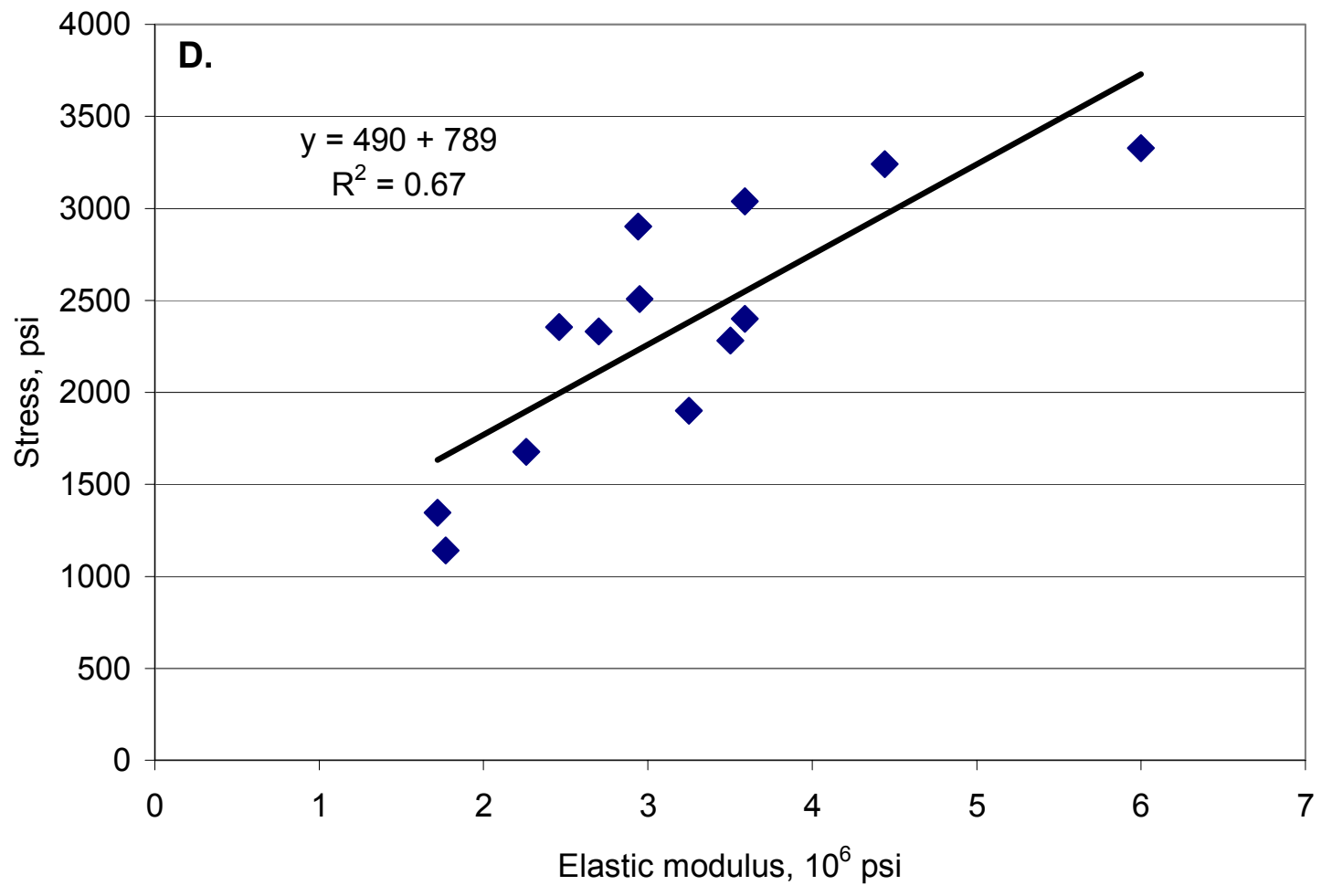

Figure 7-2D. The minimum horizontal stress versus the elastic modulus, central Appalachian region (high strain zone). 
Table 7-2 also gives the average ratio between the maximum and minimum horizontal stress for each region. Because of the regional variation of the ratio as indicated by the standard deviations, the minimum stress is not as strongly dependent on the elastic modulus as the maximum horizontal stress. This is especially true for the eastern Mid-Continent region with a standard deviation of the ratio that is about 65 percent of the regional ratio, a ratio that is the highest of any of the regions. Further, the overall lower strains with equal or larger strain variations are another reason why the minimum stress is not as dependent on the elastic modulus.

\subsubsection{Variation of Horizontal Stress with Depth}

The variation of the horizontal stress with depth is evaluated for each region using the average maximum horizontal stress measured at each site. Site averages are used to give each site the same weight. For the central Appalachian region, the analysis is conducted on the separate data sets for the high and low strain zones as well as for a combined data set. For the regression analysis, equation 3.7 is used. Figure 7-3 shows graphs of the maximum horizontal stress versus depth for each region.

Table 7-3 shows the resulting coefficients, constants and statistics for each region. The depth factor varies from 1.03 to $1.71 \mathrm{psi} / \mathrm{ft}$. However, the correlations are so poor that the depth can only explain between 9 and 24 percent of the variation of the maximum horizontal stress even though the depth range appears to be sufficient. Also, the $\mathrm{t}$ statistics for the depth factor indicates that at a 0.05 significance level, none of the depth factors are significantly greater than zero. Essentially, there is no significant increase in the maximum horizontal stress with depth in any of the regions. 
Table 7-3. Variation of the maximum horizontal stress with depth by region.

\begin{tabular}{|c|c|c|c|c|c|c|c|}
\hline Zone & $\begin{array}{c}\text { Number } \\
\text { of sites }\end{array}$ & $\begin{array}{c}\text { Depth } \\
\text { factor, } \\
\mathrm{K}_{\mathrm{D}, \mathrm{psi} / \mathrm{ft}}\end{array}$ & $\begin{array}{c}\text { Maximum } \\
\text { stress at } \\
\text { surface, } \\
\mathrm{P}_{\mathrm{S}, \mathrm{psi}}\end{array}$ & $\begin{array}{c}\text { Coefficient of } \\
\text { determination, } \\
\mathrm{R}^{2}\end{array}$ & $\begin{array}{c}\mathrm{t} \text { statistic } \\
\text { for depth } \\
\text { factor }\end{array}$ & $\begin{array}{c}\text { Significant } \\
\text { depth factor }\end{array}$ & $\begin{array}{c}\text { Range of } \\
\text { depth, ft }\end{array}$ \\
\hline \multicolumn{7}{|c|}{ Northern Appalachian } \\
\hline & 7 & 1.03 & 2784 & 0.13 & 0.85 & No & $400-2,300$ \\
\hline Low strain & 7 & 1.71 & 1527 & 0.18 & 1.06 & No & $550-1130$ \\
\hline High strain & 13 & 1.09 & 2238 & 0.09 & 1.02 & No & $350-1,600$ \\
\hline Combined & 20 & 1.26 & 2018 & 0.11 & 1.52 & No & $350-1,600$ \\
\hline & 11 & 1.07 & 1186 & 0.24 & 1.68 & No & $290-1,870$ \\
\hline
\end{tabular}

${ }^{1}$ Significant at a 0.05 significance level.

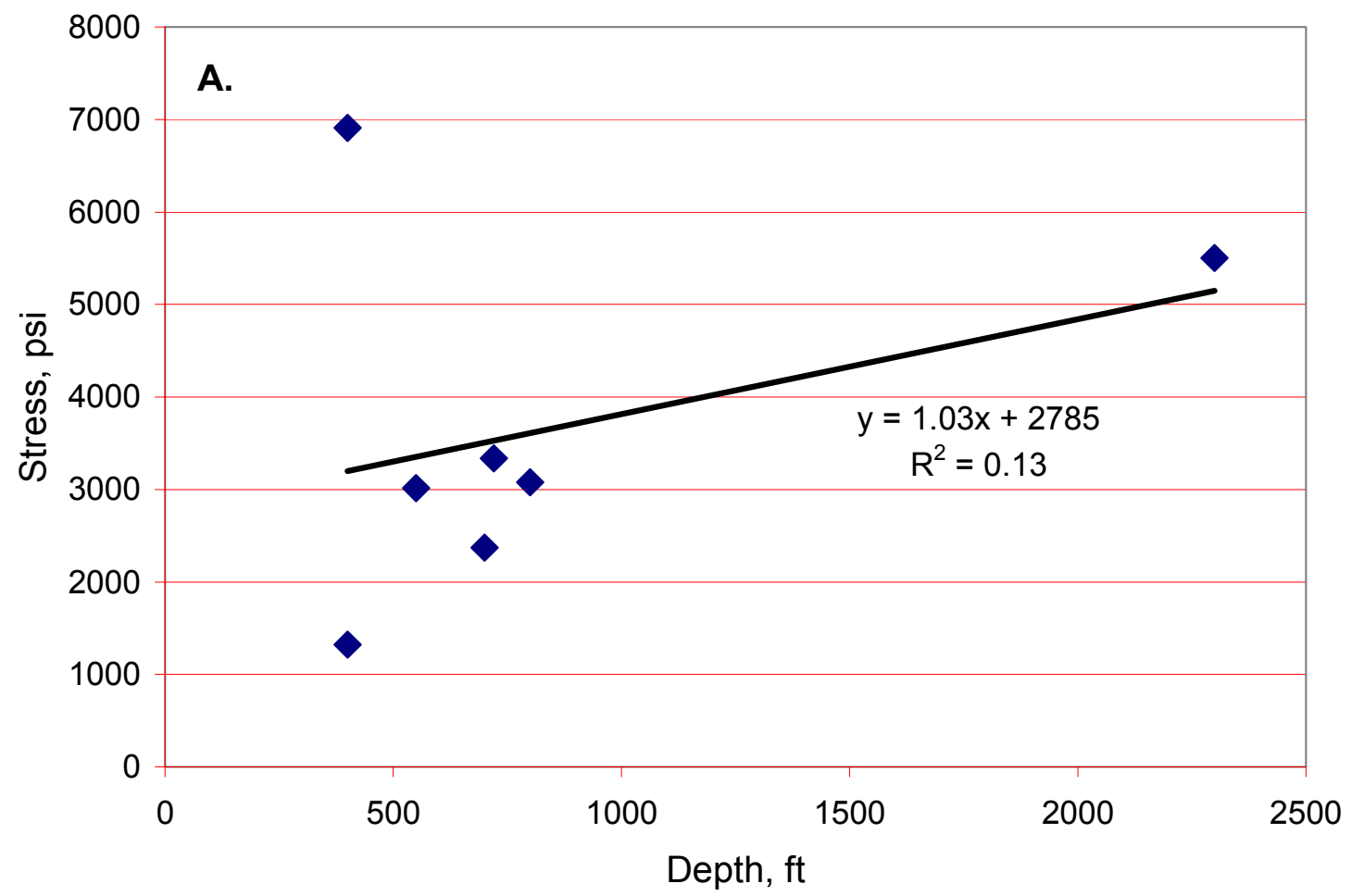

Figure 7-3A. The maximum horizontal stress versus the depth, northern Appalachian region. 


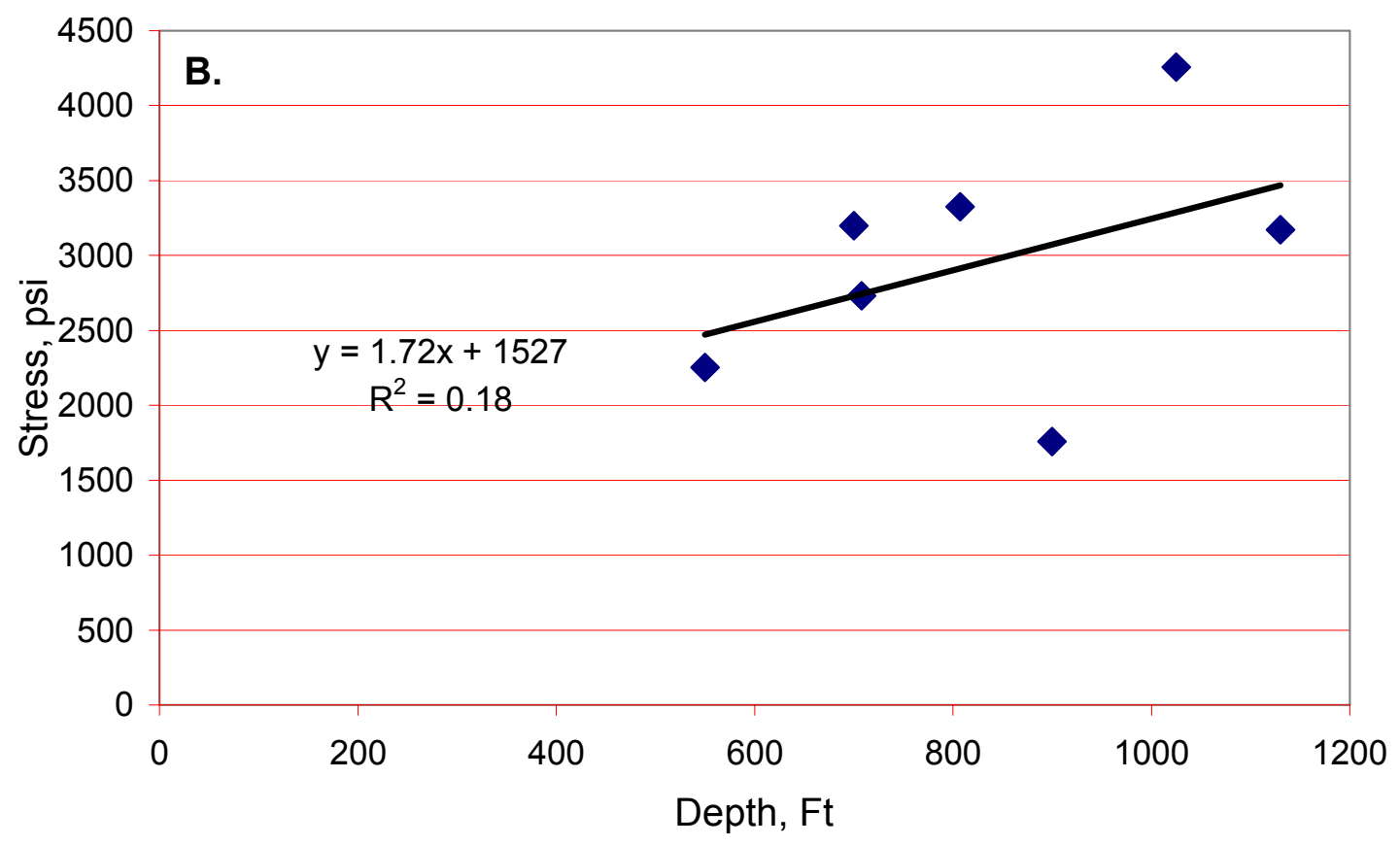

Figure 7-3B. The maximum horizontal stress versus the depth, central Appalachian region (low strain zone).

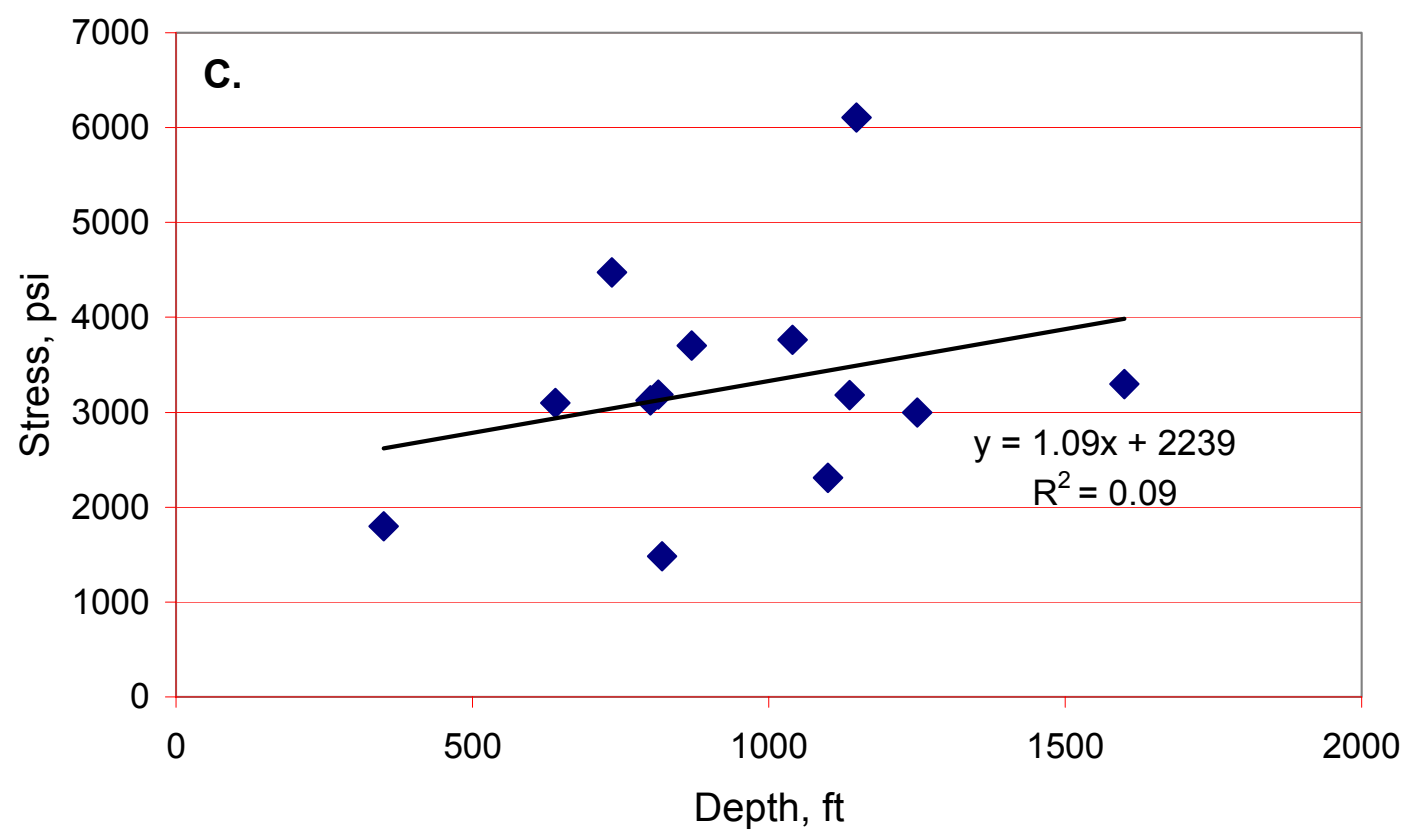

Figure 7-3C. The maximum horizontal stress versus the depth, central Appalachian region (high strain zone). 


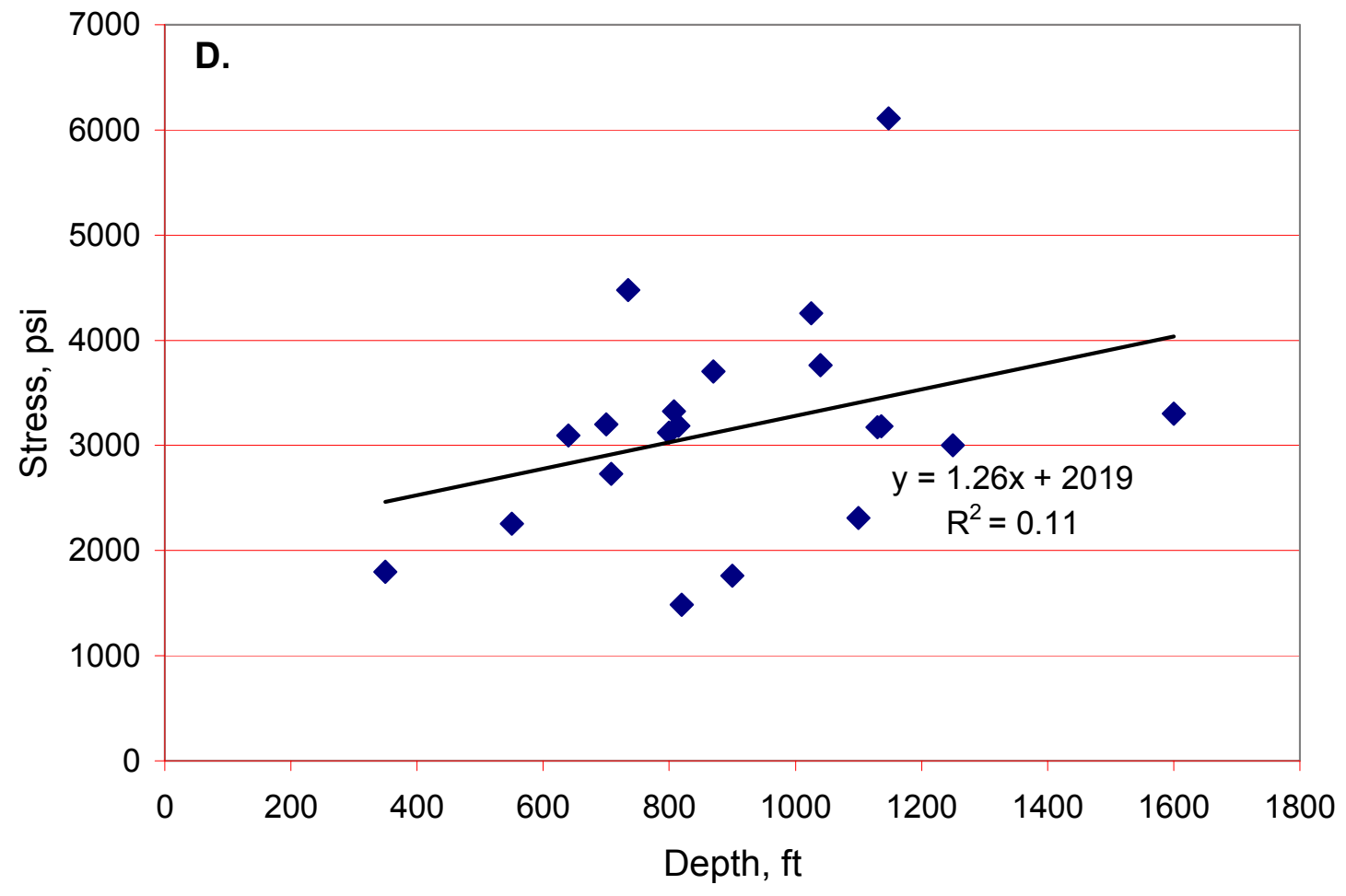

Figure 7-3D. The maximum horizontal stress versus the depth, central Appalachian region.

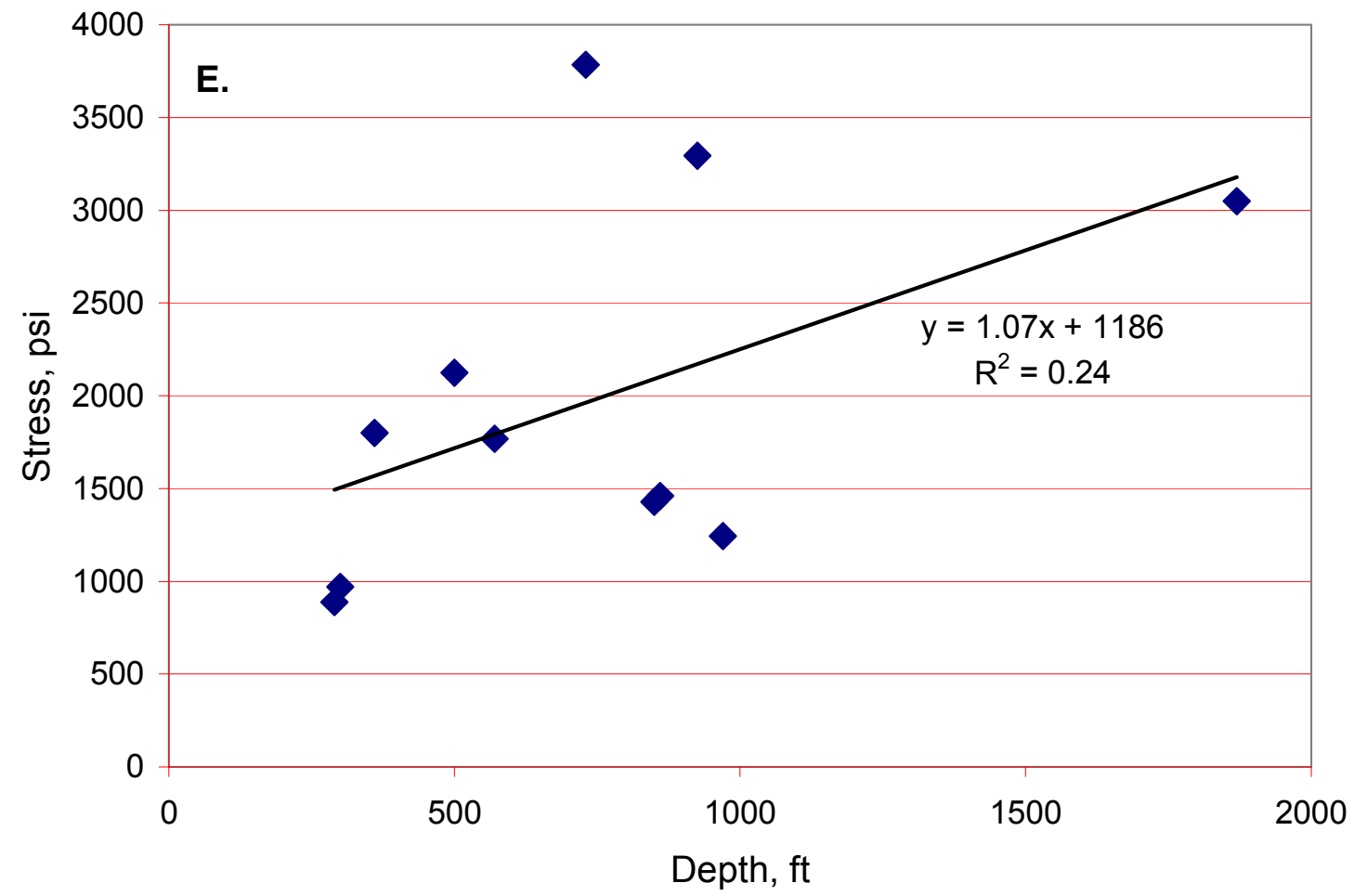

Figure 7-3E. The maximum horizontal stress versus the depth, eastern MidContinent region. 


\subsubsection{Variation of the Horizontal Stress with the Elastic Modulus and Depth}

A multiple linear regression model is fit to the data for each region where the dependent variable is the maximum horizontal stress and the independent variables, the site depth and the elastic modulus. For this analysis, the average site stress and elastic modulus are used. The regression analysis is conducted using equation 3.8.

Table 7-4 gives the resulting depth and elastic modulus coefficients, the constants and relevant statistics. In general, the coefficients of determination are fairly high indicating that the models can explain between 83 to 94 percent of the variation of the maximum horizontal stress. For the elastic modulus, the coefficients range from 350 to 1,027 micro strains. In all cases, the coefficient for the elastic modulus is significant at a 0.05 significance level.

Table 7-4. Variation of maximum horizontal stress with depth and the elastic modulus by region.

\begin{tabular}{|c|c|c|c|c|c|c|c|c|c|}
\hline Zone & $\begin{array}{c}\text { Number of } \\
\text { measurements }\end{array}$ & $\begin{array}{c}\text { Depth } \\
\text { factor, } \\
\mathrm{psi} / \mathrm{ft}\end{array}$ & $\begin{array}{c}\text { Elastic } \\
\text { modulus } \\
\text { coefficient, } \\
\text { micro } \\
\text { strain }\end{array}$ & $\begin{array}{l}\text { Con- } \\
\text { stant }\end{array}$ & $\begin{array}{l}\text { Coefficient of } \\
\text { determination, } \\
\mathrm{R}^{2}\end{array}$ & $\begin{array}{l}\text { t Statistic } \\
\text { for depth } \\
\text { factor }\end{array}$ & $\begin{array}{l}\text { Significant } \\
\text { depth } \\
\text { factor }^{1}\end{array}$ & $\begin{array}{c}\mathrm{t} \text { statistic } \\
\text { for elastic } \\
\text { modulus } \\
\text { factor }\end{array}$ & $\begin{array}{c}\text { Significant } \\
\text { elastic } \\
\text { modulus } \\
\text { factor }^{1}\end{array}$ \\
\hline \multicolumn{10}{|c|}{ Northern Appalachian } \\
\hline & 7 & 0.05 & 560 & 76 & 0.89 & 0.09 & No & 5.21 & Yes \\
\hline \multicolumn{10}{|c|}{ Central Appalachian } \\
\hline Low strain & 7 & 1.35 & 424 & -752 & 0.83 & 1.65 & No & 3.97 & Yes \\
\hline High strain & 13 & -0.52 & 1027 & 515 & 0.92 & -1.39 & No & 9.93 & Yes \\
\hline \multicolumn{10}{|c|}{ Eastern Mid-Continent } \\
\hline & 11 & 0.39 & 350 & 207 & 0.94 & 1.87 & No & 9.35 & Yes \\
\hline
\end{tabular}

${ }^{\mathrm{T}}$ Evaluated at a 0.05 significance level.

The depth factor though is more variable. One of the depth factors is negative, two others are positive while one has a rate of nearly zero. However, none of the depth factors are significantly greater than zero at a 0.05 significance level. This analysis shows that the elastic modulus is a significant factor while the depth is not a significant factor in the variation of the maximum horizontal stress for each region. 


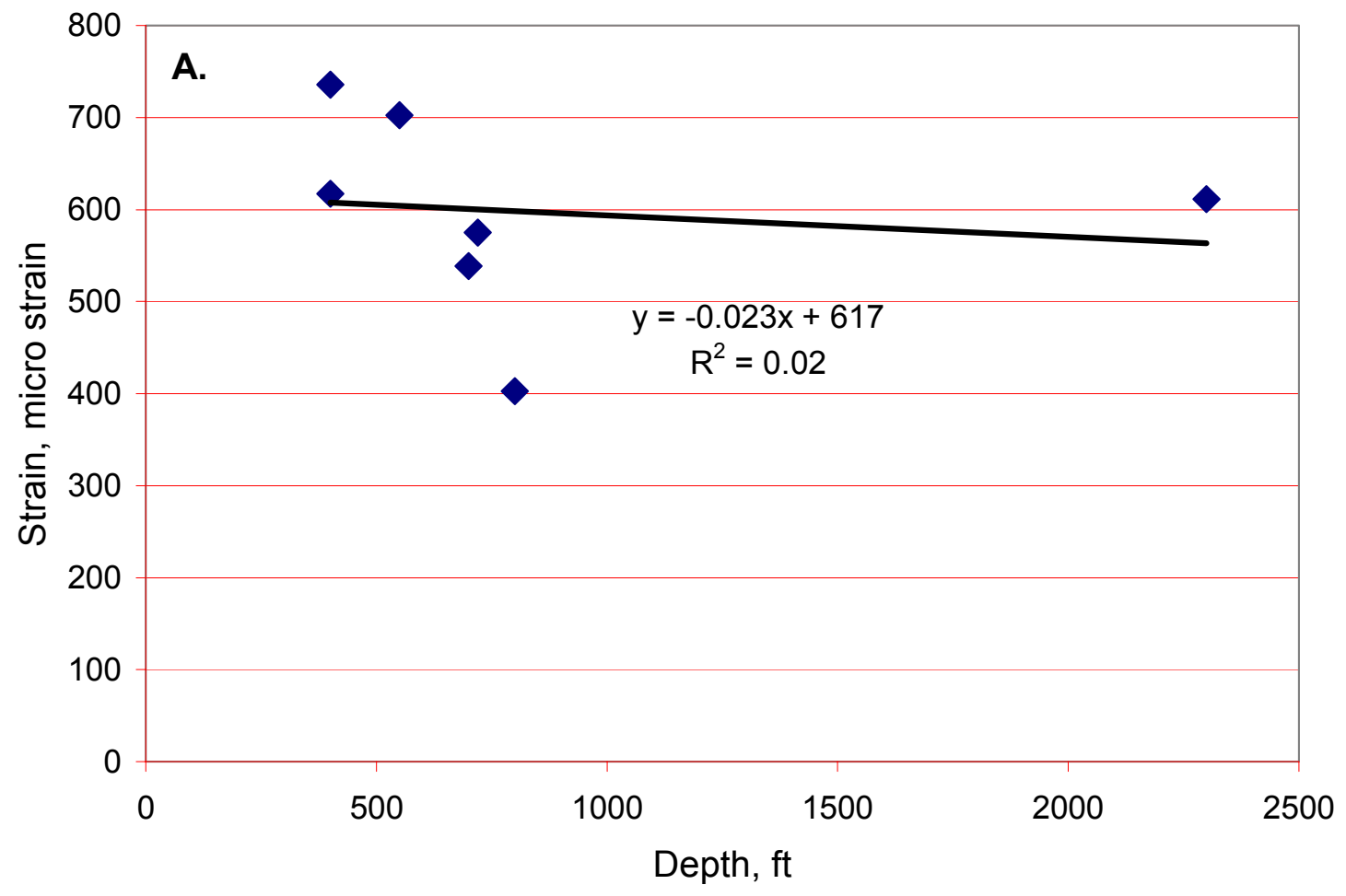

Figure 7-4A. Strain from the maximum horizontal stress versus the depth for the northern Appalachian region.

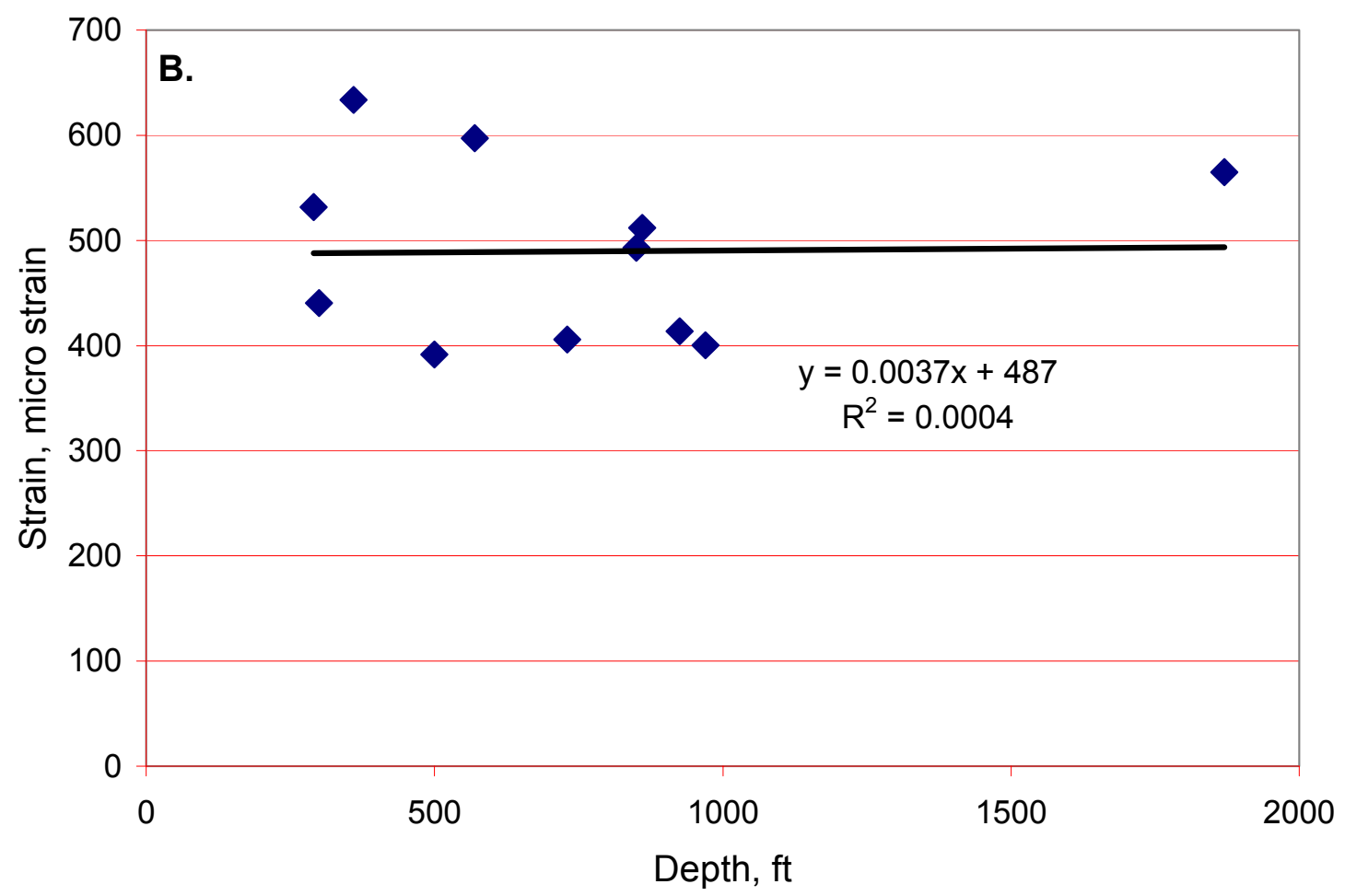

Figure 7-4B. Strain from the maximum horizontal stress versus the depth for the eastern Mid-Continent region. 


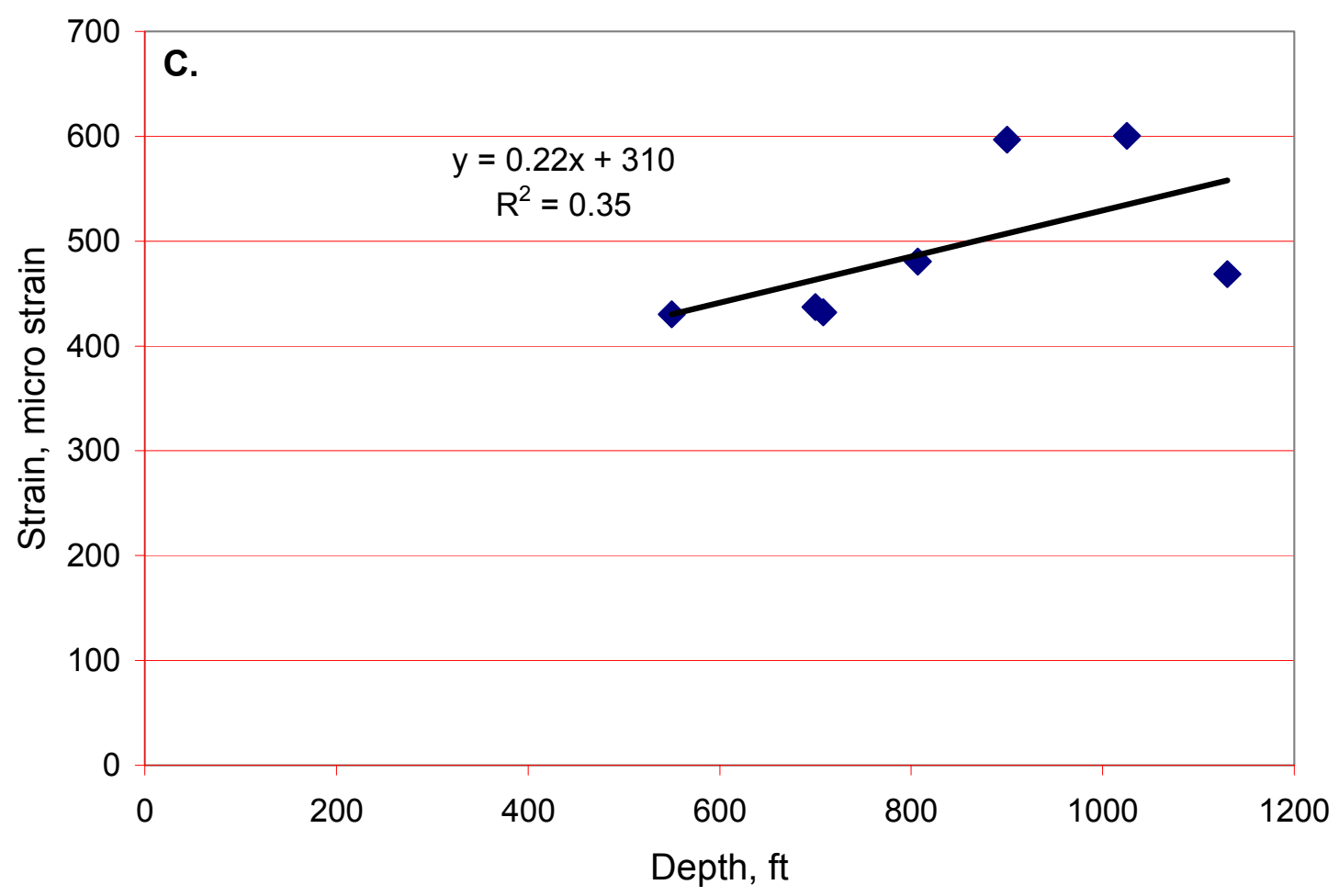

Figure 7-4C. Strain from the maximum horizontal stress versus the depth for the central Appalachian region (low strain zone).

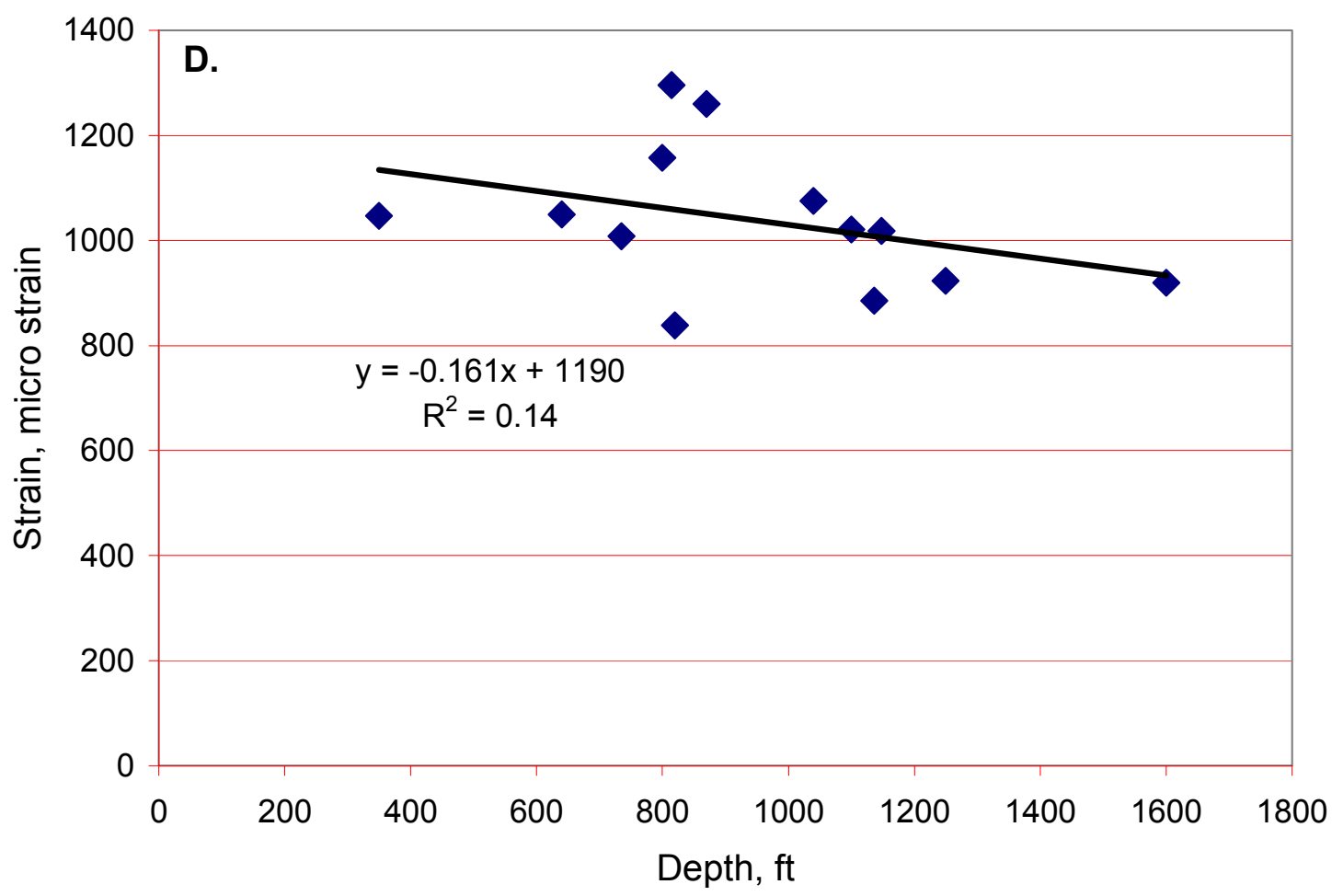

Figure 7-4D. Strain from the maximum horizontal stress versus the depth for the central Appalachian region (high strain zone). 


\subsubsection{Variation of the Strain from the Maximum Horizontal Stress with Depth}

Using the strains from the maximum horizontal stress, the affects of depth are considered without the influence of the elastic properties. These strains are calculated using equation 3.6. The maximum strains calculated by equation 3.6 can also be considered the maximum stress normalized by the elastic modulus. Essentially, the affects of the elastic modulus are removed from the data with all sites and measurements having an elastic modulus of one million psi.

Figure 7-4 shows the strain from the maximum horizontal stress versus depth for each region. A regression analysis using equation 3.9 is used to fit to the data. Table 7-5 gives the depth coefficients, strain constants and relevant statistics from the regression analysis for each region. In general, the coefficients of determination are very low where the depth can explain only between 0 to 35 percent of the variation. For two of the regions, the strain actually decreases with depth. However, none of the regional depth factors are significantly greater than zero at a 0.05 significance level. In general, it does not appear the strains are increasing with depth in any of the regions.

Table 7-5. Regression models for the strain from the maximum horizontal stress versus depth for each region.

\begin{tabular}{|l|c|c|c|c|c|}
\hline Zone & $\begin{array}{c}\text { Number } \\
\text { of sites }\end{array}$ & $\begin{array}{c}\text { Depth } \\
\text { coefficient } \\
\text { micro strain/ft }\end{array}$ & $\begin{array}{c}\text { Constant, } \\
\text { micro strain }\end{array}$ & $\begin{array}{c}\text { Coefficient of } \\
\text { determination, } \\
\mathrm{R}^{2}\end{array}$ & $\begin{array}{c}\text { Significance of } \\
\text { strain } \\
\text { coefficient }\end{array}$ \\
\hline \multicolumn{5}{|c|}{ Northern Appalachian } \\
\hline & 7 & -0.02 & 617 & 0.02 & No \\
\hline \multicolumn{5}{|c|}{ Central Appalachian } \\
\hline Low strain & 7 & 0.22 & 310 & 0.35 & No \\
\hline High Strain & 13 & -0.16 & 1190 & 0.14 & No \\
\hline \multicolumn{7}{|c|}{ Eastern Mid-Continent } \\
\hline & 11 & 0.0037 & 487 & 0.0004 & No \\
\hline
\end{tabular}

\subsubsection{Excess Horizontal Stresses}

To calculate the excess horizontal stress, a Poisson's ratio of 0.25 and the average site stresses are used. A linear regression is fit through the data with a zero intercept using equation 3.5. Table 7-6 shows the resulting coefficients and coefficients of 
determination for each region. The coefficient of the equation represents the excess or tectonic strain components related to the maximum excess horizontal stress.

Table 7-6. Regression models for the maximum excess horizontal stress versus the elastic modulus by region with a zero intercept.

\begin{tabular}{|l|c|c|c|}
\hline \multicolumn{1}{|c|}{ Site } & Number of sites & Coefficient, $\mathrm{K}_{1}$ & $\begin{array}{c}\text { Coefficient of } \\
\text { determination, } \mathrm{R}^{2}\end{array}$ \\
\hline \multicolumn{4}{|c|}{ Central Appalachian Region } \\
\hline Low strain & 7 & 436 & 0.76 \\
\hline High strain & 13 & 923 & 0.86 \\
\hline \multicolumn{4}{|c|}{ Northern Appalachian Region } \\
\hline General & 7 & 530 & 0.87 \\
\hline \multicolumn{4}{|c|}{ Eastern Mid-Continent } \\
\hline General & 11 & 391 & 0.91 \\
\hline
\end{tabular}

Theoretically, there is a basis for some increase in the horizontal stress with depth, the increase due to gravity from Poisson's effect. However, this effect appears to be masked in the depth models, possibly by the variation in the strain fields. To have a model that includes this depth factor and the elastic modulus requires building a model utilizing the excess horizontal stress. Combining equation 3.5 with the expected increase of the horizontal stress with depth results in the following type of equation

$$
\mathrm{P}=1.1[v /(1-v)] \mathrm{D}+\mathrm{K}_{1} \mathrm{E}
$$

The coefficient of the elastic modulus, $\mathrm{K}_{1}$, is a strain coefficient. This model can be used to estimate the maximum horizontal stress magnitude within a region.

A similar type of analysis using equation 3.5 is conducted for the minimum excess horizontal stress. Table 7-7 shows the resulting coefficients for the elastic modulus and the coefficients of determination for each region. Except for the northern Appalachian region and possibly the central Appalachian high strain zone, the coefficient of determination is so poor as to make the results of the regression analysis meaningless. 
Table 7-7. Regression models for the minimum excess horizontal stress versus the elastic modulus by region with a zero intercept.

\begin{tabular}{|l|c|c|c|c|c|}
\hline Zone & $\begin{array}{c}\text { Number } \\
\text { of sites }\end{array}$ & $\begin{array}{c}\text { Coefficient, } \\
\mathrm{K}_{1}\end{array}$ & $\begin{array}{c}\text { Coefficient of } \\
\text { determination, } \mathrm{R}^{2}\end{array}$ & $\begin{array}{c}\text { Stress ratio } \\
\mathrm{max} / \mathrm{min}\end{array}$ & $\begin{array}{c}\text { Standard deviation } \\
\text { of ratio }\end{array}$ \\
\hline \multicolumn{7}{|c|}{ Northern Appalachian } \\
\hline & 7 & 350 & 0.73 & 1.38 & 0.22 \\
\hline \multicolumn{7}{|c|}{ Central Appalachian } \\
\hline Low strain & 7 & 260 & 0.02 & 1.67 & 0.44 \\
\hline High strain & 13 & 610 & 0.49 & 1.47 & 0.24 \\
\hline \multicolumn{7}{|c|}{ Eastern Mid-Continent } \\
\hline & 11 & 123 & 0.03 & 4 & 4.37 \\
\hline
\end{tabular}

For the northern Appalachian region, the coefficient of determination is 0.73 . Adding in the depth factor, the equation for the minimum horizontal stress for the northern Appalachian region is

$$
\mathrm{Q}=1.1[v /(1-v)] \mathrm{D}+350 \mathrm{E} \text {. }
$$

Clearly, the minimum excess horizontal stress variation is not as dependent on the elastic modulus as is the maximum excess horizontal stress variation. Table 7-7 shows the stress ratio and the standard deviations. These ratios are based on the average for all the measurements within the region. The regional average ratios vary from 1.38 to 4.0 and are slightly different than those for the measured stresses because the depth factor is removed from the excess horizontal stresses. However, the standard deviations especially in the eastern Mid-Continent region results in the minimum excess horizontal stress not being as dependent on the elastic modulus as the maximum excess horizontal stress.

\subsection{VARIATION OF THE HORIZONTAL STRESSES WITH THE ELASTIC MODULUS FOR SPECIFIC SEAMS AND MINES}

In general, the more local the analysis of the horizontal stress and the elastic modulus, the more consistent and uniform the horizontal strain field should be. A more uniform strain field should result in a better correlation between the horizontal stress and 
the elastic modulus. However, as is seen in the evaluation of the individual sites and mines in the Beckley seam, the limitation of a more local analysis is a potential lack of a sufficient elastic modulus range. In the Beckley seam, only for the Bonny Mine, is there a sufficient range of the elastic properties and uniform strain field to result in a strong correlation. Therefore, only the analysis from those locations that have a sufficient range in the elastic modulus are presented in this section. Further, the individual stress measurements are used in this section and not the site averages.

\subsubsection{Pittsburgh Seam}

Figure 7-5 shows a graph of the maximum horizontal stress versus the elastic modulus for the three sites in the Pittsburgh seam. A linear regression fit through the data results in the following equation

$$
\mathrm{P}=370 \mathrm{E}+728
$$

The coefficient of determination is 0.87 and represents a fairly strong correlation between the elastic modulus and the maximum horizontal stress.

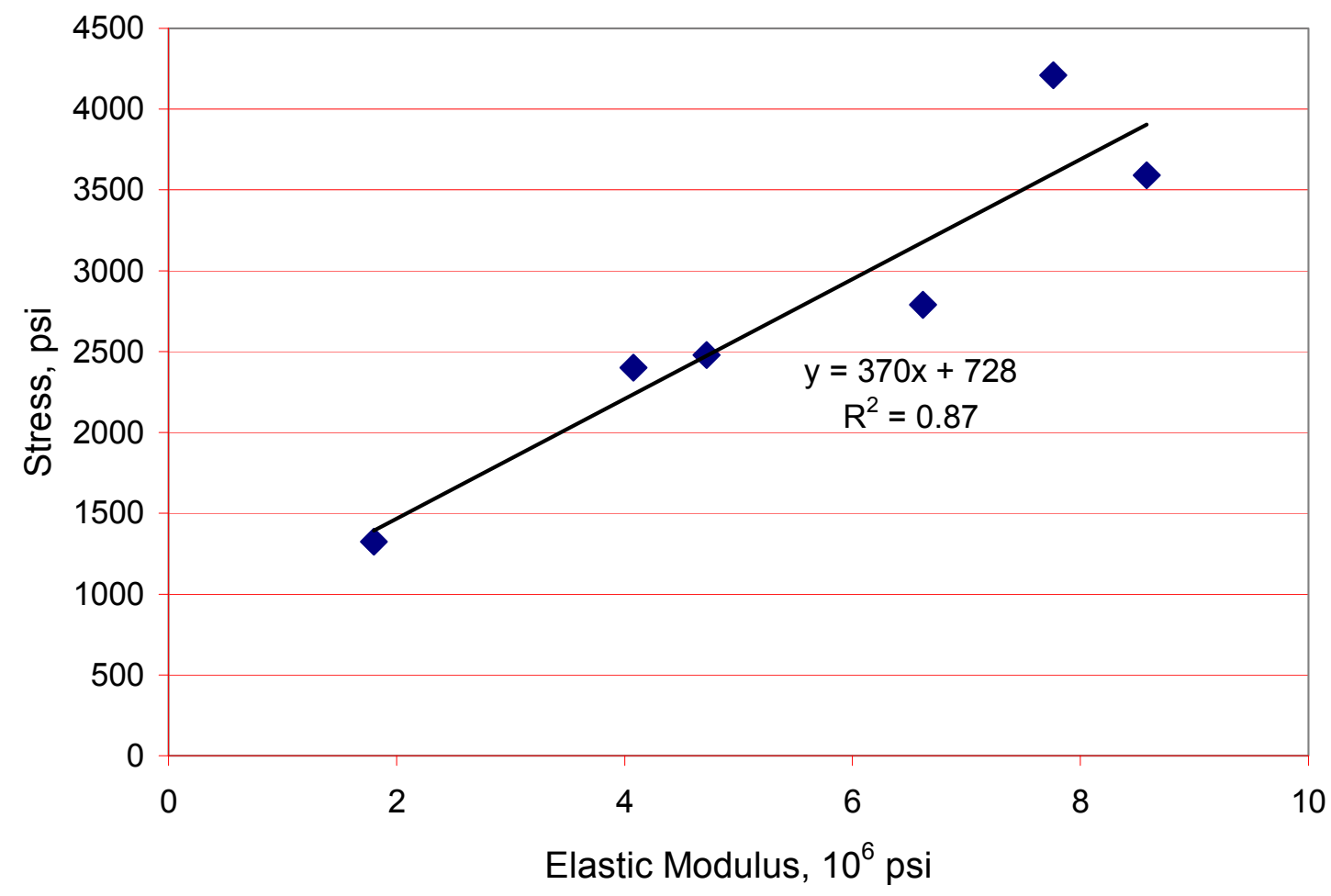

Figure 7-5. The maximum horizontal stress versus the elastic modulus for the Pittsburgh seam. 
For the 3 sites in the Pittsburgh seam, the elastic modulus ranges from 1.8 to 8.58 million psi. The average site strains from the maximum horizontal stress are for site 1, 461 micro strains, site 2, 557 micro strains and site 3, 736 micro strains. However, even with some difference in the strain fields, there is still a strong correlation between the elastic modulus and the horizontal stress because of the large difference in the elastic modulus between the sites.

The elastic modulus versus the maximum excess horizontal stress can also be examined. A linear regression fit through the data with a zero intercept results in the following equation

$$
\mathrm{P}_{\mathrm{e}}=440 \mathrm{E}
$$

The coefficient of determination is 0.79 . The coefficient for the elastic modulus results in an excess strain from the maximum horizontal stress for the Pittsburgh seam of 440 micro strains.

For the minimum horizontal stress, the resulting regression equation is

$$
\mathrm{Q}=171 \mathrm{E}+1122 .
$$

The coefficient of determination is 0.65 . The correlation is weaker than for the maximum horizontal stress but still fairly strong.

\subsubsection{Lower Kittanning Seam}

From the West Virginia site data, Aggson (1985) noted a relationship between the maximum horizontal stress and the elastic modulus. A linear regression fit through all the data produced the relationship

$$
P=600 E-69 .
$$

The resulting coefficient of determination was 0.83 . 
Figure 7-6 shows a graph of the elastic modulus versus the maximum horizontal stress for both mines. In the present analysis, only those measurements beyond 15 feet in depth are used from the West Virginia site. A linear regression is fit through the data with the resulting equation

$$
\mathrm{P}=665 \mathrm{E}+57
$$

The coefficient of determination is 0.95 . There is a very strong correlation between the elastic modulus and the maximum horizontal stress. Further, the equation is very similar to the equation developed by Aggson (1985). For both mines, the range in the elastic modulus is from 1.6 to 6.95 million psi. The average site strain from the maximum horizontal stress is for the Tanoma Mine, 575 micro strains and for the Philippi, WV mine, 721 micro strains. A strong correlation is still developed even with some difference in the strain fields.

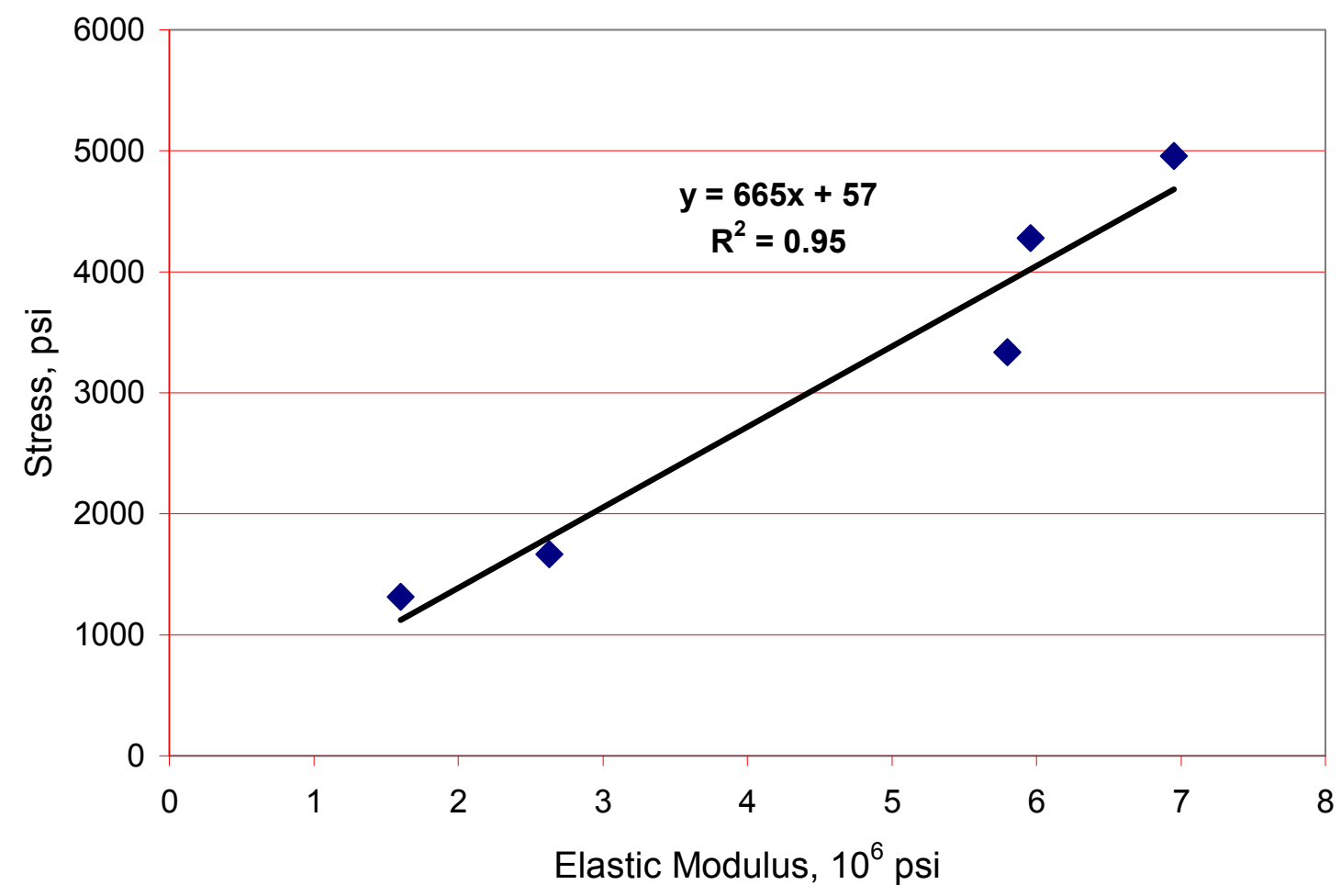

Figure 7-6. The maximum horizontal stress versus the elastic modulus for the lower Kittanning seam. 
The relationship between the elastic modulus and the maximum excess horizontal stress is also developed. For the maximum excess horizontal stress with the regression forced through zero, the equation is

$$
\mathrm{P}_{\mathrm{e}}=637 \mathrm{E}
$$

The coefficient of determination is 0.95 . Essentially, the strain from the maximum excess horizontal stress in the lower Kittanning seam is 637 micro strains.

For the minimum horizontal stress versus the elastic modulus, the following equation is developed

$$
\mathrm{Q}=497 \mathrm{E}
$$

The coefficient of determination is 0.96 . This is a very high correlation especially for the minimum horizontal stress.

The relationship between the minimum excess horizontal stress and the elastic modulus is

$$
\mathrm{Q}_{\mathrm{e}}=462 \mathrm{E} .
$$

This implies the strain from the minimum excess horizontal stress is 462 micro strains.

\subsubsection{Peabody \#10 Mine, Eastern Mid-Continent Region}

For the Peabody \#10 Mine, a strong relationship between the horizontal stress and the elastic modulus has been noted previously (Hanna et al., 1991). The range in the elastic modulus from 1.28 to 5.7 million psi appears to be sufficient to establish an adequate relationship between the elastic modulus and the maximum horizontal stress. Figure 7-7 shows a graph of the elastic modulus versus the maximum horizontal stress from the mine. In this analysis, only the three deepest measurements are used. The resulting regression equation is 


$$
\mathrm{P}=608 \mathrm{E}
$$

The coefficient of determination is 0.97 . However, there is little or no relationship between the minimum horizontal stress and the elastic modulus at the mine.

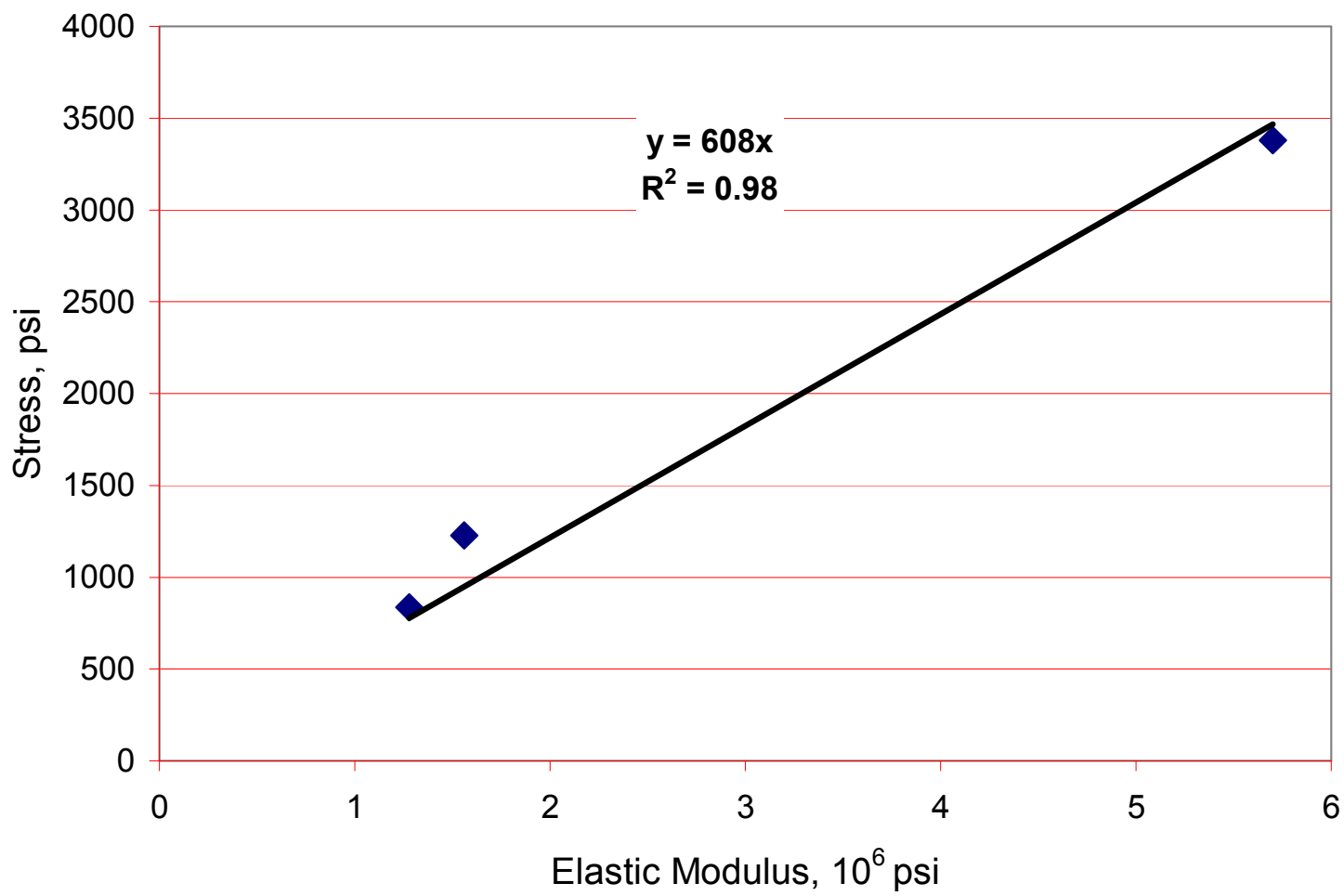

\section{Figure 7-7. The maximum horizontal stress versus the elastic modulus for the Peabody \#10 Mine.}

\subsection{REGIONAL AND LOCAL MODELS-CONCLUSIONS}

Regional models can explain a high percent of the variation of the maximum horizontal stress with the elastic modulus. The coefficients of determination for these models range from 0.72 to 0.91 .

Regional models indicate that the minimum horizontal stress variation is less dependent on the elastic modulus than the variation of the maximum horizontal stress. This is especially true in the eastern Mid-Continent region and results from the very low minimum applied horizontal strains and the high standard deviation of those strains relative to the average. 
None of the regional depth factors are significant. Further, in the models, depth can only explain between 9 and 24 percent of the variation of the maximum horizontal stress. The maximum horizontal stress normalized by the elastic modulus does not increase with depth. Essentially, the elastic modulus can be used to explain the variation that might be attributed to depth, suggesting that the depth is not a significant independent factor.

Regression models for individual mines or groups of sites were developed with the elastic modulus explaining a high degree of the maximum horizontal stress variation. However, a sufficient range of the elastic modulus is usually required to develop adequate models. 


\section{CHAPTER 8. HORIZONTAL STRESS AND DEPTH MODELS FOR THE EASTERN UNITED STATES}

An examination is made of the variation of the horizontal stress with respect to the elastic modulus and the depth for the eastern United States.

\subsection{VARIATION OF THE HORIZONTAL STRESS WITH THE ELASTIC MODULUS}

For the elastic modulus, a separate analysis is conducted for both the low and high strain sites. The high strain sites are all from the central Appalachian region and include the sites with an intermediate strain level. Therefore, the high strain model is restricted to the central Appalachian region. However, the low strain model is in general applicable for much of the eastern United States except the intermediate and high strain zones of the central Appalachian region. To eliminate the effects of depth the excess horizontal stresses are used.

Table 8-1. Coefficients and statistics for the maximum and minimum excess horizontal stress models for the eastern United States with a zero intercept.

\begin{tabular}{|c|c|c|c|c|c|}
\hline \multirow[b]{2}{*}{ Region } & \multirow[b]{2}{*}{$\begin{array}{c}\text { Number of sites/ } \\
\text { measurements }\end{array}$} & \multicolumn{2}{|c|}{ Maximum stress } & \multicolumn{2}{|c|}{ Minimum stress } \\
\hline & & $\mid \begin{array}{c}\text { Coefficient } \\
\mathrm{K}_{\mathrm{P}}\end{array}$ & $\begin{array}{c}\text { Correlation } \\
\text { coefficient } \\
\text { squared }\end{array}$ & $\begin{array}{c}\text { Coefficient } \\
\mathrm{K}_{\mathrm{Q}}\end{array}$ & $\begin{array}{l}\text { Correlation } \\
\text { coefficient } \\
\text { squared }\end{array}$ \\
\hline \multicolumn{6}{|c|}{ Low Strain Model-Individual Site Measurements } \\
\hline $\begin{array}{l}\text { Northern Appalachian/ } \\
\text { Central Appalachian/ } \\
\text { Eastern Mid-Continent }\end{array}$ & 67 & 430 & 0.71 & 212 & 0.24 \\
\hline \multicolumn{6}{|c|}{ Low Strain Models-Average Site Stresses and Elastic Modulus } \\
\hline $\begin{array}{l}\text { Northern Appalachian/ } \\
\text { Central Appalachian/ } \\
\text { Eastern Mid-Continent }\end{array}$ & 25 & 459 & 0.83 & 255 & 0.47 \\
\hline $\begin{array}{l}\text { Eastern Mid-Continent/ } \\
\text { Central Appalachian }\end{array}$ & 18 & 414 & 0.88 & 193 & 0.32 \\
\hline Northern Appalachian & 7 & 530 & 0.87 & 350 & 0.73 \\
\hline \multicolumn{6}{|c|}{ High Strain Model-Individual Measurements } \\
\hline Central Appalachian & 48 & 967 & 0.66 & 623 & 0.1 \\
\hline \multicolumn{6}{|c|}{ High Strain Model-Average Site Stresses and Elastic Modulus } \\
\hline Central Appalachian & 13 & 923 & 0.86 & 610 & 0.49 \\
\hline
\end{tabular}


To examine the variation of the maximum and minimum excess horizontal stress with the elastic modulus, equation 3.5 is fit through the data with a zero intercept. Table 8-1 shows the coefficients for the elastic modulus and the coefficients of determination for low and high strain models for both the maximum and minimum excess horizontal stress. For several of the models, the site average stress and elastic modulus are used though for comparison, models are also given based on the individual measurements. Further, several low strain models are given based on different regional combinations. Again, the main reason for developing separate regional models for the low strain group is the higher strains seen in the northern Appalachian region.

Figure 8-1 shows the maximum excess horizontal stress versus the elastic modulus when the individual measurements are used in the analysis. Regression lines are given separately for the high strain sites and for the low strain sites. There are clearly two groups of data with little overlap between the low and high strain groups. The elastic modulus can explain 71 percent of the variation of the maximum excess horizontal stress in the low strain model and 66 percent of the variation of the maximum excess horizontal stress in the high strain model.

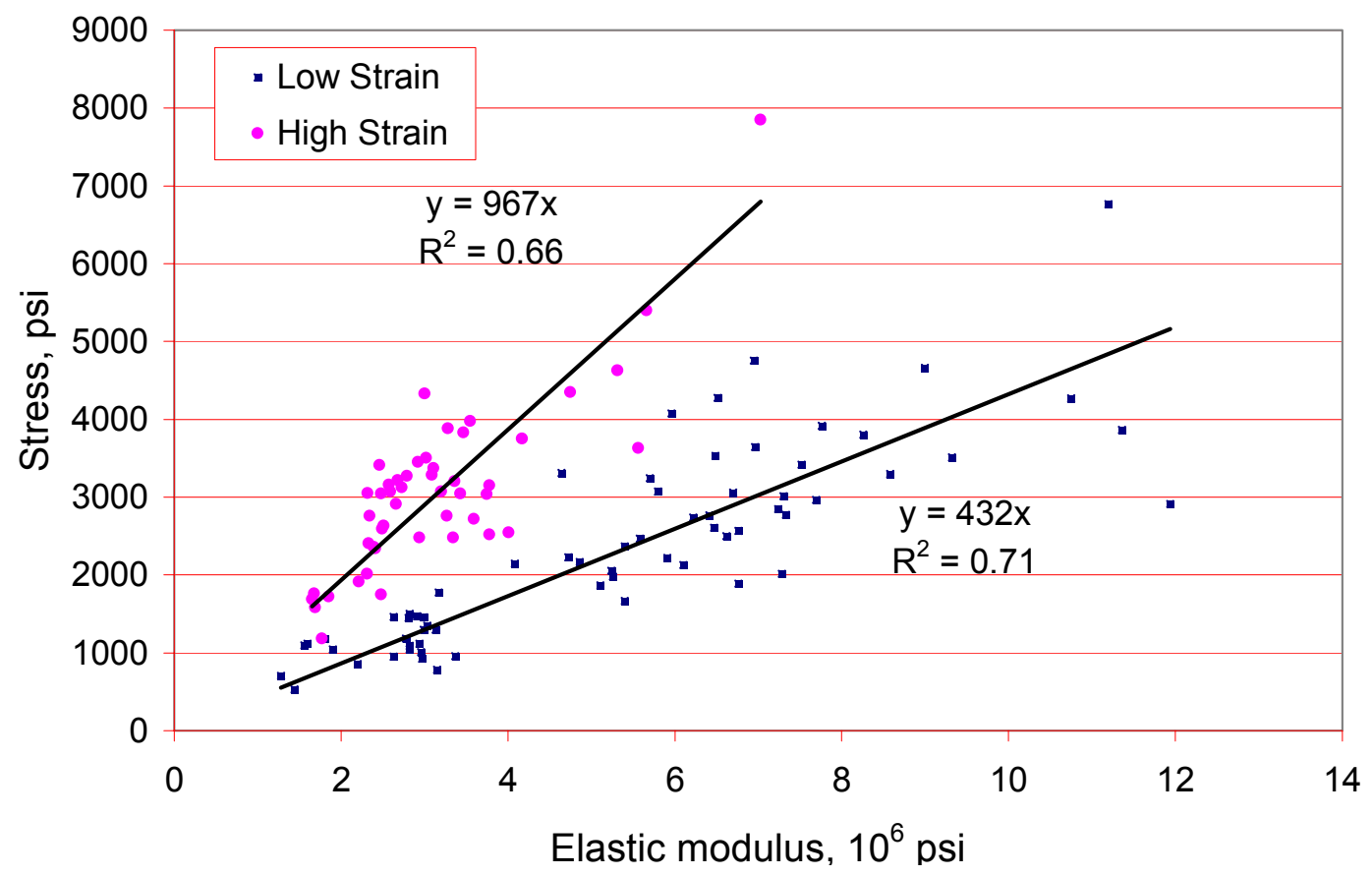

Figure 8-1. The maximum excess horizontal stress versus the elastic modulus for the eastern United States. 
Figure 8-2 shows the maximum excess horizontal stress versus the elastic modulus using the site average stresses and elastic modulus. Again, only two regression models are developed one for each strain group. With this data, the elastic modulus explains in the low strain model, 83 percent of the maximum excess horizontal stress variation and in the high strain model, 86 percent of the maximum excess horizontal stress variation. A higher coefficient of determination is achieved with site average stresses than when individual measurements are used. This results from the elimination of the local variations between the individual measurements.

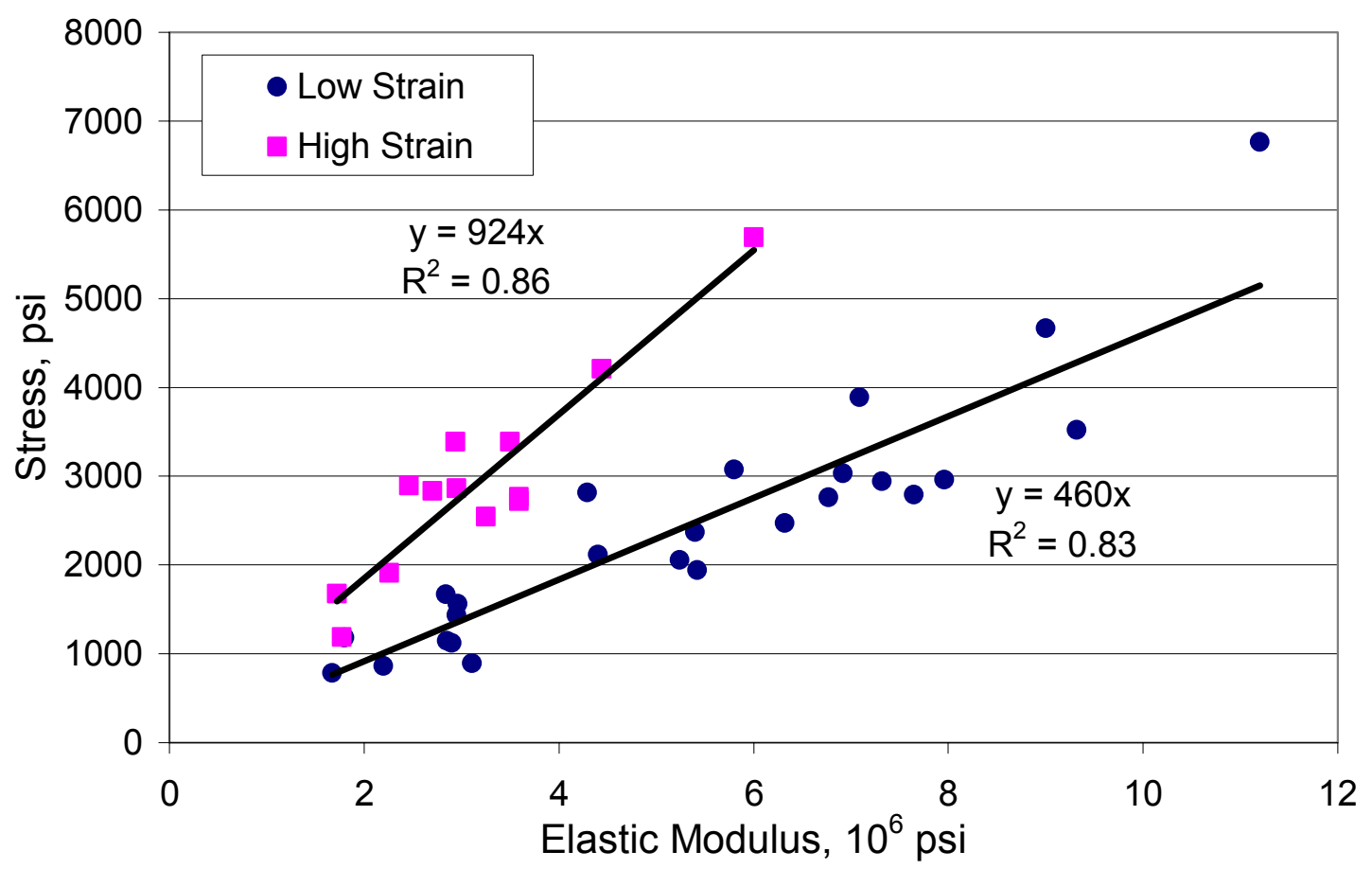

Figure 8-2. The maximum average excess horizontal stress versus the site average elastic modulus for the eastern United States.

Because the northern Appalachian region has strains that are about 20 percent higher than those of the other regions in the low strain group, the low strain group can be further separated into two groups. Again, using the site average stresses, figure 8-3 shows a graph of the maximum excess horizontal stress versus the elastic modulus with the low strain data separated into two groups. The elastic modulus now explains 88 percent of the maximum excess horizontal stress variation in the low strain zone 
without the northern Appalachian region and 87 percent of the variation in the northern Appalachian region.

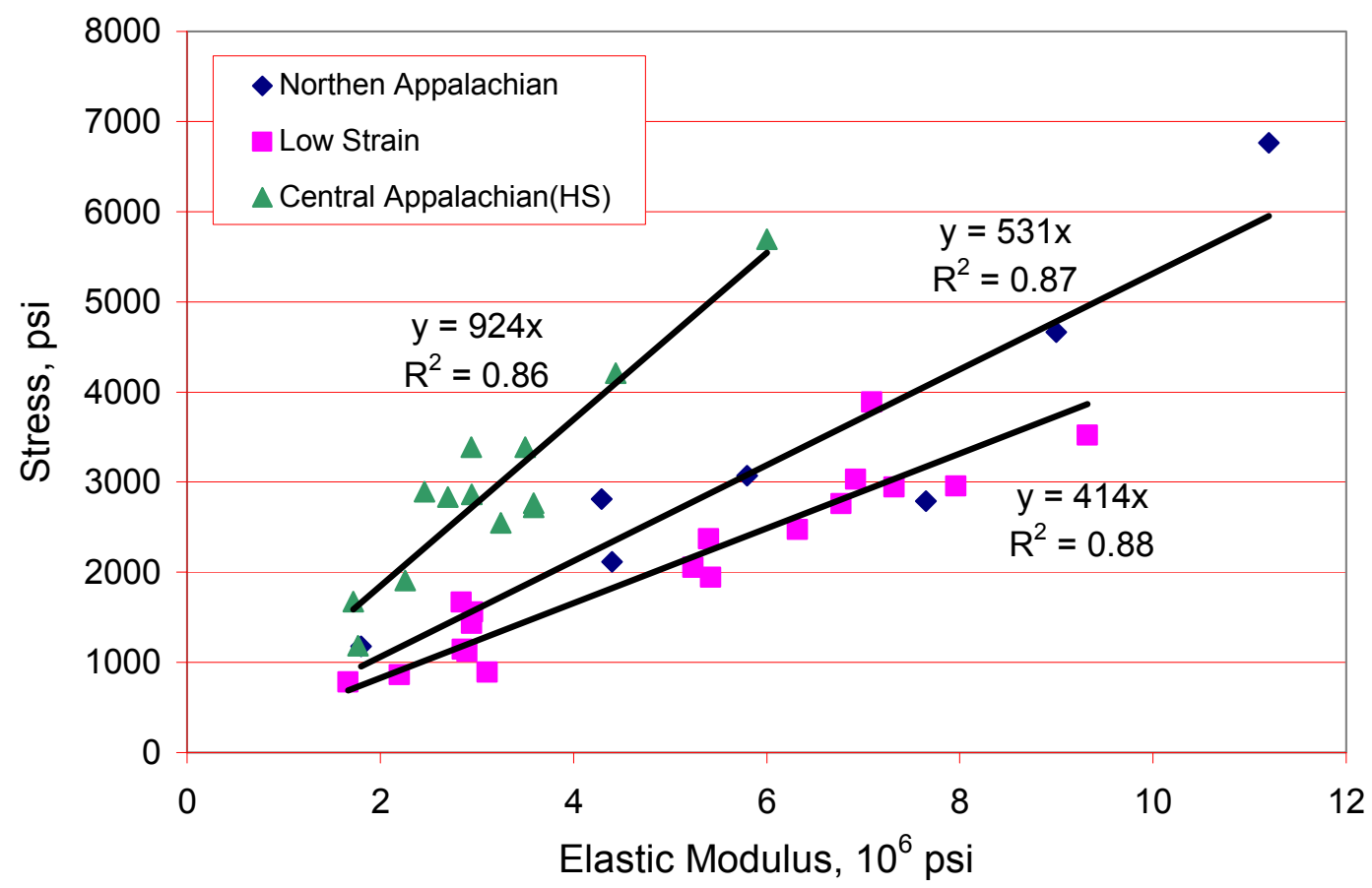

Figure 8-3. The maximum average excess horizontal stress versus the site average elastic modulus for the eastern United States (two low strain models).

These models for the maximum excess horizontal stress can be used to estimate the maximum horizontal stress. The maximum horizontal stress can be calculated for the eastern United States by adding the gravity affects from Poisson's ratio to the equations. In general, a single model for the low and high strain zones can explain a high percent of the variation in the maximum horizontal stress with the elastic modulus. Therefore, the low strain model can be used to estimate the maximum horizontal stress across much of the eastern United States for the site depth range of the data set. However, the low strain zone can be further divided into a combined eastern Mid-Continent and low strain central Appalachian regions and a northern Appalachian region with the two models explaining and even higher percent of the maximum horizontal stress variation with the elastic modulus. The high strain model encompasses the intermediate and high strain zones of the central Appalachian region. However, there are no definitive boundaries over where the model should be applied. In general, the low strain model reflects the strain field 
applied across most of the eastern United States including a portion of the central Appalachian region while the high strain model reflects a high strain region that has only been observed in the central Appalachian region.

Table 8-1 also shows the models for the minimum excess horizontal stress. In general, the coefficients of determination are much lower than for the maximum excess horizontal stress. For most of the models, the coefficients of determination are low enough as to make the models unreliable for estimating the minimum excess horizontal stress. Essentially, the minimum excess horizontal stress variation is not as dependent on the elastic modulus. The exception is the northern Appalachian region.

\subsection{MAXIMUM HORIZONTAL STRESS VERSUS DEPTH}

The change in the maximum horizontal stress with depth across the eastern United States is evaluated based on the average maximum horizontal stress from each site. The site average stresses are used to give each site the same weight. Figure 8-4 shows the depth versus the maximum horizontal stress across the eastern United States. The resulting regression equation is

$$
\mathrm{P}=1.27 \mathrm{D}+1836
$$

The coefficient of determination is only 0.15 while the $t$ statistic for the depth coefficient is 2.53. At a 0.05 significance level, the depth factor is significantly greater than zero. Therefore, in general there appears to be a significant increase of about $1.27 \mathrm{psi} / \mathrm{ft}$ of depth in the eastern United States though the depth can only explain about 15 percent of the variation. Further, the site in the Columbus limestone in Ohio has a strong influence on the regression analysis and the depth factor because of the large depth $(2,300 \mathrm{ft})$ and high maximum horizontal stress (though not high strain). Also, the depth cannot to a large extent explain the maximum horizontal stresses above $5,000 \mathrm{psi}$ at two other sites with one

of the sites having the highest maximum horizontal stress of 6,910 psi in the data set at a depth of only $400 \mathrm{ft}$. All three of these sites have a relatively high elastic modulus ranging from 6 to 11.2 million psi. These high stresses can be explained by the elastic modulus in combination with the strain field. 


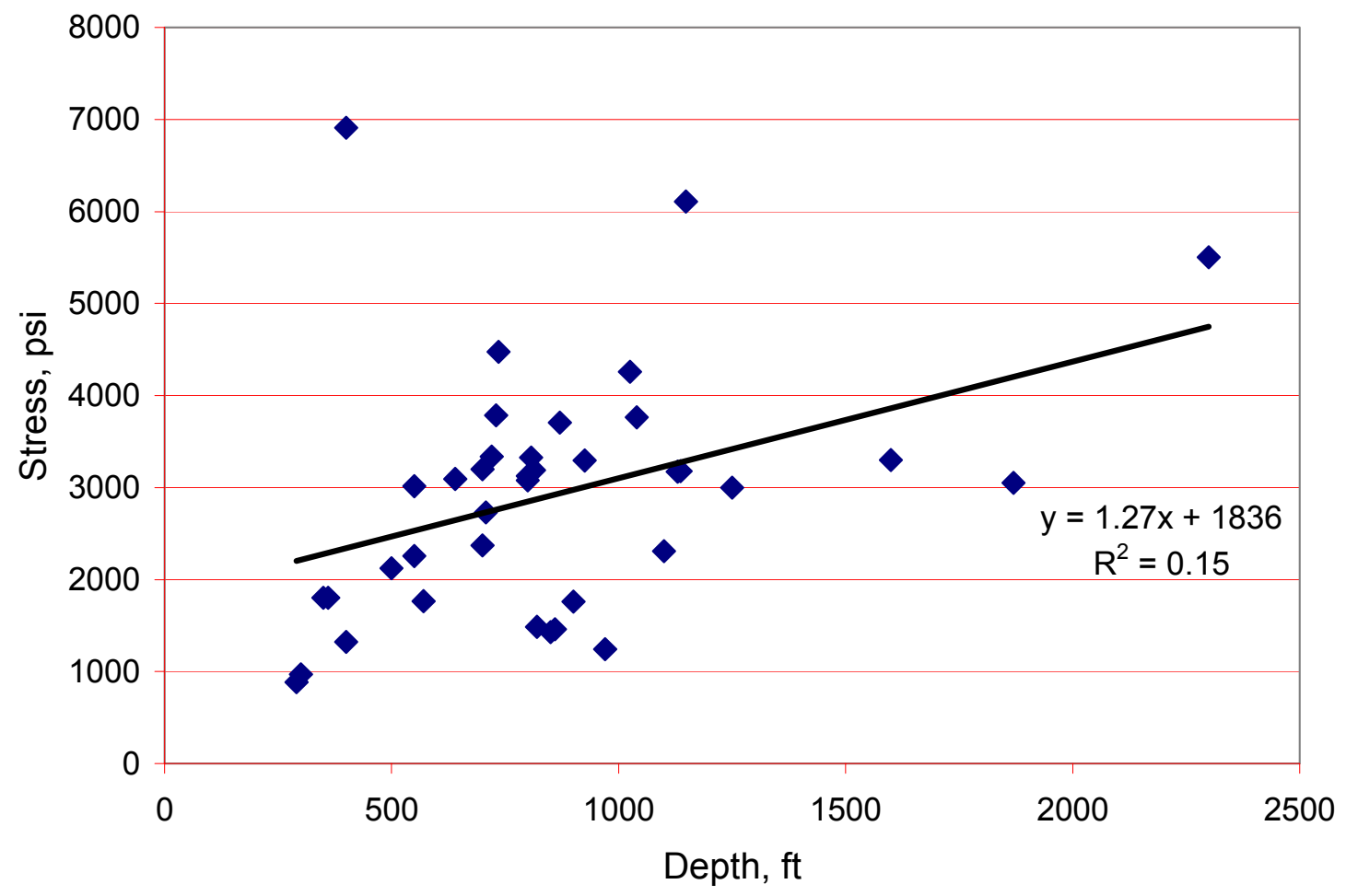

Figure 8-4. The maximum horizontal stress versus the depth in the eastern United States.

Because there was no significant increase with depth in the regional models this significant increase for the eastern United States may be due to the differences in certain parameters between regions. Table 8-2 shows the various average parameters for each region including the depth, elastic modulus and strain. The Illinois basin that includes 7 sites is shown separately from the eastern Mid-Continent region. There are differences in the average depth, elastic modulus and maximum average strain for each region. Although the average strain in the Illinois basin is similar to the other areas, except for the high strain zone, the elastic modulus is much lower and results in a much lower maximum horizontal stress. Combine these lower stresses with the lowest regional average depth and some increase in the horizontal stress will probably be observed in this data set for the eastern United States. 
Table 8-2. Summary of average parameters including the depth, maximum horizontal strain and elastic modulus for each region.

\begin{tabular}{|l|c|c|c|c|}
\hline Zone & $\begin{array}{c}\text { Number of } \\
\text { sites }\end{array}$ & Depth, ft & $\begin{array}{c}\text { Elastic modulus, } \\
10^{6} \mathrm{psi}\end{array}$ & $\begin{array}{c}\text { Maximum strain, } \\
\text { micro strain }\end{array}$ \\
\hline \multicolumn{5}{|c|}{ Northern Appalachian } \\
\hline & 7 & 839 & 6.31 & 597 \\
\hline \multicolumn{5}{|c|}{ Central Appalachian } \\
\hline Low strain & 7 & 831 & 6.09 & 492 \\
\hline High strain & 13 & 946 & 3.17 & 1038 \\
\hline \multicolumn{7}{|c|}{} & 747 & 4.24 \\
\hline & 11 & Illinois Basin & 489 \\
\hline
\end{tabular}

To eliminate the effects of the elastic properties, the relationship between the strain from the maximum horizontal stress and the depth is examined. Figure 8-5 shows the strain from the maximum horizontal stress versus the depth for the eastern United States. The resulting regression equation is

$$
\varepsilon_{\mathrm{p}}=0.08 \mathrm{D}+632 .
$$

The coefficient of determination is only 0.014 while the $t$ statistic of 1.01 indicates that the depth coefficient is not significantly greater than zero at a 0.05 significance level. The strain data is the maximum horizontal stress normalized by the elastic modulus where all sites have an elastic modulus of one million.

Once the effects of the elastic properties are removed, there is no significant increase in stress with the depth. Further, this depth model can only explain one percent of the variation in the strain or stress. This would suggest that there is some relationship between the depth and the elastic modulus. The correlation between the depth and elastic modulus is 0.24. Although this correlation is weak, it is also positive. Because, the relationship between depth and the maximum horizontal stress is also weak, this low degree of correlation is sufficient to cause the normalized stresses not to be significantly influenced by depth. 


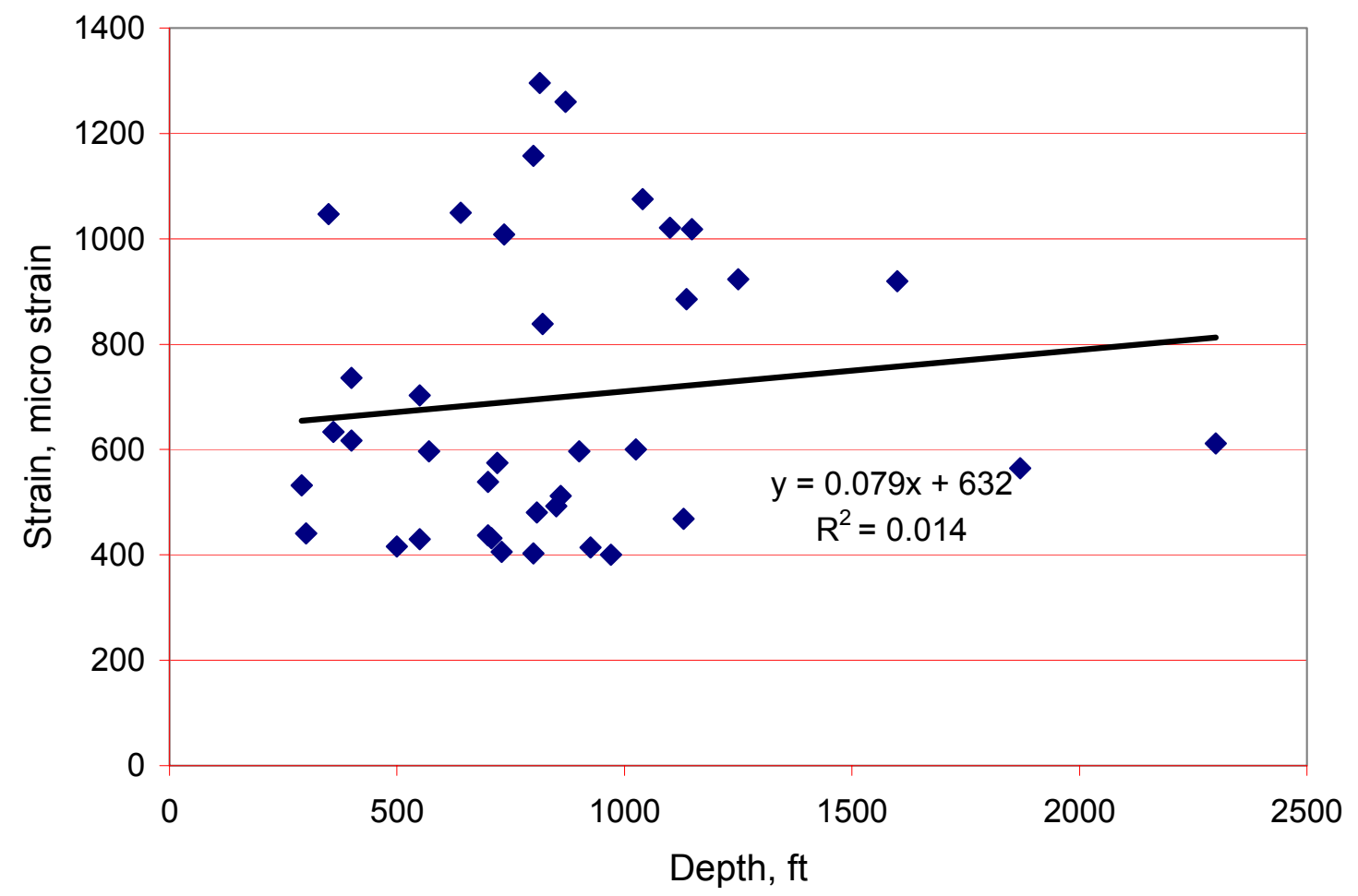

Figure 8-5. The strain from the maximum horizontal stress versus the depth for the eastern United States.

Because the stress-elastic modulus models depend on, and are developed from, a sufficiently uniform strain field, the regional differences in depth and strain are considered. If only the twenty-five low strain sites are used, then the resulting equation is

$$
\varepsilon_{\mathrm{p}}=0.007 \mathrm{D}+515 .
$$

The coefficient of determination is only 0.0009 while the $t$ statistic of 0.14 indicates that the depth coefficient is not significantly greater than zero at a 0.05 significance level. In the low strain regions there is no increase in the strain with depth.

Because the depth is not causing a significant increase in the strain in this data set, the depth cannot be used in general as an independent variable in developing the models that include the elastic modulus. Essentially, the elastic modulus can explain the increase and variation of the maximum horizontal stress. If the strains did increase with depth, then models must be developed with the strains and therefore the variation of the stress with the 
elastic modulus also dependent on the depth. In such a case, the strain or the affects of the elastic modulus would not be independent of the depth.

However, there is no significant increase in the horizontal strain with depth. The apparent significant increase of the horizontal stress with depth across the eastern United States appears to be due to the regional differences in the elastic modulus, strain and depth. Essentially, the range of depth may be too limited and the stresses obtained over too wide of a geographic area to be used to establish a depth factor for the stress or strain across the eastern United States.

\subsection{HORIZONTAL STRESS AND DEPTH MODELS FOR THE EASTERN UNITED STATES-CONCLUSIONS}

A high and low strain model developed for the eastern United States can explain 83 and 86 percent of the variation of the maximum excess horizontal stress with the elastic modulus. This implies that large areas of the eastern United States are subjected to a sufficiently uniform strain field from the maximum horizontal stress to allow for such strong correlations.

In general, the models for the minimum horizontal stress and elastic modulus have a much lower coefficient of determination than for the maximum excess horizontal stress. Essentially, the minimum horizontal stress variation is not as dependent on the elastic modulus.

Depth does cause a significant increase in the maximum horizontal stress across the eastern United States though the coefficient of determination is only 0.15. Though significant, the depth can explain little of the maximum horizontal stress variation. Further, the maximum horizontal stress normalized by the elastic modulus does not increase significantly with depth. This implies that the elastic modulus can explain some of the variation attributed to depth and suggesting that depth may not be a significant independent factor.

The minimal affects of depth may be due to the limited range of depth with stress measurements being taken over too large of an area to establish a reliable depth factor for the eastern United States from this data set. 


\section{CHAPTER 9: SUMMARY AND CONCLUSIONS}

In this study, the relationship between the horizontal stress magnitude and the elastic modulus and depth were examined based on stress measurements made at sites related to mining in bedded deposits in the eastern United States. Relationships between the horizontal stress and the elastic modulus and depth were evaluated by fitting linear regressions through the stress data. The stress data set was composed of 40 sites where the horizontal stress had been determined. Site depths ranged from 275 to 2,300 $\mathrm{ft}$. This range does encompass most of the expected depths for underground limestone and coal mines in the eastern United States.

The stress data was divided geographically into 3 main groups that included the northern and central Appalachian regions and the eastern Mid-Continent region. Initially, an analysis was made of the Beckley coal seam in the central Appalachian region where an extensive horizontal stress measurement program was conducted in the late 1970's and early 1980's. Regional and more general models for the eastern United States were then developed or evaluated for both the elastic modulus and depth. As part of the study, the strains produced by the stress fields were also considered.

To establish a strong relationship between the maximum horizontal stress and the elastic modulus in the Beckley coal seam, the data had to be separated into high and low strain zones. Geographically, 13 of the sites are in two coterminous zones with 8 sites in the high strain zone and 5 sites in the low strain zone with these zones encompassing areas of tens to hundreds of square miles. However, the Beckley \#2 Mine, with two high strain sites is separated from the high strain zone by the intervening low strain zone. In the Beckley seam analysis, the individual measurements were used in developing the regression models. Regression models for the high strain zone could explain 68 percent of the variation in the magnitude of the maximum horizontal stress with the elastic modulus. However, for the low strain zone, only 8 percent of the maximum horizontal stress variation could be explained by the elastic modulus. In part, in the low strain zone, the range of the elastic modulus was not sufficient to establish a more reliable model. For the minimum stress, the models could explain much less or little of the variation with the elastic modulus. 
The horizontal strain fields across the eastern United States were also examined using the applied strains. For the eastern United States, the typical site average maximum applied horizontal strain ranges from 300 to 600 micro strains. Sites with maximum strains below about 300 micro strains appear to be in partial strain relief. The sites with maximum strains above 550 micro strains are found only in the central Appalachian region. Further, the central Appalachian region high strain zone has site strains between 700 to 970 micro strains.

Regionally, the average maximum applied horizontal strain for the eastern MidContinent region was 376 micro strains and for the northern Appalachian region 444 micro strains. The northern Appalachian region has strains that are about 20 percent higher than the other low strain regions including the low strain zone of the central Appalachian region. For the central Appalachian region, the low strain zone has an average maximum applied horizontal strain of 369 micro strains and the high strain zone has an average maximum applied horizontal strain of 836 micro strains. Clearly, there are some very high strain zones in the central Appalachian region that have not been seen in other regions of the eastern United States.

The standard deviations of the regional maximum horizontal strains are less than about 25 percent of the average strain. Therefore, the strain fields are sufficiently uniform over large areas in the eastern United States to establish adequate regression models for the maximum excess horizontal stress based on the elastic modulus. In the case of the eastern Mid-Continent and northern Appalachian regions, these areas appear to cover thousands or hundreds of thousand of square miles. In general, the horizontal strain fields in the eastern United States can be separated into high and low strain groups in large part by geographic location. These groupings form the basis for high and low strain model development.

The minimum applied horizontal strains are for the northern Appalachian region, 264 micro strains, for the eastern Mid-Continent region 71 micro strains, for the low strain central Appalachian zone, 168 micro strains and for the high strain central Appalachian zone 437 micro strains. Clearly, the eastern Mid-Continent region has the lowest minimum applied horizontal strain. The ratios of the maximum to minimum applied horizontal strain are for the eastern Mid-Continent region 5.3, for the northern 
Appalachian region 1.68 and for the high strain central Appalachian zone 1.91. In general, the horizontal strain fields across the eastern United States are fairly biaxial with almost uniaxial strain conditions across the eastern Mid-Continent region. In general, but especially for the eastern Mid-Continent region, the standard deviation of the minimum applied horizontal strain is relatively much higher than the maximum applied horizontal strain when compared to the average strain. This results in the minimum horizontal stress being much less dependent on the elastic modulus.

Table 9-1. Regression models for the excess maximum and maximum horizontal stress versus the elastic modulus developed in study.

\begin{tabular}{|c|c|c|c|c|}
\hline Model & Number of sites & $\begin{array}{c}\text { Coefficient, } \\
\mathrm{K}_{1}\end{array}$ & $\begin{array}{c}\text { Constant, } \\
\mathrm{K}_{2}\end{array}$ & $\begin{array}{c}\text { Coefficient of } \\
\text { determination, } \mathrm{R}^{2}\end{array}$ \\
\hline \multicolumn{5}{|c|}{ Central Appalachian Region (Maximum Horizontal Stress) } \\
\hline Low strain & 7 & 444 & 252 & 0.72 \\
\hline High strain & 13 & 965 & 215 & 0.9 \\
\hline \multicolumn{5}{|c|}{ Northern Appalachian Region (Maximum Horizontal Stress) } \\
\hline General & 7 & 576 & 0 & 0.89 \\
\hline General & 7 & 564 & 94 & 0.89 \\
\hline \multicolumn{5}{|c|}{ Eastern Mid-Continent Region (Maximum Horizontal Stress) } \\
\hline General & 11 & 445 & 0 & 0.87 \\
\hline General & 11 & 375 & 393 & 0.91 \\
\hline \multicolumn{5}{|c|}{ Eastern United States (Excess Maximum Horizontal Stress) } \\
\hline Low Strain ${ }^{1}$ & 25 & 460 & 0 & 0.83 \\
\hline Low Strain ${ }^{2}$ & 18 & 414 & 0 & 0.88 \\
\hline Low Strain ${ }^{3}$ & 7 & 531 & 0 & 0.87 \\
\hline High Strain & 13 & 924 & 0 & 0.86 \\
\hline
\end{tabular}

${ }^{1}$ All low strain sites from the eastern United States were used in the analysis.

${ }^{2}$ All sites from the eastern Mid-Continent and central Appalachian low strain zone are used in the analysis.

${ }^{3}$ Only sites from the northern Appalachian region are used in the analysis.

Regional models based on the three main regions were also developed for the variation of the horizontal stress with the elastic modulus. Table 9-1 gives these regional models. The regional models can explain between 72 to 91 percent of the variation of the maximum horizontal stress. Like the Beckley seam, the central Appalachian region was divided into low and high strain zones with models developed for each. However, the geographic extent of these zones within the region is not entirely clear. These regional 
models were established using site average values. Using individual measurements in the analysis will decrease the coefficients of determination because of the local and site variation in the strain field.

For specific mines or groups of sites, strong relationships between the elastic modulus and the maximum horizontal stress were also found. In general, these are groups of sites or mines where there is a sufficient range of the elastic modulus and also a sufficiently uniform strain field. To establish a reliable model does in general require a large enough range in the elastic modulus.

High and low strain models for the variation of the maximum excess horizontal stress with the elastic modulus were also developed for the eastern United States (table 9-1). Because the northern Appalachian region had strains that were about 20 percent higher, two low strain models were developed. One low strain model incorporates the eastern Mid-Continent region and the central Appalachian region low strain zone, the other, the northern Appalachian region. The high strain model encompasses the high strain zone of the central Appalachian region. However, the exact geographic outline of the high and low strain zones in the central Appalachian region is not clearly defined. The models can explain between 83 to 88 percent of the variation of the maximum excess horizontal stress with the elastic modulus. The coefficients of the elastic modulus in the models range from between 414 to 531 micro strains for the low strain models to 924 micro strains for the high strain model. These model coefficients can be considered the strain produced from the tectonic or maximum excess horizontal stress.

In general, the relationship between the elastic modulus and the minimum horizontal stress is much weaker or almost non-existent with the minimum stress not as dependent on the elastic modulus. This is reflected in the difference and variability of the maximum to minimum horizontal stress and strain ratios within and between regions. To have a minimum horizontal stress as dependent on the elastic modulus as the maximum stress would require that the ratios be nearly constant. The minimum horizontal stress being less dependent on the elastic modulus is in part due to the lower average strains and the higher standard deviation of those strains relative to the average strain. This is especially true in the eastern Mid-Continent region where the standard deviation actually 
exceeds the minimum average applied horizontal strain. Essentially, in the eastern MidContinent region the minimum applied horizontal strain variation is so large as to preclude a sufficiently uniform strain field to develop adequate models. This results from the low average minimum horizontal strain across the region. Where there is a higher minimum applied horizontal strain with a lower standard deviation such as in the northern Appalachian region, the minimum horizontal stress is almost as dependent on the elastic modulus as the maximum horizontal stress.

From the regional analysis, no significant increase in the maximum horizontal stress with depth was observed. The depth could explain very little of the variation in the horizontal stress across any region. Further, the horizontal strains from the maximum horizontal stress do not significantly increase for any of the regions. For the eastern United States, the maximum horizontal stress does appear to increase significantly with depth though the depth could explain only 15 percent of the variation. However, there was no statistically significant increase in the strain from the maximum horizontal stress with depth and no regional increase in the maximum horizontal stress with depth, thus the cause of this statistically significant increase appears to be in part the regional differences in the other parameters such as the elastic modulus and the strain level. Further, for this data, there is some correlation between depth and the elastic modulus, though this correlation is weak, it is sufficient to result in the maximum horizontal stresses normalized by the elastic modulus not increasing significantly with depth. The depth analysis though, must be put into context where the range of depths from the sites was from 275 to 2,300 feet. This may not be a sufficient depth range with the sites located across such a wide geographic area to be able to develop an adequate or appropriate depth factor. Because the strain did not increase significantly with depth, the depth cannot in general be used as an independent variable in the models. However, if the strain did increase with depth, then the strains and the affects of the elastic modulus will be dependent in part on depth. Essentially, multiple regression models cannot be developed with both the elastic modulus and depth as independent variables. Further, none of the multiple regression analysis indicated that depth was a significant factor.

Theoretically, there is a basis for an increase in the horizontal stress with depth based on gravity and Poisson's effect. This effect is not dependent on any increase in the applied 
horizontal strains. However, if this effect does exist, the magnitude of this increase is too small to measure within the present data set. Because of regional differences in the average depth, elastic modulus and strain fields and because the affects of the elastic modulus over shadow the depth effects, no adequate depth factor could be established for the eastern United States.

The main conclusions drawn from this study are:

1. The variation of the magnitude of the maximum horizontal stress is strongly dependent on the elastic modulus across the eastern United States.

2. The horizontal strain fields are sufficiently uniform across large geographic sections of the eastern United States to allow for models to be developed for the variation of the maximum horizontal stress based on the elastic modulus that can be applied to these regions. Essentially, in this data set, the horizontal strains are more uniform than the horizontal stresses.

3. A very high strain zone does exist in the central Appalachian region that includes a portion of the Beckley coal seam though the exact extent of the zone is not known.

4. The minimum horizontal stress and strain in the eastern Mid-Continent region are much less than for the central and Northern Appalachian regions. Further, the horizontal stresses are much more biaxial or directional in the eastern MidContinent region.

5. The minimum horizontal stress variation is in general less dependent on the elastic modulus than the maximum horizontal stress. This is due in large part to the lower average minimum horizontal strains and the relatively higher standard deviation of the strain. This can be seen in the eastern Mid-Continent region with a standard deviation that is larger than the average applied horizontal strain.

6. Although the depth did cause a significant increase in the maximum horizontal stress across the eastern United States, the depth did not cause a significant increase in the strains from the maximum horizontal stress. Therefore, depth cannot be used independently of the elastic modulus and strain in the development of the regression models for this data set. Essentially, the elastic modulus can 
explain the variations of the stress that could be attributed to depth in this data set. However, a theoretical basis is used in this study based on Poisson's effect and gravity though this effect is small. Further, the development of an adequate depth factor may require a greater depth range than found in the data set.

7. The elastic modulus of the rock utilizing the developed regression models provides a much better estimate of the maximum horizontal stress variation than does the depth in this data set. 


\section{BIBLIOGRAPHY}

Agapito, J. F. T., S. J. Mitchell, M. P. Hardy and W. N. Hoskins. 1980A. Determination of In Situ Horizontal Rock Stress on Both a Mine-Wide and District-Wide Basis. Final Technical Report, USBM Contract No. JO 285020, 174 pp.

Agapito, J. F. T., S. J. Mitchell, M. P. Hardy and J. R. Aggson. 1980B. A Study of Ground Control Problems in Coal Mines with High Horizontal Stresses. Rock Mechanics, A State of the Art, Proceeding: $21^{\text {st }}$ Rock Mechanics Symposium, University of Missouri-Rolla, May 28-30, pp. 820-828.

Agapito, J. F. T and L. J. Gilbride. 2002. Horizontal Stresses as Indicators of Roof Stability. Society of Mining Engineers, Preprint no. 02-056, SME Annual Meeting, Phoenix, AR, Feb. 25-27, 11 pp.

Aggson, J. R. 1978. Coal Mine Floor Heave in the Beckley Coalbed, An Analysis. U.S. Bureau of Mines Report of Investigation, RI 8274, 32 pp.

Aggson, J. R. 1979A. How to Plan Ground Control. Coal Mining \& Processing, Dec. 1979, pp. 70-73.

Aggson, J. R. 1979B. Stress-Induced Failures in Mine Roof. U.S. Bureau of Mines Report of Investigation, RI 8338, 16 pp.

Aggson, J. R. 1985. In-Situ Stress Determinations in the C-15 Entries of the Kitt \#1 Mine - Philippi, West Virginia. Report to the Standard Oil Company (Ohio), Agapito \& Associates, April 18, 44 pp.

Aggson, J. R. and D. P. Mouyard. 1988A. Geomechanical Evaluation of a Coal Mine Arched Entry. International Journal of Mining and Geologic Engineering, 1988, pp. 185193. 
Aggson, J. R. and D. P. Mouyard. 1988B. Geomechanical Evaluation of a Coal Mine Arched Entry. Society of Mining Engineers, Preprint no. 88-5, SME Annual Meeting, Phoenix, AR, Jan 25-28, 7 pp.

Agarwal, R. and S. Mayer. 1979. Longwall Subsidence Measurement using Photogrammetric and Surface Surveying Techniques. Final Report, USBM Contract No. J0366031, 8 pp.

Amadi, B. 1992. Importance of Anisotropy When Estimating and Measuring In Situ Stresses in Rock. International Journal of Rock Mechanics and Mining Sciences, April, pp. 293-325.

Beerkircher, M. 1994. Monterey Coal Company's Longwall Project. Proceedings: Illinois Mining Institute, Annual Meeting Collinsville, Illinois, Sept 22-23, pp. 85-94.

Bickel, D. L. 1993. Rock Stress Determinations From Overcoring-An Overview. U.S. Bureau of Mines Bulletin, B 694, 146 pp.

Bickel, D. 1985. Overcoring Equipment and Techniques Used in Rock Stress Determination (An Update of IC 8618). BuMines IC 8618, 27 pp.

Bigby, D., P. Cartwright and J. Cassie. 1995. Lateral Stress Relief for Longwall Access and Trunk Roadways. Final report on Project $7220-\mathrm{AB} / 834$ for European Coal and Steel Community, June, $251 \mathrm{pp}$.

Blevins, C. T. 1982. Coping with High Lateral Stresses in an Underground Illinois Coal Mine. Society of Mining Engineers, Preprint no. 82-156, SME Annual Meeting, Dallas, TX, Feb. 14-18, 7 pp. 
Blevins, C. T. and D. Dopp. 1985. Ground Control in a High Horizontal Stress Field at Inland Steel Coal Mine No. 2. Proceedings: $4^{\text {th }}$ Conference on Ground Control in Mining. WV Univ. Morgantown, WV, July 22-24, pp. 227-233.

Brasfield, J and G. Hendon. 1994. Yield Pillar Behavior at Jim Walter No. 7 Mine Stress and Strata Measurements of Yield and Abutment Pillars. Proceedings: $13^{\text {th }}$ International Conference on Ground Control in Mining. WV Univ. Morgantown, WV, August 2-4, pp. 91-99.

Brown, E. T. and E. Hoek. 1978. Trends in Relationship Between Measured In-Situ Stresses and Depth. International Journal of Rock Mechanics, Mining Science and Geomechanical Abstracts, Vol. 15, pp. 211-215.

Campoli, A, D.C. Oyler and F. E. Chase. 1990. Performance of a Novel Bump Control Pillar Extracting Technique During Room-and Pillar Retreat Coal Mining. U. S. Bureau of Mines Report of Investigation, RI 9240, 40 pp.

Cartwright, P. B. 1997. A review of Recent In-Situ Stress Measurements in United Kingdom Coal Measure Strata. Proceedings: International Symposium on Rock Stress, Kumamoto, Japan, Oct. 7-10, pp. 469-474.

Crawford, J. and A. Hoagland. 1968. The Mascot-Jefferson City Zinc District. Tennessee. Chapter in Ore Deposits of the United States, 1933-1967, editor J. D. Ridge, The American Institute of Mining, Metallurgical and Petroleum Engineers, Inc., pp. 240-255.

Dolinar, D. R., J. R. Aggson and V. E. Hooker. 1982. In Situ Stress Distribution and Related Ground Control Problems. Proceedings: $2^{\text {nd }}$ Conference in Room and Pillar Mining, Society of Mining Engineers of AIME, pp. 35-40.

Dolinar, D. R., T. Mucho, D. Oyler and J. Pablic. 2000. Utilizing the "Advance and Relieve" Method to Reduce Horizontal Stress Affects on the Mine Roof, A Case Study. 
Proceedings: $19^{\text {th }}$ International Conference on Ground Control in Mining. WV Univ. Morgantown, WV, August 8-10, pp. 137-148.

Duvall, W. and J. R. Aggson. 1980. Least Squares Calculation of Horizontal Stresses from More Than Three Diametral Deformations in Vertical Boreholes. U. S. Bureau of Mines Report of Investigation, RI 8414, 12 pp.

Guangyu, L, B. Shiwei and L. Jiguang. 1986. Twenty Years of Experience on In-Situ Stress Measurements in China. Proceedings: International Symposium on Rock Stress and Rock Stress Measurements, Stockholm, Sweden, Sept. 1-3, pp. 79-88.

Hanna, K, K. Haramy and D. Conover. 1986. Effect of High Horizontal Stress on Coal Mine Entry Intersection Stability. Proceedings: $5^{\text {th }}$ Conference on Ground Control in Mining. WV Univ. Morgantown, WV, June 11-13, pp. 167-182.

Hanna, K, D. Conover and K. Haramy. 1991. Coal Mine Entry Intersection Behavior Study. U. S. Bureau of Mines Report of Investigation, RI 9337, 78 pp.

Hayes, A. W. and P. F. R. Altounyan. 1995. Strata Control-The State of the Art. Mining Technology December 1995 vol. 77 No. 892, pp. 354-358.

Hendon, G., F. Carr, A. Lewis, and J. Cassie. 1995. A Cooperative Study of Gate Entry Designs Welbeck Colliery and Jim Walters Resources (USA). Proceedings: $14^{\text {th }}$ International Conference on Ground Control in Mining. WV Univ. Morgantown, WV, August 1-3, pp. 94-103.

Herget, G. 1986. Changes of Ground Stress with Depth in the Canadian Shield. Proceedings: International Symposium on Rock Stress and Rock Stress Measurements, Stockholm, Sweden, Sept. 1-3, pp. 61-68.

Herget, G. 1988. Stresses in Rock. A.A. Balkema, Rotterdam, Brookfield, VT, 179 pp. 
Iannacchione, A. D. Dolinar and T. Mucho. 2002. High Stress Mining Under Shallow Overburden in Underground Stone Mines. Australian Center for Geomechanics First International Seminar on Deep and High Stress Mining. November 6-8, Perth, Australia.

Iannacchione, A. D. Dolinar L. Prosser T. Marshall D. Oyler and C. Compton. 1998 Controlling Roof Beam Failures from High Horizontal Stresses in Underground Stone Mines. Proceedings: $17^{\text {th }}$ International Conference on Ground Control in Mining. WV Univ. Morgantown, WV, August 4-6, pp. 102-112.

Ingram, D. K. and G. M. Molinda. 1988. Relationship Between Horizontal Stresses and Geologic Anomalies in Two Coal Mines in Southern Illinois. U.S. Bureau of Mines Report of Investigation, RI 9189, 18 pp.

International Society of Rock Mechanics. 1987. Suggested Methods for Rock Stress Determination. Inter. J. Rock Mech. and Mining Science, Vol., 24, pp 53-73.

Jaeger, J. C. and N. G. W. Cook. 1969. Fundamentals of Rock Mechanics. John Wiley and Sons, London, $585 \mathrm{pp}$.

Mark, C., G. Molinda and D. Dolinar. 2001. Analysis of Roof Bolt Systems. Proceedings: $21^{\text {st }}$ International Conference on Ground Control in Mining. WV Univ. Morgantown, WV, August 7-9, pp. 218-225.

Mark, C. and T. P. Mucho. 1994. Longwall Mine Design for Control of Horizontal Stress. New Technology for Longwall Ground Control. Proceedings: U. S. Bureau of Mines Technology Transfer Seminar, Special Publication 01-94, pp. 53-76.

Miller, D. 1998. Progression of Longwall Gateroad Support as Conditions Change at Lodestar Energy's Baker Mine. Proceedings: $17^{\text {th }}$ International Conference on Ground Control in Mining. WV Univ. Morgantown, WV, August 4-6, pp. 212-220. 
Obert, L. 1962. In Situ Determination of Stress in Rock. Mining Engineering Aug., pp. 51-58.

Obert, L and W. Duvall. 1967. Rock Mechanics And The Design Of Structures In Rock. John Wiley and Sons, New York, 650 pp.

Oyler, D. 2001. Development and Use of a High Pressure Packer for Measuring Horizontal Stress Using the Hydraulic Fracturing Method. Rock Mechanics in the National Interest, Proceedings of the $38^{\text {th }}$ Rock Mechanics Symposium, DC Rocks 2001, Washington, DC, July 7-10, pp. 227-234.

Sheorey, P. R., G. Murali Mohan and A. Sinha. 2002. Influence of Elastic Constants on the horizontal In Situ Stress. International Journal of Rock Mechanics and Mining Sciences, December, Vol. 38, no. 8. pp. 1211-1216.

Sheorey, P. R. 1994. A Theory for In Situ Stresses in Isotropic and Transversely Isotropic Rock. International Journal of Rock Mechanics and Mining Sciences. February, Vol 31, no.1, pp. 23-34.

Unrug, K., G. Herget and A. Smith. 1984. Ground Stress and Roof Failure in Coal Mine Strata. Proceedings: $2^{\text {nd }}$ International Conference on Stability in Underground Mining. Univ. KY, Lexington, KY, pp. 377-408,

Wortnicki, G and R. Walton. 1976. Triaxial "Hollow-Inclusion" Gauges For Determination of Rock Stresses In Situ. International Society of Rock Mechanics Symposium, Investigation of Stress in Rock-Advances in Stress Measurement, Sidney, Australia, National Conference Publication 76/4, Supplement, pp 1-8.

Wright, F. D., R. C. Howell and J. A. Dearinger. 1979. Rock Mechanics Study of Shortwall Mining. Final Technical Report U. S. DOE ET-73-C-0109010, 120 pp. 
Wright, F. D., Gesund, H. and R. C. Howell. 1980. Stresses and Safe Bolting Patterns in Coal Mine Roof Rocks at Intersections. Final Technical Report, USBM Contract No. HO 144108, 225 pp.

Zoback, M. L., C. Barton, M. Brudy, D. Castillo,T. Finkbeiner, B. Grollimund, D. Moss, P. Peska, C. Ward and D. Wiprut. 2003. Determination of Stress Orientaion and Magnitude in Deep Wells. International Journal of Rock Mechanics and Mining Sciences, October-December, no. 40, pp. 1049-1076.

Zoback, M. L. 1992. First- and Second-Order Patterns of Stress in the Lithosphere: The World Stress Map Project. J. Geophys Res, v 97 , No. B8, July, pp. 11703-11728.

Zoback. M. L. and M. D. Zoback. 1989. Tectonic Stress Field of the Continental United States. Ch. In Geophysical Framework of the Continental United States. Geol. Soc. of America Memoir 172, pp. 523-539. 


\section{Appendix A}

Table A-1. Measured horizontal stresses in the Beckley coal field.

\begin{tabular}{|c|c|c|c|c|c|c|c|c|}
\hline Mine & Hole & $\begin{array}{c}\text { Measurement } \\
\text { depth, } \mathrm{ft}\end{array}$ & $\begin{array}{l}\text { Maximum } \\
\text { horizontal } \\
\text { stress, psi }\end{array}$ & $\begin{array}{l}\text { Minimum } \\
\text { horizontal } \\
\text { stress, psi }\end{array}$ & $\begin{array}{l}\text { Maximum }^{1} \\
\text { horizontal strain, } \\
\text { micro strain }\end{array}$ & $\begin{array}{c}\text { Minimum }^{1} \\
\text { horizontal strain, } \\
\text { micro strain }\end{array}$ & $\begin{array}{l}\text { Elastic } \\
\text { modulus, } \\
10^{6} \mathrm{psi}\end{array}$ & $\begin{array}{c}\text { Site } \\
\text { depth, ft }\end{array}$ \\
\hline Beckley \#4 & 1 & 18 & 1484 & 1141 & 838 & 645 & 1.77 & 820 \\
\hline Beckley \#1 & 2 & 5.2 & 3306 & 1738 & 396 & 208 & 8.34 & 1130 \\
\hline Beckley \#1 & 2 & 9.2 & 3152 & 1983 & 507 & 319 & 6.22 & 1130 \\
\hline Beckley \#1 & 2 & 14.4 & 3184 & 1961 & 434 & 268 & 7.33 & 1130 \\
\hline Beckley \#2 & 3 & 10.2 & 2317 & 1689 & 1048 & 764 & 2.21 & 1100 \\
\hline Beckley \#2 & 3 & 12.3 & 2416 & 1725 & 1046 & 747 & 2.31 & 1100 \\
\hline Bonny & 4 & 14.7 & 4390 & 3335 & 1237 & 939 & 3.55 & 1136 \\
\hline Bonny & 4 & 16 & 3175 & 2845 & 971 & 870 & 3.27 & 1136 \\
\hline Bonny & 4 & 18.4 & 2933 & 1972 & 776 & 522 & 3.78 & 1136 \\
\hline Bonny & 4 & 19.6 & 3451 & 2689 & 920 & 717 & 3.75 & 1136 \\
\hline Bonny & 5 & 15.8 & 5047 & 2389 & 950 & 450 & 5.31 & 1148 \\
\hline Bonny & 5 & 16.8 & 5816 & 3061 & 1028 & 541 & 5.66 & 1148 \\
\hline Bonny & 5 & 22.3 & 8264 & 5062 & 1176 & 720 & 7.03 & 1148 \\
\hline Maple Meadows & 6 & 15.4 & 2383 & 2141 & 391 & 351 & 6.1 & 708 \\
\hline Maple Meadows & 6 & 16.1 & 3022 & 2896 & 471 & 452 & 6.41 & 708 \\
\hline Maple Meadows & 6 & 17.7 & 2862 & 2792 & 442 & 432 & 6.47 & 708 \\
\hline Maple Meadows & 7 & 15.3 & 4615 & 2969 & 972 & 625 & 4.75 & 735 \\
\hline Maple Meadows & 7 & 16.8 & 4594 & 3325 & 1531 & 1108 & 3 & 735 \\
\hline Maple Meadows & 7 & 24.4 & 3900 & 2449 & 701 & 440 & 5.56 & 735 \\
\hline Maple Meadows & 8 & 21 & 3901 & 2110 & 601 & 325 & 6.49 & 1025 \\
\hline Maple Meadows & 8 & 22 & 4648 & 2478 & 714 & 381 & 6.51 & 1025 \\
\hline Maple Meadows & 8 & 23 & 4177 & 2492 & 506 & 302 & 8.26 & 1025 \\
\hline
\end{tabular}


Table A-1. Measured horizontal stresses in the Beckley coal field (Cont.).

\begin{tabular}{|c|c|c|c|c|c|c|c|c|}
\hline Mine & Hole & $\begin{array}{l}\text { Measurement } \\
\text { depth, } \mathrm{ft}\end{array}$ & $\begin{array}{l}\text { Maximum } \\
\text { horizontal } \\
\text { stress, psi }\end{array}$ & $\begin{array}{l}\text { Minimum } \\
\text { horizontal } \\
\text { stress, psi }\end{array}$ & $\begin{array}{l}\text { Maximum }^{1} \\
\text { horizontal strain, } \\
\text { micro strain }\end{array}$ & \begin{tabular}{|c|} 
Minimum $^{1}$ \\
horizontal strain, \\
micro strain \\
\end{tabular} & $\begin{array}{l}\text { Elastic } \\
\text { modulus, } \\
10^{6} \text { psi }\end{array}$ & $\begin{array}{c}\text { Site } \\
\text { depth, } \mathrm{ft}\end{array}$ \\
\hline Maple Meadows & 9 & 9.1 & 2636 & 1597 & 1094 & 663 & 2.41 & 814 \\
\hline Maple Meadows & 9 & 12 & 2893 & 2025 & 1162 & 813 & 2.49 & 814 \\
\hline Maple Meadows & 9 & 13.5 & 3058 & 2105 & 1307 & 900 & 2.34 & 814 \\
\hline Maple Meadows & 9 & 14.5 & 3705 & 2692 & 1506 & 1094 & 2.46 & 814 \\
\hline Maple Meadows & 9 & 18.8 & 3344 & 3019 & 1348 & 1217 & 2.48 & 814 \\
\hline Maple Meadows & 9 & 19.3 & 3456 & 2652 & 1345 & 1032 & 2.57 & 814 \\
\hline Maple Meadows & 10 & 18.7 & 3939 & 1584 & 566 & 228 & 6.96 & 807 \\
\hline Maple Meadows & 10 & 19.7 & 2860 & 1465 & 423 & 217 & 6.76 & 807 \\
\hline Maple Meadows & 10 & 20.7 & 3138 & 1646 & 433 & 227 & 7.24 & 807 \\
\hline Maple Meadows & 10 & 22.9 & 3356 & 1892 & 501 & 282 & 6.7 & 807 \\
\hline Beckley Mining & 11 & 10.3 & 2711 & 2261 & 812 & 677 & 3.34 & 640 \\
\hline Beckley Mining & 11 & 15.7 & 3385 & 1206 & 898 & 319 & 3.78 & 640 \\
\hline Beckley Mining & 11 & 16.7 & 3303 & 3069 & 1032 & 959 & 3.2 & 640 \\
\hline Beckley Mining & 11 & 22.2 & 3146 & 2362 & 1183 & 888 & 2.66 & 640 \\
\hline Beckley Mining & 11 & 23.2 & 3287 & 2649 & 1417 & 1142 & 2.32 & 640 \\
\hline Beckley Mining & 11 & 24.8 & 2596 & 1991 & 1086 & 833 & 2.39 & 640 \\
\hline Beckley Mining & 12 & 15.1 & 4202 & 3598 & 1281 & 1097 & 3.28 & 870 \\
\hline Beckley Mining & 12 & 16.5 & 3690 & 2958 & 1186 & 951 & 3.11 & 870 \\
\hline Beckley Mining & 12 & 20.3 & 3819 & 2743 & 1265 & 908 & 3.02 & 870 \\
\hline Beckley Mining & 12 & 21.8 & 3538 & 2630 & 1320 & 981 & 2.68 & 870 \\
\hline Beckley Mining & 12 & 22.8 & 3391 & 2629 & 1309 & 1015 & 2.59 & 870 \\
\hline Beckley Mining & 13 & 13.8 & 3416 & 2433 & 1251 & 891 & 2.73 & 800 \\
\hline Beckley Mining & 13 & 18.2 & 3746 & 2935 & 1283 & 1005 & 2.92 & 800 \\
\hline Beckley Mining & 13 & 20.7 & 2701 & 1995 & 1159 & 856 & 2.33 & 800 \\
\hline Beckley Mining & 13 & 23.3 & 2772 & 1949 & 943 & 663 & 2.94 & 800 \\
\hline
\end{tabular}


Table A-1. Measured horizontal stresses in the Beckley coal field (Cont.).

\begin{tabular}{|l|c|c|c|c|c|c|c|c|}
\hline \multicolumn{1}{|c|}{ Mine } & Hole & $\begin{array}{c}\text { Measurement } \\
\text { depth, ft }\end{array}$ & $\begin{array}{c}\text { Maximum } \\
\text { horizontal } \\
\text { stress, psi }\end{array}$ & $\begin{array}{c}\text { Minimum } \\
\text { horizontal } \\
\text { stress, psi }\end{array}$ & $\begin{array}{c}\text { Maximum } \\
\text { horizontal strain, } \\
\text { micro strain }\end{array}$ & $\begin{array}{c}\text { Minimum } \\
\text { horizontal strain, } \\
\text { micro strain }\end{array}$ & $\begin{array}{c}\text { Elastic } \\
\text { modulus, } \\
10^{6} \text { psi }\end{array}$ & $\begin{array}{c}\text { Site } \\
\text { depth, ft }\end{array}$ \\
\hline Beckley Mining & 13 & 24.5 & 2927 & 2193 & 1166 & 874 & 2.51 & 800 \\
\hline Beckley Mining & 13 & 25.5 & 3566 & 2916 & 1278 & 1045 & 2.79 & 800 \\
\hline Beckley Mining & 14 & 16.3 & 4209 & 2563 & 1213 & 739 & 3.47 & 1040 \\
\hline Beckley Mining & 14 & 17.4 & 3664 & 2312 & 1186 & 748 & 3.09 & 1040 \\
\hline Beckley Mining & 14 & 18.4 & 3581 & 1993 & 1066 & 593 & 3.36 & 1040 \\
\hline Beckley Mining & 14 & 22.6 & 3426 & 2134 & 999 & 622 & 3.43 & 1040 \\
\hline Beckley Mining & 14 & 24.2 & 4132 & 2401 & 991 & 576 & 4.17 & 1040 \\
\hline Beckley \#1 & 15 & 9.5 & 3221 & 1879 & 419 & 244 & 7.69 & 700 \\
\hline Beckley \#1 & 15 & 10.7 & 3672 & 2170 & 488 & 289 & 7.52 & 700 \\
\hline Beckley \#1 & 15 & 13.6 & 2144 & 1227 & 317 & 182 & 6.76 & 700 \\
\hline Beckley \#2 & 16 & 12 & 1852 & 1447 & 1001 & 782 & 1.85 & 350 \\
\hline Beckley \#2 & 16 & 13.1 & 1711 & 1324 & 1012 & 783 & 1.69 & 350 \\
\hline Beckley \#2 & 16 & 14.2 & 1814 & 1297 & 1099 & 786 & 1.65 & 350 \\
\hline Beckley \#2 & 16 & 15.25 & 1887 & 1281 & 1123 & 763 & 1.68 & 350 \\
\hline
\end{tabular}

${ }^{1}$ The horizontal strains are from the maximum and minimum stresses. 
Table A-2. Excess horizontal stresses and strains in the Beckley coal field.

\begin{tabular}{|c|c|c|c|c|c|c|c|c|}
\hline Mine & Hole & $\begin{array}{c}\text { Measurement } \\
\text { depth, ft }\end{array}$ & $\begin{array}{l}\text { Maximum } \\
\text { horizontal } \\
\text { stress, psi }\end{array}$ & $\begin{array}{l}\text { Minimum } \\
\text { horizontal } \\
\text { stress, psi }\end{array}$ & $\begin{array}{l}\text { Maximum }^{1} \\
\text { horizontal strain, } \\
\text { micro strain }\end{array}$ & $\begin{array}{l}\text { Minimum }^{1} \\
\text { horizontal } \\
\text { strain, micro } \\
\text { strain } \\
\end{array}$ & $\begin{array}{l}\text { Elastic } \\
\text { modulus, } \\
10^{6} \text { psi }\end{array}$ & $\begin{array}{l}\text { Site depth, } \\
\mathrm{ft}\end{array}$ \\
\hline Beckley \#4 & 1 & 18 & 1186 & 843 & 670 & 476 & 1.77 & 820 \\
\hline Beckley \#1 & 2 & 5.2 & 2896 & 1328 & 347 & 159 & 8.34 & 1130 \\
\hline Beckley \#1 & 2 & 9.2 & 2742 & 1573 & 441 & 253 & 6.22 & 1130 \\
\hline Beckley \#1 & 2 & 14.4 & 2774 & 1551 & 378 & 212 & 7.33 & 1130 \\
\hline Beckley \#2 & 3 & 10.2 & 1918 & 1290 & 868 & 584 & 2.21 & 1100 \\
\hline Beckley \#2 & 3 & 12.3 & 2017 & 1326 & 873 & 574 & 2.31 & 1100 \\
\hline Bonny & 4 & 14.7 & 3978 & 2923 & 1121 & 823 & 3.55 & 1136 \\
\hline Bonny & 4 & 16 & 2763 & 2433 & 845 & 744 & 3.27 & 1136 \\
\hline Bonny & 4 & 18.4 & 2521 & 1560 & 667 & 413 & 3.78 & 1136 \\
\hline Bonny & 4 & 19.6 & 3039 & 2277 & 810 & 607 & 3.75 & 1136 \\
\hline Bonny & 5 & 15.8 & 4630 & 1972 & 872 & 371 & 5.31 & 1148 \\
\hline Bonny & 5 & 16.8 & 5399 & 2644 & 954 & 467 & 5.66 & 1148 \\
\hline Bonny & 5 & 22.3 & 7847 & 4645 & 1116 & 661 & 7.03 & 1148 \\
\hline Maple Meadows & 6 & 15.4 & 2126 & 1884 & 349 & 309 & 6.1 & 708 \\
\hline Maple Meadows & 6 & 16.1 & 2765 & 2639 & 431 & 412 & 6.41 & 708 \\
\hline Maple Meadows & 6 & 17.7 & 2605 & 2535 & 403 & 392 & 6.47 & 708 \\
\hline Maple Meadows & 7 & 15.3 & 4348 & 2702 & 915 & 569 & 4.75 & 735 \\
\hline Maple Meadows & 7 & 16.8 & 4327 & 3058 & 1442 & 1019 & 3 & 735 \\
\hline Maple Meadows & 7 & 24.4 & 3633 & 2182 & 653 & 392 & 5.56 & 735 \\
\hline Maple Meadows & 8 & 21 & 3529 & 1738 & 544 & 268 & 6.49 & 1025 \\
\hline Maple Meadows & 8 & 22 & 4276 & 2106 & 657 & 324 & 6.51 & 1025 \\
\hline Maple Meadows & 8 & 23 & 3805 & 2120 & 461 & 257 & 8.26 & 1025 \\
\hline Maple Meadows & 9 & 9.1 & 2341 & 1302 & 971 & 540 & 2.41 & 814 \\
\hline Maple Meadows & 9 & 12 & 2598 & 1730 & 1043 & 695 & 2.49 & 814 \\
\hline
\end{tabular}


Table A-2. Excess horizontal stresses and strains in the Beckley coal field. (Cont.)

\begin{tabular}{|c|c|c|c|c|c|c|c|c|}
\hline Mine & Hole & $\begin{array}{c}\text { Measurement } \\
\text { depth, } \mathrm{ft}\end{array}$ & $\begin{array}{l}\text { Maximum } \\
\text { horizontal } \\
\text { stress, psi }\end{array}$ & $\begin{array}{l}\text { Minimum } \\
\text { horizontal } \\
\text { stress, psi }\end{array}$ & $\begin{array}{l}\text { Maximum }^{1} \\
\text { horizontal strain, } \\
\text { micro strain }\end{array}$ & $\begin{array}{l}\text { Minimum }^{1} \\
\text { horizontal } \\
\text { strain, micro } \\
\text { strain }\end{array}$ & $\begin{array}{l}\text { Elastic } \\
\text { modulus, } \\
10^{6} \mathrm{psi}\end{array}$ & $\begin{array}{c}\text { Site depth, } \\
\mathrm{ft}\end{array}$ \\
\hline Maple Meadows & 9 & 13.5 & 2763 & 1810 & 1181 & 774 & 2.34 & 814 \\
\hline Maple Meadows & 9 & 14.5 & 3410 & 2397 & 1386 & 974 & 2.46 & 814 \\
\hline Maple Meadows & 9 & 18.8 & 3049 & 2724 & 1229 & 1098 & 2.48 & 814 \\
\hline Maple Meadows & 9 & 19.3 & 3161 & 2357 & 1230 & 917 & 2.57 & 814 \\
\hline Maple Meadows & 10 & 18.7 & 3646 & 1291 & 524 & 185 & 6.96 & 807 \\
\hline Maple Meadows & 10 & 19.7 & 2567 & 1172 & 380 & 173 & 6.76 & 807 \\
\hline Maple Meadows & 10 & 20.7 & 2845 & 1353 & 393 & 187 & 7.24 & 807 \\
\hline Maple Meadows & 10 & 22.9 & 3063 & 1599 & 457 & 239 & 6.7 & 807 \\
\hline Beckley Mining & 11 & 10.3 & 2479 & 2029 & 742 & 607 & 3.34 & 640 \\
\hline Beckley Mining & 11 & 15.7 & 3153 & 974 & 834 & 258 & 3.78 & 640 \\
\hline Beckley Mining & 11 & 16.7 & 3071 & 2837 & 960 & 887 & 3.2 & 640 \\
\hline Beckley Mining & 11 & 22.2 & 2914 & 2130 & 1095 & 801 & 2.66 & 640 \\
\hline Beckley Mining & 11 & 23.2 & 3055 & 2417 & 1317 & 1042 & 2.32 & 640 \\
\hline Beckley Mining & 11 & 24.8 & 2364 & 1759 & 989 & 736 & 2.39 & 640 \\
\hline Beckley Mining & 12 & 15.1 & 3886 & 3282 & 1185 & 1001 & 3.28 & 870 \\
\hline Beckley Mining & 12 & 16.5 & 3374 & 2642 & 1085 & 850 & 3.11 & 870 \\
\hline Beckley Mining & 12 & 20.3 & 3503 & 2427 & 1160 & 804 & 3.02 & 870 \\
\hline Beckley Mining & 12 & 21.8 & 3222 & 2314 & 1202 & 863 & 2.68 & 870 \\
\hline Beckley Mining & 12 & 22.8 & 3075 & 2313 & 1187 & 893 & 2.59 & 870 \\
\hline Beckley Mining & 13 & 13.8 & 3126 & 2143 & 1145 & 785 & 2.73 & 800 \\
\hline Beckley Mining & 13 & 18.2 & 3456 & 2645 & 1184 & 906 & 2.92 & 800 \\
\hline Beckley Mining & 13 & 20.7 & 2411 & 1705 & 1035 & 732 & 2.33 & 800 \\
\hline Beckley Mining & 13 & 23.3 & 2482 & 1659 & 844 & 564 & 2.94 & 800 \\
\hline
\end{tabular}


Table A-2. Excess horizontal stresses and strains in the Beckley coal field. (Cont.)

\begin{tabular}{|c|c|c|c|c|c|c|c|c|}
\hline Mine & Hole & $\begin{array}{l}\text { Measurement } \\
\text { depth, } \mathrm{ft}\end{array}$ & $\begin{array}{l}\text { Maximum } \\
\text { horizontal } \\
\text { stress, psi }\end{array}$ & $\begin{array}{l}\text { Minimum } \\
\text { horizontal } \\
\text { stress, psi }\end{array}$ & $\begin{array}{l}\text { Maximum }^{1} \\
\text { horizontal strain, } \\
\text { micro strain }\end{array}$ & $\begin{array}{l}\text { Minimum }^{1} \\
\text { horizontal } \\
\text { strain, micro } \\
\text { strain }\end{array}$ & $\begin{array}{l}\text { Elastic } \\
\text { modulus, } \\
10^{6} \mathrm{psi}\end{array}$ & $\begin{array}{l}\text { Site depth, } \\
\mathrm{ft}\end{array}$ \\
\hline Beckley Mining & 13 & 24.5 & 2637 & 1903 & 1051 & 758 & 2.51 & 800 \\
\hline Beckley Mining & 13 & 25.5 & 3276 & 2626 & 1174 & 941 & 2.79 & 800 \\
\hline Beckley Mining & 14 & 16.3 & 3831 & 2185 & 1104 & 630 & 3.47 & 1040 \\
\hline Beckley Mining & 14 & 17.4 & 3286 & 1934 & 1063 & 626 & 3.09 & 1040 \\
\hline Beckley Mining & 14 & 18.4 & 3203 & 1615 & 953 & 481 & 3.36 & 1040 \\
\hline Beckley Mining & 14 & 22.6 & 3048 & 1756 & 889 & 512 & 3.43 & 1040 \\
\hline Beckley Mining & 14 & 24.2 & 3754 & 2023 & 900 & 485 & 4.17 & 1040 \\
\hline Beckley \#1 & 15 & 9.5 & 2967 & 1625 & 386 & 211 & 7.69 & 700 \\
\hline Beckley \#1 & 15 & 10.7 & 3418 & 1916 & 455 & 255 & 7.52 & 700 \\
\hline Beckley \#1 & 15 & 13.6 & 1890 & 973 & 280 & 144 & 6.76 & 700 \\
\hline Beckley \#2 & 16 & 12 & 1724 & 1319 & 932 & 713 & 1.85 & 350 \\
\hline Beckley \#2 & 16 & 13.1 & 1583 & 1196 & 936 & 706 & 1.69 & 350 \\
\hline Beckley \#2 & 16 & 14.2 & 1686 & 1169 & 1022 & 708 & 1.65 & 350 \\
\hline Beckley \#2 & 16 & 15.25 & 1759 & 1153 & 1047 & 686 & 1.68 & 350 \\
\hline
\end{tabular}

${ }^{1}$ The strains are from the maximum and minimum excess horizontal stresses. 


\section{APPENDIX B}

Table B-1. Measured and excess horizontal stresses and strains in the central Appalachian region (excluding the Beckley coal field).

\begin{tabular}{|c|c|c|c|c|c|c|c|c|c|c|c|c|c|}
\hline Site & $\begin{array}{c}\text { Measurement } \\
\text { depth, ft }\end{array}$ & $\begin{array}{c}\text { Maxi. } \\
\text { horizontal } \\
\text { stress, psi }\end{array}$ & $\begin{array}{c}\text { Min. } \\
\text { horizontal } \\
\text { stress, psi }\end{array}$ & $\begin{array}{l}\text { Direction } \\
\text { of max. } \\
\text { stress }\end{array}$ & $\begin{array}{c}\text { Elastic } \\
\text { modulus, } \\
10^{6} \mathrm{psi}\end{array}$ & $\begin{array}{c}\text { Depth, } \\
\mathrm{ft}\end{array}$ & $\begin{array}{l}\text { Max. } \\
\text { strain, } \\
\text { micro } \\
\text { strain }\end{array}$ & $\begin{array}{l}\text { Min. } \\
\text { strain, } \\
\text { micro } \\
\text { strain }\end{array}$ & $\begin{array}{c}\text { Max. } \\
\text { excess } \\
\text { stress, } \\
\text { psi }\end{array}$ & $\begin{array}{c}\text { Min. } \\
\text { excess } \\
\text { stress, } \\
\text { psi }\end{array}$ & $\begin{array}{l}\text { Max. } \\
\text { excess } \\
\text { strain, } \\
\text { micro } \\
\text { strain }\end{array}$ & $\begin{array}{l}\text { Min. } \\
\text { excess } \\
\text { strain, } \\
\text { micro } \\
\text { strain }\end{array}$ & $\begin{array}{l}\text { Used in } \\
\text { general } \\
\text { analysis }\end{array}$ \\
\hline $\begin{array}{l}\text { Pocahontas } \\
\# 4-1\end{array}$ & 5.8 & 2800 & 1800 & $\mathrm{~N} 54^{\circ} \mathrm{E}$ & 3.1 & 1600 & 903 & 581 & 2219 & 1219 & 716 & 393 & No \\
\hline $\begin{array}{l}\text { Pocahontas } \\
\# 4-1\end{array}$ & 12.9 & 3300 & 2400 & $\mathrm{~N} 62^{\circ} \mathrm{E}$ & 3.59 & 1600 & 919 & 669 & 2719 & 1819 & 757 & 507 & Yes \\
\hline $\begin{array}{l}\text { Pocahontas } \\
\# 4-2\end{array}$ & 2.3 & 3100 & 900 & $\mathrm{~N} 67^{\circ} \mathrm{E}$ & 3.8 & 1250 & 816 & 237 & 2646 & 446 & 696 & 117 & No \\
\hline $\begin{array}{l}\text { Pocahontas } \\
\# 4-2\end{array}$ & 3.8 & 2400 & 1300 & $\mathrm{~N} 78^{\circ} \mathrm{E}$ & 2.52 & 1250 & 952 & 516 & 1946 & 846 & 772 & 336 & No \\
\hline $\begin{array}{l}\text { Pocahontas } \\
\# 4-2\end{array}$ & 5.2 & 3000 & 1700 & $\mathrm{~N} 71^{\circ} \mathrm{E}$ & 3.23 & 1250 & 929 & 526 & 2546 & 1246 & 788 & 386 & No \\
\hline $\begin{array}{l}\text { Pocahontas } \\
\# 4-2\end{array}$ & 6.6 & 2600 & 1400 & $\mathrm{~N} 67^{\circ} \mathrm{E}$ & 3.59 & 1250 & 724 & 390 & 2146 & 946 & 598 & 264 & No \\
\hline $\begin{array}{l}\text { Pocahontas } \\
\# 4-2\end{array}$ & 8 & 3000 & 1900 & $\mathrm{~N} 64^{\circ} \mathrm{E}$ & 4.01 & 1250 & 748 & 474 & 2546 & 1446 & 635 & 361 & Yes \\
\hline $\begin{array}{l}\text { Pocahontas } \\
\# 4-2\end{array}$ & 11.8 & 2200 & 1100 & $\mathrm{~N} 29^{\circ} \mathrm{W}$ & 2.48 & 1250 & 887 & 444 & 1746 & 646 & 704 & 260 & Yes \\
\hline \begin{tabular}{|l|} 
Eagle Seam \\
\end{tabular} & 8.9 & 1781 & 1541 & $\mathrm{~N} 40^{\circ} \mathrm{E}$ & 2.99 & 900 & 596 & 515 & 1454 & 1214 & 486 & 406 & Yes \\
\hline Eagle Seam & 9.9 & 1832 & 1440 & $\mathrm{~N} 56^{\circ} \mathrm{E}$ & 2.82 & 900 & 650 & 511 & 1505 & 1113 & 534 & 395 & Yes \\
\hline Eagle Seam & 10.9 & 1678 & 1109 & $\mathrm{~N} 47^{\circ} \mathrm{E}$ & 3.03 & 900 & 554 & 366 & 1351 & 782 & 446 & 258 & Yes \\
\hline Elkhorn \#3 & $13.7-23.4$ & 2269 & 1822 & $\mathrm{~N} 56^{\circ} \mathrm{E}$ & 5.24 & 550 & 433 & 348 & 2069 & 1622 & 395 & 310 & Yes \\
\hline
\end{tabular}




\section{APPENDIX C}

Table C-1. Measured and excess horizontal stresses and strains in the northern Appalachian region.

\begin{tabular}{|c|c|c|c|c|c|c|c|c|c|c|c|}
\hline Site & $\begin{array}{c}\text { Measurement } \\
\text { depth, } \mathrm{ft}\end{array}$ & $\begin{array}{c}\text { Maxi. } \\
\text { horizontal } \\
\text { stress, psi }\end{array}$ & $\begin{array}{l}\text { Min. } \\
\text { horizontal } \\
\text { stress, psi }\end{array}$ & $\begin{array}{c}\text { Max. } \\
\text { excess } \\
\text { stress, } \\
\text { psi }\end{array}$ & $\begin{array}{c}\text { Min. } \\
\text { excess } \\
\text { stress, } \\
\text { psi }\end{array}$ & \begin{tabular}{|c} 
Max. \\
horizontal \\
strain, \\
micro \\
strain
\end{tabular} & \begin{tabular}{|c} 
Min. \\
horizontal \\
strain, \\
micro \\
strain
\end{tabular} & $\begin{array}{l}\text { Min. } \\
\text { excess } \\
\text { strain, } \\
\text { micro } \\
\text { strain }\end{array}$ & $\begin{array}{l}\text { Min. } \\
\text { excess } \\
\text { strain, } \\
\text { micro } \\
\text { strain }\end{array}$ & $\begin{array}{c}\text { Elastic } \\
\text { modulus, } \\
10^{6} \text { psi }\end{array}$ & $\begin{array}{c}\text { Depth, } \\
\mathrm{ft}\end{array}$ \\
\hline $\begin{array}{l}\text { Tanoma, PA- } \\
\text { Kittanning Seam }\end{array}$ & 16.1 & 3335 & 2787 & 3074 & 2526 & 575 & 481 & 530 & 436 & 5.8 & 720 \\
\hline $\begin{array}{l}\text { Phillippi, WV- } \\
\text { Kittanning Seam }\end{array}$ & 15.3 & 4279 & 2861 & 4079 & 2661 & 718 & 480 & 684 & 446 & 5.96 & 550 \\
\hline $\begin{array}{l}\text { Phillippi, WV- } \\
\text { Kittanning Seam }\end{array}$ & 18.3 & 1664 & 1344 & 1464 & 1144 & 633 & 511 & 557 & 435 & 2.63 & 550 \\
\hline $\begin{array}{l}\text { Phillippi, WV- } \\
\text { Kittanning Seam }\end{array}$ & 18.7 & 1316 & 1151 & 1116 & 951 & 823 & 719 & 698 & 594 & 1.6 & 550 \\
\hline $\begin{array}{l}\text { Phillippi, WV- } \\
\text { Kittanning Seam }\end{array}$ & 23.1 & 4959 & 3525 & 4759 & 3325 & 714 & 507 & 685 & 478 & 6.95 & 550 \\
\hline $\begin{array}{l}\text { Loyalhanna Formation, } \\
\text { PA }\end{array}$ & $10-12$ & 6910 & 3975 & 6765 & 3830 & 617 & 355 & 604 & 342 & 11.2 & 400 \\
\hline $\begin{array}{l}\text { Columbus Limestone, } \\
\mathrm{OH}\end{array}$ & - & 5500 & 4000 & 4665 & 3165 & 611 & 444 & 518 & 352 & 9 & 2300 \\
\hline Pittsburgh Seam Site 1 & $13-20$ & 1324 & 1024 & 1179 & 879 & 736 & 569 & 655 & 488 & 1.8 & 400 \\
\hline Pittsburgh Seam Site 2 & 11 & 2400 & 2190 & 2146 & 1936 & 588 & 537 & 526 & 475 & 4.08 & 700 \\
\hline \begin{tabular}{|l|} 
Pittsburgh Seam Site 2 \\
\end{tabular} & 13 & 2480 & 2260 & 2226 & 2006 & 525 & 479 & 472 & 425 & 4.72 & 700 \\
\hline Pittsburgh Seam Site 3 & 17 & 4210 & 2540 & 3920 & 2250 & 543 & 327 & 505 & 290 & 7.76 & 800 \\
\hline Pittsburgh Seam Site 3 & 18.5 & 3590 & 2340 & 3300 & 2050 & 418 & 273 & 385 & 239 & 8.58 & 800 \\
\hline Pittsburgh Seam Site 3 & 19.8 & 2790 & 2110 & 2500 & 1820 & 421 & 319 & 378 & 275 & 6.62 & 800 \\
\hline Average & & - & - & - & - & 609 & 462 & 554 & 406 & - & - \\
\hline
\end{tabular}

${ }^{1}$ Strains from the maximum or minimum horizontal stress component. 


\section{APPENDIX D}

Table D-1. Measured and excess horizontal stresses and strains in the Illinois Basin and eastern Mid-Continent region.

\begin{tabular}{|c|c|c|c|c|c|c|c|c|c|c|c|c|c|}
\hline Hole & $\begin{array}{c}\text { Measurement } \\
\text { depth, ft }\end{array}$ & $\begin{array}{c}\text { Maxi. } \\
\text { horizontal } \\
\text { stress, psi }\end{array}$ & $\begin{array}{c}\text { Min. } \\
\text { horizontal } \\
\text { stress, psi }\end{array}$ & $\begin{array}{c}\text { Direction } \\
\text { of max. } \\
\text { stress }\end{array}$ & $\begin{array}{c}\text { Elastic } \\
\text { modulus, } \\
10^{6} \mathrm{psi}\end{array}$ & $\begin{array}{l}\text { Max. } \\
\text { strain, } \\
\text { micro } \\
\text { strain }\end{array}$ & $\begin{array}{l}\text { Min. } \\
\text { strain, } \\
\text { micro } \\
\text { strain }\end{array}$ & $\begin{array}{c}\text { Depth, } \\
\mathrm{ft}\end{array}$ & $\begin{array}{c}\text { Max. } \\
\text { excess } \\
\text { stress, psi }\end{array}$ & $\begin{array}{c}\text { Min. } \\
\text { excess } \\
\text { stress, psi }\end{array}$ & $\begin{array}{l}\text { Max. } \\
\text { excess } \\
\text { strain, } \\
\text { micro } \\
\text { strain }\end{array}$ & $\begin{array}{l}\text { Min. } \\
\text { excess } \\
\text { strain, } \\
\text { micro } \\
\text { strain }\end{array}$ & $\begin{array}{l}\text { Used in } \\
\text { general } \\
\text { analysis }\end{array}$ \\
\hline \multicolumn{14}{|c|}{ Wabash Mine, IL, Springfield \#5 Seam } \\
\hline 1 & 10.7 & 1134 & 965 & $\mathrm{~N} 44^{\circ} \mathrm{E}$ & 3.15 & 360 & 306 & 970 & 782 & 613 & 248 & 195 & Yes \\
\hline 1 & 12.1 & 1313 & 867 & $\mathrm{~N} 79^{\circ} \mathrm{W}$ & 3.37 & 390 & 257 & 970 & 961 & 515 & 285 & 153 & Yes \\
\hline 1 & 13.5 & 1362 & 1030 & $\mathrm{~N} 89^{\circ} \mathrm{E}$ & 2.96 & 460 & 348 & 970 & 1010 & 678 & 341 & 229 & Yes \\
\hline 1 & 16.5 & 1274 & 888 & $\mathrm{~N} 88^{\circ} \mathrm{W}$ & 2.97 & 429 & 299 & 970 & 922 & 536 & 310 & 180 & Yes \\
\hline 2 & 8.4 & 1533 & 949 & $\mathrm{~N} 89^{\circ} \mathrm{E}$ & 3.39 & 452 & 280 & 850 & 1224 & 640 & 361 & 189 & No \\
\hline 2 & 9.9 & 1606 & 981 & $\mathrm{~N} 81^{\circ} \mathrm{E}$ & 3.13 & 513 & 313 & 850 & 1297 & 672 & 415 & 215 & Yes \\
\hline 2 & 14.1 & 1423 & 768 & $\mathrm{~N} 76^{\circ} \mathrm{E}$ & 2.94 & 484 & 261 & 850 & 1114 & 459 & 379 & 156 & Yes \\
\hline 2 & 15.8 & 1263 & 735 & $\mathrm{~N} 84^{\circ} \mathrm{E}$ & 2.63 & 480 & 279 & 850 & 954 & 426 & 363 & 162 & Yes \\
\hline 3 & 7.2 & 1451 & 670 & $\mathrm{~N} 82^{\circ} \mathrm{W}$ & 3.33 & 436 & 201 & 860 & 1139 & 358 & 342 & 107 & No \\
\hline 3 & 8.4 & 1599 & 572 & $\mathrm{~N} 89^{\circ} \mathrm{W}$ & 2.94 & 544 & 195 & 860 & 1287 & 260 & 438 & 88 & No \\
\hline 3 & 9.9 & 1405 & 589 & $\mathrm{~N} 72^{\circ} \mathrm{W}$ & 2.82 & 498 & 209 & 860 & 1093 & 277 & 388 & 98 & Yes \\
\hline 3 & 13.1 & 1493 & 559 & $\mathrm{~N} 69^{\circ} \mathrm{W}$ & 2.78 & 537 & 201 & 860 & 1181 & 247 & 425 & 89 & Yes \\
\hline 3 & 14.4 & 1356 & 540 & $\mathrm{~N} 77^{\circ} \mathrm{W}$ & 2.82 & 481 & 191 & 860 & 1044 & 228 & 370 & 81 & Yes \\
\hline 3 & 15.9 & 1606 & 643 & $\mathrm{~N} 81^{\circ} \mathrm{W}$ & 2.99 & 537 & 215 & 860 & 1294 & 331 & 433 & 111 & Yes \\
\hline \multicolumn{14}{|c|}{ Monterey Mine, IL, Springfield\#5 Seam } \\
\hline 1 & 4.33 & 2277 & 707 & $\mathrm{~N} 59^{\circ} \mathrm{E}$ & 7.83 & 291 & 90 & 290 & 2172 & 602 & 277 & 77 & No \\
\hline 1 & 6.33 & 905 & 238 & $\mathrm{~N} 66^{\circ} \mathrm{E}$ & 2.47 & 366 & 96 & 290 & 800 & 133 & 324 & 54 & No \\
\hline 1 & 9.4 & 1148 & 728 & $\mathrm{~N} 69^{\circ} \mathrm{E}$ & 1.9 & 604 & 383 & 290 & 1043 & 623 & 549 & 328 & Yes \\
\hline 1 & 11.8 & 636 & 410 & $\mathrm{~N} 55^{\circ} \mathrm{E}$ & 1.44 & 442 & 285 & 290 & 531 & 305 & 369 & 212 & Yes \\
\hline \multicolumn{14}{|c|}{ Galatia Mine, IL, Springfield \#5 Seam } \\
\hline 1 & 6 & 1448 & 388 & $\mathrm{~N} 78^{\circ} \mathrm{E}$ & 2.9 & 499 & 134 & 570 & 1241 & 181 & 428 & 62 & No \\
\hline 1 & 10.1 & 1980 & 586 & $\mathrm{~N} 72^{\circ} \mathrm{E}$ & 3.17 & 625 & 185 & 570 & 1773 & 379 & 559 & 120 & Yes \\
\hline 1 & 11.6 & 1674 & 467 & $\mathrm{~N} 77^{\circ} \mathrm{E}$ & 2.91 & 575 & 160 & 570 & 1467 & 260 & 504 & 89 & Yes \\
\hline
\end{tabular}


Table D-1. Measured and excess horizontal stresses and strains in the Illinois Basin and eastern Mid-Continent region. (Cont.)

\begin{tabular}{|c|c|c|c|c|c|c|c|c|c|c|c|c|c|}
\hline Hole & $\begin{array}{c}\text { Measurement } \\
\text { depth, } \mathrm{ft}\end{array}$ & $\begin{array}{c}\text { Maxi. } \\
\text { horizontal } \\
\text { stress, psi }\end{array}$ & $\begin{array}{c}\text { Min. } \\
\text { horizontal } \\
\text { stress, psi }\end{array}$ & $\begin{array}{c}\text { Direction } \\
\text { of max. } \\
\text { stress }\end{array}$ & $\begin{array}{c}\text { Elastic } \\
\text { modulus, } \\
10^{6} \mathrm{psi}\end{array}$ & $\begin{array}{l}\text { Max. } \\
\text { strain, } \\
\text { micro } \\
\text { strain }\end{array}$ & $\begin{array}{l}\text { Min. } \\
\text { strain, } \\
\text { micro } \\
\text { strain }\end{array}$ & $\begin{array}{c}\text { Depth, } \\
\mathrm{ft}\end{array}$ & $\begin{array}{c}\text { Max. } \\
\text { excess } \\
\text { stress, psi }\end{array}$ & $\begin{array}{c}\text { Min. } \\
\text { excess } \\
\text { stress, psi }\end{array}$ & $\begin{array}{l}\text { Max. } \\
\text { excess } \\
\text { strain, } \\
\text { micro } \\
\text { strain }\end{array}$ & $\begin{array}{l}\text { Min. } \\
\text { excess } \\
\text { strain, } \\
\text { micro } \\
\text { strain }\end{array}$ & $\begin{array}{l}\text { Used in } \\
\text { general } \\
\text { analysis }\end{array}$ \\
\hline 1 & 13.1 & 1654 & 533 & $\mathrm{~N} 71^{\circ} \mathrm{E}$ & 2.81 & 589 & 190 & 570 & 1447 & 326 & 515 & 116 & Yes \\
\hline \multicolumn{14}{|c|}{ Turris Mine, IL, Springfield \#5 Seam } \\
\hline 1 & 6.1 & 2208 & 1122 & $\mathrm{~N} 38^{\circ} \mathrm{E}$ & 9.05 & 244 & 124 & 275 & 2108 & 1022 & 233 & 113 & No \\
\hline 2 & 5.8 & 1846 & 814 & $\mathrm{~N} 61^{\circ} \mathrm{E}$ & 8.08 & 228 & 101 & 275 & 1746 & 714 & 216 & 88 & No \\
\hline \multicolumn{14}{|c|}{ Peabody \# 10, Il, Herrin \#6 Seam } \\
\hline 1 & 3 & 1293 & 409 & $\mathrm{~N} 39^{\circ} \mathrm{E}$ & 5.52 & 234 & 74 & 360 & 1162 & 278 & 211 & 50 & No \\
\hline 1 & 4 & 1582 & -24 & $\mathrm{~N} 52^{\circ} \mathrm{E}$ & 9 & 176 & -3 & 360 & 1451 & -155 & 161 & -17 & No \\
\hline 1 & 5 & 2490 & 46 & $\mathrm{~N} 65^{\circ} \mathrm{E}$ & 5.46 & 456 & 8 & 360 & 2359 & -85 & 432 & -16 & No \\
\hline 1 & 6 & 2435 & -458 & $\mathrm{~N} 66^{\circ} \mathrm{E}$ & 6.62 & 368 & -69 & 360 & 2304 & -589 & 348 & -89 & No \\
\hline 1 & 7 & 3588 & 371 & $\mathrm{~N} 67^{\circ} \mathrm{E}$ & 7.37 & 487 & 50 & 360 & 3457 & 240 & 469 & 33 & No \\
\hline 1 & 8 & 2519 & -85 & $\mathrm{~N} 65^{\circ} \mathrm{E}$ & 5.64 & 447 & -15 & 360 & 2388 & -216 & 423 & -38 & No \\
\hline 1 & 9 & 1227 & 1041 & East West & 1.56 & 787 & 667 & 360 & 1096 & 910 & 703 & 584 & Yes \\
\hline 1 & 10 & 835 & 518 & $\mathrm{~N} 79^{\circ} \mathrm{E}$ & 1.28 & 652 & 405 & 360 & 704 & 387 & 550 & 303 & Yes \\
\hline 1 & 11 & 3379 & 749 & $\mathrm{~N} 67^{\circ} \mathrm{E}$ & 5.7 & 593 & 131 & 360 & 3248 & 618 & 570 & 108 & Yes \\
\hline \multicolumn{14}{|c|}{ Peabody \# 2, KY , Springfield \#5 Seam } \\
\hline 1 & 3.5 & 1146 & 994 & $\mathrm{~N} 16^{\circ} \mathrm{E}$ & 2 & 573 & 497 & 300 & 1037 & 885 & 519 & 443 & No \\
\hline 1 & 4.92 & 1251 & 1167 & $\mathrm{~N} 40^{\circ} \mathrm{E}$ & 2.4 & 521 & 486 & 300 & 1142 & 1058 & 476 & 441 & No \\
\hline 1 & 6.67 & 1613 & 1575 & $\mathrm{~N} 82{ }^{\circ} \mathrm{E}$ & 3 & 538 & 525 & 300 & 1504 & 1466 & 501 & 489 & No \\
\hline 1 & 21 & 969 & 896 & $\mathrm{~N} 81^{\circ} \mathrm{E}$ & 2.2 & 440 & 407 & 300 & 860 & 787 & 391 & 358 & Yes \\
\hline \multicolumn{14}{|c|}{ Ft. Campbell Limestone, Campbell County, KY } \\
\hline NA & NA & 3784 & 1320 & $\mathrm{~N} 78^{\circ} \mathrm{E}$ & 9.32 & 406 & 142 & 730 & 3519 & 1055 & 360 & 43 & Yes \\
\hline \multicolumn{14}{|c|}{ Immel Mine, $\mathbf{T N}$} \\
\hline 3 & 8.8 & 4609 & 1980 & $\mathrm{~N} 65^{\circ} \mathrm{E}$ & 10.75 & 429 & 184 & 925 & 4273 & 1644 & 405 & 161 & Yes \\
\hline 3 & 14.2 & 4203 & 818 & $\mathrm{~N} 59^{\circ} \mathrm{E}$ & 11.36 & 370 & 72 & 925 & 3867 & 482 & 348 & 50 & Yes \\
\hline 4 & 13.7 & 2354 & 1518 & $\mathrm{~N} 65^{\circ} \mathrm{E}$ & 7.28 & 323 & 208 & 925 & 2018 & 1182 & 288 & 174 & Yes \\
\hline
\end{tabular}


Table D-1. Measured and excess horizontal stresses and strains in the Illinois Basin and eastern Mid-Continent region. (Cont.)

\begin{tabular}{|c|c|c|c|c|c|c|c|c|c|c|c|c|c|}
\hline Hole & $\begin{array}{c}\text { Measurement } \\
\text { depth, } \mathrm{ft}\end{array}$ & $\begin{array}{c}\text { Maxi. } \\
\text { horizontal } \\
\text { stress, psi }\end{array}$ & $\begin{array}{l}\text { Min. } \\
\text { horizontal } \\
\text { stress, psi }\end{array}$ & $\begin{array}{l}\text { Direction } \\
\text { of max. } \\
\text { stress }\end{array}$ & $\begin{array}{l}\text { Elastic } \\
\text { modulus, } \\
10^{6} \mathrm{psi}\end{array}$ & $\begin{array}{l}\text { Max. } \\
\text { strain, } \\
\text { micro } \\
\text { strain }\end{array}$ & $\begin{array}{l}\text { Min. } \\
\text { strain, } \\
\text { micro } \\
\text { strain }\end{array}$ & $\begin{array}{c}\text { Depth, } \\
\mathrm{ft}\end{array}$ & $\begin{array}{c}\text { Max. } \\
\text { excess } \\
\text { stress, psi }\end{array}$ & $\begin{array}{c}\text { Min. } \\
\text { excess } \\
\text { stress, psi }\end{array}$ & $\begin{array}{l}\text { Max. } \\
\text { excess } \\
\text { strain, } \\
\text { micro } \\
\text { strain }\end{array}$ & $\begin{array}{l}\text { Min. } \\
\text { excess } \\
\text { strain, } \\
\text { micro } \\
\text { strain }\end{array}$ & $\begin{array}{l}\text { Used in } \\
\text { general } \\
\text { analysis }\end{array}$ \\
\hline 4 & 15.7 & 3647 & 1543 & $\mathrm{~N} 42^{\circ} \mathrm{E}$ & 4.64 & 786 & 333 & 925 & 3311 & 1207 & 731 & 278 & Yes \\
\hline 4 & 16.7 & 3248 & 825 & $\mathrm{~N} 67^{\circ} \mathrm{E}$ & 11.94 & 272 & 69 & 925 & 2912 & 489 & 251 & 48 & Yes \\
\hline 4 & 18.7 & 3352 & 720 & $\mathrm{~N} 58^{\circ} \mathrm{E}$ & 7.3 & 459 & 99 & 925 & 3016 & 384 & 424 & 64 & Yes \\
\hline 4 & 19.7 & 2805 & 1469 & $\mathrm{~N} 70^{\circ} \mathrm{E}$ & 5.58 & 502 & 263 & 925 & 2469 & 1133 & 457 & 218 & Yes \\
\hline 4 & 20.8 & 2503 & 996 & $\mathrm{~N} 71^{\circ} \mathrm{E}$ & 4.86 & 515 & 205 & 925 & 2167 & 660 & 463 & 153 & Yes \\
\hline \multicolumn{14}{|c|}{ North River, AL, Pratt Seam } \\
\hline 1 & 7.25 & 2404 & 404 & $\mathrm{~N} 54^{\circ} \mathrm{E}$ & 5.91 & 407 & 68 & 500 & 2223 & 223 & 376 & 38 & Yes \\
\hline 1 & 8.4 & 2050 & 391 & $\mathrm{~N} 58^{\circ} \mathrm{E}$ & 5.11 & 401 & 77 & 500 & 1869 & 210 & 366 & 41 & Yes \\
\hline 1 & 9.4 & 1849 & 117 & $\mathrm{~N} 54^{\circ} \mathrm{E}$ & 5.4 & 342 & 22 & 500 & 1668 & -65 & 309 & -12 & Yes \\
\hline 1 & 11.25 & 2163 & 261 & $\mathrm{~N} 63^{\circ} \mathrm{E}$ & 5.26 & 411 & 50 & 500 & 1982 & 80 & 377 & 15 & Yes \\
\hline 2 & 6.5 & 647 & 306 & $\mathrm{~N} 69^{\circ} \mathrm{E}$ & 4.38 & 148 & 70 & 470 & 476 & 135 & 109 & 31 & No \\
\hline 2 & 7.6 & 1032 & 485 & $\mathrm{~N} 71^{\circ} \mathrm{E}$ & 5.12 & 202 & 95 & 470 & 861 & 314 & 168 & 61 & No \\
\hline 2 & 8.6 & 1015 & 197 & N $69^{\circ} \mathrm{E}$ & 4.59 & 221 & 43 & 470 & 844 & 26 & 184 & 6 & No \\
\hline 2 & 9.6 & 1081 & 469 & $\mathrm{~N} 66^{\circ} \mathrm{E}$ & 4.45 & 243 & 105 & 470 & 910 & 298 & 205 & 67 & No \\
\hline \multicolumn{14}{|c|}{ Jim Walters \#7, AL, Blue Creek/Mary Lee Seam } \\
\hline NA & NA & 3050 & 1520 & $\mathrm{~N} 71^{\circ} \mathrm{E}$ & 5.4 & 565 & 281 & 1870 & 2364 & 834 & 439 & 156 & Yes \\
\hline
\end{tabular}

${ }^{1}$ Strains from the maximum or minimum stress component. 